\title{
Atualização dinâmica de modelo de regressão logística binária para detecção de fraudes em transações eletrônicas com cartão de crédito
}

\author{
Fidel Beraldi
}

DisSERTAÇÃO APRESENTADA $\mathrm{AO}$

Instituto DE MATEMÁtica e Estatística DA Universidade De SÃo Paulo PARA OBTENÇÃo DO TÍTULO $\mathrm{DE}$ Mestre em CiênCIAS

Área de Concentração: Ciência da Computação Orientador: Prof. Dr. Alair Pereira do Lago 


\section{Atualização dinâmica de modelo de regressão logística binária para detecção de fraudes em transações eletrônicas com cartão de crédito}

Esta versão da dissertação contém as correções e alterações sugeridas pela Comissão Julgadora durante a defesa da versão original do trabalho, realizada em 01/12/2014. Uma cópia da versão original está disponível no

Instituto de Matemática e Estatística da Universidade de São Paulo.

Comissão Julgadora:

- Prof. Dr. Alair Pereira do Lago (orientador) - IME-USP

- Profa. Dra. Chang Chiann - IME-USP

- Prof. Dr. André Carlos Ponce de L. F. de Carvalho - ICMC-USP 


\section{Agradecimentos}

Primeiramente, agradeço a Deus por me guiar por esse caminho e encontrar pessoas fantásticas durante esse trajeto.

Agradeço ao Prof. Alair Pereira do Lago por todo apoio e conhecimento compartilhado no desenvolvimento desta dissertação. Seus comentários precisos, direcionamentos e conselhos fizeram com que me mantivesse motivado para seguir em frente.

Para chegar até aqui, existiram pessoas tanto no âmbito profissional como acadêmico que fizeram a diferença na minha vida. Agradeço ao Prof. Marco (Marcão) pelos ensinamentos em matemática que fazem muita diferença em minha vida profissional, à Profa. Chang Chiann por ser minha mentora na graduação em estatística e por todo incentivo e conselhos que me deu para meu crescimento dentro e fora da academia. Sou muito grato pela oportunidade de estudar no IME USP, um instituto sério e de excelentes professores e estudantes.

Profissionalmente, tenho de agradecer ao Leonardo Toscano pelos conselhos, discussões e orientações que tive ainda no começo da minha carreira, ao Alexandre Bratt por me mostrar que podemos criar e trabalhar em um excelente ambiente profissional, e que pode ser interessante e divertido, e também ao Fábio Escaleira pelas demonstrações de um profissional de caráter e valores.

Também expresso meus agradecimentos aos amigos e colegas Luis Silvestre pelas demonstrações de buscar fazer as coisas de modo diferente para evoluirmos profissionalmente, e ao Moisés dos Santos pelo apoio logo quando comecei o mestrado e pelas conversas que tivemos tanto no âmbito pessoal como profissional.

Agradeço ao Leonardo Mendes pela confiança, disponibilidade e esclarecimentos no desenvolvimento deste trabalho e Pedro Egydio pelo incentivo incondicional para concluí-lo.

Um agradecimento especial ao amigo Antônio Candido Neto por todo o suporte, confiança e colaboração nesse trabalho. Seus conhecimentos na área contribuíram do início ao fim, além de estar sempre disposto a discutir sobre os temas de fraude.

Agradeço ao amigo de mestrado Paulo Oliveira por dividirmos dúvidas, questões, conselhos e preocupações nessa caminhada. Foram muitas conversas, mas em nenhum momento pensamos em desistir, mesmo que tenha sido o caminho mais fácil a seguir em alguns momentos.

Agradeço à minha família por todo o suporte em minha vida, e principalmente meus pais pelos incentivos nos meus estudos desde criança. Esse suporte foi imprescindível para que eu estudasse em uma grande universidade como a USP. 
Meu agradecimento para minha querida e amada avó que faleceu logo após a defesa do meu mestrado. Por outro lado, agradeço pela alegria de ser tio da Gabriela e Alice.

Por fim, agradeço à minha amiga e companheira Indaiá de Santana Bassani pelo seu companheirismo, apoio, amor e paciência em todos esses anos em que vivemos felizes juntos. Seus conselhos acadêmicos e apoio me ajudaram a chegar à conclusão desta dissertação. 


\section{Resumo}

BERALDI, F. Atualização dinâmica de modelo de regressão logística binária para detecção de fraudes em transações eletrônicas com cartão de crédito. 2014. 156 f. Dissertação (Mestrado) - Instituto de Matemática e Estatística, Universidade de São Paulo, São Paulo, 2014.

Com o avanço tecnológico e econômico, que facilitaram o processo de comunicação e aumento do poder de compra, transações com cartão de crédito tornaram-se o principal meio de pagamento no varejo nacional e internacional (Bolton e Hand, 2002). Neste aspecto, o aumento do número de transações com cartão de crédito é crucial para a geração de mais oportunidades para fraudadores produzirem novas formas de fraudes, o que resulta em grandes perdas para o sistema financeiro (Chan et al. , 1999).

Os índices de fraudes têm mostrado que transações no comércio eletrônico (e-commerce) são mais arriscadas do que transações presencias em terminais, pois aquelas não fazem uso de processos seguros e eficientes de autenticação do portador do cartão, como utilização de senha eletrônica. Como os fraudadores se adaptam rapidamente às medidas de prevenção, os modelos estatísticos para detecção de fraudes precisam ser adaptáveis e flexíveis para evoluir ao longo do tempo de maneira dinâmica. Raftery et al. (2010) desenvolveram um método chamado Dynamic Model Averaging (DMA), ou Ponderação Dinâmica de Modelos, que implementa um processo de atualização contínuo ao longo do tempo.

Nesta dissertação, desenvolvemos modelos DMA no espaço de transações eletrônicas oriundas do comércio eletrônico que incorporem as tendências e características de fraudes em cada período de análise. Também desenvolvemos modelos de regressão logística clássica com o objetivo de comparar as performances no processo de detecção de fraude. Os dados utilizados para tal são provenientes de uma empresa de meios de pagamentos eletrônico.

O experimento desenvolvido mostra que os modelos DMA apresentaram resultados melhores que os modelos de regressão logística clássica quando analisamos a medida $\mathrm{F}$ e a área sob a curva ROC (AUC). A medida F para o modelo DMA ficou em $58 \%$ ao passo que o modelo de regressão logística clássica ficou em 29\%. Já para a AUC, o modelo DMA alcançou 93\% e o modelo de regressão logística clássica $84 \%$.

Considerando os resultados encontrados para os modelos DMA, podemos concluir que sua característica de atualização ao longo do tempo se mostra um grande diferencial em dados como os de fraude, que sofrem mudanças de comportamento a todo momento. Deste 
modo, sua aplicação se mostra adequada no processo de deteç̧ão de transações fraudulentas no ambiente de comércio eletrônico.

Palavras-chave: prevenção e detecção de fraude, modelagem estatística, ponderação dinâmica de modelos, cartão de crédito, comércio eletrônico. 


\section{Abstract}

BERALDI, F. Dynamic update of binary logistic regression model for fraud detection in electronic credit card transactions. 2014. 156 f. Dissertação (Mestrado) Instituto de Matemática e Estatística, Universidade de São Paulo, São Paulo, 2014.

Regarding technological and economic development, which made communication process easier and increased purchasing power, credit card transactions have become the primary payment method in national and international retailers (Bolton e Hand, 2002). In this scenario, as the number of transactions by credit card grows, more opportunities are created for fraudsters to produce new ways of fraud, resulting in large losses for the financial system (Chan et al. , 1999).

Fraud indexes have shown which e-commerce transactions are riskier than card present transactions, since those do not use secure and efficient processes to authenticate the cardholder, such as using personal identification number (PIN). Due to fraudsters adapt quickly to fraud prevention measures, statistical models for fraud detection need to be adaptable and flexible to change over time in a dynamic way. Raftery et al. (2010) developed a method called Dynamic Model Averaging (DMA), which implements a process of continuous updating over time.

In this thesis, we develop DMA models within electronic transactions coming from ecommerce environment, which incorporate the trends and characteristics of fraud in each period of analysis. We have also developed classic logistic regression models in order to compare their performances in the fraud detection processes. The database used for the experiment was provided by a electronic payment service company.

The experiment shows that DMA models present better results than classic logistic regression models in respect to the analysis of the area under the ROC curve (AUC) and F measure. The F measure for the DMA was $58 \%$ while the classic logistic regression model was $29 \%$. For the AUC, the DMA model reached $93 \%$ and the classical model reached $84 \%$.

Considering the results for DMA models, we can conclude that its update over time characteristic makes a large difference when it comes to the analysis of fraud data, which undergo behavioral changes continuously. Thus, its application has proved to be appropriate for the detection process of fraudulent transactions in the e-commerce environment.

Keywords: fraud prevention and detection, statistical model, dynamic model averaging, credit card, e-commerce. 


\section{Sumário}

Lista de Figuras $\quad$ viii

Lista de Tabelas $\quad$ xi

1 Introdução 1

2 Mercado de Cartões de Crédito $\quad 4$

2.1 Definição . . . . . . . . . . . . . . . . . . . . . . . . 4

2.2 Histórico . . . . . . . . . . . . . . . . . . . . . . . 5

2.3 Números do Mercado Brasileiro . . . . . . . . . . . . . . . . . . . . 7

2.4 Funcionamento do Cartão de Crédito . . . . . . . . . . . . . . . . . . 9

3 Fraude em Cartão de Crédito $\quad 15$

3.1 Definição . . . . . . . . . . . . . . . . . . . . . . 15

3.2 Tipos de Fraude . . . . . . . . . . . . . . . . . . . . . . 17

3.3 Métodos para Cometer Fraudes . . . . . . . . . . . . . . . . . . 18

3.4 Custos e Ciclo da Fraude . . . . . . . . . . . . . . . . . . . . . 20

3.5 Medidas para prevenir fraudes em cartão de crédito . . . . . . . . . . . . . 22

3.6 Fraudes no Comércio Eletrônico . . . . . . . . . . . . . . . . . . . . . 22

3.7 Legislação brasileira contra fraudes . . . . . . . . . . . . . . . . . . . . . 24

4 Métodos de Prevenção e Detecção de Fraudes $\quad 27$

4.1 Definição . . . . . . . . . . . . . . . . . . . . . . . 27

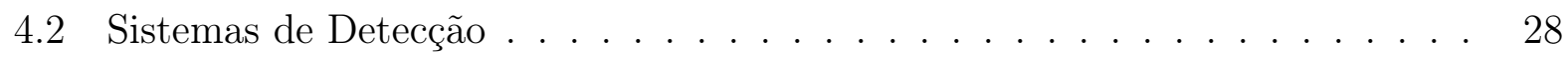

4.3 Métodos Estatísticos . . . . . . . . . . . . . . . . . . . . . . . 29

4.4 Fraude em Transações no Comércio Eletrônico . . . . . . . . . . . . . . . . . 35

5 Ponderação Dinâmica de Modelos para Classificação Binária $\quad 37$

5.1 A Ponderação de Modelos . . . . . . . . . . . . . . . . . . . . . . 38

5.2 Modelo Dinâmico de Regressão Logística Bayesiana . . . . . . . . . . . . . . 38

5.3 Ponderação Dinâmica de Modelos

(Dynamic Model Averaging- DMA) . . . . . . . . . . . . . . . . . 41

5.4 Relatos de Aplicações do Método DMA . . . . . . . . . . . . . . . . . . . . 43

5.5 Algoritmo do Método DMA . . . . . . . . . . . . . . . . . . 50

5.6 Estratégia de Seleção de Modelos . . . . . . . . . . . . . . . . . . . . 51 
6 Metodologia do Experimento

6.1 Preparação do Banco de Dados . . . . . . . . . . . . . . . . . . . . 53

6.2 Identificação de Transações Fraudulentas . . . . . . . . . . . . . . . . . . 57

6.3 Tipo de Variáveis . . . . . . . . . . . . . . . . . . . . . . . . . . . . . . 58

6.4 Dados Faltantes . . . . . . . . . . . . . . . . . . . . . . 59

6.5 Variáveis Independentes Derivadas . . . . . . . . . . . . . . . . . 62

6.6 Valor da Informação e Peso da Evidência . . . . . . . . . . . . . . . . . . 65

6.7 Variáveis Independentes Finais . . . . . . . . . . . . . . . . . . . 66

6.8 Amostragem . . . . . . . . . . . . . . . . . . . . . . . 67

7 Desenvolvimento dos Modelos $\quad 69$

7.1 Análise Descritiva . . . . . . . . . . . . . . . . . . . . . . . 69

7.2 Regressão Logística Binária Clássica . . . . . . . . . . . . . . . . . . . 76

7.2 .1 Ajuste do Modelo . . . . . . . . . . . . . . . . . . . 76

7.2 .2 Medidas de Ajuste do Modelo . . . . . . . . . . . . . . . . . . . . 78

7.2.3 Validação do Modelo . . . . . . . . . . . . . . . . . . . . 82

7.2.4 Indicadores de Performance . . . . . . . . . . . . . . 86

7.2.5 Variáveis adicionadas por conhecimento do domínio . . . . . . . . . . 87

7.3 Modelagem com o Método DMA . . . . . . . . . . . . . . 88

7.3.1 Seleção de Modelos e Variáveis . . . . . . . . . . . . . . . . . . . . . 89

7.3.2 Ajuste do Modelo . . . . . . . . . . . . . . . . . . . . . 92

7.3.3 Medidas de Ajuste do Modelo . . . . . . . . . . . . . . . . . . . 98

7.3.4 Validação do Modelo . . . . . . . . . . . . . . . . . . . . . . . 101

7.3.5 Indicadores de Performance . . . . . . . . . . . . . . . . . 104

7.4 Sumário dos Resultados Experimentais . . . . . . . . . . . . . . . . . 105

7.5 Comparação Final dos Modelos . . . . . . . . . . . . . . . . 106

8 Conclusões e Trabalhos Futuros 108

8.1 Conclusões . . . . . . . . . . . . . . . . . . . . . . . . . 108

8.2 Trabalhos Futuros . . . . . . . . . . . . . . . . . . 108

$\begin{array}{ll}\text { Apêndices } & 109\end{array}$

A Análise Descritiva . . . . . . . . . . . . . . . . . 110

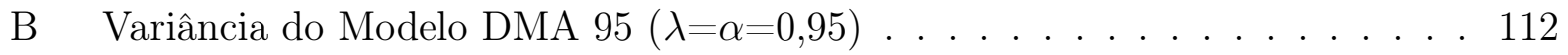

C Modelo de Regressão Logística Clássica com Stepwise Modificado . . . . . . 115

D Modelo DMA $99(\lambda=\alpha=0,99) \ldots \ldots \ldots \ldots \ldots$

$\begin{array}{ll}\text { Referências Bibliográficas } & 139\end{array}$ 


\section{Lista de Figuras}

2.1 Percentual do uso de cartão como meio de pagamento no consumo das famílias no Brasil. Fonte: ABECS (ABECS , 2012) . . . . . . . . . . 7

2.2 Faturamento por função do cartão no Brasil (em R $\$$ bilhões). Fonte: ABECS

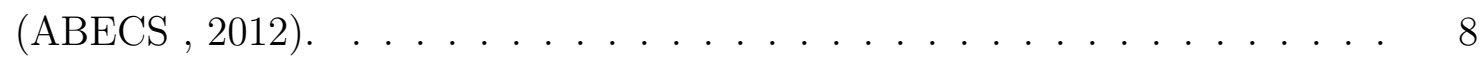

2.3 Quantidade de transações por função do cartão no Brasil (em $\mathrm{R} \$$ milhões).

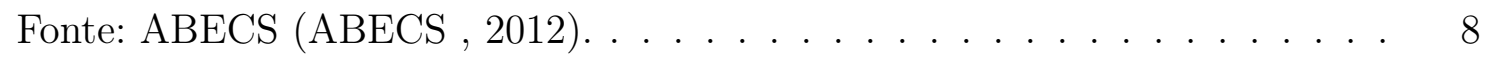

2.4 Estrutura do cartão de crédito. . . . . . . . . . . . . . . . . . . 11

2.5 Fluxo da Transação. Fonte: Mastercard. . . . . . . . . . . . . . . . . . . . . 12

3.1 Pesquisa Cybersource 2013 sobre ferramentas para gestão de fraudes (Cybersource ,

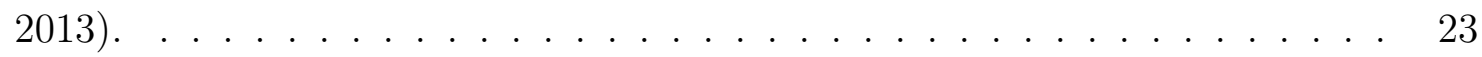

5.1 Comparação dos erros de predição do modelo $M_{3}$ e DMA com 17 modelos Raftery et al. (2010). . . . . . . . . . . . . . . . . 45

5.2 Odds ratio da variável idade do modelo com todos preditores. (McCormick et al. , 2012). . . . . . . . . . . . . . . . . . . . . 47

5.3 Odds ratio das variáveis raça hispânico e afro-americano do modelo com todos preditores. (McCormick et al. , 2012). . . . . . . . . . . . . . 47

5.4 Probabilidade marginais de nove preditores. (McCormick et al. , 2012). . . . 48

5.5 Número de variáveis preditoras para inflação baseada no GPD. (Koop e Korobilis ,

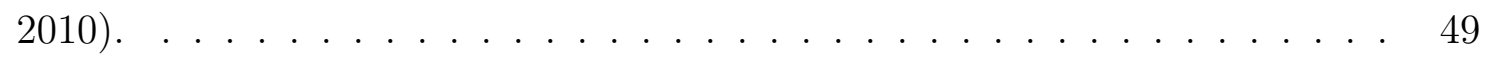

5.6 Número de variáveis preditoras para inflação baseada no PCE. (Koop e Korobilis ,

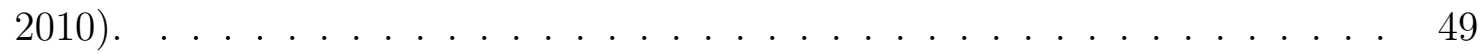

6.1 Preparação da base de dados. . . . . . . . . . . . . . . . . . . . . 54

6.2 Fluxo para análise dos dados. . . . . . . . . . . . . . . . . . . . . . . . . . . . . . .

6.3 Dados faltantes observados nos períodos. . . . . . . . . . . . . . 60

6.4 Dados faltantes em relação ao total de variáveis e períodos. . . . . . . . . . . 60

6.5 Dados faltantes em relação às variáveis e períodos finais após análise e ajustes. 61

6.6 Fluxo do processo de amostragem. . . . . . . . . . . . . . . . . 68

7.1 Poder discriminatório (valor da informação) das variáveis candidatas. . . . . 70

7.2 Correlação entre as variáveis candidatas para o modelo. . . . . . . . . . . . . 71

7.3 Boxplot do peso da evidência das variáveis candidatas para o modelo. . . . . 73 
7.4 Médias do peso da evidência das variáveis candidatas com intervalo de $95 \%$ de confiança. . . . . . . . . . . . . . . . . . . 75

7.5 Resíduos deviance do modelo ajustado com stepwise. . . . . . . . . . . . . 78

7.6 Densidade de fraude e não fraude do modelo ajustado com stepwise. . . . . . 81

7.7 Curva ROC do modelo ajustado com stepwise (ponto de corte para probabilidade $=0,6) \ldots \ldots \ldots \ldots \ldots$. . . . . . . . . . . . . . 82

7.8 Índice de estabilidade populacional do modelo ajustado com stepwise. . . . . 83

7.9 Boxplox das amostras de treinamento e validação do modelo ajustado com stepwise. . . . . . . . . . . . . . . . . . . . 84

7.10 Histograma da amostra de treinamento e validação do modelo ajustado com stepwise . . . . . . . . . . . . . . . . . . .

7.11 Densidade das amostras de treinamento e validação do modelo ajustado com stepwise. . . . . . . . . . . . . . . . . . . .

7.12 Curva ROC da amostra de validação (ponto de corte para probabilidade $=0,6$ ) do modelo ajustado com stepwise. . . . . . . . . . . . . . . . .

7.13 Média das probabilidades a posteriori dos modelos selecionados para o modelo DMA 95. . . . . . . . . . . . . . . . . . .

7.14 Histogramas das probabilidades a posteriori dos modelos selecionados para o modelo DMA 95.

7.15 Probabilidade a posteriori dos modelos selecionados para o modelo DMA 95 a cada 1.000 transações no tempo. . . . . . . . . . . . . . . . . .

7.16 Probabilidade a posteriori dos modelos selecionados para o modelo DMA 95 a cada 10.000 transações no tempo. . . . . . . . . . . . . . . . . .

7.17 Estimativas dos parâmetros dos modelos selecionados para o modelo DMA 95 a cada 1.000 transações no tempo $(\lambda=\alpha=0,95) \ldots \ldots \ldots 7$

7.18 Resíduos deviance do modelo DMA 95 . . . . . . . . . . . . . . . . . 98

7.19 Densidade de fraude e não fraude do modelo DMA 95. . . . . . . . . . . . . 100

7.20 Curva ROC da amostra de desenvolvimento do modelo DMA 95. . . . . . . . 100

7.21 Índice de estabilidade populacional do modelo DMA 95 . . . . . . . . . . . . 101

7.22 Boxplox das amostras de treinamento e validação do modelo DMA 95. . . . . 102

7.23 Histograma das amostras de treinamento e validação do modelo DMA 95. . . 102

7.24 Densidade das amostras de treinamento e validação do modelo DMA 95. . 103

7.25 Curva ROC da amostra de validação do modelo DMA 95 . . . . . . . . . . . 103

7.26 Curva ROC dos modelos ajustados. . . . . . . . . . . . . . . . . 107

B.1 Variância dos parâmetros dos modelos selecionados para o modelo DMA 95 a cada 1.000 transações no tempo. . . . . . . . . . . . . . . . . . . . . . . . . 114

C.1 Resíduos deviance do modelo ajustado com stepwise modificado. . . . . . . . 116

C.2 Densidade de fraude e não fraude do modelo ajustado com stepwise modificado.118

C.3 Curva ROC do modelo ajustado com stepwise modificado (ponto de corte para probabilidade $=0,6) \ldots \ldots \ldots$. . . . . . . . . . . . 118 
C.4 Boxplox das amostras de treinamento e validação do modelo ajustado com stepwise modificado. . . . . . . . . . . . . . . . . . . . . . . . . . 119

C.5 Histograma da amostra de treinamento e validação do modelo ajustado com stepwise modificado. . . . . . . . . . . . . . . . . . . . . . . . . . . 120

C.6 Densidade das amostras de treinamento e validação do modelo ajustado com stepwise modificado. . . . . . . . . . . . . . . . . . . . . . . . . . . 120

C.7 Curva ROC da amostra de validação do modelo ajustado com stepwise modificado (ponto de corte para probabilidade $=0,6$ ).

D.1 Médias das probabilidades a posteriori dos modelos selecionados para o modelo DMA 99

D.2 Histogramas das probabilidades a posteriori dos modelos selecionados para o

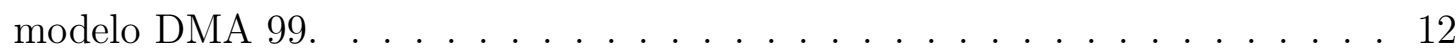

D.3 Probabilidades a posteriori dos modelos selecionados para o modelo DMA 99 a cada 1.000 transações no tempo. . . . . . . . . . . . . . . . . . 125

D.4 Probabilidades a posteriori dos modelos selecionados para o modelo DMA 99 a cada 10.000 transações no tempo. . . . . . . . . . . . . . . . . . . 126

D.5 Estimativas dos parâmetros dos modelos selecionados para o modelo DMA 99 a cada 1.000 transações no tempo. . . . . . . . . . . . . . . . . . . . . . . . . 129

D.6 Variância dos parâmetros dos modelos selecionados para o modelo DMA 99 a cada 1.000 transações no tempo. . . . . . . . . . . . . . . . . . . . . . . . . 132

D.7 Resíduos deviance do modelo DMA 99. . . . . . . . . . . . . . . . . . 133

D.8 Densidade de fraude e não fraude do modelo DMA 99. . . . . . . . . . . . 134

D.9 Curva ROC do modelo DMA 99. . . . . . . . . . . . . . . . . . . 135

D.10 Boxplox das amostras de treinamento e validação do modelo DMA 99. . . . . 136

D.11 Histograma das amostras de treinamento e validação do modelo DMA 99. . 136

D.12 Densidade das amostras de treinamento e validação do modelo DMA 99. . 137

D.13 Curva ROC da amostra de validação do modelo DMA 99 . . . . . . . . . . . . 137 


\section{Lista de Tabelas}

2.1 Ranking de países considerando o volume financeiro transacionado em cartões de crédito. Fonte: ABECS. . . . . . . . . . . . . . . . . . . 7

2.2 Identificação da indústria. . . . . . . . . . . . . . . . . . . . . 11

2.3 Identificação da bandeira. . . . . . . . . . . . . . . . . . . . . . . . . . . 12

2.4 Padrão de Segurança de Dados do PCI - Visão Geral Alto Nível (PCI-Council , 2012) . . . . . . . . . . . . . . . . . . . 14

4.1 Indicadores de Performance. . . . . . . . . . . . . . . . . . . . . . . 33

4.2 Comparação de técnicas estatísticas para detecção de fraude em cartão de crédito Al-Khatib (2012). . . . . . . . . . . . . . . . 34

5.1 Lista de preditores usados em cada modelo Raftery et al. (2010). . . . . . . 44

5.2 Estatísticas do erro de predição.

MSE: Erro Médio Quadrático, MaxAE: Máximo Erro Absoluto e \#AE>10: número de erros acima de 10 microns em valor absoluto. (Raftery et al. , 2010). 45

5.3 Comparação do método DMA com as predições do Banco Central dos Estados Unidos Koop e Korobilis (2010). . . . . . . . . . . . . . . . . 49

6.1 Ações para as variáveis originais com dados faltantes. . . . . . . . . . . . . . . 61

6.2 Poder de discriminação (Valor da Informação) das variáveis independentes candidatas finais. . . . . . . . . . . . . . . . . . 66

7.1 Variáveis selecionadas e estatísticas do modelo ajustado com stepwise. . . . . 77

7.2 Testes para avaliação do modelo ajustado com stepwise. . . . . . . . . . . . 78

7.3 Tabela para avaliação do valor de KS. . . . . . . . . . . . . . . . . . . 79

7.4 Cálculo do KS do modelo ajustado com stepwise. . . . . . . . . . . . . . . 79

7.5 Tabela de classificação das transações e intervalo de pontuação pelo modelo ajustado com stepwise. . . . . . . . . . . . . . . . . . . . 80

7.6 Tabela para avaliação do valor de AUC. . . . . . . . . . . . . . . . . . 81

7.7 Valores de referência para IEP. . . . . . . . . . . . . . . . . 83

7.8 Tabela de classificação das transações pelo modelo ajustado com stepwise (ponto de corte para probabilidade=0,6) . . . . . . . . . . . 86

7.9 Indicadores de performance do modelo de regressão logística clássica com stepwise . . . . . . . . . . . . . . . . . . . . . 87 
7.10 Indicadores de performance do modelo de regressão logística clássica com as técnicas stepwise e stepwise modificado. . . . . . . . . . . . . . . . . . . 88

7.11 Avaliação de $\lambda$ e $\alpha$ para o modelo DMA. . . . . . . . . . . . . . . . . . . 89

7.12 Modelos e variáveis selecionadas. . . . . . . . . . . . . . . . . . . . 90

7.13 Cálculo do KS do modelo DMA 95 . . . . . . . . . . . . . . . . . . . 98

7.14 Tabela de classificação das transações e intervalo de pontuação pelo modelo DMA $95 \ldots \ldots \ldots \ldots \ldots$

7.15 Tabela de classificação das transações pelo modelo DMA 95 (ponto de corte para probabilidade $=0,6) \ldots \ldots \ldots$. . . . . . . . . . . . . . 104

7.16 Indicadores de performance do modelo DMA 95. . . . . . . . . . . . . . . 104

7.17 Comparação da performance dos modelos ajustados. . . . . . . . . . . . . . 106

7.18 Valores da medida F para os modelos ajustados. . . . . . . . . . . . . 107

A.1 Matriz de correlação das variáveis candidatas. . . . . . . . . . . . . . 111

C.1 Variáveis selecionadas e estimativas dos parâmetros do modelo com stepwise modificado. . . . . . . . . . . . . . . . . 115

C.2 Testes para avaliação do modelo ajustado com stepwise modificado. . . . . . 116

C.3 Cálculo do KS do modelo ajustado com stepwise modificado. . . . . . . . . . 117

C.4 Tabela de classificação das transações e intervalo de pontuação pelo modelo ajustado com stepwise modificado. . . . . . . . . . . . . . . . . . . . 117

C.5 Índice de estabilidade populacional do modelo ajustado com stepwise modificado. . . . . . . . . . . . . . . . . . . . . 119

C.6 Tabela de classificação das transações pelo modelo ajustado com stepwise modificado (ponto de corte para probabilidade $=0,6$ ) . . . . . . . . . . . . 121

C.7 Indicadores de performance do modelo ajustado com stepwise modificado. . . 122

D.1 Cálculo do KS do modelo DMA 99. . . . . . . . . . . . . . . . . . . 133

D.2 Tabela de classificação das transações e intervalo de pontuação pelo modelo DMA 99. . . . . . . . . . . . . . . . . . . . . . 134

D.3 Índice de estabilidade populacional do modelo DMA 99. . . . . . . . . . . . . 135

D.4 Tabela de classificação das transações pelo modelo DMA 99 (ponto de corte para probabilidade $=0,6) \ldots \ldots \ldots \ldots$. . . . . . . . . . . . . 138

D.5 Indicadores de performance do modelo DMA 99 . . . . . . . . . . . . . 138 


\section{Capítulo 1}

\section{Introdução}

Com os avanços tecnológicos e econômicos, que facilitaram o processo de comunicação e aumento do poder de compra, transações com cartão de crédito tornaram-se o principal meio de pagamento no varejo nacional e internacional (Bolton e Hand , 2002). Neste aspecto, o aumento do número de transações com cartão de crédito foi crucial para a geração de mais oportunidades para fraudadores produzirem novas maneiras de fraudes, o que resulta em grandes perdas financeiras para o sistema (Chan et al. , 1999).

Mesmo com o avanço da segurança nas transações com cartão de crédito, proveniente, por exemplo, da criação de cartões com chip e senha em alguns mercados, o problema da fraude persiste e evolui na mesma velocidade em transações onde o cartão não está presente (por exemplo, transações pela internet ou telefone), fazendo com que métodos muitas vezes sofisticados sejam utilizados para apropriação de consideráveis volumes de dinheiro.

No Brasil, segundo pesquisa realizada pela Federação Brasileira de Bancos (FEBRABAN , 2012), de cada $R \$ 100$ roubados de bancos, pelo menos $R \$ 95$ são fraudes eletrônicas, realizadas por cartões ou internet banking. Em 2012, o prejuízo somou cerca de R $\$ 1,4$ bilhão para os bancos.

Apesar dos riscos, o cartão de crédito tornou-se a primeira opção de pagamento em muitos segmentos, tais como supermercados, postos de gasolina e lojas virtuais, seja através de transações com o cartão presente $(\mathrm{CP})$ ou com cartão não presente $(\mathrm{CNP})$.

A transação com CP acontece quando o cartão está presente fisicamente no momento da transação, e as informações do cartão são lidas através da trilha ou chip por leitores denominado POS (Point of Sale) ou Pin Pad (Personal Information Number - Peripheral Adapter Device), frequentemente utilizado em supermercados. Já as transações com CNP são realizadas pelo telefone, catálogos ou internet, e consistem em situações em que o cartão não está presente fisicamente e, dessa maneira, os dados do cartão são digitados ou transmitidos verbalmente.

Os índices de fraudes têm mostrado que transações CNP são mais arriscadas do que as $\mathrm{CP}$, pois aquelas não fazem uso do mesmo processo de autenticação do portador do cartão, como a utilização de senha eletrônica. 
Nesse cenário de CNP, os brasileiros só ficam atrás dos alemães quando o assunto é preocupação com segurança nas compras e transações bancárias pela internet e com vírus e spam, segundo pesquisa realizada em dez países pela Unisys Security Index (Unisys , 2010).

Apesar de investimentos em prevenção serem a melhor maneira de reduzir o volume de fraude, os fraudadores adaptam-se rapidamente e, na maioria das vezes, encontram outra maneira de fraudar. Por esse motivo, metodologias para detecção são essenciais dado que o processo de prevenção pode falhar.

Para combater ações de fraudadores, as instituições financeiras brasileiras vêm adotando sistemas e métodos estatísticos cada vez mais sofisticados a fim de separar o cliente legítimo do fraudador. Tais métodos são classificados como não supervisionados e supervisionados. No conjunto dos métodos supervisionados, os sistemas baseados em regras e modelos de pontuação são os tradicionalmente adotados pelo mercado.

Outra dificuldade de buscar informações nessa área vem da escassez de dados reais disponíveis publicamente para realização de experimentos e a falta de publicações que descrevam métodos e técnicas (Leonard , 1993). Também soma-se a essa questão a presença de dados desbalanceados, pois a porcentagem de transações fraudulentas é bem pequena em relação às transações legítimas, durabilidade do modelo e custo relacionado ao falso positivo e falso negativo (Gadi et al. , 2008).

\section{Motivação}

Pode-se dizer que o principal objetivo de um sistema de detecção de fraudes em transações de cartão de crédito é identificar, com menor número de "alarmes falsos", as transações fraudulentas de maneira a não gerar grandes atritos com o cliente legítimo e proteger os ativos das entidades participantes da transação (estabelecimento, adquirente, bandeira e emissor). Em outras palavras, deve existir o equilíbrio entre impacto nas receitas e volume de fraudes.

Os "alarmes falsos"podem ser exemplificados por situações em que transações atípicas, porém legítimas, são classificadas como suspeitas.

Com a velocidade dos fraudadores na adoção de novas técnicas de fraude e a dificuldade dos modelos para se adaptarem de modo a captar essa mudança de comportamento, surge a necessidade de uma estrutura de modelagem capaz de, ao longo do tempo, identificar as mudanças mais recentes de comportamento para que novos parâmetros do modelo estejam atualizados em um espaço de tempo menor.

Existem alguns trabalhos publicados sobre várias técnicas estatísticas utilizadas no processo de detecção de fraudes para transações com cartão de crédito. No entanto, poucos mencionam a questão de atualização dos modelos e qual o melhor momento de realizá-la de maneira a potencializar a identificação de transações fraudulentas. Também não encontramos na literatura trabalhos sobre modelos de predição de transações fraudulentas que envolvam a questão da atualização dinâmica. 
Para trabalhar esse processo de atualização, Raftery et al. (2010) desenvolveram um método chamado Dynamic Model Averaging (DMA), ou Ponderação Dinâmica de Modelos, que implementa um processo de atualização contínuo ao longo do tempo.

\section{Objetivo}

Nesse trabalho, buscamos desenvolver modelos de regressão logística com atualização dinâmica (DMA) no espaço de transações eletrônicas oriundas do comércio eletrônico (ecommerce), que incorpore as tendências e características de fraudes em cada período de análise.

Para atingir esse objetivo, uma empresa de meios de pagamentos eletrônico forneceu os dados para o desenvolvimento dos modelos DMA e os modelos de regressão logística clássica para compararmos suas performances no processo de deteç̧ão de fraude.

\section{Organização da Dissertação}

O nosso trabalho foi estruturado em 8 capítulos. No capítulo 1 fizemos uma introdução e apresentamos o objetivo do trabalho, no capítulo 2 mostramos o mercado de cartões e nos capítulos 3 e 4 descrevemos o processo de fraude em cartão de crédito e métodos de prevenção, respectivamente. Já no capítulo 5, apresentamos a técnica de ponderação dinâmica de modelos, também conhecido como DMA (Dynamic Modeling Averaging). Foi exposto no capítulo 6 a metodologia utilizada para fazermos o experimento e no capítulo 7 desenvolvemos os modelos de regressão logística clássica e DMA e discutimos os resultados das comparações dos modelos. Por fim, no capítulo 8 mostramos nossas conclusões e trabalhos futuros. 


\section{Capítulo 2}

\section{Mercado de Cartões de Crédito}

\subsection{Definição}

De maneira geral, pode-se classificar o mercado de cartões como um mercado de dois lados (M2L), ou seja, tem como característica a existência de uma plataforma que organiza e permite o encontro de dois grupos distintos de consumidores finais. No mercado de cartões, os grupos de consumidores finais identificados são a rede de consumidores portadores de cartões e a rede de estabelecimentos comerciais. Observe que do ponto de vista do gerenciador do sistema de cartão de crédito, os estabelecimentos são também consumidores.

Essa estrutura é caracterizada pela presença de externalidades de rede, que podem ser definidas da seguinte forma: o valor (utilidade) dado pelo consumidor final de um dos grupos depende da quantidade de consumidores finais existentes no outro grupo, e do número de oportunidades de realizar transações intergrupo que utilizam a mesma plataforma. Assim, a plataforma é responsável por criar condições para que os consumidores de ambos os lados se encontrem e realizem o maior número de transações possíveis (Rochet e Tirole , 2004).

Para o sistema de pagamentos com cartões se tornar bem sucedido, deve-se atrair um número mínimo de portadores de cartão de modo que a plataforma seja suficientemente atraente para os estabelecimentos comerciais, sendo que o argumento recíproco também é válido, ou seja, deve existir, também, um número mínimo de estabelecimentos comercias para que seja atrativo para os portadores de cartão.

Para que o mercado de dois lados possa ser considerado eficiente, cada grupo de consumidores deve pagar o custo da plataforma, descontada (ou acrescida) das externalidades, ou seja, cada grupo internaliza (através do preço) as externalidades de rede geradas no mercado de cartões.

Portanto, o mercado de dois lados no qual o segmento de cartões está inserido é definido pela interdependência entre dois mercados através de uma plataforma na qual uma ação (des)estimuladora em um desses mercados traz consequências diretas ao outro mercado. 


\subsection{Histórico}

Cartões de crédito têm se tornado cada vez mais um instrumento financeiro essencial na vida das pessoas, em substituição aos cheques, cédulas e moedas como meio de pagamento. Com um cartão de crédito é possível comprar quase tudo ao seu redor. Isso inclui fazer compras no supermercado, adquirir ingressos para cinemas e jogos, abastecer automóveis, e até mesmo adquirir produtos com maior valor, como carros.

Com limites de créditos definidos pelos emissores dos cartões que alcançam muitas vezes mais que o dobro de sua renda mensal, portadores realizam suas compras sem a preocupação de saber quanto dinheiro levam em suas carteiras, além da possibilidade de parcelamento de compras para valores mais elevados. Uma das vantagens desse método de pagamento para os estabelecimentos é o fato de receber esses valores diretamente na conta bancária, evitando o manuseio de cheques e dinheiro, e, por outro lado, para o portador de cartão está no fato de que as despesas ficam concentradas em um único lugar e a participação de programas de fidelidade, por exemplo. A facilidade e rapidez de se fazer uma transação com cartão de crédito tem contribuído para a expansão desse método de pagamento em diversos ramos de atividade.

Conforme informações do Banco Central do Brasil, os cartões de crédito não são dinheiro real, simplesmente registram a intenção de pagamento do consumidor mediante sua assinatura ou senha e demais verificações. Por sua vez, o consumidor terá que pagar as despesas do cartão em data pré-determinada, por meio de débito automático, boleto, espécie ou cheque (BACEN , 2013). Desta maneira, o cartão de crédito é uma forma imediata de crédito.

A seguir, mostramos os principais marcos históricos relacionados ao mercado de cartão de crédito no mundo, desde sua invenção até os dias atuais (Sesame , 2013):

1887 Edward Bellamy inventa o conceito de fazer compras usando cartão em seu utópico romance Looking Backward;

1914 Nos Estados Unidos, muitos varejistas começam a emitir cartões para seus clientes mais ricos em uma tentativa de fidelizá-los e aumentar as vendas de seus produtos mais caros;

1928 Varejistas começam a emitir um tipo de cartão que era embossado em uma pedaço de metal;

1934 American Airlines cria o cartão Air Travel para seus clientes; 
1938 Western Union começa a emitir um cartão de despesas ( Charge $_{\text {card }}{ }^{1}$ ) para clientes frequentes;

$194150 \%$ da receita da American Airlines é oriunda do cartão Air Travel;

1948 O cartão Air Travel torna-se o primeiro cartão de despesas internacionalmente aceito;

1950 O cartão Diners Club é criado. Originalmente, o seu uso seria para pagamento de contas em restaurantes, e mais tarde iria se tornar um cartão universal que permitia ao portador comprar serviços e bens em uma variedade de estabelecimentos;

1959 O conceito de saldo rotativo (revolving balance) é introduzido pela Master Charge;

1966 American Express cria seu próprio cartão de crédito. Bank of America também decide criar sua própria bandeira chamada BankAmericard;

1970s Sistemas de cartão de crédito baseados em papel são substituídos por sistemas eletrônicos;

1976 BankAmericard muda seu nome para Visa com o objetivo de desenvolver um imagem internacional;

1980 Master Charge muda seu nome para Mastercard;

1986 A loja de departamento Sears, grande varejista americano, lança o cartão Discover;

1990s As empresas de cartão de crédito começam a oferecer recompensas e incentivos para estimular o uso do cartão de crédito;

2005 Paypal é fundado, permitindo receber e realizar pagamentos através da internet com cartão de crédito;

2010 A empresa Square é criada, permitindo usuários aceitarem cartão de crédito através de celulares;

2011 O sistema de pagamento móvel Google Wallet é lançado, o que cria o cartão de crédito virtual em dispositivos móveis.

No Brasil, o precursor dos cartões de crédito foi o empresário tcheco Hanus Tauber, que comprou a franquia do Diners Club nos Estados Unidos em 1954 e propôs sociedade no cartão com o empresário Horácio Klabin. Em 1956, foi então lançado no Brasil o cartão Diners Club.

\footnotetext{
${ }^{1}$ Apesar dos cartões de despesa Charge Card e cartão de crédito Credit Card parecerem ser a mesma coisa, eles possuem protocolos distintos das transações financeiras. Cartões de crédito possuem um limite no crédito rotativo e, ao final de cada mês, o total das despesas não precisa ser pago integralmente. Para pagamento parcial da dívida, o portador terá que pagar juros acrescidos ao restante da dívida no mês subsequente. Cartões de despesa são geralmente emitidos sem limite de gasto e o portador é obrigado a pagar o total das despesas.
} 
Em 1968, foi lançado no Brasil o primeiro cartão de crédito de banco nacional, intitulado como ELO e criado pelo Banco Bradesco. Em 1983, foi lançado o primeiro cartão de débito, e em 1984 a Credicard comprou o Diners Club no Brasil (fraudes.org , 2013).

\subsection{Números do Mercado Brasileiro}

Segundo relatório da Associação Brasileira das Empresas de Cartão de Crédito e Serviços (ABECS , 2012), o Brasil ocupava em 2010 a $9^{a}$ posição em relação ao volume financeiro em transações com cartão de crédito (tabela 2.1).

\begin{tabular}{|c|c|c|c|}
\hline 2010 & 2009 & 2008 & País \\
\hline 10 & 10 & 10 & EUA \\
\hline $2^{\circ}$ & $2^{\circ}$ & $2^{\circ}$ & China \\
\hline $3^{\circ}$ & 40 & $4^{\circ}$ & Japão \\
\hline $4^{\circ}$ & $3^{\circ}$ & 30 & França \\
\hline $5^{\circ}$ & $5^{\circ}$ & 50 & Coréia do Sul \\
\hline $6^{\circ}$ & $6^{\circ}$ & 70 & Canadá \\
\hline 70 & 70 & $6^{\circ}$ & Inglaterra \\
\hline $8^{\circ}$ & $8^{\circ}$ & $8^{\circ}$ & Austrália \\
\hline $9^{\circ}$ & 90 & $10^{\circ}$ & Brasil \\
\hline $10^{\circ}$ & $10^{\circ}$ & 90 & Turquia \\
\hline
\end{tabular}

Tabela 2.1: Ranking de países considerando o volume financeiro transacionado em cartões de crédito. Fonte: ABECS.

Considerando cartões de crédito, débito e de redes/lojas, pagamentos com esses cartões representam 26,8\% do consumo das famílias em 2011. Se compararmos com o mercado americano, inglês e canadense, observa-se o grande potencial de crescimento desse meio de pagamento (figura 2.1) (ABECS , 2012).

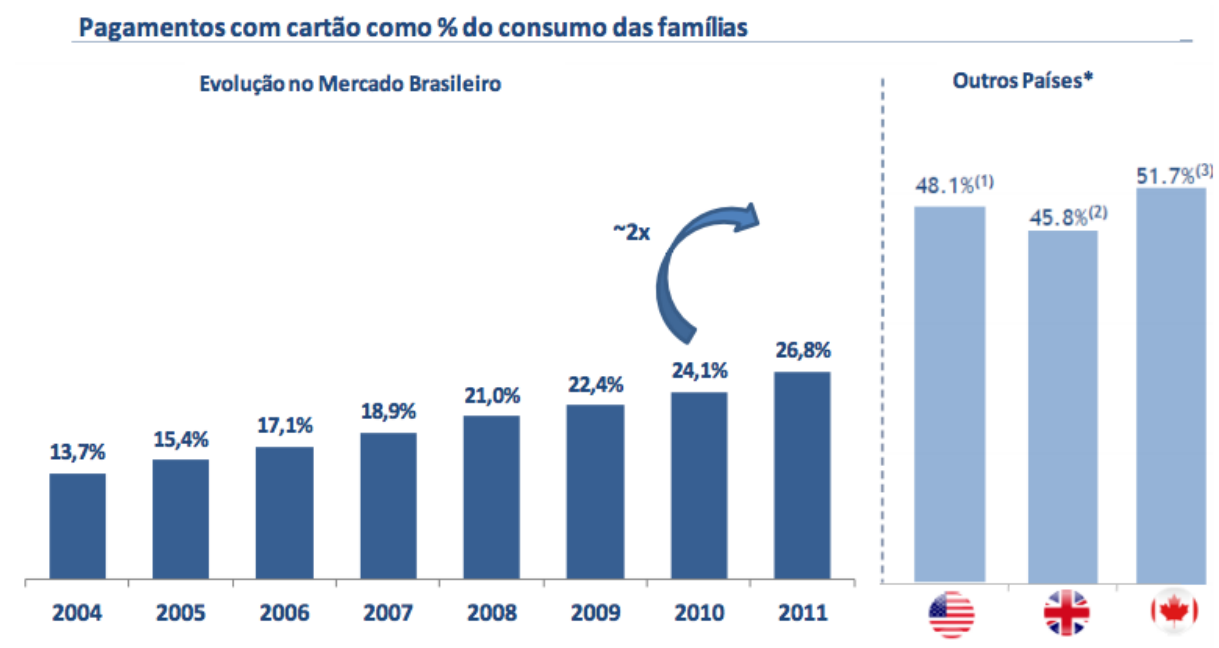

Figura 2.1: Percentual do uso de cartão como meio de pagamento no consumo das famílias no Brasil. Fonte: ABECS (ABECS, 2012). 
O faturamento, tanto da modalidade crédito como débito, aumentou mais de $150 \%$ se analisarmos os anos de 2007 e 2012 (figura 2.2).

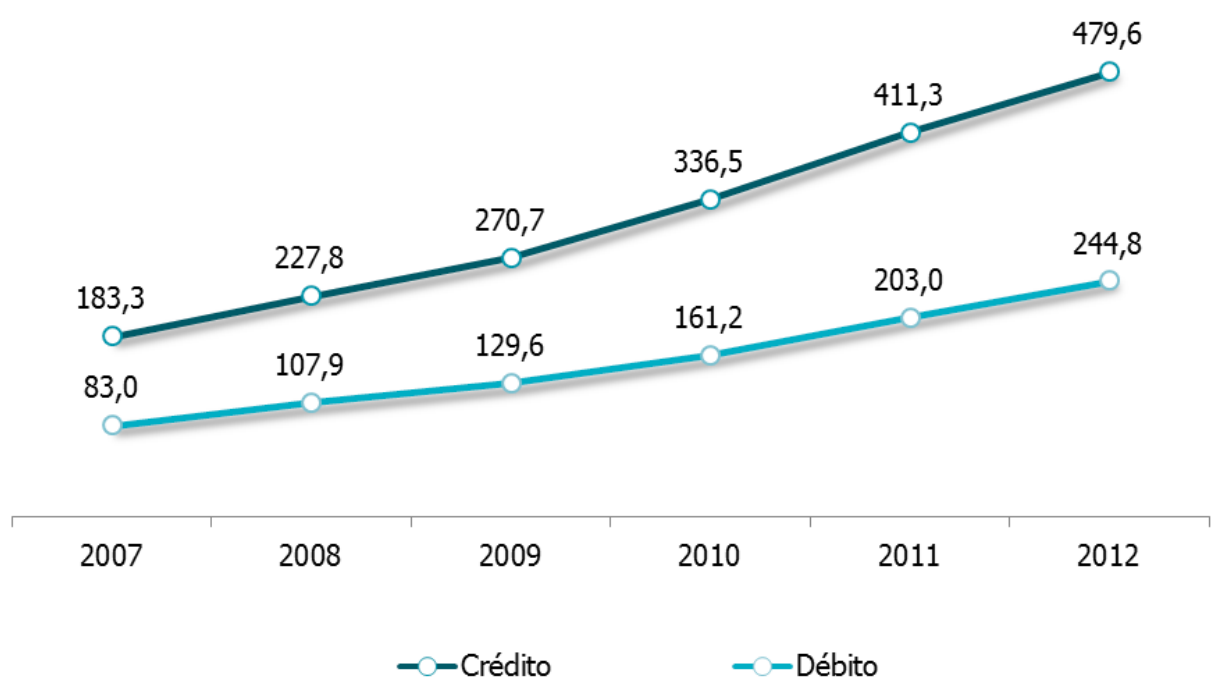

Figura 2.2: Faturamento por função do cartão no Brasil (em $R \$$ bilhões). Fonte: ABECS (ABECS , 2012).

Essa mesma tendência de crescimento acompanha os números de quantidade de transações, que aumentaram mais de 100\% em relação a 2007 e 2012 (figura 2.3).

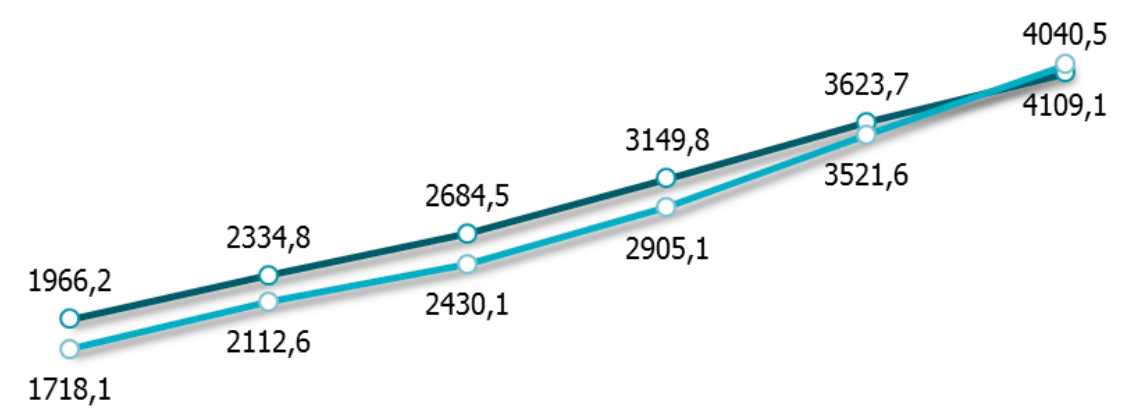

\begin{tabular}{|c|c|c|c|c|c|}
\hline 2007 & 2008 & 2009 & 2010 & 2011 & 2012 \\
\hline
\end{tabular}

Figura 2.3: Quantidade de transações por função do cartão no Brasil (em R\$ milhões). Fonte: $A B E C S$ (ABECS , 2012).

Com essa tendência de crescimento, especialistas do setor prevêem que o mercado de cartões brasileiro cresça entre $15 \%$ e $20 \%$ anualmente pelos próximos cinco anos. 


\subsection{Funcionamento do Cartão de Crédito}

Nessa seção apresentamos os agentes envolvidos no mercado de cartões de crédito, a estrutura de um cartão, o fluxo de uma transação, além dos padrões de segurança utilizados nesse mercado.

\section{Agentes do Cartão de Crédito}

Atualmente, os cartões de crédito possuem cinco agentes envolvidos em seu funcionamento: portador (card holder), estabelecimento (merchant), adquirente (acquirer), bandeira (card brand or association) e emissor (issuer).

A seguir, apresentamos uma breve descrição desses agentes (Gadi , 2006):

Portador: indivíduo que possui o cartão, sendo esse o responsável por iniciar o funcionamento do sistema ao decidir pagar suas compras com seu cartão de crédito.

Estabelecimento: qualquer empresa, pessoa física ou jurídica credenciada que aceite o cartão de crédito por meio de um equipamento específico.

Adquirente: a função da empresa adquirente é de credenciar, supervisionar e repassar os valores de compra aos estabelecimentos que aceitam o cartão de crédito, além de ser responsável pela implementação e manutenção das maquinetas, denominadas POS (point of sales), e dos programas de captura de transações.

Emissor: em geral, os emissores são bancos, responsáveis pela distribuição dos cartões de crédito aos seus clientes mediante a aprovação do risco de crédito por políticas próprias de cada instituição. Até 2005, no Brasil, a maioria dos cartões de crédito pertenciam a emissores independentes dos bancos. As principais receitas dos emissores provêm do financiamento rotativo dos clientes, das anuidades e de seguros ou serviços agregados ao produto cartão de crédito.

Bandeira: responsáveis pelas definições das regras de política (relacionamento entre emissores e adquirentes), operações da rede global de comunicações, execuções de marketing institucional e pesquisas e desenvolvimentos de novas tecnologias e serviços. As principais fontes de receitas das Bandeiras são as multas aplicadas aos clientes devido ao não cumprimento de regras e prazos e um percentual da taxa cobrada aos estabelecimentos por transação, conhecido como MDR (Merchant Discount Rate). São exemplos de bandeiras: Visa, MasterCard, Amex e Hipercard. 


\section{Bandeiras de Cartões de Crédito}

A seguir são apresentadas as principais bandeiras de cartões de crédito no mercado. São elas:

Visa É uma associação de 21.000 instituições financeiras no mundo todo, que emitem o cartão com a bandeira Visa. Existem 1,3 bilhões de cartões Visa em circulação, aceitos em mais de 24 milhões de estabelecimentos em mais de 150 países. No ano de 2005, o volume de transações gerado por esses cartões foi de 3 trilhões de dólares.

Mastercard Possui mais de 25.000 parceiros emissores no mundo. Existem cerca de 720 milhões de cartões Mastercard em circulação, aceitos em 32 milhões de estabelecimentos comerciais e em mais de 210 países. No ano de 2005, o volume de transações gerado por cartões da Mastercard foi de aproximadamente 1,2 trilhões de dólares.

American Express É uma instituição fundada em 1850, mas o primeiro cartão foi emitido somente em 1958. Os cerca de 57 milhões de cartões Amex em circulação são aceitos em mais de 200 países. No ano de 2005, os cartões Amex geraram cerca de 150 bilhões de dólares em transações.

Outras bandeiras de cartões difundidas no mundo, com maior ou menor concentração, dependendo da região, são: Diners Club, JCB (Japanese Credit Bureau), Discover e Solo. No Brasil, existem ainda algumas bandeiras nacionais com boa divulgação, dentre as quais podemos citar o HiperCard (Itaú-Unibanco), Cartão Aura (Grupo BNP Paribas) e o Elo (Banco do Brasil, Bradesco e Caixa Econômica Federal).

\section{Tendências para o Futuro}

Nesta subseção elencamos algumas das principais tendências para o mercado de cartões observadas ao redor do mundo.

- Pagamento Móvel: a aceitação de pagamentos com cartão de crédito através de smartphones e tablets tende a aumentar devido à expansão desses dispositivos.

- Cartão por Aproximação: também conhecido como cartão contactless, adiciona a funcionalidade de realizar transações com a aproximação do cartão no terminal do estabelecimento. Utilizando a tecnologia de RFID (Radio Frequency IDentification), identificação por rádio frequência, ou NFC (Near Field Communication), comunicação por aproximação. Essa tecnologia procura otimizar o tempo do processo de pagamento, o que eliminaria longas filas em estabelecimentos com grandes fluxos de pessoas, como restaurantes e cafeterias.

- Cartão Inteligente: também conhecido como display card, esse cartão reúne as tecnologias chip e senha dinâmica (token), a qual se altera após um determinado período 
de tempo. Essa tecnologia poderá permitir maior segurança nas transações não presenciais com a utilização do token para autenticar o portador do cartão.

- Cartão Dinâmico: um único cartão físico que possui um chip que controla vários números de cartões. Existirá um pequeno teclado para acessar os múltiplos cartões com segurança.

\section{Estrutura do cartão de crédito}

Normalmente, o número do cartão de crédito tem 16 dígitos e é descrito como a parte 1 da ISO/IEC 7812 publicada pela Organização Internacional de Normalização (ISO). Bandeiras de cartões de crédito como Visa e Mastercard têm adotado a seguinte estrutura para cartões:

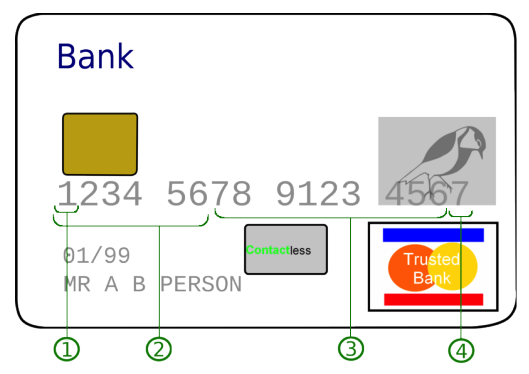

$\begin{array}{ll} & \text { Posição do Dígito } \\ \text { (1) MII/Bandeira } & 1 \\ \text { (2) IIN ou BIN } & 1 \text { a } 6 \\ \text { (3) Número da conta } & 7 \text { a } 15 \\ \text { (4) Dígito verificador } & 16\end{array}$

Figura 2.4: Estrutura do cartão de crédito.

O primeiro dígito do número do cartão de crédito é o identificador da indústria MII(Major Industry Identifier), que representa a categoria da entidade que emitiu o cartão de crédito para o portador. Diferentes MII representam as seguintes indústrias:

\begin{tabular}{|c|l|}
\hline Dígito MII & Categoria \\
\hline 0 & ISO/TC 68 e atribuições de outras indústrias \\
1 & Companhias aéreas \\
2 & Companhias aéreas e outras atribuições da indústria \\
3 & Viagem e entretenimento (como American Express e Diners Club) \\
4 & Financeiro e bancário (Visa) \\
5 & Financeiro e bancário (MasterCard) \\
6 & Merchandizing e bancário (Discover) \\
7 & Petróleo \\
8 & Telecomunicações e outras atribuições da indústria \\
9 & Atribuição nacional \\
\hline
\end{tabular}

Tabela 2.2: Identificação da indústria.

Os seis primeiros dígitos são conhecidos como o Número de Identificação do Emissor IIN (Issuer Identification Number) ou Número de Identificação Bancário BIN (Bank Identification Number). Eles identificam a instituição financeira que emitiu o cartão para o portador. Podemos dizer que algumas das bandeiras mais conhecidas são identificadas pelo primeiro dígito, como Mastercard e Visa, dígitos 5 e 4, respectivamente (tabela 2.3). 


\begin{tabular}{llc}
\hline Bandeira & Identificador & $\begin{array}{c}\text { Quantidade de } \\
\text { dígitos do cartão }\end{array}$ \\
\hline American Express & 34XXXX, 37XXXX & 15 \\
Visa & 4XXXXX & 13,16 \\
Mastercard & SXXXXX & 16 \\
Discover & $6011 \mathrm{XX}$ & 16 \\
Diners Club/Carte Blanche & $300 \mathrm{xxx}-305 \mathrm{xxx}, 36 \mathrm{xxxx}, 38 \mathrm{xxxx}$ & 14 \\
\hline
\end{tabular}

Tabela 2.3: Identificação da bandeira.

Além disso, um fato curioso sobre o cartão de crédito é a sua forma geométrica. O cartão tem uma forma de retângulo, muito próxima ao retângulo de ouro. No retângulo de ouro, ao dividirmos a largura pela altura, o resultado será a razão áurea.

\section{Passo a passo da transação}

Uma transação é uma compra que se inicia com o portador do cartão. O fluxo a seguir descreve, resumidamente, o processo da transação com o cartão:

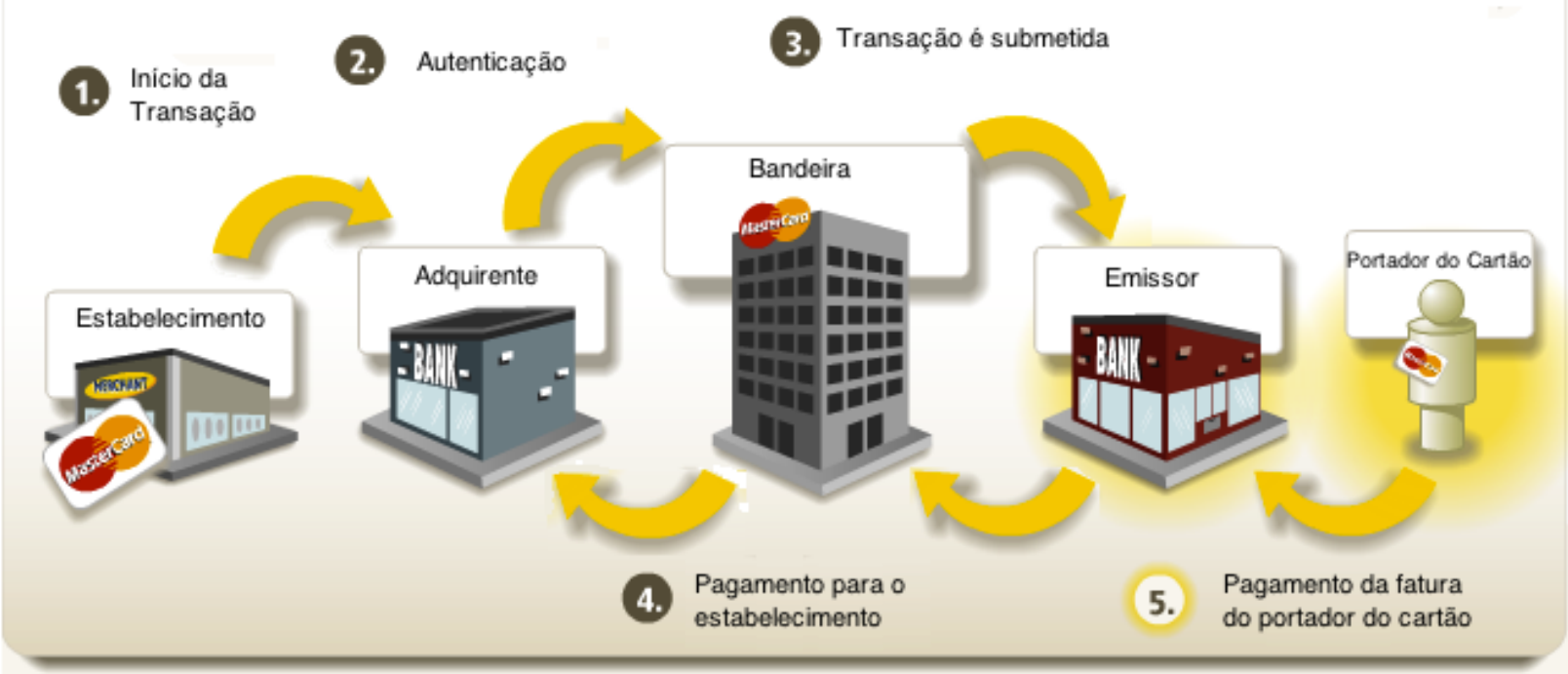

Figura 2.5: Fluxo da Transação. Fonte: Mastercard.

1. Início da transação: o portador do cartão compra bens ou serviços de um estabelecimento, o qual envia, em seguida, a informação da transação para o adquirente;

2. Autenticação: o estabelecimento, através dos sistemas dos adquirentes, captura a transação, sendo descontado do valor da transação uma taxa pelo serviço;

3. Submissão: o adquirente submete a transação, que transita antes pelos sistemas das bandeiras, para o emissor do cartão. A transação pode ser aprovada, negada ou referida pelo emissor mediante análises de crédito e fraude; 
4. Pagamento para o estabelecimento: o emissor do cartão paga o adquirente que, por sua vez, realiza o pagamento para o estabelecimento;

5. Pagamento para o emissor: finalmente, o portador do cartão paga para o emissor os valores correspondentes aos bens ou serviços que adquiriu do estabelecimento.

Existem muitos detalhes dos sistemas de autorização de cartões de crédito que incorporam técnicas sofisticadas de comunicação, algoritmos paralelos, criptografia e algoritmos para evitar intrusos. Esses sistemas buscam ser os mais seguros contra invasão em comparação aos sistemas bancários existentes. Outra característica importante do sistema de autorizações é a alta disponibilidade, que através de algumas inteligências de negócio, como o STAND-IN (autorização da transação pela bandeira quando o sistema do emissor não está disponível), mantém o sistema disponível por muito mais tempo em relação aos outros sistemas bancários (Gadi , 2006).

\section{Transações na Internet (Comércio Eletrônico - E-commerce)}

A idéia de pagar por bens e serviços eletronicamente não é nova. Desde a década de 1970 e início dos anos 1980, uma variedade de estruturas têm sido propostas para permitir o pagamento a ser efetuado através de uma rede de computadores. Após um período de crescimento exponencial, estima-se que mais de 2,7 bilhões de pessoas têm acesso a internet em 2013, isso representa 39\% da população mundial naquele ano (Users , 2013).

O sistema de pagamento eletrônico começou no final de 1996 e na primeira parte de 1997, com uma enorme variedade de métodos de pagamento. Alguns deles foram lançados no mercado, porém, não conseguiram alcançar uma grande população.

Com o crescente interesse no comércio eletrônico, as técnicas de pagamentos eletrônicos aumentaram cada vez mais. O pagamento com cartão de crédito é a forma mais popular provavelmente por causa de sua simplicidade e conveniência para o comprador. O usuário simplesmente insere os dados do cartão (geralmente número do cartão, validade, nome do titular e código de segurança), o comerciante valida a informação e, com a aprovação do emissor do cartão, envia as mercadorias ou fornece o serviço requisitado.

Em 2013, o mercado de e-commerce no Brasil apresentou um faturamento de $\mathrm{R} \$ 28,8$ bilhões, aumento de $28 \%$ no faturamento comparado a 2012. O valor médio de compras foi de $\mathrm{R} \$ 327$ e 9,1 milhões de pessoas fizeram sua primeira compra na internet no decorrer de 2013 (E-bit , 2014).

\section{Padrões de Segurança}

O conjunto de padrões de segurança de dados da indústria de pagamentos com cartão, conhecido como PCI DSS (Payment Card Industry Data Security Standard), é um padrão de segurança da informação para organizações que lidam e armazenam as informações do portador do cartão. 
O padrão foi criado para aumentar os controles em torno dos dados do portador e reduzir a fraude de cartão de crédito. O PCI é composto por 6 objetivos e 12 requisitos descritos na tabela 2.4 a seguir:

\begin{tabular}{|c|c|}
\hline $\begin{array}{l}\text { Construir e manter } \\
\text { uma rede segura }\end{array}$ & $\begin{array}{l}\text { 1. Instalar e manter uma configuração de firewall para proteger os dados } \\
\text { do titular do cartão } \\
\text { 2. Não usar padrões disponibilizados pelo fornecedor para senhas do sistema } \\
\text { e outros parâmetros de segurança }\end{array}$ \\
\hline $\begin{array}{l}\text { Proteger os dados do } \\
\text { portador do cartão }\end{array}$ & $\begin{array}{l}\text { 3. Proteger os dados armazenados do titular do cartão } \\
\text { 4. Criptografar a transmissão dos dados do titular do cartão em redes abertas } \\
\text { e públicas }\end{array}$ \\
\hline $\begin{array}{l}\text { Manter um programa } \\
\text { de gerenciamento de } \\
\text { vulnerabilidades }\end{array}$ & $\begin{array}{l}\text { 5. Usar e atualizar regularmente o software ou programas antivírus } \\
\text { 6. Desenvolver e manter sistemas e aplicativos seguros }\end{array}$ \\
\hline $\begin{array}{l}\text { Implementar medidas } \\
\text { de controle de acesso } \\
\text { rigorosas }\end{array}$ & $\begin{array}{l}\text { 7. Restringir o acesso aos dados do titular do cartão de acordo com a } \\
\text { necessidade de conhecimento para o negócio } \\
\text { 8. Atribuir uma identidade exclusiva para cada pessoa que tenha acesso ao } \\
\text { computador } \\
\text { 9. Restringir o acesso físico aos dados do titular do cartão }\end{array}$ \\
\hline $\begin{array}{l}\text { Monitorar e testar as } \\
\text { redes regularmente }\end{array}$ & $\begin{array}{l}\text { 10. Acompanhar e monitorar todos os acessos com relação aos recursos da } \\
\text { rede e aos dados do titular do cartão } \\
\text { 11. Testar regularmente os sistemas e processos de segurança }\end{array}$ \\
\hline $\begin{array}{l}\text { Manter uma política de } \\
\text { segurança de informações }\end{array}$ & $\begin{array}{l}\text { 12. Manter uma política que aborde a segurança das informações para todas } \\
\text { as equipes. }\end{array}$ \\
\hline
\end{tabular}

Tabela 2.4: Padrão de Segurança de Dados do PCI - Visão Geral Alto Nível (PCI-Council, 2012). 


\section{Capítulo 3}

\section{Fraude em Cartão de Crédito}

\subsection{Definição}

O dicionário Houaiss da Língua Portuguesa define fraude como "qualquer ato ardiloso, enganoso, de má-fé, com o intuito de lesar ou ludibriar outrem, ou de não cumprir determinado dever; logro".

Recorrendo ao Wikipedia, encontra-se a seguinte definição: "em direito penal, fraude é o crime ou ofensa de deliberadamente enganar outros com o propósito de prejudicá-los, usualmente para obter propriedade ou serviços dele ou dela injustamente. Fraude pode ser efetuada através de auxílio de objetos falsificados".

No mundo dos cartões de crédito, de maneira geral e simples, a fraude pode ser caracterizada por uma transação que não é reconhecida pelo legítimo portador do cartão de crédito.

Quando as instituições financeiras perdem dinheiro devido às transações fraudulentas em cartões de crédito, os seus portadores pagam parcialmente e indiretamente por isso através de taxas de juros mais altas, benefícios reduzidos e anuidades. Assim, o interesse de instituições financeiras de começarem a desenvolver processos e sistemas de detecção de fraudes é despertado (Maes et al. , 2002).

A facilidade de acesso a cartões de crédito e o aumento da sua utilização têm atraído criminosos interessados em ganhos ilícitos originados de transações fraudulentas. Um dos maiores atrativos é o ganho de grandes quantias de dinheiro em um curto espaço de tempo sem exposição a grandes riscos. Isto porque raramente criminosos são descobertos e presos por um longo tempo na atual legislação brasileira para esse tipo de crime.

Os fraudadores, em geral, são bem organizados e sempre procuram a maneira mais fácil e barata de se obter vantagens. Segundo Hand et al. (2002), a fraude é um "negócio" rentável, estável e muito bem organizado e administrado.

Uma questão que emerge é: por que as pessoas cometem fraude? Não há uma única razão por trás da fraude e qualquer explicação precisa levar em conta vários fatores. Olhando do ponto de vista do fraudador, é necessário levar em conta os seguintes pontos segundo 
Doody et al. (2008):

- Motivação dos potenciais fraudadores;

- Condições de compreensão/racionalização do crime;

- Oportunidades para cometer o crime;

- Identificação do alvo para cometer a fraude;

- Habilidade técnica do fraudador;

- Risco esperado e real de descoberta depois que a fraude foi realizada;

- Expectativas de consequências da descoberta (incluindo consequências não-criminais, tais como: perda de emprego e estigma por parte da família e amigos).

Um modelo que reúne uma série desses aspectos é o Triângulo da Fraude. Esse modelo baseia-se na premissa de que a fraude pode resultar de uma combinação de três fatores: motivação, oportunidade e racionalização, descritos a seguir:

Motivação É tipicamente baseada em qualquer ganância ou necessidade. A ganância tem se mostrado como a principal causa de eventos de fraudes, totalizando $63 \%$ dos casos conforme pesquisa realizada em 2007 (BDO , 2008). Outras causas citadas foram problemas de dívidas e jogos de azar.

Muitas pessoas se deparam com a oportunidade de cometer fraude, porém, apenas uma minoria dos gananciosos e necessitados cometem. Soma-se também o quanto as pessoas temem e se assustam com as consequências de assumir riscos para executar determinada fraude. Algumas pessoas com bons princípios e objetivos podem cair em má companhia e desenvolver o gosto pelo dinheiro rápido, o que os guiam para o caminho da fraude. Outros são tentados apenas quando enfrentam momentos difíceis em suas vidas.

Oportunidade Em termos de oportunidade, a fraude é mais provável em empresas onde existe um fraco sistema de controle interno, falta de segurança sobre os ativos da empresa, ausência de sistemas de detecção e punição, como também, políticas pouco claras no que diz respeito ao comportamento aceitável. Pesquisas mostram que alguns funcionários são totalmente honestos, alguns são totalmente desonestos, mas que muitos são seduzidos pela oportunidade de cometer fraude.

Racionalização Muitas pessoas obedecem a lei porque acreditam nela e/ou têm medo de serem humilhadas ou rejeitadas por pessoas caso sejam apanhadas em algum ato fraudulento. No entanto, algumas pessoas tentam racionalizar ações fraudulentas como:

Necessárias: especialmente quando feita contra a empresa que atua; 
Inofensivas: porque a vítima é grande o suficiente para absorver o impacto;

Justificadas: porque a vítima "merecia" ou porque o fraudador acreditava ser maltratado.

Uma das maneiras mais eficazes para combater o problema da fraude é a adoção de métodos que irão diminuir as oportunidades para o fraudador. Motivação e racionalização são aspectos e escolhas pessoais do indivíduo e mais difícil de combater de maneira abrangente e eficiente. Entretanto, se a empresa possuir forte cultura e valores claros, essa pode se tornar uma ferramenta de prevenção útil.

A atuação de um fraudador pode ser enquadrada em uma das seguintes categorias:

Fraudadores Pré-planejados: começam desde o início com a intenção de cometer uma fraude. Esses podem ser fraudadores de curto prazo, como muitos que usam cartões de crédito roubados ou números de identificação falsos. Ou podem ser de longo prazo, como os fraudadores que executam esquemas complexos de lavagem de dinheiro.

Fraudadores Intermediários: começam sendo honestos e se transformam em fraudadores quando os tempos ficam difíceis ou quando ocorre algum tipo de evento em suas vidas, como irritação por não ter sido escolhido para a promoção ou a necessidade de pagar os cuidados médicos de um membro da família.

Fraudadores Endividados: simplesmente continuam a negociar, mesmo quando, objetivamente, eles não possuem condições de pagar suas dívidas. Esse tipo de perfil de fraudador pode ser observado tanto em comerciantes comuns, como também em grandes empresários e empreendedores.

\subsection{Tipos de Fraude}

Entre os tipos de fraude cometidos em transações com cartão de crédito, os seguintes são observados com maior frequência:

Invasão de conta: envolve criminosos que obtiveram informações pessoais de clientes, como número de contas e senhas. Esses criminosos tentam tomar posse das contas bancárias ou número de cartões de crédito de clientes. O fraudador, ao se passar pelo verdadeiro cliente, costuma solicitar pagamentos, empréstimos e outros produtos bancários que estejam disponíveis, como também, alterar informações cadastrais para solicitação de cartões de crédito;

Cartão perdido ou roubado: nesse tipo de fraude, fraudadores ou pessoas com má intenção buscam realizar transações se passando pelos verdadeiros portadores dos cartões, que tiverem os seus cartões perdidos ou roubados; 
Falsificação (Skimming): a falsificação ou clonagem de um cartão acontece quando um cartão é criado, com as informações de um outro cartão já existente, sem a autorização do emissor do cartão. As informações para a criação desse cartão "clone" são muitas vezes obtidas através da trilha magnética do cartão verdadeiro;

E-commerce/MOTO (Mail Order Telephone Order): é um tipo de fraude realizada através da internet, telefone, fax ou por carta, onde não existe a presença física do cartão. $\mathrm{Na}$ maioria das vezes, para realizar esse tipo de fraude, os dados dos cartões foram obtidos fisicamente através da cópia da trilha magnética do cartão ou vazamento de informações de transações anteriores que foram armazenadas por estabelecimentos que atuam no comércio eletrônico.

Extravio: acontece quando cartões de crédito são furtados no processo de envio do emissor do cartão para o portador. Os riscos para esse tipo de fraude envolvem empresas de entregas conhecidas como couriers e o sistema postal nacional (serviço prestado pela Empresa Brasileira de Correios e Telégrafos, ou simplesmente Correios, no Brasil);

Roubo de identidade: é na maioria dos casos relacionado a grupos criminosos organizados que têm informações de pessoas idôneas e legítimas. Fazem uso de tais informações para obter produtos financeiros e ganhos através deles. Basicamente, é o uso ilegal de informações de terceiros para realizar transações fraudulenta. Em algumas situações, as informações são roubadas através de métodos computacionais sofisticados, como o uso de cavalo de Tróia e phishing, como também através de engenharia social.

\subsection{Métodos para Cometer Fraudes}

Os métodos para cometer fraude são renovados ou criados por fraudadores a todo momento. No entanto, existem alguns métodos que se repetem e são mais conhecidos, como os apresentados a seguir.

Clonagem: as informações da tarja magnética do cartão são copiadas através de aparelhos conhecidos como skimmers. Depois disso, um outro cartão é produzido com a mesma informação.

Dumpster Diving: fraudadores procuram em latas de lixo, ou outros tipos de dispensadores de materiais, por informações pessoais que podem ser usadas para fraude.

Roubo de Correspondência: fraudadores buscam em caixas de correspondência, roubam carteiros ou aliciam funcionários de serviços de entregas para obterem cartões de créditos novos e faturas.

Fraude Interna: um funcionário desonesto com acesso a informações pessoais, folha de pagamento ou número de contas pode comercializar esse tipo de informação com terceiros para efetuarem fraudes. 
Impostores: pessoas que usam a identidade de outras pessoas (comprovadas por documentos falsos) para abertura de contas, solicitação de cartões de crédito e empréstimos.

Online Data: fraudadores acessam informações disponíveis em bancos de dados públicos, redes sociais, bureaus de crédito, entre outras fontes de informação.

Programas Maliciosos: existem diversos tipos de programas maliciosos, porém, todos buscam roubar informações pessoais e financeiras armazenadas nos computadores pessoais. Entre eles, destacam-se: o vírus de computador (replicado entre computadores), cavalo de Tróia (instalado com outros programas, mas captura informações do teclado e pode deter o controle do computador) e spywares (recolhe as informações do computador invadido e transmite para uma entidade externa sem ter o controle do computador).

Phishing: criminosos obtêm dados pessoais através de e-mails e websites falsos de empresas conhecidas no mercado, como instituições financeiras e comércios eletrônicos. Geralmente, a vítima recebe um e-mail de uma instituição financeira solicitando o preenchimento de algumas informações pessoais em um website falso.

Acesso a documentos pessoais em casa: o roubo de identidade acontece através de pessoas que possuem acesso a informações pessoais do proprietário da residência e seus moradores.

Roubo de Carteira/Bolsa: é usual que carteiras e bolsas contenham cartões de crédito e documentos de identificação, e a fraude pode ocorrer quando essas são roubadas por criminosos.

Hacking: criminosos têm a habilidade de invadir sistemas e banco de dados de comércios eletrônicos, processadores de cartão de crédito, fornecedores de serviços de pagamento, entre outras instituições, para obter informações pessoais de consumidores e de transações financeiras.

Engenharia Social: criminosos contatam clientes de instituições financeiras se passando por funcionários da mesma. Eles usam, na maioria das vezes, informações de clientes divulgadas em redes sociais para fazê-lo acreditar que está realmente em contato com a instituição financeira. Após essa etapa de convencimento, os clientes acabam informando número de cartões de crédito, números de contas bancárias, senhas e outros tipos de informações.

\section{Alguns Tipos de Ataques}

Carding é um termo utilizado para um processo que verifica a validade e código de segurança de um cartão roubado. O ladrão apresenta as informações do cartão em um 
website que processa e valida a informação em tempo real. Se o cartão for processado com sucesso, o ladrão sabe que o cartão ainda é válido. Muitas vezes, o fraudador busca testar esses cartões em comércios eletrônicos que vendem serviços, jogos ou produtos de valores baixos, para com isso evitar chamar atenção dos sistemas de prevenção e detecção dos emissores e não comprometer o limite do cartão.

Ataque em BIN: cartões de crédito são produzidos em várias categorias de BIN. Quando o emissor não usa geração aleatória do número do cartão, ou seja, produz os números dos cartões sequencialmente, o fraudador pode obter um número de cartão verdadeiro e gerar números de cartões válidos que foram produzidos na sequência.

\subsection{Custos e Ciclo da Fraude}

No desafio de encontrar o equilíbrio entre evitar transações fraudulentas e incomodar o menos possível o legítimo portador do cartão, existem custos tangíveis e intangíveis, que são listados a seguir (de Moraes, 2008).

\section{Custos Tangíveis da Fraude (Financeiros)}

- Perda financeira decorrente do uso indevido do cartão;

- Custo da investigação e prisão do fraudador;

- Reemissão do cartão e entrega;

- Chamadas no atendimento ao cliente;

- Intercâmbio (requisições e disputas com as bandeiras). Em alguns casos é possível recuperar a perda financeira, mas esse processo tem um custo;

- Custo das transações referidas. É uma tarifa paga à bandeira para cada transação negada, por desconfiança de fraude, quando ultrapassa um certo ponto de corte;

- Custo de cancelamento de cartões. Clientes cancelam seus cartões e migram para a concorrência;

- Custos de boletim de proteção com as bandeiras. Custo para inclusão e manutenção de números de cartões na "lista negativa" mantida pelas bandeiras;

- Potencial redução de receitas;

- Redução de market share. Redução do tamanho da instituição e perda de posição para algum concorrente.

\section{Custos Intangíveis da fraude (Não Financeiros)}

- Insatisfação do cliente;

- Sentimento de violação e vulnerabilidade em relação à empresa; 
- Ameaça ao negócio e às pessoas ligadas a ele (funcionários e terceiros);

- Perda de lealdade à marca e às bandeiras;

- Custo de Oportunidade: O investidor (sócio) da instituição poderia estar investindo seu dinheiro em algo menos arriscado do ponto de vista de fraude, podendo obter maior retorno do investimento (ROI).

Adicionalmente, o ciclo da fraude pode ser descrito em oito estágios:

1) Intimidação: caracterizada por ações destinadas a inibir ou desanimar o fraudador antes que o mesmo execute a fraude;

2) Prevenção: compreende atividades que tornam a execução da fraude mais difícil, endurecendo as defesas contra os fraudadores. Isso inclui a identificação pessoal de números para os cartões de crédito, sistemas de segurança para transações via internet e o uso de senhas pessoais para o acesso de contas no sistema, tanto via computadores quanto por telefone. Esses métodos não são perfeitos e é necessário determinar um meio termo entre as despesas envolvidas na gestão de fraude e a inconveniência que pode gerar para o cliente;

3) Detecção: conjunto de ações e atividades que são utilizadas para identificar a fraude. Esses métodos de deteç̧ão são utilizados quando os métodos de prevenção da fraude falham. Na prática, a detecção de fraude é utilizada continuamente, ignorando a prevenção;

4) Medidas: tomada de medidas que evitam a ocorrência de perdas ou a sua continuidade e/ou impeçam que um fraudador continue a fraudar ou termine a sua atividade de fraude;

5) Análise: são identificados e estudados, através de modelagem estatística, os fatores que levam os fraudadores a cometerem as fraudes;

6) Política: conjunto de atividades que pretendem criar, avaliar, comunicar e ajudar na implantação de políticas para reduzir a incidência de fraudes;

7) Investigação: envolve a obtenção de evidências e informações suficientes para reduzir ou inibir completamente as atividades fraudulentas, com o intuito de recuperar recursos ou obter a restituição dos mesmos;

8) Acusação: neste estágio, está clara a necessidade de suporte jurídico para condenar os criminosos.

Através de uma interação equilibrada entre os estágios citados acima, pode-se alcançar resultados bastante eficientes. Cada instituição deve descobrir o melhor equilíbrio para seu negócio. Esses estágios interagem entre si de forma dinâmica e não são necessariamente executados na ordem descrita anteriormente. 


\subsection{Medidas para prevenir fraudes em cartão de crédito}

Diante de todo esse cenário de risco em transações com cartão de crédito, existem algumas medidas preventivas que contribuem para que uma fraude não se concretize ou para que se desestimule ações de fraudadores. Essas medidas são apresentadas a seguir.

- Verificar na fatura mensal se todas as transações são reconhecidas. Reportar para o emissor do cartão transações não reconhecidas;

- Nunca enviar informações de pagamento por e-mail, como senha e número de cartão. Informações que trafegam na internet podem ser lidas por terceiros;

- Quando fornecer informações para pagamento na internet, procure por um ícone de cadeado. Este sinal indica que o tráfego da informação será segura através de métodos de criptografia de dados;

- Proteja as informações em seu computador. Use softwares de antivírus, filtros de spyware e e-mails, bem como programas de firewall para manter as informações em seu computador seguras;

- Não responda e-mails ou telefonemas que solicitam informações pessoais, tais como senhas, número de cartão de crédito ou número de conta;

- Nunca divulgue sua senha para ninguém. Nenhum funcionário de instituições financeiras e estabelecimentos deveriam perguntar, verbalmente, pela sua senha;

- Quando possível, sempre mantenha os olhos em seu cartão no momento da transação, a fim de evitar que dados do cartão sejam copiados/clonados;

- Caso seu cartão seja roubado ou perdido, reporte imediatamente para a instituição financeira que o emitiu;

- Destrua todas as informações pessoais, como ofertas de novos cartões de crédito, recibos de caixas eletrônicos e faturas antes de jogá-las fora.

\subsection{Fraudes no Comércio Eletrônico}

Os brasileiros só ficam atrás dos alemães quando o assunto é preocupação com segurança nas compras e transações bancárias pela internet e com vírus e spam, segundo pesquisa em dez países realizada pela Unisys Security Index (Unisys, 2010). A pesquisa mostra que o brasileiro é o mais preocupado com fraudes bancárias, como, por exemplo, as fraudes em cartões de crédito. Em outra pesquisa, realizada pela Fecomércio, aponta que o medo de ser alvo de uma fraude impede que um quarto das pessoas faça compras on-line (FecomércioSP , 2014). 
O aumento no volume de fraudes em transações no comércio eletrônico, no Brasil e em outros países, tem sido explicado por dois principais motivos: crescimento do volume das transações e a chipagem de cartões de crédito.

Em relação ao primeiro motivo, com a expansão das tecnologias e acesso a internet para um número maior de pessoas, o comércio eletrônico tem se tornado uma boa opção para compradores que buscam comodidade e preços muitas vezes menores comparados aos preços cobrados nas lojas físicas. Com o crescimento a taxa de 2 dígitos, o volume de fraude vem acompanhando essa tendência.

No que se refere ao segundo motivo, ao chipar o cartão de crédito, os emissores buscam diminuir, consideravelmente, a fraude oriunda da falsificação de cartões de crédito (clonagem). Esse tipo de fraude tinha grande representatividade no passado devido à facilidade de cópia das informações da trilha magnética para, posteriormente, criação de um novo cartão com essas informações. Como os fraudadores não conseguem obter mais êxito com esse tipo de fraude, tendem a migrar para outros tipos de fraude que consideram mais vulneráveis, como, por exemplo, fraudes no comércio eletrônico.

No mercado americano, um dos maiores mercados do comércio eletrônico do mundo, as empresas relataram uma perda média de $0,9 \%$ da receita total devido à fraude em 2012. Utilizando os números de vendas da indústria de 2012, foi estimada uma perda total de 3,5 bilhões de dólares (Cybersource, 2013).

No relatório divulgado pela Cybersource (2013), quando se trata de ferramenta mais efetiva para gestão de fraudes no comércio eletrônico, e quando se possui as informações do cliente, $54 \%$ dos estabelecimentos entrevistados concordam em adotar um modelo de pontuação de fraude, como descrito na figura 3.1 .

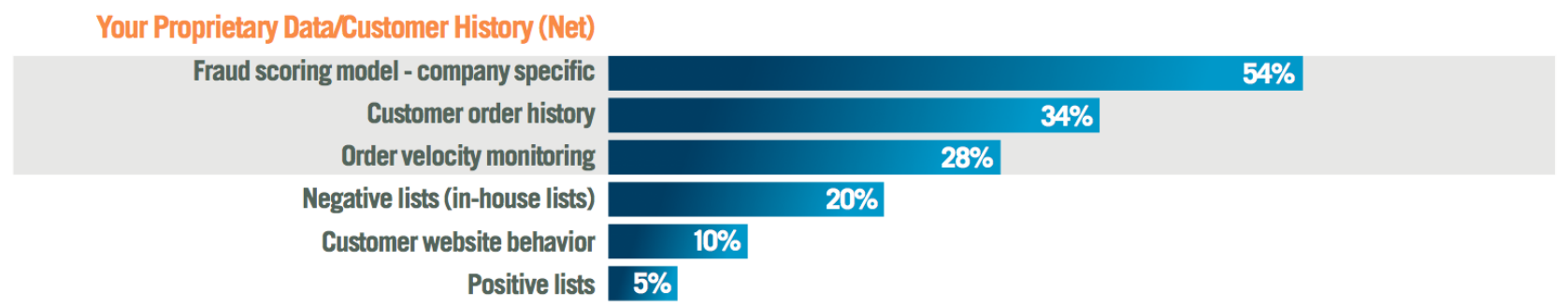

Figura 3.1: Pesquisa Cybersource 2013 sobre ferramentas para gestão de fraudes (Cybersource, 2013).

Apesar de vários mecanismos para prevenção de fraudes disponíveis no comércio eletrônico, eles podem falhar, pois não protegem contra "as falhas humanas de segurança".

A engenharia social é uma das armadilhas mais utilizadas para a obtenção de informações sigilosas e importantes, especialmente dos usuários domésticos. Através disso, junto com a natureza aberta da internet, os fraudadores têm conseguido transpor a barreira imposta pelo modelo tradicional de segurança.

Entre as abordagens de engenharia social usadas pelos fraudadores, phishing é uma das 
formas mais comuns para roubar dos usuários os detalhes para autenticação em contas de e-mail, internet banking ou outro sistema de interesse do fraudador.

Normalmente, essa abordagem acontece na forma de e-mail tentando convencer usuários a abrirem anexos ou então os direcionam para algum website falso. Na maioria das vezes, essas páginas são tão bem elaboradas que muitos usuários são induzidos, e convencidos, a informar os detalhes de suas informações pessoais e financeiras.

\subsection{Legislação brasileira contra fraudes}

Considerando a legislação brasileira para combate a fraude, temos muito a avançar para que o fraudador se sinta oprimido e desencorajado a cometer esse ato ilícito. No Código Penal Brasileiro, a fraude está declarada sob o artigo $n^{\circ} 171$.

Abaixo, reproduzimos o conteúdo da lei que aborda o tema de fraude.

\section{CAPÍTULO VI DO ESTELIONATO E OUTRAS FRAUDES}

Art. 171 - Obter, para si ou para outrem, vantagem ilícita, em prejuízo alheio, induzindo ou mantendo alguém em erro, mediante artifício, ardil, ou qualquer outro meio fraudulento: Pena - reclusão, de um a cinco anos, e multa.

$\S 1^{o}$ - Se o criminoso é primário, e é de pequeno valor o prejuízo, o juiz pode aplicar a pena conforme o disposto no art. $155, \S 2^{\circ}$.

$\S 2^{\circ}$ - Nas mesmas penas incorre quem:

Disposição de coisa alheia como própria

I - vende, permuta, dá em pagamento, em locação ou em garantia coisa alheia como própria; Alienação ou oneração fraudulenta de coisa própria;

II - vende, permuta, dá em pagamento ou em garantia coisa própria inalienável, gravada de ônus ou litigiosa, ou imóvel que prometeu vender a terceiro, mediante pagamento em prestações, silenciando sobre qualquer dessas circunstâncias; Defraudação de penhor;

III - defrauda, mediante alienação não consentida pelo credor ou por outro modo, a garantia pignoratícia, quando tem a posse do objeto empenhado; Fraude na entrega de coisa;

IV - defrauda substância, qualidade ou quantidade de coisa que deve entregar a alguém; Fraude para recebimento de indenização ou valor de seguro;

$\mathrm{V}$ - destrói, total ou parcialmente, ou oculta coisa própria, ou lesa o próprio corpo ou a saúde, ou agrava as consequências da lesão ou doença, com o intuito de haver indenização ou valor de seguro; Fraude no pagamento por meio de cheque;

VI - emite cheque, sem suficiente provisão de fundos em poder do sacado, ou lhe frustra o pagamento. 
$\S 30$ - A pena aumenta-se de um terço, se o crime é cometido em detrimento de entidade de direito público ou de instituto de economia popular, assistência social ou beneficência.

Adicionalmente, no final de 2012, a Lei Brasileira 12.737/2012, conhecida popularmente como Lei Carolina Dieckmann, foi sancionada pela Presidente Dilma Rousseff. Essa lei promoveu alterações no Código Penal Brasileiro de maneira a tipificar os chamados delitos ou crimes informáticos.

\section{Lei Carolina Dickeman}

A Lei Carolina Dieckmann é o apelido que recebeu a Lei Brasileira 12.737/2012, sancionada em 3 de dezembro de 2012 pela Presidente Dilma Rousseff (publicada no DOU 03/12/12 PÁG 01 COL 03.), que promoveu alterações no Código Penal Brasileiro (Decreto-Lei 2.848 de 7 de dezembro de 1940), tipificando os chamados delitos ou crimes informáticos.

O Projeto de Lei foi proposto diante da situação específica experimentada pela atriz, em maio de 2011, que supostamente teve copiadas de seu computador pessoal 36 (trinta e seis) fotos que acabaram divulgadas na internet.

A lei vem merecendo críticas de juristas, peritos, especialistas e profissionais de segurança da informação, pois seus dispositivos são amplos, confusos e ambíguos. Tais características podem gerar interpretação subjetiva, o que pode ser utilizado para enquadramento criminal de condutas triviais ou mesmo para a defesa e respaldo de infratores cibernéticos, o que tornaria a lei injusta e ineficaz. Para outra corrente, ainda, as penas são pouco inibidoras, sendo muitas situações enquadráveis nos procedimentos dos Juizados Especiais, o que poderia contribuir para a não eficiência no combate ao crime cibernético no Brasil.

A seguir, reproduzimos o conteúdo da lei.

Art. $1^{\circ}$ Esta Lei dispõe sobre a tipificação criminal de delitos informáticos e dá outras providências.

Art. $2^{\circ}$ O Decreto-Lei no 2.848, de 7 de dezembro de 1940 - Código Penal, fica acrescido dos seguintes arts. 154-A e 154-B:

\section{Invasão de dispositivo informático}

Art. 154-A. Invadir dispositivo informático alheio, conectado ou não à rede de computadores, mediante violação indevida de mecanismo de segurança e com o fim de obter, adulterar ou destruir dados ou informações sem autorização expressa ou tácita do titular do dispositivo ou instalar vulnerabilidades para obter vantagem ilícita:

Pena - detenção, de 3 (três) meses a 1 (um) ano, e multa.

$\S 1^{\circ} \mathrm{Na}$ mesma pena incorre quem produz, oferece, distribui, vende ou difunde dispositivo ou programa de computador com o intuito de permitir a prática da conduta definida no caput.

$\S 2^{\circ}$ Aumenta-se a pena de um sexto a um terço se da invasão resulta prejuízo econômico.

$\S 3^{\circ}$ Se da invasão resultar a obtenção de conteúdo de comunicações eletrônicas privadas, 
segredos comerciais ou industriais, informações sigilosas, assim definidas em lei, ou o controle remoto não autorizado do dispositivo invadido:

Pena - reclusão, de 6 (seis) meses a 2 (dois) anos, e multa, se a conduta não constitui crime mais grave.

$\S 4^{\circ} \mathrm{Na}$ hipótese do $\S 3^{\circ}$, aumenta-se a pena de um a dois terços se houver divulgação, comercialização ou transmissão a terceiro, a qualquer título, dos dados ou informações obtidos.

§ 5o Aumenta-se a pena de um terço à metade se o crime for praticado contra:

I - Presidente da República, governadores e prefeitos;

II - Presidente do Supremo Tribunal Federal;

III - Presidente da Câmara dos Deputados, do Senado Federal, de Assembleia Legislativa de Estado, da Câmara Legislativa do Distrito Federal ou de Câmara Municipal; ou

IV - dirigente máximo da administração direta e indireta federal, estadual, municipal ou do Distrito Federal.

\section{Ação penal}

Art. 154-B. Nos crimes definidos no art. 154-A, somente se procede mediante representação, salvo se o crime é cometido contra a administração pública direta ou indireta de qualquer dos Poderes da União, Estados, Distrito Federal ou Municípios ou contra empresas concessionárias de serviços públicos.

Art. 3o Os arts. 266 e 298 do Decreto-Lei no 2.848, de 7 de dezembro de 1940 - Código Penal, passam a vigorar com a seguinte redação:

Interrupção ou perturbação de serviço telegráfico, telefônico, informático, telemático ou de informação de utilidade pública

Art. 266.

$\S 1^{o}$ Incorre na mesma pena quem interrompe serviço telemático ou de informação de utilidade pública, ou impede ou dificulta-lhe o restabelecimento.

$\S 2^{\circ}$ Aplicam-se as penas em dobro se o crime é cometido por ocasião de calamidade pública. (NR)

\section{Falsificação de documento particular}

Art. 298.

\section{Falsificação de cartão}

Parágrafo único. Para fins do disposto no caput, equipara-se a documento particular o cartão de crédito ou débito. (NR)

A "Lei Carolina Dieckmann"entrou em vigor no dia 02 de abril de 2013. 


\section{Capítulo 4}

\section{Métodos de Prevenção e Detecção de Fraudes}

\subsection{Definição}

De maneira geral, a detecção de fraudes é um problema de previsão. O seu objetivo é maximizar a previsão correta e manter predições incorretas em um nível aceitável de custos (Al-Khatib , 2012). Para entendermos os métodos de prevenção e detecção de fraudes, temos que primeiramente distinguir o que é tido como prevenção e deteç̧ão (Bolton e Hand , 2002).

Prevenção à fraude consiste em um conjunto de medidas e processos para evitar que a fraude ocorra. Essas medidas e processos consistem em ações como incluir marcas d'agua e hologramas em documentos, senhas dinâmicas, senhas para cartões de crédito, entre outras medidas. Certamente, não existe um método perfeito. No entanto, é preciso que o custo e a inconveniência para o cliente sejam ponderadas com a efetividade do método.

Por outro lado, deteç̧ão de fraude envolve ações para detectar uma fraude rapidamente uma vez que ela tenha acontecido. É definido como o processo de identificar transações fraudulentas no conjunto de todas as transações. Em outras palavras, o processo de detecção é o processo de classificar as transações em duas classes: transações legítimas e transações fraudulentas.

Prevenção e detecção estão fortemente relacionadas, já que a deteç̧ão de fraude entra em jogo uma vez que os processos de prevenção falham. É um processo em contínuo desenvolvimento, pois sempre que um método de detecção é conhecido ou descoberto por criminosos, esses irão adaptar as suas estratégias para tentar outros tipos de fraudes. Muitos deles não estarão cientes dos métodos de detecção de fraudes que foram bem sucedidos no passado, e irão buscar novas estratégias que levam a fraudes não-identificáveis por um tempo.

Um dos grandes problemas associados ao desenvolvimento de novos métodos de prevenção e deteç̧ão de fraudes é a ausência de literatura que forneça resultados experimentais e dados reais para que pesquisadores realizem novos experimentos. Isto acontece porque o processo de prevenção e deteç̧ão de fraudes é associado a informações financeiras sensíveis dos clientes, 
que devem ser mantidas em ambiente seguro e privado. Adicionalmente, não é recomendável que se descrevam as técnicas de prevenção e detecção de fraudes em grande detalhe no domínio público, pois isso dá aos criminosos a informação de que necessitam para evitar a detecção (Leonard, 1993).

\subsection{Sistemas de Detecção}

Uma das dificuldades com a deteç̧ão de fraude é que, normalmente, é preciso que muitos casos legítimos sejam analisados para identificar uma transação fraudulenta, o que gera um custo considerável para essa análise. Na prática, algum ponto de equilíbrio tem de ser alcançado, muitas vezes uma avaliação econômica, entre o custo de detectar uma fraude e as economias a serem feitas para detectá-la.

Isso nos leva a uma conclusão mais geral: a fraude pode ser reduzida a um nível muito baixo, mas apenas em virtude de um alto nível de esforço e custo.

Conforme observado por Maes et al. (2002), para produzir bons resultados, um sistema eficiente de detecção de fraude deve ser capaz de:

- Trabalhar com distribuições desbalanceadas, pois apenas um pequeno percentual das transações são fraudulentas. Para resolver esse problema, frequentemente, um conjunto de dados de treinamento é dividido em partes cuja distribuição é menos desbalanceada (Chan e Stolfo , 1998);

- Controlar ruídos. Isto significa controlar a presença de erros de dados, como, por exemplo, datas e valores incorretos. Uma maneira de resolver esse problema é estruturar um processo de limpeza de dados (Fawcett e Provost , 1997);

- Se adaptar a novos tipos de fraude. Um método conhecido de fraude se torna menos eficiente quando se torna mais conhecido, o que produz novas tentativas para realizar a fraude;

- Gerar bons indicadores para avaliar a performance do sistema em classificação de transações legítimas e fraudulentas;

- Levar em conta o custo de detectar uma transação com comportamento fraudulento e o custo de evitá-la.

Na contramão, os seguintes motivos têm criado dificuldades para a construção de um sistema de detecção de fraude eficaz (Stolfo et al. , 1997):

- Instituições financeiras não compartilham as informações de fraude por razões de competição e motivos legais;

- As bases de dados de transações são enormes e o número de registros crescem rapidamente, o que demanda um sistema escalável e muito bem estruturado; 
- Análises em tempo real são altamente desejáveis para atualizar os modelos quando um novo evento de fraude for detectado;

- Fácil distribuição dos modelos para manter atualizado o processo de detecção;

- Sobreposição de dados é outro tipo de problema. Muitas transações boas talvez se assemelhem a transações fraudulentas, e vice-versa.

Processar esse volume de dados em busca de transações fraudulentas requer mais do que modelos estatísticos, requer algoritmos rápidos e eficientes, além de que técnicas de mineração de dados são também relevantes. Esse volume de dados indica o valor potencial de detecção de fraudes: se $0,1 \%$ ou 10 pontos base (basis points) de 100 milhões de transações são fraudulentas, e o valor médio da transações for $R \$ 100$, então estima-se que a empresa perderá $\mathrm{R} \$ 10$ milhões com fraudes.

Outra maneira de pensar é a seguinte: se uma instituição financeira tem receita de $2 \%$ em cada transação, para desembolsar R $\$ 100$ de fraude, ela terá que ter uma transação no valor de $\mathrm{R} \$ 5.000$ para igualar ao valor da fraude. Isso sem contar o prejuízo com os custos operacionais envolvidos na transação.

\subsection{Métodos Estatísticos}

Os métodos estatísticos frequentemente utilizados para detecção de fraude podem ser classificados em não supervisionados ou supervisionados (Bolton e Hand , 2002). Detalhamos os dois tipos a seguir.

\section{Métodos Não Supervisionados}

Os métodos não supervisionados buscam informações de contas, clientes, números de cartões, entre outras, que possuam um comportamento diferente do normal, e que muitas vezes são designados como anomalias ou outliers e caracterizados como uma forma básica não padrão de observação.

As ferramentas para o controle da qualidade dos dados podem ser usadas, mas a detecção de erros acidentais é um problema bastante diferente da detecção de dados deliberadamente falsificados ou dados que descrevem com precisão um padrão fraudulento.

O processo de análise consiste na modelagem de uma distribuição de referência, que representa um comportamento normal, e, em seguida, a tentativa de detectar observações que mostrem desvios em relação a essa distribuição. A análise de dígitos, usando a lei de Benford $^{2}$, é um exemplo de tal método (Hill , 1995).

\footnotetext{
${ }^{2} \mathrm{~A}$ lei de Benford, chamado também lei do primeiro-dígito, refere-se a distribuição de frequencia dos dígitos de um conjunto de números. Em um conjunto de números, se o primeiro dígito $d \in(1, \ldots, 9)$ ocorre com probabilidade $\log _{10}(1+1 / d)$, pode-se dizer que satifaz a lei de Benford.
} 


\section{Métodos Supervisionados}

Nos métodos supervisionados, as amostras dos casos fraudulentos e legítimos são usadas para construir modelos que permitem atribuir novas observações a uma das duas classes. Certamente, isso exige discriminar um conjunto de variáveis que possam classificar de maneira correta, entre essas classes, os dados originais utilizados para construir os modelos. Além disso, só pode ser usado para detectar fraudes que tenham ocorrido anteriormente em um determinado espaço de tempo.

Métodos estatísticos tradicionais, como análise de discriminante e árvore de decisão, têm se mostrado ferramentas efetivas para deteç̧ão de fraude (Hand , 1981) (McLachlan , 1992). No entanto, ferramentas mais poderosas, como redes neurais e regressão logística binária, têm sido extensamente utilizadas (Ripley , 1996) (Webb , 1999).

No conjunto dos métodos supervisionados, dois deles têm sido, tradicionalmente, adotados pela maioria das instituições financeiras para detectar fraudes: sistemas baseados em regras e modelos de pontuação.

\section{Sistemas baseados em regras}

Sistemas baseados em regras são algoritmos de aprendizagem supervisionados que produzem classificadores usando regras da seguinte forma:

\section{$S e$ (determinada condição é verdadeira) Então (faça determinada ação).}

Uma das vantagens desse método é a fácil configuração e agilidade para colocar novas regras em ambiente de produção. No entanto, requer atualizações frequentes e experts para o desenvolvimento de regras, além de refletir um padrão limitado.

Essa estratégia pode ser utilizada para segmentar clientes e produtos, focando em segmentos de maior risco de fraude, como cartões com limites muito altos. Abaixo, elencamos pontos positivos e negativos associados aos sistemas baseados em regras.

\section{Pontos Positivos}

- Atualização dinâmica (usualmente uma nova regra entra em poucos segundos em ambiente de produção);

- Facilidade de desenvolvimento e implantação;

- Controle;

- Baixo custo e rapidez. 


\section{Pontos Negativos}

- Requer atualização frequente;

- Grande volume de regras;

- Necessidade de experts para o desenvolvimento de regras;

- Reflete um padrão limitado;

- Difícil entendimento da relação entre as regras e duplicidade de regras.

\section{Modelos de Pontuação}

Os modelos de pontuação, também conhecidos como modelo de scoring, utilizam-se de técnicas estatísticas para retornar uma pontuação (score) para uma determinada transação. Geralmente, quanto maior a pontuação, maior a probabilidade (suspeita) de uma transação ser fraudulenta.

A pontuação pode ser computada para cada transação no banco de dados e utilizada no processo de prevenção para aprovar, negar ou referir uma transação, bem como ser utilizada em sistemas baseados em regras em combinação com outras variáveis. Com o valor da pontuação, os casos com maior pontuação podem ser priorizados no processo de investigação da transação.

Nesse momento, questões de custo são consideradas, dado que é muito caro realizar uma investigação detalhada de todos os casos. Uma investigação deve se concentrar sobre casos com maior suspeita de fraude.

Em geral, modelos de regressão logística binária e redes neurais são utilizados para gerar essa pontuação. Mede-se em uma escala de 0 a 100, ou 0 a 1000, a probabilidade de uma transação ser fraudulenta com base em características como hora da transação, ramo de atividade do estabelecimento, valor, entre outras variáveis. Pontos de corte são adotados para adequar a capacidade de tratamento do volume de casos/alertas gerados em filas de trabalho. Abaixo, destacamos pontos positivos e negativos associados aos modelos de pontuação.

\section{Pontos Positivos}

- Utilizado por toda a indústria financeira dada a sua efetividade na decisão;

- Ideal para grandes volumes de transações nos quais a decisão precisa ser tomada rapidamente;

- Abrange perfis de comportamentos individuais. 


\section{Pontos Negativos}

- Não acompanha as tendências de fraudes recentes;

- Dependendo da modelagem, pode não refletir características da fraude local;

- Alto custo;

- Sem controle para mudanças rápidas;

- Pode gerar resultados que não se pode explicar.

Apesar de modelos de pontuação apresentarem boa efetividade na detecção de fraude, atuarem com grandes volumes de transações e abrangerem perfis de comportamentos individuais, a questão que emerge é a frequência com que esses modelos são atualizados de maneira a acompanhar as tendências de fraudes recentes. Neste estudo trabalharemos o problema de atualização desses modelos com o objetivo de refletir as características da fraude ao longo do tempo.

\section{Indicadores de Performance}

Uma maneira de avaliar a acurácia do sistema em detectar fraudes é através de indicadores, como o falso negativo e falso positivo (Stolfo et al. , 1997). A seguir, apresentamos os indicadores que são frequentemente utilizados para medir a performance da detecção de fraudes (Montague , 2004) e foram utilizados neste trabalho para medição da performance dos modelos. Para o conjunto de transações que o modelo não classificou como fraude, chamaremos de não fraude.

Taxa de Detecção (Cobertura ou Sensibilidade): corresponde ao percentual de fraudes observadas e classificadas como fraude em relação ao total de fraudes observadas.

Taxa de Verdadeiro Negativo (Especificidade): corresponde ao percentual de não fraudes observadas e classificadas como não fraude em relação ao total de não fraudes observadas.

Taxa de Falso Positivo (1-Especificidade): corresponde ao percentual de não fraudes observadas e classificadas como fraude em relação ao total de não fraudes observadas.

Relação Não Fraude/Fraude: corresponde ao número de transações observadas não fraude e classificadas como fraude dividido pelo número de transações observadas e classificadas como fraude.

Precisão (Fraude): corresponde ao percentual de fraudes observadas e classificadas como fraude em relação ao total de transações classificadas como fraudes. 
Precisão (Não Fraude): corresponde ao percentual de não fraudes observadas e classificadas como não fraude em relação ao total de transações classificadas como não fraudes.

Acurácia: representa a quantidade de transações classificadas corretamente como fraude e não fraude, em relação ao observado, divido pelo total de transações.

Na tabela a seguir, apresentamos um resumo dos indicadores de performance, com suas respectivas fórmulas para cálculos, utilizando um modelo como classificador.

\begin{tabular}{|c|c|c|c|c|}
\hline \multirow{2}{*}{$\begin{array}{l}\text { Classificação } \\
\text { do Modelo }\end{array}$} & \multicolumn{2}{|c|}{ Observado } & & \\
\hline & Fraude & Não Fraude & & \\
\hline Fraude & $\begin{array}{l}\text { (VP) Verdadeiro } \\
\text { Positivo }\end{array}$ & $\begin{array}{l}\text { (FP) Falso Positivo } \\
\text { (Erro Tipo I) }\end{array}$ & $\begin{array}{l}\text { Precisão (Fraude) } \\
\text { VP / (VP+FP) }\end{array}$ & $\begin{array}{c}\text { Relação } \\
\text { Não Fraude/Fraude } \\
\text { FP/VP }\end{array}$ \\
\hline \multirow[t]{2}{*}{ Não Fraude } & $\begin{array}{l}\text { (FN) Falso Negativo } \\
\text { (Erro Tipo II) }\end{array}$ & $\begin{array}{l}\text { (VN) Verdadeiro } \\
\text { Negativo }\end{array}$ & $\begin{array}{c}\text { Precisão (Não Fraude) } \\
\text { VN / (VN+FN) }\end{array}$ & \\
\hline & $\begin{array}{l}\text { Sensibilidade } \\
\text { VP / (VP+FN) }\end{array}$ & $\begin{array}{l}\text { Especificidade } \\
\text { VN / (VN+FP) }\end{array}$ & $\begin{array}{c}\text { Acurácia } \\
(\mathrm{VP}+\mathrm{VN}) / \\
(\mathrm{VP}+\mathrm{VN}+\mathrm{FP}+\mathrm{FN})\end{array}$ & \\
\hline
\end{tabular}

Tabela 4.1: Indicadores de Performance.

\section{Técnicas Estatísticas Tradicionais para Detecção de Fraude}

Algumas técnicas estatísticas, como redes neurais, árvore de decisão, regressão, entre outras, têm se mostrado eficazes para resolver o problema de classificação que existe no processo de detecção de fraudes. No trabalho de Al-Khatib (2012), há um resumo das vantagens e desvantagens das técnicas estatísticas tradicionais utilizadas para detectar fraudes em cartão de crédito, que apresentamos na tabela 4.2 a seguir. 


\begin{tabular}{|c|c|c|}
\hline Técnica & Vantagem & Desvantagem \\
\hline $\begin{array}{l}\text { Redes } \\
\text { Neurais }\end{array}$ & $\begin{array}{l}\text { Eficaz para lidar com dados com ruído (con- } \\
\text { junto de dados que aparentemente é incon- } \\
\text { sistente com o restante dos dados existentes) } \\
\text { para identificação de padrões, resolução de } \\
\text { problemas complexos e no processamento de } \\
\text { novas instâncias. O código pode ser gerado } \\
\text { para ser utilizado em sistemas em tempo } \\
\text { real, de alta precisão, portátil, rápido e tem } \\
\text { melhor desempenho que outras técnicas. }\end{array}$ & $\begin{array}{l}\text { Pouca capacidade de explicação, menos efi- } \\
\text { ciente no processamento de grandes conjun- } \\
\text { tos de dados, difícil de configurar e operar, } \\
\text { sensível ao formato de dados, diferentes re- } \\
\text { presentações de dados podem produzir re- } \\
\text { sultados diferentes. Além disso, só trabalha } \\
\text { com dados numéricos com valores entre } 0 \text { e } \\
1 \text {; dados não numéricos precisam ser conver- } \\
\text { tidos e normalizados. }\end{array}$ \\
\hline $\begin{array}{l}\text { Árvore } \\
\text { de } \\
\text { Decisão }\end{array}$ & $\begin{array}{l}\text { Escalável, alta precisão de previsão, fácil de } \\
\text { usar, fácil de explicar os resultados, fácil de } \\
\text { interpretar as regras criadas pela árvore e } \\
\text { fácil de implementar em aplicações. }\end{array}$ & $\begin{array}{l}\text { Não é fácil de lidar com dados contínuos, di- } \\
\text { fícil de lidar com dados faltantes, problemas } \\
\text { de overfitting podem ocorrer, o tamanho dos } \\
\text { dados e atributos a serem usados para a divi- } \\
\text { são na construção da árvore pode impactar } \\
\text { a performance. }\end{array}$ \\
\hline $\begin{array}{l}\text { Sistemas } \\
\text { Baseados } \\
\text { em } \\
\text { Regras }\end{array}$ & $\begin{array}{l}\text { Fácil de modificar, fácil de desenvolver, } \\
\text { construir e implementar. Tem alto grau de } \\
\text { precisão, facilidade para explicação e tem } \\
\text { um bom desempenho. Regras de outras téc- } \\
\text { nicas, tais como redes neurais e árvore de } \\
\text { decisão, podem ser extraídas, modificadas e } \\
\text { armazenadas no sistema. }\end{array}$ & $\begin{array}{l}\text { Pobre em lidar com dados faltantes ou valo- } \\
\text { res de dados inesperados. }\end{array}$ \\
\hline $\begin{array}{l}\text { Sistemas } \\
\text { Baseados } \\
\text { em } \\
\text { Casos Pas- } \\
\text { sados }\end{array}$ & $\begin{array}{l}\text { Útil em domínio que tem um grande número } \\
\text { de exemplos, tem a capacidade de trabalhar } \\
\text { com dados incompletos ou com ruído, eficaz, } \\
\text { flexível, fácil de atualizar e manter, pode ser } \\
\text { usado em uma abordagem híbrida. }\end{array}$ & $\begin{array}{l}\text { Pode sofrer do problema de dados incomple- } \\
\text { tos ou com ruído. }\end{array}$ \\
\hline $\begin{array}{l}\text { Algoritmos } \\
\text { Genéticos }\end{array}$ & $\begin{array}{l}\text { Trabalha bem com dados com ruído e é fá- } \\
\text { cil de integrar a outros sistemas. Frequente- } \\
\text { mente combinado com outras técnicas para } \\
\text { aumentar a performance dessas. }\end{array}$ & $\begin{array}{l}\text { Requer conhecimento técnico aprofundado } \\
\text { para instalar e operar. }\end{array}$ \\
\hline $\begin{array}{l}\text { Programação } \\
\text { Lógica } \\
\text { Indutiva }\end{array}$ & $\begin{array}{l}\text { Tem linguagem de modelagem poderosa que } \\
\text { pode modelar relações complexas. }\end{array}$ & $\begin{array}{l}\text { Tem baixo poder de predição, muito sensí- } \\
\text { vel a ruído e sua performance se deteriora } \\
\text { rapidamente na presença de outliers. }\end{array}$ \\
\hline Regressão & $\begin{array}{l}\text { Fácil de entender, fácil de construir e usado } \\
\text { com duas classes de classificação. A regres- } \\
\text { são logística pode ser mais precisa do que } \\
\text { técnicas de aprendizado para pequenos con- } \\
\text { juntos de dados. }\end{array}$ & $\begin{array}{l}\text { Pobre com ruído ou outliers, não é aplicável } \\
\text { a aplicações complexas, não trabalha bem } \\
\text { com dados não numéricos, precisão é boa, } \\
\text { mas não alta. }\end{array}$ \\
\hline
\end{tabular}

Tabela 4.2: Comparação de técnicas estatísticas para detecção de fraude em cartão de crédito Al-Khatib (2012).

No processo de modelagem, vale ressaltar que os seguintes fatores podem impactar significativamente a performance das técnicas estatísticas:

Dados Incorretos: a ausência de acurácia nos dados e inconsistência impactam diretamente no poder de predição da técnica utilizada;

Dados Faltantes: podem causar problemas no processo de classificação de variáveis relevantes para o modelo. Existem técnicas que são usadas para tratar esse tipo de problema; 
Sistema Escalável: geralmente grandes bases de dados são utilizadas no processo de modelagem. Mesmo utilizando algoritmos de rápida execução, computadores com sistemas escaláveis são necessários para manter o processo a longo prazo;

Distribuição Desbalanceada: dados para detecção de fraudes são frequentemente desbalanceados, o que exige técnicas apropriadas para lidar com essa característica.

\subsection{Fraude em Transações no Comércio Eletrônico}

Quando o cartão de crédito não está presente no ponto de venda, cria-se um conjunto de diferentes desafios quando se trata de fraude. Nesse cenário, emerge o problema da autenticação das transações, ou seja, a capacidade de verificar se o comprador é realmente o titular do cartão ou se a compra foi autorizada pelo mesmo.

Os pedidos de compra de produtos, serviços ou assinaturas flui anonimamente a partir de um computador, localizado em algum lugar do mundo, e a loja virtual não consegue autenticar com $100 \%$ de certeza se o número do cartão apresentado está associado com as informações do comprador. Nesse ponto, existem algumas soluções oferecidas pelo mercado, como o 3D Secure e sistemas de monitoração.

O 3D Secure é um protocolo baseado em XML projetado para ser uma camada adicional de segurança para transações de crédito e débito na internet. É um serviço desenvolvido pelas bandeiras e oferecido aos estabelecimentos através dos adquirentes. A partir do momento em que o estabelecimento contrata esse serviço, o ônus da transação fraudulenta passa a ser do emissor do cartão. No entanto, a taxa de aprovação do estabelecimento tende a diminuir e, consequentemente, diminuir o número de vendas. Isso ocorre porque o emissor do cartão está assumindo o risco da transação e tende a avaliar com mais cautela as transações 3D secure.

Os sistemas de monitoração, com desenvolvimento interno ou externo do estabelecimento, buscam, de maneira geral, analisar as características do pedido do comprador, dados do computador, histórico de compras, entre outras variáveis, para decidir se segue ou não com a aprovação do pedido de compra. Nesse cenário, o estabelecimento é responsável por qualquer transação fraudulenta que venha a sofrer e as taxas de aprovação são mantidas em níveis altos. É o contrário do cenário observado na utilização do serviço 3D Secure. Os emissores tendem a monitorar essas transações com menos prioridade apenas para manter em níveis aceitáveis de fraude para as bandeiras.

Outro fato são transações fraudulentas na internet que são classificadas como "fraude amigável". Uma transação pode ser legitimamente iniciada pelo titular do cartão de crédito, porém, quando confrontado por alguém, muitas vezes familiares, sobre a compra de um produto ou serviço, o portador do cartão nega o conhecimento da transação e a relata como sendo uma fraude. Esse tipo de situação acontece muitas vezes em compras de serviços como pornografia. 
Uma abordagem para combater a fraude na internet, que é seguida por muitos emissores, é o uso do Card Verification Value 2 (CVV2) ou Card Verification Code (CVC), também conhecido como código de segurança. O código de segurança é o conjunto de três dígitos encontrados no verso da maioria dos cartões de crédito e é exclusivo para cada cartão. Os estabelecimentos virtuais usualmente solicitam que os portadores de cartão introduzam estes números juntamente com o número do cartão para, com isso, adicionar uma camada de segurança na transação.

Como os três dígitos só podem ser encontrados no próprio cartão, há uma maior probabilidade de que o comprador esteja realmente em posse do cartão. No entanto, se o cartão a ser utilizado tiver sido roubado ou perdido, e o portador do cartão não tenha avisado o emissor, essa não é, obviamente, uma medida preventiva eficaz.

Existem também programas de computador encontrados facilmente na internet para gerar sequências de números de cartão de crédito, que são validados pelo algoritmo de Luhn. Após a geração desses números, fraudadores tentam descobrir a data de expiração e código de segurança do cartão simulando transações em websites de comércio eletrônico com fragilidades no processo de pagamento.

Como dito antes, a autenticação do titular do cartão é um requisito fundamental na gestão de fraudes no comércio eletrônico, e não existem soluções universalmente aceitas. Como resultado, o volume de fraudes com cartão de crédito em transações oriundas da internet é substancialmente maior do que as transações com o cartão presente. 


\section{Capítulo 5}

\section{Ponderação Dinâmica de Modelos para Classificação Binária}

Conforme dito anteriormente, os fraudadores se adaptam rapidamente às novas medidas de prevenção e detecção adotadas pelo mercado. Dessa maneira, o processo de detecção de fraude precisa ser adaptável e evoluir ao longo do tempo. Os modelos de pontuação podem ser atualizados de forma esporádica ou contínua ao longo do tempo, o que levanta a questão de atualização dinâmica dos parâmetros do modelo para detecção de fraude. Raftery et al. (2010) desenvolveram um método chamado Dynamic Model Averaging (DMA), ou Ponderação Dinâmica de Modelos, que implementa um processo de atualização mais contínuo ao longo do tempo. Essa abordagem pode também ser usada para a seleção dinâmica de modelos (Dynamic Model Selection - DMS), na qual um único modelo é selecionado com base em sua performance para predição em cada período de tempo. O método DMS faz o equivalente a atribuir probabilidade 1 ao modelo com melhor performance no método DMA e 0 para os demais modelos.

A aplicação desse método é adequada à modelagem estatística que envolve grande volume de dados e variáveis em que o processo de geração de dados se altere ao longo do tempo. Especificamente, é um classificador binário, em tempo real, que altera dinamicamente os parâmetros do modelo ao longo do tempo (McCormick et al. , 2012).

Para os casos de fraude que não foram de nenhuma maneira captados pelos modelos, a criação de novas variáveis é recomendável a fim de aumentar o poder de predição do método DMA.

Nas próximas seções, descreveremos o conceito de ponderação de modelo, o modelo de regressão logística bayesiana, para o caso do modelo simples, e a ponderação dinâmica de modelos (DMA), para múltiplos modelos. 


\subsection{A Ponderação de Modelos}

O estudo de ponderação de modelos foi sistematizado por Leamer (1978), mas somente a partir de 1990 começou a ser mais aprofundado e aplicado em diversas situações. Da mesma maneira que outras metodologias estatísticas, a ponderação de modelos pode ser analisada pelo enfoque frequentista ou bayesiano.

Em ambos os contextos, há o consenso de que a incerteza diante da escolha de um modelo deve ser totalmente incorporada no processo de análise de dados sempre que a estimação dos parâmetros for sensível à escolha do modelo (Leamer , 1978).

Na concepção de Leamer, a sensibilidade na estimação dos parâmetros pode ser detectada quando diferentes modelos fornecem diferentes estimativas para um mesmo coeficiente.

Sob o enfoque frequentista, os pesos de cada modelo podem ser obtidos pelo critério de informação AIC, critério de informação BIC e pelo método de bootstrap (Nunes , 2005).

Já pela perspectiva bayesiana, alguns autores argumentam que os resultados obtidos pela aplicação da ponderação podem ser sensíveis à escolha da distribuição a priori para os parâmetros do modelo. Hoeting (1994) apresenta um estudo de sensibilidade que adota três conjuntos de valores de parâmetros da distribuição a priori conjugada normal-gama atribuída aos parâmetros do modelo. Tal estudo mostra que os resultados empíricos, condicionados a cada priori, não se diferenciam de forma significativa. Resultados semelhantes são obtidos por Lewis e Raftery (1997) utilizando os mesmos conjuntos de valores (Nunes , 2005).

Candolo (2004) compara o desempenho das metodologias de ponderação frequentista e bayesiana através de dados simulados. Os resultados empíricos indicam desempenho semelhante determinado pelas variâncias dos coeficientes das variáveis preditoras obtidas por cada uma das metodologias. Neste trabalho, adotaremos a perspectiva bayesiana devido aos métodos e resultados observados por Raftery et al. (2010) e McCormick et al. (2012).

\subsection{Modelo Dinâmico de Regressão Logística Bayesiana}

Nesta seção, apresentamos o modelo dinâmico de regressão logística bayesiana com as mesmas características descritas por Raftery et al. (2010). Porém, variáveis binárias são consideradas como variáveis dependentes ao invés de variáveis contínuas. Também é descrito o procedimento de estimação recursiva para um único modelo.

O procedimento de estimação recursiva do modelo é realizado em duas etapas: atualização e predição, conforme mencionado por McCormick et al. (2012). 


\section{Modelo estado-espaço para estimação intra-modelo}

Dado um modelo com variável resposta binária $y_{t}$ e variáveis preditoras $x_{t}=\left(x_{1, t}, x_{2, t}, \ldots, x_{d, t}\right)$ em um tempo $t$ :

$$
y_{t} \sim \operatorname{Bernoulli}\left(p_{t}\right)
$$

onde

$$
\operatorname{logit}\left(p_{t}\right)=\ln \left(\frac{p_{t}}{1-p_{t}}\right)=x_{t}^{T} \theta_{t}
$$

e $\theta_{t}$ é o vetor dos coeficientes da regressão logística.

Em dado tempo t, o procedimento assume o modo a posteriori de $\theta$ a partir do tempo (t-1) e a utiliza para construir a posteriori para o tempo t. Esse processo é realizado até o tempo (t-1) para construir uma estimativa para os parâmetros para o tempo t, o que produz a equação de predição.

Essa equação prevê o valor da observação para o tempo t baseada nos dados até o tempo (t-1). A equação de predição então combina os dados observados no tempo $t$ e as novas informações atualizadas dos parâmetros pela equação de atualização.

Como descrito por Raftery et al. (2010), os parâmetros de regressão $\theta_{t}$ podem evoluir conforme a seguinte equação de estado:

$$
\theta_{t}=\theta_{t-1}+\delta_{t}
$$

onde o estado de inovação $\delta_{t} \sim N\left(0, W_{t}\right)$, independentes. E $W_{t}$ representa a matriz de covariância no estado $t$.

Para um conjunto de observações da variável dependente $Y^{t-1}=y_{1}, y_{2}, \ldots, y_{t-1}$, o processo recursivo de estimação se inicia supondo:

$$
\theta_{t-1} \mid Y^{t-1} \sim N\left(\hat{\theta}_{t-1}, \hat{\Sigma}_{t-1}\right)
$$

Desta maneira, a equação de predição é dada por:

$$
\theta_{t} \mid Y^{t-1} \sim N\left(\hat{\theta}_{t-1}, R_{t}\right)
$$

em que

$$
R_{t}=\hat{\Sigma}_{t-1} / \lambda_{t}
$$

O fator de esquecimento é especificado pela equação $5.6 \mathrm{com} \lambda_{t}$ assumindo valor pouco menor que 1.

O modelo poderia ser especificado sem o fator de esquecimento usando a matriz de covariância $W_{t}$, o que resultaria em $R_{t}=\hat{\Sigma}_{t-1}+W_{t}$. Porém, essa abordagem requisita que 
a matriz de covariância $W_{t}$ seja especificada, o que seria uma matriz muito grande, além de exigir intenso processamento computacional (McCormick et al. , 2012).

O fator de esquecimento tem a função de calibrar a influência de observações passadas, bem como eliminar a necessidade de matrizes de transição entre os estados, o que torna a predição online computacionalmente razoável. É similar a aplicar pesos para a amostra, em que observações passadas recebem pesos menores que as observações mais recentes. Nesse caso, ele calibra a influência das observações passadas.

A ideia geral dentro de cada modelo-candidato é centralizar a priori para o estado ainda não observado do processo no tempo t no centro da posteriori na (t-1) observação, e fixar a priori da variância do estado no tempo t igual à variância posteriori no tempo $(\mathrm{t}-1)$ inflado pelo fator de esquecimento.

Combinando a equação dada em 5.5 com as informações disponíveis no tempo t, podemos construir estimativas atualizadas.

A distribuição a posteriori da estimativa atualizada $\theta_{t}$, tendo observado $y_{t}$, pode ser definida como:

$$
p\left(\theta_{t} \mid Y^{t}\right) \propto p\left(y_{t} \mid \theta_{t}\right) p\left(\theta_{t} \mid Y^{t-1}\right) .
$$

A equação 5.7 é o produto da equação 5.5 pela probabilidade no tempo t. O termo $p\left(\theta_{t} \mid Y^{t-1}\right)$ representa a priori.

Analisando o lado direito da equação 5.7, pode-se aproximá-la para uma distribuição normal com a média assumindo a moda da equação 5.7.

É usado $\hat{\theta}_{t-1}$ como um valor inicial, produzindo:

$$
\hat{\theta}_{t}=\hat{\theta}_{t-1}-D^{2} l\left(\hat{\theta}_{t-1}\right)^{-1} D l\left(\hat{\theta}_{t-1}\right)
$$

onde $l(\theta)=\log p\left(y_{t} \mid \theta\right) p\left(\theta \mid Y^{t-1}\right)$.

$\mathrm{E}$

$$
\operatorname{Dl}\left(\hat{\theta}_{t-1}\right)=\left(y_{t}-\hat{y}_{t}\right) x_{t}
$$

onde $\operatorname{logit}\left(\hat{y}_{t}\right)=x_{t}^{T} \hat{\theta}_{t-1}$. Também

$$
D^{2} l\left(\hat{\theta}_{t-1}\right)=R_{t}^{-1}+\hat{y}_{t}\left(1-\hat{y}_{t}\right) x_{t} x_{t}^{T}
$$

Podemos substituir nas equações 5.9 e 5.10 na equação 5.8 para obter a estimativa atualizada $\hat{\theta}_{t}$.

A variância da distribuição normal aproximada é atualizada usando $\hat{\Sigma}_{t}=\left(-D^{2} l\left(\hat{\theta}_{t-1}\right)\right)^{-1}$.

McCormick et al. (2012) propõem um procedimento adaptativo em tempo real usando a seguinte equação de probabilidade preditiva:

$$
f\left(y_{t} \mid Y^{t-1}\right)=\int_{\theta_{t}} p\left(y_{t} \mid \theta_{t}, Y^{t-1}\right) p\left(\theta_{t} \mid Y^{t-1}\right) d \theta_{t}
$$


Como a integral anterior não está disponível em sua forma fechada, a aproximação de Laplace é usada, produzindo:

$$
f\left(y_{t} \mid Y^{t-1}\right) \approx(2 \pi)^{d / 2}\left|D^{2}\left(\hat{\theta}_{t}\right)^{-1}\right|^{1 / 2} p\left(y_{t} \mid Y^{t-1}, \hat{\theta}_{t}\right) p\left(\hat{\theta}_{t} \mid Y^{t-1}\right) .
$$

Lewis e Raftery (1997) mostram que essa aproximação tem uma grande acurácia. A aproximação de Laplace torna a computação do modelo praticável e rápida porque $p\left(y_{t} \mid Y^{t-1}, \hat{\theta}_{t}\right)$ é a função de probabilidade logística avaliada em $\hat{\theta}_{t}$ e $\left(x_{t}, y_{t}\right)$, e $p\left(\hat{\theta}_{t} \mid Y^{t-1}\right)$ tem densidade normal com média $\hat{\theta}_{t}$ e variância $\hat{\Sigma}_{t-1} / \lambda_{t}$. O valor de $\lambda$ é escolhido de maneira a maximizar a equação 5.12. Isto é:

$$
\lambda_{t}=\arg \max _{\lambda_{t}} \int_{\theta_{t}} p\left(y_{t} \mid \theta_{t}, Y^{t-1}\right) p\left(\theta_{t} \mid Y^{t-1}\right) d \theta_{t}
$$

Devidos aos $\theta$ s mudarem em diferentes taxas, McCormick et al. (2012) sugerem que cada parâmetro dentro de cada modelo e em cada tempo tenha seu próprio fator de esquecimento. Embora essa abordagem adicione flexibilidade, ela pode ser computacionalmente muito onerosa.

Neste trabalho, analisamos a melhor maneira de adotar o fator de esquecimento para que não sejam gerados grandes impactos de processamento computacional.

\subsection{Ponderação Dinâmica de Modelos (Dynamic Model Averaging - DMA)}

A metodologia DMA combina algumas ideias existentes: ponderação de modelos bayesianos (Bayesian Model Averaging - BMA), cadeias de Markov e fator de esquecimento em modelagem estado-espaço.

O método DMA é uma extensão dinâmica do método BMA em que as probabilidades do modelo a posteriori são atualizadas ao longo do tempo. Considerando um conjunto finito de modelos candidatos e assumindo que os dados seguem uma cadeia de Markov, dentro de cada modelo candidato, os parâmetros seguem um modelo estado-espaço. Tanto a cadeia de Markov como o modelo estado-espaço são atualizados recursivamente.

No caso em que temos $K$ modelos candidatos $M_{1}, M_{2}, \ldots, M_{k}$, a principal característica do método é o fato de que as probabilidades do modelo também são dinâmicas, tornando o modelo flexível ao longo do tempo e evitando super ajustamento dos parâmetros (overfitting).

Seja $L_{t}$ uma variável indicadora do modelo, tal que se $L_{t}=k$, o processo é comandado pelo modelo $M_{k}$ no tempo t. Assim, para o caso de múltiplos modelos temos:

$$
y_{t} \mid L_{t}=k \sim \operatorname{Bernoulli}\left(p_{t}^{(k)}\right),
$$


onde

$$
\operatorname{logit}\left(p_{t}^{(k)}\right)=x_{t}^{(k) T} \theta_{t}^{(k)}
$$

A atualização de $\theta_{t}^{(k)}$ ocorrerá quando $L_{t}=k$, conforme mostrado no trabalho de Raftery et al. (2010).

Da mesma maneira que se dá no caso do método BMA, o processo de estimação ocorre em dois passos: predição e atualização. A diferença é que para o caso de múltiplos modelos teremos o par $\left(L_{t}, \theta_{t}\right)$, onde $\theta_{t}=\left(\theta_{t}^{(1)}, \ldots\right.$, thet $\left.a_{t}^{(k)}\right)$ e o vetor $\theta_{t}^{(k)}$ existe somente quando $L_{t}=k$.

Nessa situação, a estimação recursiva atua no par $\left(L_{t}, \theta_{t}\right)$ :

$$
\sum_{l=1}^{K} p\left(\theta_{t}^{(l)} \mid L_{t}=l, Y^{t-1}\right) p\left(L_{t}=l, Y^{t-1}\right)
$$

Note que na equação 5.16 o termo $\theta_{t}^{(l)}$ está presente condicionado a $L_{t}=l$.

A equação de predição do modelo é dada por:

$$
P\left(L_{t}=k \mid Y^{t-1}\right)=\sum_{l=1}^{K} p\left(L_{t-1}=l \mid Y^{t-1}\right) p\left(L_{t}=k \mid L_{t-1}=l\right) .
$$

Para evitar a especificação da matriz de transição $K \times K$, do termo $p\left(L_{t}=k \mid L_{t-1}=l\right)$, a atualização é feita com o uso do fator de esquecimento para o modelo especificado por $\alpha_{t}$, com $\alpha_{t} \leq 1$. Dessa forma, apenas um único valor para o fator de esquecimento deve ser definido em vez de uma matriz de transição inteira.

$$
P\left(L_{t}=k \mid Y^{t-1}\right)=\frac{P\left(L_{t-1}=k \mid Y^{t-1}\right)^{\alpha_{t}}}{\sum_{l=1}^{k} P\left(L_{t-1}=l \mid Y^{t-1}\right)^{\alpha_{t}}} .
$$

Com isso, a equação de atualização é definida como:

$$
P\left(L_{t}=k \mid Y^{t}\right)=\frac{w_{t}^{(k)}}{\sum_{l=1}^{K} w_{t}^{(l)}},
$$

onde

$$
w_{t}^{(l)}=P\left(L_{t}=l \mid Y^{t-1}\right) f^{(l)}\left(y_{t} \mid Y^{t-1}\right) .
$$

Como o procedimento para selecionar o fator de esquecimento $\lambda_{t}^{(l)}$ já calcula $f^{(l)}\left(y_{t} \mid Y^{t-1}\right)$, não existe a necessidade de cálculos adicionais para a equação 5.20.

Adicionalmente, para ajustar $\alpha_{t}$, utiliza-se a probabilidade preditiva entre os modelos candidatos $f\left(y_{t} \mid Y^{t-1}\right)$ de maneira que: 


$$
\begin{aligned}
\mathbf{f}\left(\mathbf{y}_{\mathbf{t}} \mid \mathbf{Y}^{\mathbf{t}-\mathbf{1}}\right)= & \sum_{k=1}^{K} f^{(k)}\left(y_{t} \mid Y^{t-1}\right) P\left(L_{t}=k \mid Y^{t-1}\right) \\
= & \sum_{k=1}^{K}\left(\int_{\theta_{t}^{(k)}} P\left(y_{t} \mid \theta_{t}^{(k)}, Y^{t-1}\right) p\left(\theta_{t}^{(k)} \mid Y^{t-1}\right) d \theta_{t}^{(k)}\right) \\
& \times \frac{P\left(L_{t-1}=k \mid Y^{t-1}\right)^{\alpha_{t}}}{\sum_{l=1}^{k} P\left(L_{t-1}=l \mid Y^{t-1}\right)^{\alpha_{t}}} .
\end{aligned}
$$

Como computamos anteriormente $f^{(k)}\left(y_{t} \mid Y^{t-1}\right)$, podemos usar esse resultado, com mínima computação adicional, para selecionar $\alpha_{t}$ seguindo:

$$
\alpha_{t}=\arg \max _{\alpha_{t}} \sum_{k=1}^{K} f^{(k)}\left(y_{t} \mid Y^{t-1}\right) P\left(L_{t}=k \mid Y^{t-1}\right) .
$$

Dado isso, para predição de $\hat{y}_{t}$ temos:

$$
\hat{y}_{t}=\sum_{l=1}^{K} P\left(L_{t}=l \mid Y^{t-1}\right) \hat{y}_{t}^{(l)}
$$

no qual $\hat{y}_{t}^{(l)}$ é o valor predito para o modelo $l$ no tempo $t$.

\subsection{Relatos de Aplicações do Método DMA}

Existem alguns trabalhos que têm apresentado resultados interessantes obtidos através da aplicação do método DMA.

\section{Estudo 1}

No estudo de Raftery et al. (2010), a questão de predição online é aplicada no processo de laminação a frio. Esse processo é realizado por uma máquina que busca diminuir a espessura de uma placa de metal até atingir uma medida definida antecipadamente. É esperado, como resultado do processo de modelagem, uma predição da espessura com alta acurácia.

Para esse problema, as seguintes variáveis são candidatas para a construção do modelo: $u_{t}$ : a diferença da espessura inicial e seu valor nominal para a amostra t;

$v_{t}$ : a posição do rolamento (em microns) após aplicar a força na placa;

$w_{t}$ : a razão entre a velocidade de saída do rolamento e a velocidade de entrada do rolamento; $z_{t}$ : a força de rolamento aplicada à amostra t. 
Em trabalhos anteriores, três tipos de modelos foram usados, dois dos quais são modelos fisicamente motivados $\left(M_{1}\right.$ e $\left.M_{2}\right)$ e um baseado em trabalho empírico exploratório $\left(M_{3}\right)$. Os preditores que correspondem aos três modelos são os seguintes:

$$
\begin{aligned}
& M_{1}: x_{t}^{(1)}=\left(1, v_{t}, z_{t}\right)=\theta_{0 t}+\theta_{1 t} v_{t}+\theta_{2 t} z_{t}, \\
& M_{2}: x_{t}^{(2)}=\left(1, v_{t}, u_{t} w_{t}\right)=\theta_{0 t}+\theta_{1 t} v_{t}+\theta_{2 t} u_{t} w_{t}, \\
& M_{3}: x_{t}^{(3)}=\left(1, u_{t}, v_{t}, w_{t}\right)=\theta_{0 t}+\theta_{1 t} u_{t}+\theta_{2 t} v_{t}+\theta_{3 t} w_{t},
\end{aligned}
$$

com $\theta_{i t}$ representando os coeficientes da regressão.

Raftery et al. (2010) consideram a predição usando cada um desses modelos individualmente e o modelo de DMA baseado nos três modelos. Consideram também o DMA com 17 modelos, isto é, todas as possíveis combinações dos quatro preditores (o que resulta em 16 modelos) mais o modelo $M_{2}$. A lista completa de modelos está descrita na tabela 5.1, com quatro variáveis preditoras primárias $(u, v, w, z)$ e uma derivada $(u w)$.

\begin{tabular}{cccccc}
\hline & \multicolumn{5}{c}{ Variáveis } \\
\cline { 2 - 6 } \# Modelos & $u_{t}$ & $v_{t}$ & $w_{t}$ & $z_{t}$ & $\left(u_{t} w_{t}\right)$ \\
\hline 1 & - & $\checkmark$ & - & $\checkmark$ & - \\
2 & - & - & $\checkmark$ & - & $\checkmark$ \\
3 & $\checkmark$ & $\checkmark$ & $\checkmark$ & - & - \\
4 & - & - & - & - & - \\
5 & - & - & - & $\checkmark$ & - \\
6 & - & - & $\checkmark$ & - & - \\
7 & - & - & $\checkmark$ & $\checkmark$ & - \\
8 & - & $\checkmark$ & - & - & - \\
9 & - & $\checkmark$ & $\checkmark$ & - & - \\
10 & - & $\checkmark$ & $\checkmark$ & $\checkmark$ & - \\
11 & $\checkmark$ & - & - & - & - \\
12 & $\checkmark$ & - & - & $\checkmark$ & - \\
13 & $\checkmark$ & - & $\checkmark$ & - & - \\
14 & $\checkmark$ & - & $\checkmark$ & $\checkmark$ & - \\
15 & $\checkmark$ & $\checkmark$ & - & - & - \\
16 & $\checkmark$ & $\checkmark$ & - & $\checkmark$ & - \\
17 & $\checkmark$ & $\checkmark$ & $\checkmark$ & $\checkmark$ & - \\
\hline
\end{tabular}

Tabela 5.1: Lista de preditores usados em cada modelo Raftery et al. (2010).

Os resultados dos experimentos apontaram que não houve ganho no uso de diferentes fatores de esquecimento e, por isso, $\lambda=\alpha$ foi usado, deixando apenas um fator de esquecimento a ser especificado. $\lambda=\alpha=0,99$ foi utilizado nos experimentos.

Os resultados principais estão descritos na tabela 5.2, e indicam que o modelo $M_{3}$ mostrou-se melhor do que os modelos $M_{1}$ e $M_{2}$ para ambos os períodos de amostras (Período Inicial: amostras 26-200; Período Final: amostras 201-19058). 
No período inicial, DMA com 3 modelos foi levemente melhor do que $M_{3}$ em todos os três critérios relatados (MSE, MaxAE e \#AE $>10$ ), enquanto no período estável, DMA foi basicamente o mesmo que $M_{3}$. Nesse caso, DMA permitiu que se evitasse o pagamento de uma penalidade pela incerteza sobre a estrutura do modelo.

DMA com 17 modelos no período inicial atingiu uma performance significativamente melhor do que $M_{3}$ ou DMA com 3 modelos, em todos os três critérios. No período final, DMA com 17 modelos foi um pouco melhor do que DMA com 3 modelos e do que $M_{3}$ sozinho. Sobretudo, a inclusão de todas as possíveis combinações de preditores levou a uma performance melhor.

\begin{tabular}{|c|c|c|c|c|c|c|}
\hline \multirow[b]{2}{*}{ Method } & \multicolumn{3}{|c|}{ Samples 26-200 } & \multicolumn{3}{|c|}{ Samples 201-19,058 } \\
\hline & MSE & $\operatorname{MaxAE}$ & \#AE $>10$ & MSE & MaxAE & $\# \mathrm{AE}>10$ \\
\hline Observed & 2179.8 & 68.8 & 175 & 30.6 & 43.1 & 1183 \\
\hline Model 1 & 243.6 & 38.3 & 86 & 26.2 & 31.1 & 989 \\
\hline Model 2 & 345.5 & 41.7 & 118 & 26.8 & 41.4 & 914 \\
\hline Model 3 & 77.5 & 27.3 & 46 & 20.7 & 31.1 & 523 \\
\hline DMA-3 models & 76.1 & 26.3 & 45 & 20.7 & 31.1 & 520 \\
\hline DMA-17 models & 68.9 & 22.0 & 42 & 20.6 & 31.1 & 519 \\
\hline
\end{tabular}

Tabela 5.2: Estatísticas do erro de predição.

MSE: Erro Médio Quadrático, MaxAE: Máximo Erro Absoluto e \#AE>10: número de erros acima de 10 microns em valor absoluto. (Raftery et al. , 2010).

Os autores investigam porque DMA com 17 modelos foi tão bom no período inicial instável. A figura 5.1(a) apresenta os erros de predição para $M_{3}$ e DMA com 17 modelos e a figura 5.1(b) mostra o erro de predição absoluto para DMA menos o erro de predição absoluto para $M_{3}$. DMA é melhor no período inicial porque é mais adaptativo do que um único modelo, mesmo um bom modelo como $M_{3}$. E essa característica é mais importante no período inicial do que no período final. Outro ponto importante é que o DMA com 3 e 17 modelos não torna fixo e estático os coeficientes, permitindo alterá-los dinamicamente.

(a)

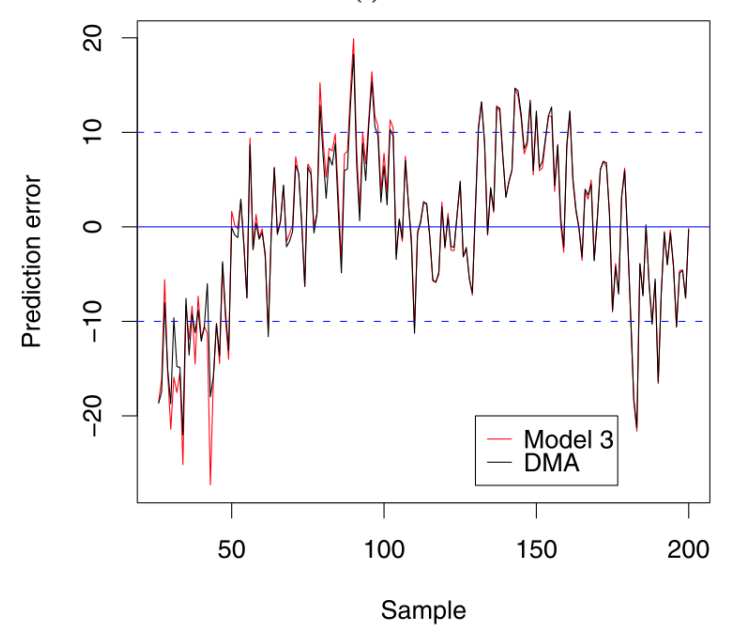

(b)

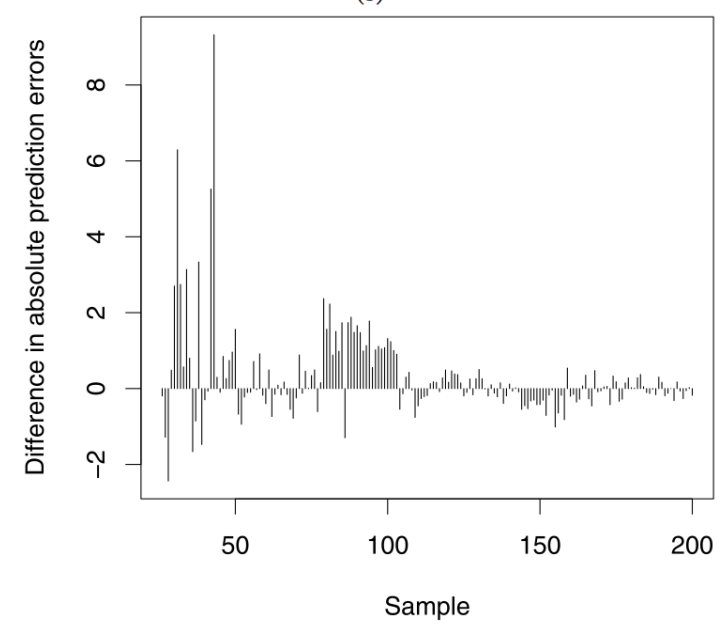

Figura 5.1: Comparação dos erros de predição do modelo $M_{3}$ e DMA com 17 modelos Raftery et al. (2010). 
No que se refere à metodologia, os autores ressaltam que é importante para uma aplicação em tempo real, como essa, que os métodos sejam rápidos. Os experimentos foram rodados no software R em um laptop Apple Powerbook G4 2005. DMA levou cerca de 2 milisegundos por modelo por amostra.

Em suma, Raftery et al. (2010) concluem que em experimentos com dados de um processo de laminação a frio com medição do tempo de atraso, o método DMA levou a uma melhoria de performance no período inicial instável em relação ao melhor modelo considerado em trabalhos anteriores.

\section{Estudo 2}

O estudo de McCormick et al. (2012) é aplicado ao seguinte problema em cirurgia pediátrica: como determinar quais as características que distinguem qual tipo de apendicectomia (por método aberto tradicional ou por laparoscopia) uma criança deve ser exposta. Estudos em adultos sugerem que a laparoscopia pode reduzir o tempo de recuperação e diminuir custos quando comparada ao método aberto, mas tais evidências são menos convincentes em crianças. Apesar disso, o número de apendicectomia por laparoscopia em crianças tem aumentado. Tal fato sugere que outras razões podem estar guiando a escolha por esse método, que não o benefício direto ao paciente, tais como difusão tecnológica ou treinamento, ou razões não médicas, tais como tipo de plano de saúde e raça.

O método foi aplicado a uma amostra de 72.189 crianças com menos de 15 anos do banco de dados Nationwide Inpatient Sample que passaram por apendicectomia entre 1996 e 2002. Os autores relatam que estudos prévios sugerem que existem diferenças socioeconômicas e raciais na apresentação e na gravidade da apendicite em crianças. O estudo observou as seguintes variáveis: a raça do paciente (branco, afro-americano, hispânico, asiático ou outros), idade, sexo, modo de pagamento (plano de saúde, convênio particular, outros), número de doenças crônicas e gravidade da apendicite. Em informações sobre o hospital, observou-se: hospital escola ou não, hospital urbano ou não, volume de apendicectomias, e se hospital pediátrico (não é hospital pediátrico, é hospital pediátrico ou é uma unidade pediátrica em um hospital adulto).

Primeiramente, os autores utilizaram um modelo de regressão logística dinâmico considerando todas as variáveis descritas anteriormente e um fator de esquecimento $(\lambda=0,99)$.

Hagendorf et al. (2007) descobriram que quanto maior a idade do paciente, maior a propensão para uso de laparoscopia, o que faz sentido porque o tratamento normal para apendicite aguda passou a ser esse em adultos no período estudado. No entanto, a figura 5.2 (McCormick et al. , 2012) indica que o coeficiente para idade aumentou de forma estável de 1996 a 1999 e, então, se estabilizou. Esse resultado está de acordo com o fato de que em meados dos anos 90 os procedimentos por laparoscopia eram novos mesmo para adultos, mas se tornaram comuns no fim da década. 


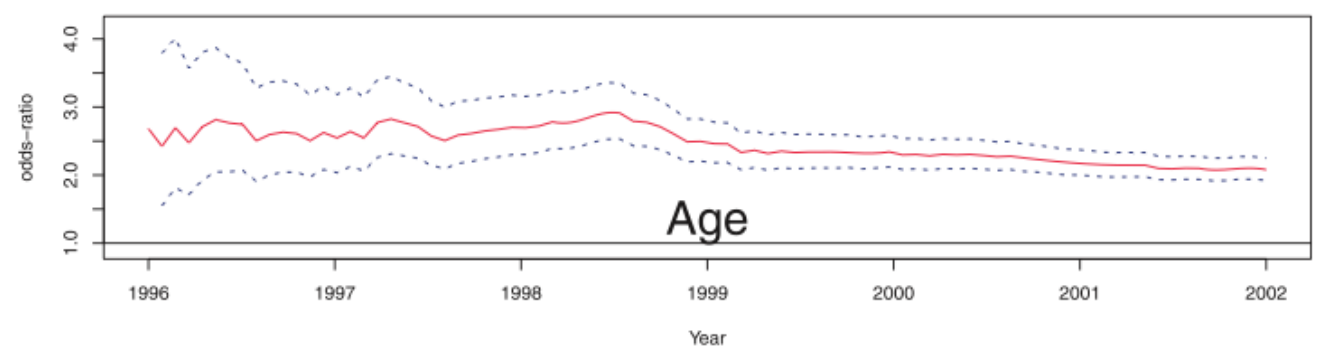

Figura 5.2: Odds ratio da variável idade do modelo com todos preditores. (McCormick et al. , 2012).

No que se refere à raça, os autores mostram que modelos dinâmicos podem revelar informações adicionais. A figura 5.3 mostra os indicadores de raça, com branco como o grupo de referência. O estudo de Hagendorf et al. (2007) não considerou o coeficiente como estatisticamente relevante quando o indicador hispânico foi considerado. Com o modelo dinâmico, o odds ratio foi perto de 1 de 1996 até 2001 e então aumentou para perto de 1,5 no fim de 2002. Ainda, Hagendorf et al. (2007) constataram que odds ratio era significativamente menor que 1 para afro-americano, mas o modelo dinâmico, apesar de confirmar essa observação, constata que a tendência foi aumentando e que, em 2001, o odds ratio estava perto de 1.
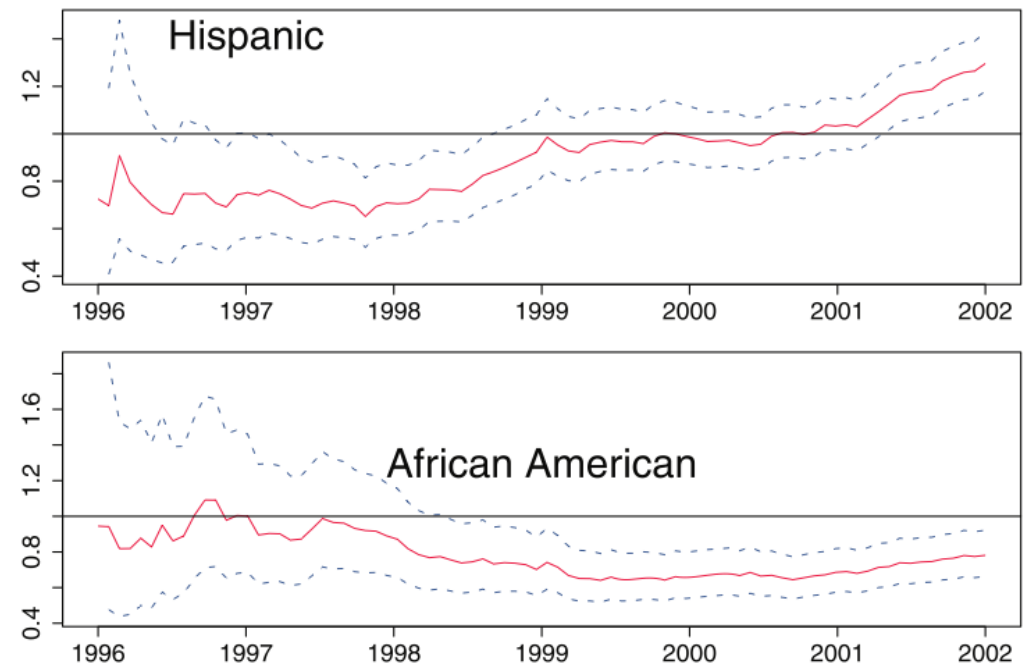

Figura 5.3: Odds ratio das variáveis raça hispânico e afro-americano do modelo com todos preditores. (McCormick et al. , 2012).

McCormick et al. (2012) apresentam na figura 5.4 a probabilidade marginal para cada preditor. O método DMA encontrou evidência para a importância de raça e forma de pagamento, apesar da variação no tempo. Por exemplo, a raça do paciente teve probabilidade marginal baixa durante os dois primeiros anos de observação, mas aumentou e permaneceu alta até 1998. 


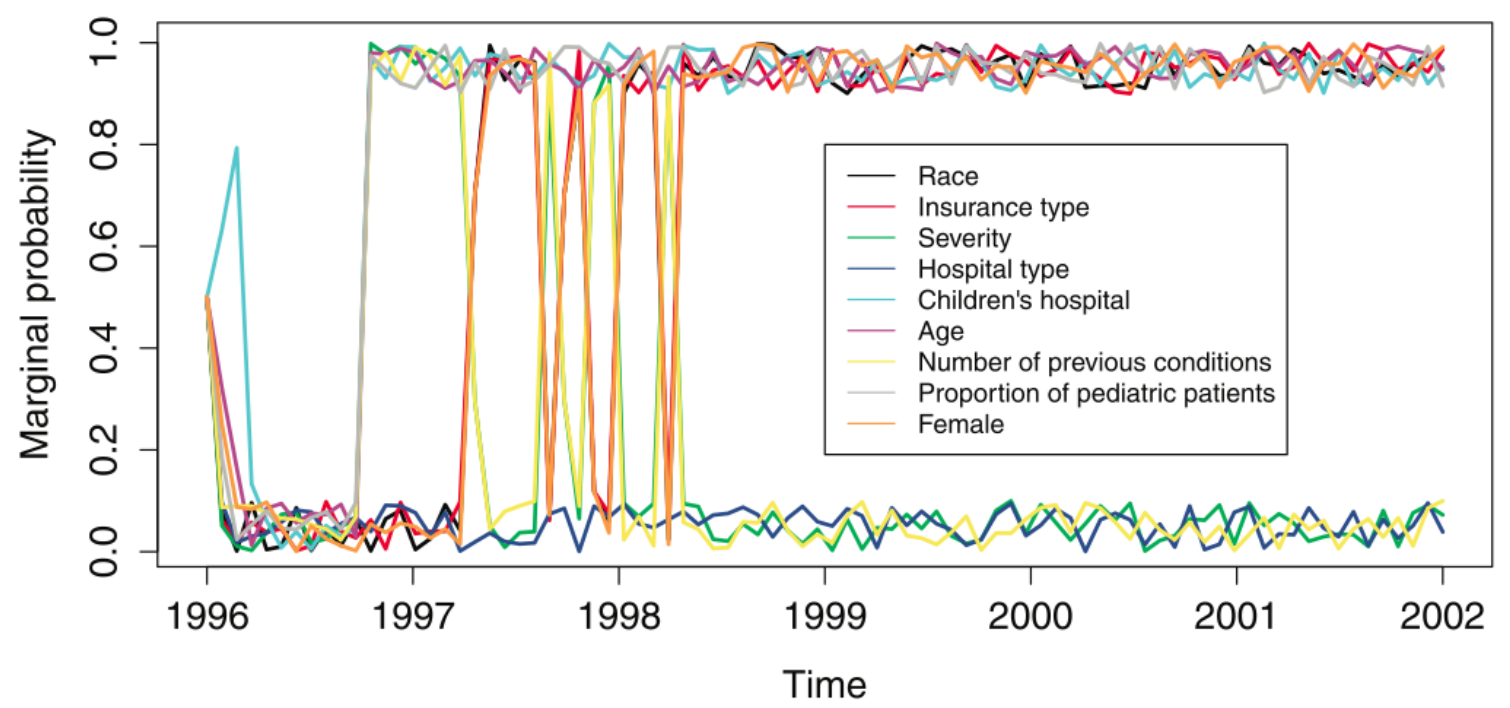

Figura 5.4: Probabilidade marginais de nove preditores. (McCormick et al., 2012).

Os autores também compararam a performance do DMA com outros 521 modelos estáticos. Cada modelo estático incluiu variáveis indicadoras por ano. Usando Brier score, que mede a acurácia da probabilidade da predição, foi encontrado o valor de 0,14 com uso de DMA e o melhor modelo de regressão estático. No entanto, o modelo estático previu um elevado número de respostas zero, levando a uma baixa sensibilidade de pontuação. A sensibilidade de pontuação para o DMA foi 0,12 frente a 0,02 para o melhor modelo estático.

Em conclusão, o método DMA forneceu informações para o tratamento de apendicite que não estavam claras com métodos de regressão logística estática, mesmo quando a variável ano foi considerada como uma covariável. As análises podem ser feitas online e as estimativas atualizadas ao passo que dados adicionais são disponibilizados. Essa característica torna o método aplicável a outras situações em que dados podem ser coletados e processados sequencialmente ou quando o armazenamento de dados é pouco atraente, como é muitas vezes o caso de registros médicos.

\section{Estudo 3}

No trabalho de Koop e Korobilis (2010), podemos encontrar a utilização dos métodos DMA e DMS aplicados na previsão da inflação dos Estados Unidos da América baseado na curva de Phillips ${ }^{3}$. Os autores buscavam com os métodos a solução de três problemas: 1) coeficientes de variáveis preditoras que podem mudar ao longo do tempo; 2) o número de potenciais variáveis preditoras pode ser muito grande; 3) o modelo de previsão pode se alterar ao longo do tempo.

O período de análise se estendeu do primeiro trimestre de 1960 até o quarto trimestre de 2008, resultando em 196 observações. Foram usadas 2 medidas para inflação (inflação baseada

\footnotetext{
${ }^{3}$ Em macroeconomia, a curva de Phillips representa uma relação de "perda e ganho" entre inflação e desemprego. Segundo Willian Phillips, desenvolvedor da teoria, uma menor taxa de desemprego leva a um aumento da inflação.
} 
no produto interno bruto (GPD) e aumento de preços de consumo pessoal doméstico (PCE)) e 14 variáveis preditoras na aplicação do método.

Para um período de previsão de 1, 4 e 8 trimestres, temos que o método DMA é fortemente favorável a modelos parcimoniosos, pois utiliza 5 das 14 possíveis variáveis preditoras no processo de estimação das 2 medidas da inflação (figura 5.6 e 5.5).

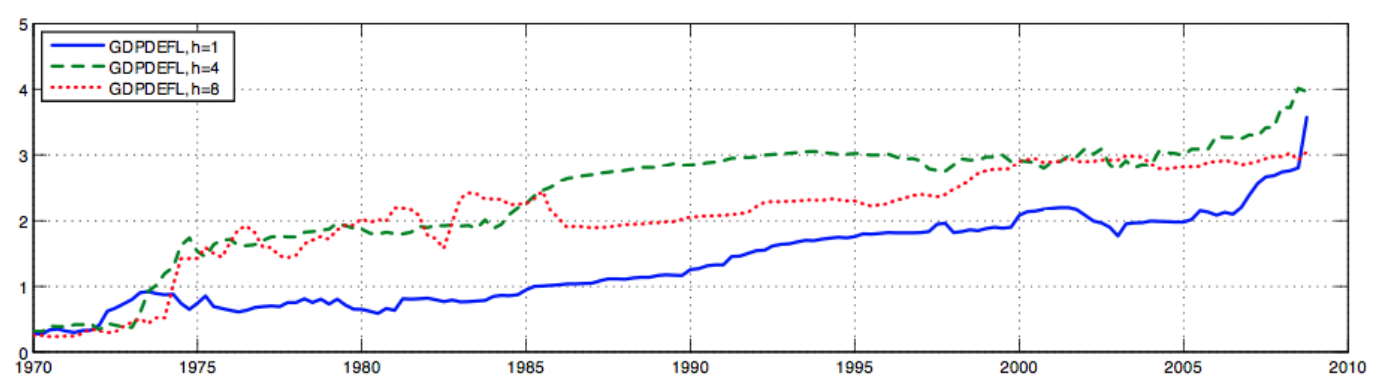

Figura 5.5: Número de variáveis preditoras para inflação baseada no GPD. (Koop e Korobilis , 2010).

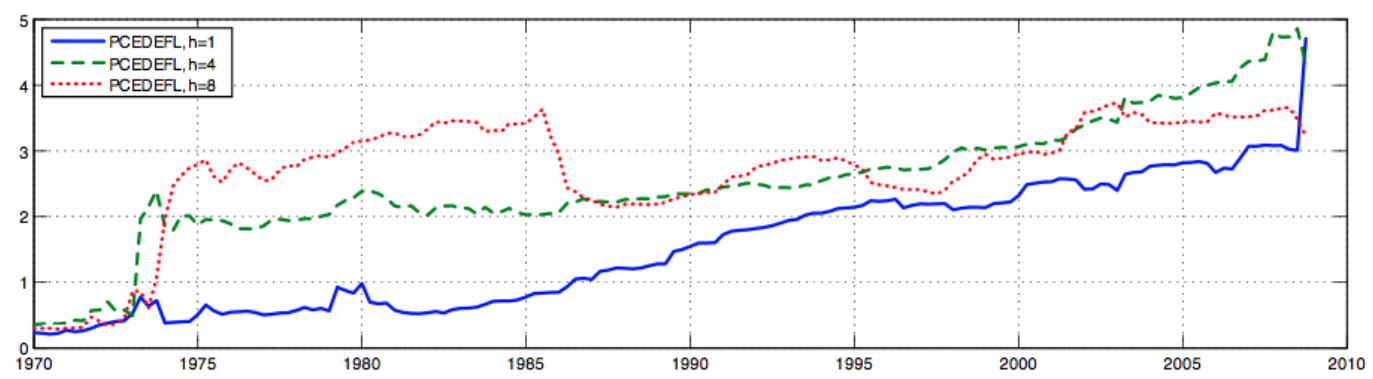

Figura 5.6: Número de variáveis preditoras para inflação baseada no PCE. (Koop e Korobilis , 2010).

Comparando com as predições do Banco Central dos Estados Unidos (Federal Reserve), conhecido também como FED, temos que para $\alpha=\lambda=0,99$ o método DMA melhora em $12 \%$ e para $\alpha=\lambda=0,95$ em $15 \%$, aproximadamente, para prever 1 trimestre adiante.

Ao prever 4 trimestres adiante, a predição do FED é $10 \%$ melhor que o DMA com $\alpha=\lambda=0,99$, porém o DMA com $\alpha=\lambda=0,95$ é levemente melhor. Os resultados podem ser observados na tabela 5.3.

\begin{tabular}{lcc} 
& $h=1$ & $h=4$ \\
\hline \hline Federal Reserve (FED) & 0.91 & 0.84 \\
DMA $\alpha=\lambda=0.99$ & 0.80 & 0.94 \\
DMA $\alpha=\lambda=0.95$ & 0.77 & 0.83 \\
\hline
\end{tabular}

Tabela 5.3: Comparação do método DMA com as predições do Banco Central dos Estados Unidos Koop e Korobilis (2010).

Como conclusão, o trabalho menciona que os métodos DMA e DMS foram eficazes para lidar com os três problemas descritos anteriormente e trouxeram uma melhora substancial na acurácia das predições. 


\subsection{Algoritmo do Método DMA}

Para o cálculo do método DMA, o seguinte algoritmo foi proposto por Koop e Korobilis (2010):

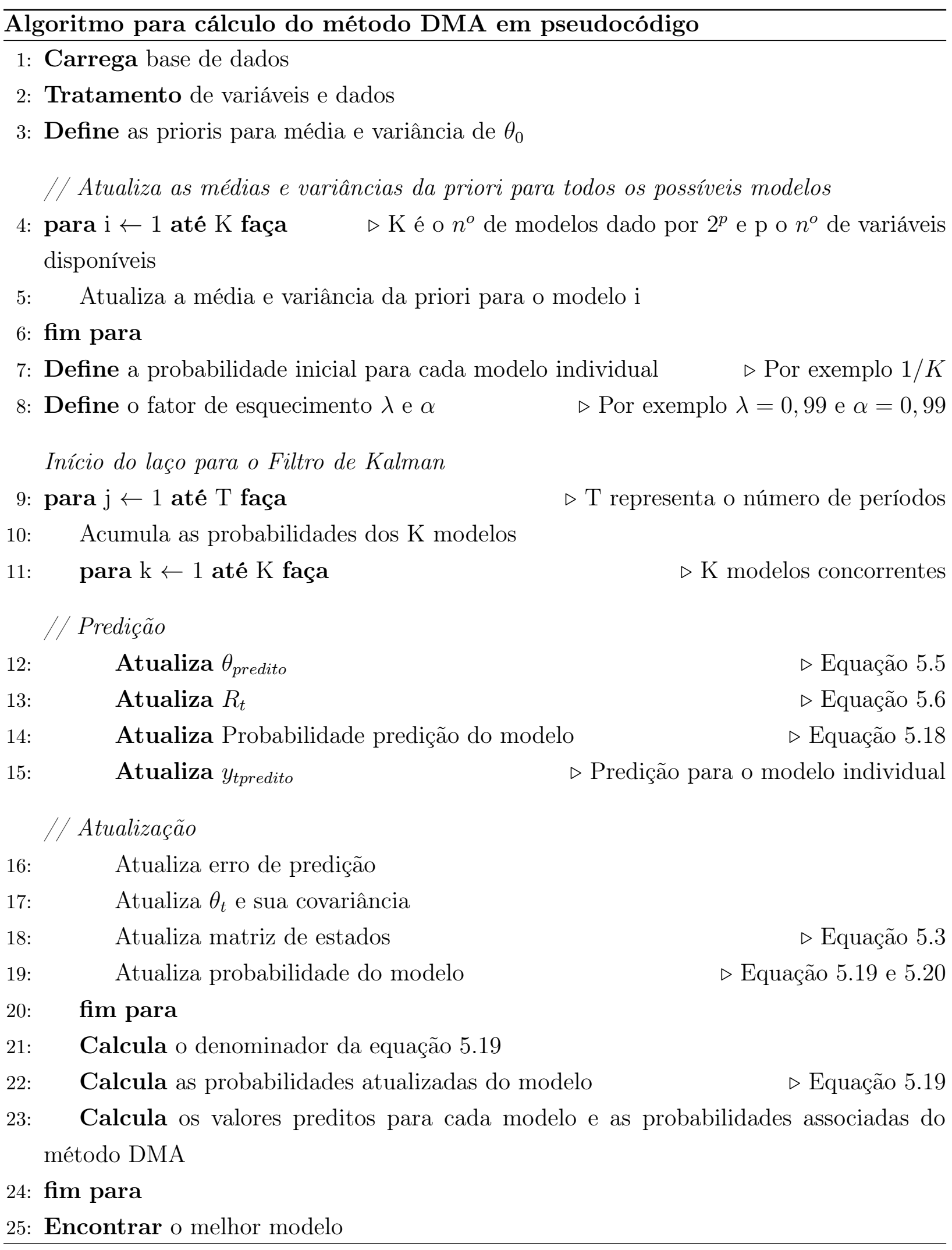




\subsection{Estratégia de Seleção de Modelos}

Considerando o problema de seleção de modelos quando se trabalha com altas dimensões, uma abordagem muitas vezes utilizada é a estratégia chamada stepwise, no qual múltiplos testes estatísticos são realizados e baseados no valor-p até que se obtenha um modelo único. Toda inferência se dá com base nesse modelo escolhido. Nos testes baseados no valor-p, um dos aspectos relevantes está em que tendem a rejeitar modelos satisfatórios quando o tamanho da amostra é grande, bem como as aproximações assintóticas para o valor-p tendem a ficar sem aplicação quando a amostra é pequena (Madigan e Raftery , 1994).

Diante desse cenário, a abordagem DMA parece maximizar a predição da quantidade de interesse do modelo. No entanto, a aplicação dessa técnica encontra dificuldades computacionais para o cálculo de um número muito grande de modelos que competem entre si.

Considerando a abordagem DMA, podemos procurar por um conjunto de modelos menor que possa reunir uma grande quantidade da probabilidade a posteriori. Em Moulton (1991) (apud Madigan e Raftery (1994)), para um modelo de regressão com $2^{12}=4.096$ modelos, foram necessários aproximadamente 800 modelos para reunir $90 \%$ da probabilidade a posteriori.

\section{Seleção de Modelos por Occam's Window}

A abordagem de Occam's Window utiliza dois princípios básicos. Primeiramente, se um modelo tem poder de predição muito distante do modelo que possui melhor capacidade de predição, então esse modelo é descartado e não é mais considerado. Isso significa que ele não pertence ao conjunto $\mathcal{A}^{\prime}$ descrito na equação 5.24 .

$$
\mathcal{A}^{\prime}=\left\{M_{k}: \frac{\max _{l}\left\{p r\left(M_{l} \mid D\right)\right\}}{\operatorname{pr}\left(M_{k} \mid D\right)} \leq c\right\},
$$

onde c é escolhido pelo analista dos dados. Costuma-se adotar $\mathrm{c}=20$.

Como analogia, o valor de c equivale ao valor-p de 0,05 que se costuma adotar nos testes que utilizam esse tipo de estatística.

O segundo princípio, usando Occam's razor ${ }^{4}$, consiste na exclusão de todos os modelos que recebem menos suporte dos dados do que qualquer submodelo mais simples, ou seja, se um modelo é rejeitado, todos os submodelos também o são. Isso pode ser melhor descrito na equação 5.25 .

$$
\mathcal{B}=\left\{M_{k}: \exists M_{l} \in \mathcal{A}, M_{l} \subset M_{k}, \frac{\operatorname{pr}\left(M_{l} \mid D\right)}{\operatorname{pr}\left(M_{k} \mid D\right)}>1\right\}
$$

\footnotetext{
${ }^{4}$ Do filósofo inglês William de Occam (1285-1347), é um princípio científico e filosófico que propõe que, entre hipóteses formuladas sobre as mesmas evidências, é mais racional acreditar na mais simples. Ou seja: diante de várias explicações para um problema, a mais simples tende a ser a mais correta. O termo razor (navalha) sugere que com o uso da parcimônia, a hipótese mais complicada é "cortada".
} 
Dado isso, temos o conjunto $\mathcal{A}$ definido da seguinte maneira pela equação 5.26 :

$$
\mathcal{A}=\mathcal{A}^{\prime} \backslash \mathcal{B} .
$$




\section{Capítulo 6}

\section{Metodologia do Experimento}

Neste capítulo, apresentamos a metodologia utilizada para estruturação do experimento realizado. Os passos que compõem a metodologia são: a preparação do banco de dados para a coleta das variáveis candidatas utilizadas para o desenvolvimento do modelo e os procedimentos de amostragem para selecionar os registros, dado que os dados de fraude são desbalanceados.

\subsection{Preparação do Banco de Dados}

Para o desenvolvimento do trabalho, uma empresa de meios de pagamento eletrônico disponibilizou os dados de transações que foram realizados pelo seu sistema de pagamentos. Para a análise dos dados, foi concedido acesso remoto a um servidor específico que segue as diretrizes de segurança do PCI. Adicionalmente, um acordo de não divulgação, também conhecido como NDA (Non-Disclosure Agreement), foi assinado como recomenda os padrões de segurança e armazenamento de dados de cartão de crédito (PCI-DSS , 2013).

Por meio das análises desses dados, foi possível comparar a técnica DMA com o modelo de regressão logística clássica. Esse último frequentemente utilizado no processo de deteç̧ão de fraudes.

Para isso, executamos etapas de preparação e seleção dos dados, descritas abaixo e ilustradas em sequência na figura 6.1 :

Etapa 1 - Banco de dados Original: criação da estrutura para acesso a tabelas e campos para exportação dos dados. A estruturação foi feita no sistema de gerenciamento de banco de dados SQL.

Etapa 2 - Seleção de tabelas e campos: nesta etapa, foram selecionadas e exportadas todas as tabelas e campos analisados junto com a equipe de negócios da empresa de meios de pagamento. Foram exportadas 28 tabelas que no total somam 354 campos.

Etapa 3 - Aplicação de filtros e estruturação de dados: foram selecionados somente os registros com transações de cartão de crédito aprovadas no período de julho de 2009 
a janeiro de 2014. Para esse período, os registros identificados como fraudulentos, seja pelo portador do cartão ou por análise interna da empresa de meios de pagamento, já foram identificados no banco de dados. Toda a seleção dos campos e relacionamento de tabelas foi realizada utilizando um objeto de banco de dados conhecido como view. Assim, conseguimos preservar a originalidade dos dados armazenados nos campos das tabelas exportadas. Denominamos os campos exportados como variáveis originais.

Etapa 4 - Desenvolvimento e implementação de variáveis derivadas: com base nas variáveis originais, e utilizando views para realizar os cálculos, foram criadas variáveis derivadas para o processo de modelagem.

Etapa 5 - Base final para amostragem: por fim, chegamos ao conjunto final de registros e variáveis para amostragem e modelagem. Adicionalmente, para fins de validação, selecionamos alguns registros na base de dados no sistema interno da empresa a fim de verificar se os dados das variáveis coletadas eram iguais aos originais.

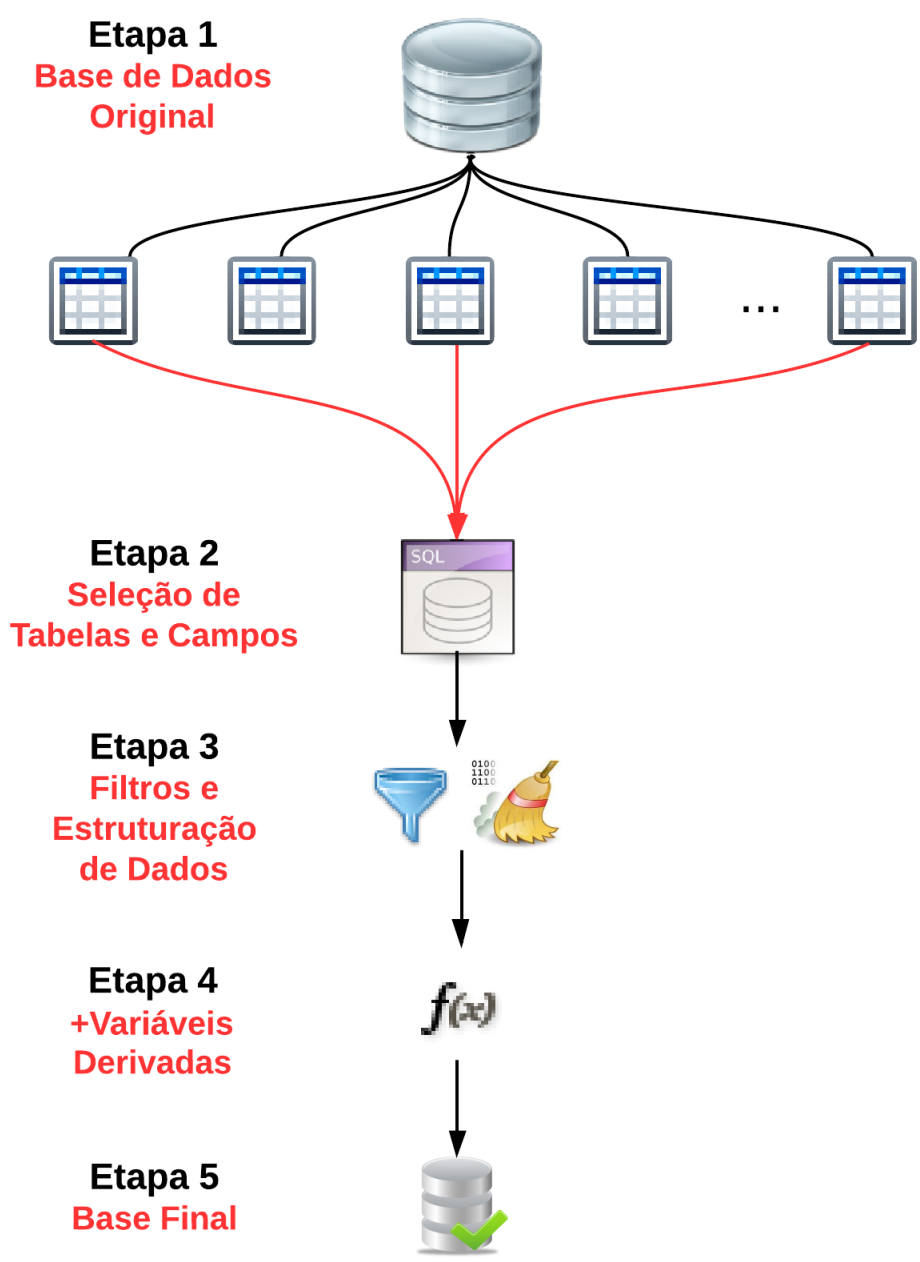

Figura 6.1: Preparação da base de dados. 
A base de dados para o estudo contém 7.716.091 (sete milhões, setecentos e dezesseis mil e noventa e um) registros de transações de cartão de crédito, distribuídos no período de julho de 2009 a janeiro de 2014.

Para cada registro extraído, existem 41 variáveis independentes originais candidatas e 1 variável dependente, totalizando, assim, 42 variáveis. Adotaremos como variáveis originais aquelas que não sofreram qualquer tipo de modificação em seu valor ou atributo extraído do banco de dados.

As transações negadas, independentemente do motivo da negativa, foram excluídas da base de dados. Assim, para o processo de modelagem, são consideradas somente as transações aprovadas.

As variáveis originais utilizadas são:

\section{- Variável Dependente (Resposta)}

1. Classe Fraude (Fraude/Não Fraude)

\section{- Variáveis Independentes (Explicativa)}

\section{Dados da transação}

2. Identificação da Transação

3. Data da Transação

4. Hora da Transação

5. IP da Transação

6. País do IP

7. Estado do IP

8. Cidade do IP

9. Provedor de Serviço de Internet

10. Valor da Transação

11. Status da Transação

12. Tipo de Pagamento

13. Número de Parcelas

14. BIN (identificação do emissor do cartão)

15. Últimos 4 números do Cartão

16. Data de Expiração do Cartão

17. Tipo de Terminal 


\section{Dados do comprador}

18. Categoria do Comprador

19. Nome

20. Email

21. CPF - Cadastro de Pessoa Física

22. CEP

23. Número da Residência

24. Estado

25. Telefone

26. Login Filiação

27. Data de Nascimento

28. Data de Filiação

29. Verificação do CPF

30. Tipo de Filiação

\section{Dados do titular do cartão usado na compra}

31. Nome

32. Data de Nascimento

33. $\mathrm{CPF}$

34. Telefone

\section{Dados do estabelecimento}

35. Identificação do Estabelecimento

36. Nome do Proprietário

37. Tipo de Conta

38. CNPJ - Cadastro Nacional de Pessoa Jurídica

39. Verificação do CNPJ

40. Nome

41. Tipo de Serviço

42. Data de Filiação

Outras variáveis úteis para caracterizar compras fraudulentas são dados que constam no pedido de compra, como, por exemplo, a categoria/tipo de produto e a quantidade que está sendo adquirida. Para exemplificar, na maioria das vezes, não se espera que um comprador 
adquira 10 jogos iguais de video game ou compre 10 televisões de uma só vez em um pedido de compra para pessoa física realizado pela internet.

Infelizmente, essas variáveis não estão disponíveis no banco de dados e recomendamos que futuramente sejam coletadas e adicionadas como variáveis candidatas no modelo.

Adicionalmente, ilustramos abaixo como se dá o procedimento de análise de dados.

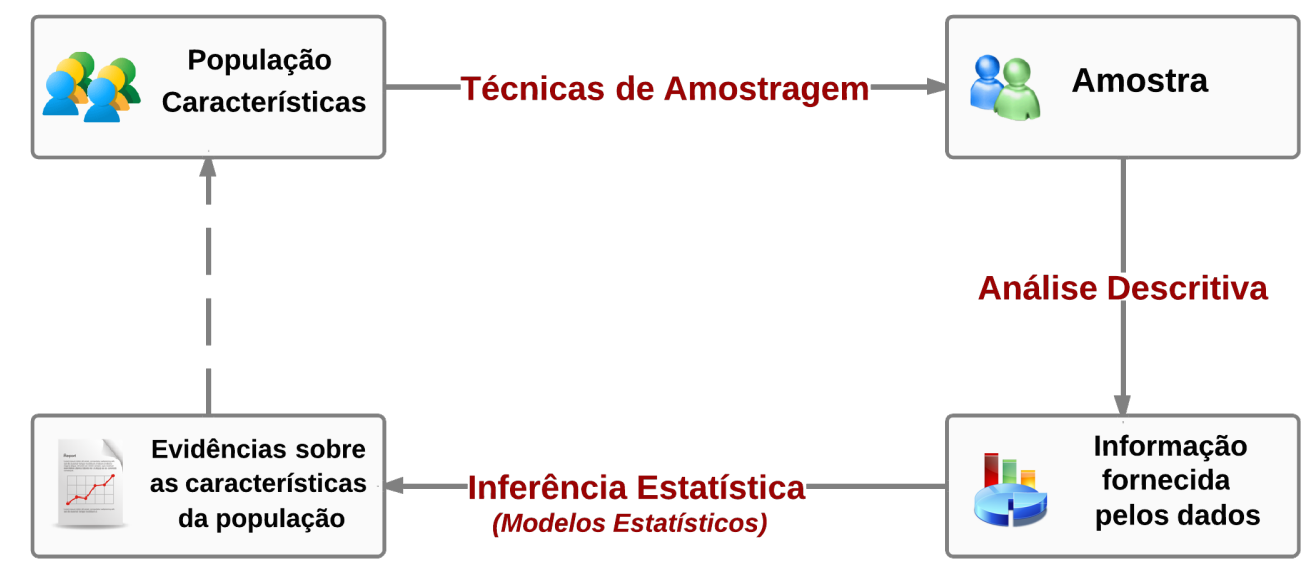

Figura 6.2: Fluxo para análise dos dados.

\subsection{Identificação de Transações Fraudulentas}

As transações fraudulentas foram identificadas de duas maneiras: por meio das informações de estornos (também conhecidos como chargebacks) fornecidas pelos adquirentes e por meio das análises do time interno de prevenção e detecção de fraudes da empresa de meios de pagamento eletrônico. De qualquer modo, ambas as formas de detecção resultaram na classificação de transações como fraude na base de dados final. Transações não classificadas como fraude foram identificadas como não fraude.

\section{Processo de Estorno (Chargeback)}

O processo de estorno é iniciado pelo portador do cartão quando o mesmo não reconhece ou questiona alguma transação que está em sua fatura de cartão de crédito. A fim de proteger o portador do cartão de crédito, o regulamento das bandeiras permite que qualquer valor indevido seja revertido para o emissor ou estabelecimento na maioria dos casos.

Qualquer portador de cartão de crédito pode iniciar um processo de estorno, desde que apresente uma queixa fundamentada sobre o produto ou serviço fornecido, ou não, pelo estabelecimento.

Estornos justificados com os seguintes motivos geralmente não são relacionados a transações fraudulentas: o produto recebido apresenta defeito ou não apresenta as condições especificadas no ato da compra, cobrança duplicada e o produto não recebido. 
Diferentemente, são classificados como fraudes os estornos classificados como transações que o portador não reconhece a transação, que são situações em que o verdadeiro portador do cartão não autorizou ou não reconhece a transação.

Também não podemos deixar de mencionar os estornos de fraude amigável, casos em que a transação foi autorizada pelo portador do cartão, mas o mesmo tenta reverter fraudulentamente as transações. Identificada essa situação, existem regras de cobrança retroativa para o portador do cartão.

Como referência do processo de estornos, existem maiores informações nos sites das bandeiras de cartão de crédito, como Mastercard e VISA (Wikipedia-Chargeback, 2014).

\section{Análise Interna}

As análises internas realizadas pela empresa, também conhecidas por análise manual, são as situações em que a ferramenta de prevenção e detecção de fraude da empresa acusou alguma transação com suspeita de fraude. Após identificada essa suspeita, a transação é avaliada por um analista de risco. Se identificada a fraude, é realizada uma marcação dessa transação no sistema, que é cancelada em seguida. Caso contrário, a transação segue o fluxo normal de aprovação.

\subsection{Tipo de Variáveis}

As variáveis coletadas no banco de dados possuem características não numéricas (qualitativa) e numéricas (quantitativa). Dessa maneira, as variáveis foram classificadas do seguinte modo:

Qualitativa $\begin{cases}\text { Nominal: } & \text { não assume valor numérico e nem pode ser ordenada, apenas } \\ & \text { lista as possíveis categorias que podem ser classificada. } \\ & \text { Ex. bandeira do cartão e estado. } \\ \text { Ordinal: } & \text { não assume valores numéricos, porém existe uma relação de } \\ & \text { ordem nas categorias da variável. } \\ & \text { Ex. tipo de conta do estabelecimento. }\end{cases}$

Contínua: assume características mensuráveis em uma escala contínua na qual os valores são fracionados.

Ex. valor da transação.

Quantitativa Discreta: assume características mensuráveis podendo assumir um número finito ou infinito contável de valores, ou seja, números inteiros.

Ex. número de parcelas da transação. 
Ambos os tipos de variáveis, quantitativas e qualitativas, foram categorizadas conforme o nível de discriminação (separação) entre as transações não fraude e fraude.

\subsection{Dados Faltantes}

Dados faltantes (missing values) são dados ausentes para uma ou mais variáveis que não foram registradas na base de dados por algum motivo, seja por falha no registro ou porque nunca foram coletadas. Um banco de dados com dados faltantes faz com que sejam adotadas técnicas estatísticas que auxiliem no processo de análise inferencial, o que torna o processo mais complexo. Além do mais, dados faltantes afetam propriedades de estimadores (médias, variâncias, percentis, etc) e testes estatísticos em geral. Quando nos deparamos com essa situação, alguns métodos podem ser utilizados. Os métodos mais populares são:

Exclusão: as observações com dados faltantes são excluídas antes do processo de análise. Apesar da facilidade operacional, essa abordagem pode gerar estimativas viesadas e inferências inválidas. Dependendo do número de dados faltantes e do tamanho da amostra, após a exclusão, o tamanho final da amostra pode ficar muito reduzido.

Imputação: utilizando técnicas estatísticas como média ou mediana, esses valores são imputados nas observações faltantes de determinada variável. É uma técnica de fácil aplicação, porém pode conduzir a problemas nas análises inferenciais e não é útil para dados categorizados. Além disso, na maioria das vezes, a estimativa da variância será subestimada, o que leva a uma análise inferencial incorreta.

Criação de Categoria: uma categoria ou valor é adotado para dados faltantes e seu comportamento é avaliado no processo de modelagem.

Nos registros extraídos do banco de dados utilizado, foram observados dados faltantes para as variáveis originais consideradas no estudo. Para o total dos períodos e variáveis originais, em média, observou-se aproximadamente $23 \%$ de dados faltantes (figura 6.3). 


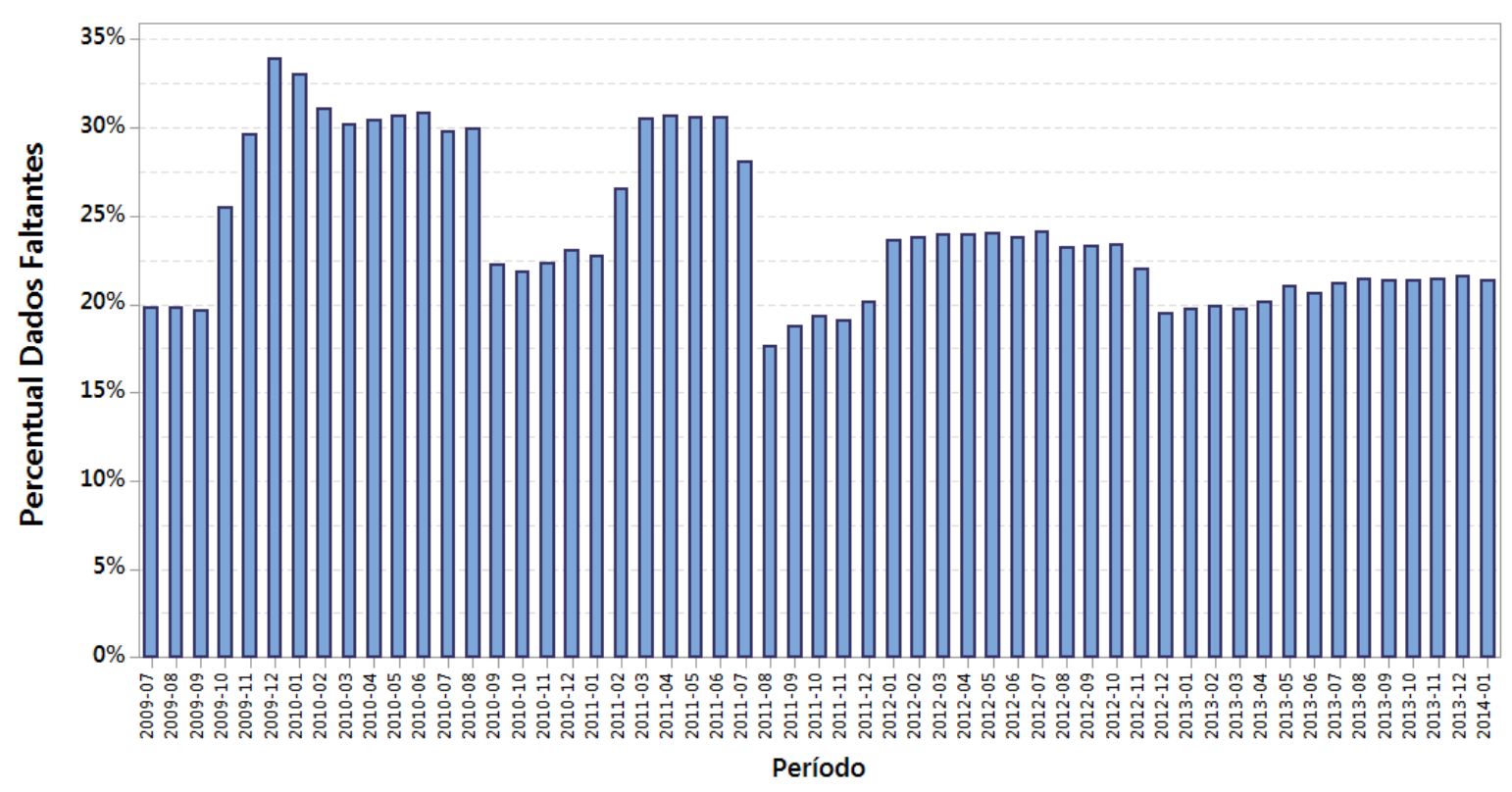

Figura 6.3: Dados faltantes observados nos períodos.

Considerando o período de julho de 2009 até janeiro de 2014, existem 55 períodos em agrupamento mensal. E analisando as 42 variáveis originais, obtemos 2310 períodos pelas variáveis (55 períodos x 42 variáveis). Dado isso, temos na figura 6.4 a distribuição dos dados faltantes mencionada.

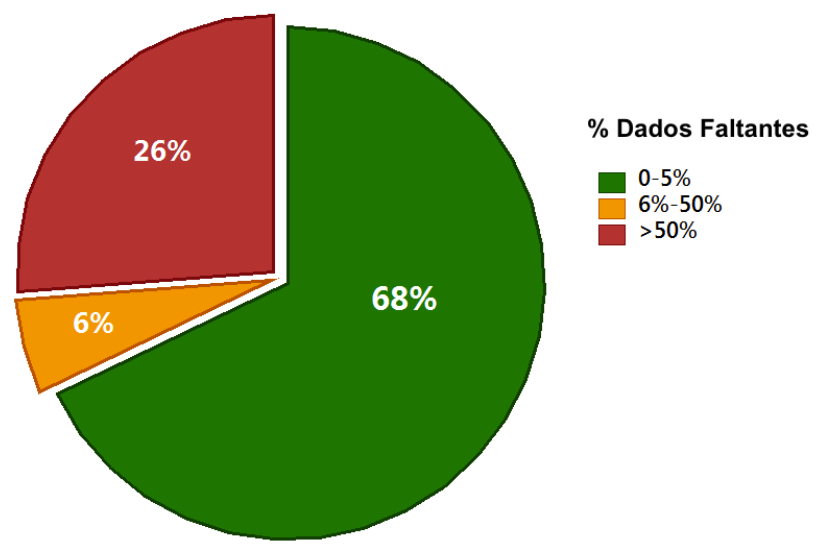

Figura 6.4: Dados faltantes em relação ao total de variáveis e períodos.

Após uma análise detalhada das variáveis que apresentaram mais de 50\% de dados faltantes, as quais totalizaram 14, verificou-se o seguinte:

- 6 variáveis (variáveis 21, 26, 27, 28, 29 e 30) não possuem informações por se tratarem de variáveis que depende do comprador ter um cadastro como membro;

- 4 variáveis $(14,15,16$ e 17) possuíam dados faltantes nos 25 primeiros meses dos 55 meses extraídos. Por se tratarem de variáveis importantes a serem avaliadas, e não possuírem dados faltantes nas informações mais recentes, elas foram mantidas para o desenvolvimento do modelo; 
- encontramos que as variáveis 6, 7, 8 e 9 apresentaram mais que 50\% de dados faltantes em 45 meses, assim desconsideramos essas variáveis da análise.

Após a análise, ficamos com 38 variáveis originais consideradas para o processo de modelagem. Na tabela 6.1, apresentamos um resumo das ações tomadas com base nas análises descritas anteriormente.

\begin{tabular}{|c|c|}
\hline Variável Original & Ação \\
\hline 21. CPF - Cadastro de Pessoa Física & \multirow{6}{*}{$\begin{array}{l}\text { Compradores sem cadastro como } \\
\text { membro. } \\
\text { Manter no processo de modelagem. }\end{array}$} \\
\hline 26. Login de Filiação & \\
\hline 27. Data de Nascimento & \\
\hline 28. Data de Filiação & \\
\hline 29. Verificação do CPF & \\
\hline 30. Tipo de Filiação & \\
\hline 14. BIN & \multirow{4}{*}{$\begin{array}{l}\text { Dados faltantes para períodos } \\
\text { iniciais. } \\
\text { Manter no processo de modelagem. }\end{array}$} \\
\hline 15. Último 4 números do Cartãox & \\
\hline 16. Data Expiração do Cartão & \\
\hline 17. Tipo de Terminal & \\
\hline 6. Pais do IP & \multirow{4}{*}{ Excluir Modelagem. } \\
\hline 7. Estado do IP & \\
\hline 8. Cidade do IP & \\
\hline 9. Provedor de Serviço de Internet & \\
\hline
\end{tabular}

Tabela 6.1: Ações para as variáveis originais com dados faltantes.

Por fim, chegamos a $88 \%$ das variáveis originais no período selecionado com $5 \%$ ou menos dados faltantes. Os $2 \%$ com variáveis originais com mais de $50 \%$ de dados faltantes se referem à variável data de expiração do cartão que apresentou dados faltantes apenas no início do período selecionado. Para os dados mais recentes, essa variável se encontra com valores registrados. Os 10\% restantes apresentaram entre 6\% e $50 \%$ de dados faltantes (figura 6.5).

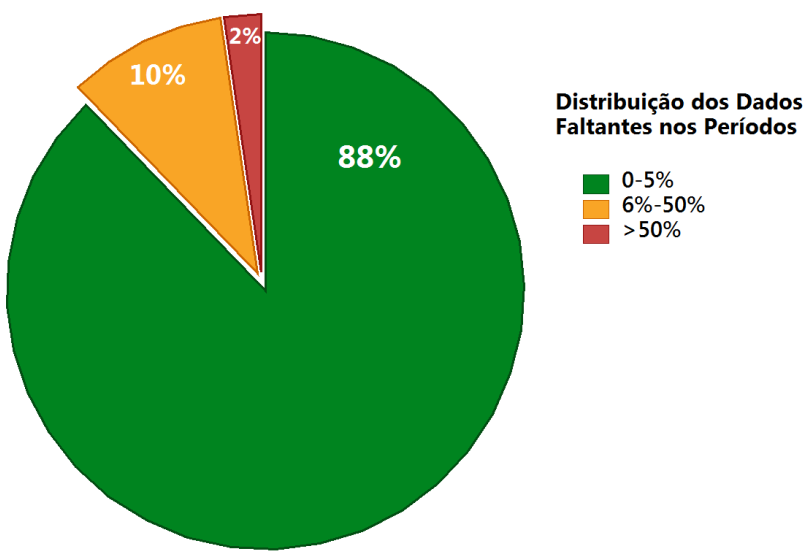

Figura 6.5: Dados faltantes em relação às variáveis e períodos finais após análise e ajustes.

Como a maioria das variáveis da base de dados são categóricas e o número de dados faltantes não é elevado, foi criada uma categoria chamada default para representar os dados faltantes no processo de modelagem. 


\subsection{Variáveis Independentes Derivadas}

Denominamos variáveis independentes derivadas aquelas que foram obtidas a partir das variáveis independentes originais por meio de algum tipo de cálculo ou lógica. A seguir, mostramos como elas foram definidas.

\section{Dados da Transação}

1. Dia da Semana da Transação: foi obtido o dia da semana correspondente à data da transação.

2. Período da Transação: através do horário da transação, registramos se a transação ocorreu pela manhã, tarde, noite ou madrugada.

3. Categoria Valor da Transação: os valores da transação foram categorizados conforme o nível de risco de transações fraudulentas.

4. Número de Parcelas da Transação: número de parcelas escolhido pelo comprador.

5. Categoria do BIN: o BIN do cartão foi classificado em grupos de acordo com o índice de fraude da quantidade das transações em pontos base - basis points - (\#Fraudes/\#Transações x 10.000).

6. Tempo de Validade do Cartão: diferença entre data de expiração do cartão e data da transação.

7. Ticket Médio do Estabelecimento: soma dos valores das transações dividida pela quantidade de transações do estabelecimento.

8. Valor da Transação Maior que Ticket Médio: verifica se o valor da transação é maior que o valor do ticket médio das transações do estabelecimento.

9. Percentil 95 da Transação: verifica se o valor da transação é maior que o valor do percentil 95 das transações do estabelecimento.

10. Limite Superior da Transação: é o valor do ticket médio somado a três vezes o desvio padrão dividido pela raiz quadrada da quantidade de transações no período especificado do estabelecimento.

11. Diferença Valor Transação e Ticket Médio: diferença do valor da transação e o ticket médio do estabelecimento agrupados em categorias.

12. Diferença Valor Transação e Percentil 95: diferença do valor da transação e o percentil 95 do estabelecimento agrupados em categorias.

13. Diferença Valor Transação e Limite Superior : diferença do valor da transação e limite superior do estabelecimento agrupados em categorias. 


\section{Dados do Comprador}

14. Tempo de Filiação do Comprador: obtido pelo cálculo da diferença entre a data da transação e a data de filiação do comprador em dias.

15. Idade do Comprador: obtido pelo cálculo da diferença entre a data da transação e a data de nascimento do comprador em anos.

16. Estado Comprador: os estados nos quais estavam localizados os compradores no momento da transação foram padronizados para evitar erros previsíveis de categorização, como, por exemplo,"SP" e "São Paulo" serem classificados em categorias distintas. Dessa maneira, temos 27 estados e uma categoria "default" para dados faltantes.

17. Estado do CPF do Comprador: estado de emissão do CPF do comprador obtido pela verificação do nono dígito do número de CPF.

18. Estado do Telefone do Comprador: estado de registro do número de telefone informado pelo comprador e identificado pelos dois dígitos do número de telefone conforme tabela do DDD (discagem direta à distância) de cada cidade ou região.

19. Região do CEP: região a que pertence o CEP informado pelo comprador, obtido pela verificação do primeiro dígito do número que compõe o CEP.

20. Subregião do CEP: subregião a que pertence o CEP informado pelo comprador, obtido pela verificação do segundo dígito do número que compõe o CEP.

21. Setor do CEP: setor a que pertence o CEP informado pelo comprador, obtido pela verificação do terceiro dígito do número que compõe o CEP.

22. Tamanho do E-mail: número de caracteres do e-mail usado na compra.

23. Domínio do E-mail: domínio do e-mail utilizado pelo comprador.

24. Tamanho do E-mail Categorizado: tamanho do e-mail agrupado em categorias.

\section{Dados do Titular do Cartão de Crédito Usado na Compra}

25. Idade do Titular do Cartão

26. Idade do Titular do Cartão Categorizado

27. Estado do CPF do Titular do Cartão

28. Estado do Telefone do Titular do Cartão 


\section{Dados do Estabelecimento}

29. Tempo de Filiação do Estabelecimento por Período: obtido pelo cálculo da diferença entre a data da transação e a data de filiação do estabelecimento e categorizado em períodos mensais.

30. Tempo de Filiação do Estabelecimento em Dias: diferença entre a data da transação e a data de filiação do estabelecimento em dias agrupados em categorias.

\section{Comparações}

31. Comparação CPF: comparação do CPF do comprador e do titular do cartão.

32. Comparação Datas de Nascimento: comparação entre as datas de nascimento do comprador e do titular do cartão.

33. Comparação Diferença Datas de Nascimento: diferença entre a data de nascimento do comprador e do titular do cartão em meses.

34. Comparação Telefone: comparação do telefone do comprador e do titular do cartão.

35. Comparação Telefone e CEP: verifica se o telefone e CEP informados pelo comprador estão na mesma região.

36. Comparação Telefone e CPF: verifica se o telefone e CPF informados pelo comprador estão na mesma região.

37. Comparação CEP e CPF: verifica se o CEP e CPF informado pelo comprador estão na mesma região.

38. Comparação OSA1: comparação do e-mail do comprador e o nome do titular do cartão pelo algoritmo $\mathrm{OSA}^{5}$.

39. Comparação OSA2: comparação do nome do comprador e nome titular do cartão pelo algoritmo OSA.

40. Comparação OSA3: comparação do nome do comprador e e-mail do comprador pelo algoritmo OSA.

41. Comparação QGRAM1: comparação do e-mail do comprador e o nome do titular do cartão pelo algoritmo QGRAM ${ }^{6}$ usando tamanho da subsequência igual a 1.

\footnotetext{
${ }^{5}$ Optimal String Alignment distance (OSA), ou distância de alinhamento de string ótima, é parecido com a distância de edição (Levenshtein), que é dada pelo número mínimo de operações necessárias para transformar uma string em outra. Porém, também permite a transposição de caracteres adjacentes e cada substring podem ser editada apenas uma vez.

${ }^{6} \mathrm{Q}$-gram é uma subsequência de q caracteres consecutivos de uma seqüência. Se $x(y)$ é um vetor que conta a ocorrência de q-gram em $a(b)$, sendo a e b as sequências comparadas, a distância de q-gram é dada pela soma das diferenças absolutas de $\left|x_{i}-y_{i}\right|$. O cálculo é anulado quando q é maior do que o comprimento de qualquer das strings.
} 
42. Comparação QGRAM2: comparação do nome do comprador e nome titular do cartão pelo algoritmo QGRAM usando tamanho da subsequência igual a 1.

43. Comparação QGRAM3: comparação do nome do comprador e e-mail do comprador pelo algoritmo QGRAM usando tamanho da subsequência igual a 1.

\subsection{Valor da Informação e Peso da Evidência}

A estatística Valor da Informação, também conhecido como Information Value (IV), é uma técnica utilizada frequentemente para selecionar variáveis preditoras qualitativas em modelagem por meio de regressão logística binária (Land e Brotherton , 2014). Quanto maior o seu valor, maior o poder de discriminação. Para se obter o IV para determinada variável qualitativa são necessários dois passos de cálculos.

Primeiramente, calcula-se o Peso da Evidência (Weight of Evidence - WOE) para cada categoria da variável.

$$
W O E_{i}=\ln \left(\frac{\# \text { Fraudes }_{i}}{\# \text { Não Fraudes }} i\right.
$$

onde $i$ é a categoria da variável em questão e fraudes/não fraudes as categorias da variável dependente utilizada no experimento.

No segundo passo, executa-se o seguinte cálculo para obter o IV:

$$
I V=\sum_{i=1}^{k}\left(\% \# \text { Fraudes }_{i}-\% \# \text { Não Fraudes }\right) * W O E_{i}
$$

onde a variável em questão tem categorias variando de $i$ a $k$.

Para se decidir o quão forte é o poder de discriminação de uma variável com base no IV, conforme comentado em Land e Brotherton (2014), existem os seguintes valores recomendados descritos a seguir.

\section{Classificação dos valores de IV}

- IV $<0,02$ : muito baixo - recomenda-se não incluir no modelo.

- $0,02 \leq \mathrm{IV}<0,10$ : baixo.

- $0,10 \leq \mathrm{IV}<0,30$ : médio.

- $0,30 \leq \mathrm{IV}<0,50$ : forte.

- $\mathrm{IV} \geq 0,50$ : questionável/suspeito.

Em situações em que há variáveis quantitativas, é necessário categorizá-las antes de aplicar essa técnica.

Apresentadas as vantagens desse método, o usamos para obter o conjunto das variáveis finais. 


\subsection{Variáveis Independentes Finais}

Obtivemos as variáveis independentes finais para o processo de modelagem aplicando o método de peso de evidência e valor da informação.

O conjunto final de variáveis independentes é composto pelas variáveis independentes originais e derivadas apresentadas na tabela 6.2 a seguir, em que são apresentados também o valor da informação e a nova nomeação.

\begin{tabular}{|c|c|c|c|}
\hline Origem & Nome da Variável & $\begin{array}{c}\text { Valor da } \\
\text { Informação }\end{array}$ & $\begin{array}{c}\text { Nova } \\
\text { Nomeação }\end{array}$ \\
\hline VO 17 & Tipo de Terminal & 0,643 & V01 \\
\hline VD 41 & Comparação QGRAM1 & 0,366 & V02 \\
\hline VD 38 & Comparação OSA1 & 0,362 & V03 \\
\hline VD 30 & Tempo de Filiação do Estabelecimento em Dias Categorizado & 0,322 & V04 \\
\hline VD 12 & Diferença valor transação e Percentil 95 & 0,308 & V05 \\
\hline VD 28 & Estado do Telefone do Titular do Cartão & 0,304 & V06 \\
\hline VD 05 & Categoria do BIN & 0,285 & V07 \\
\hline VD 11 & Diferença Valor Transação e Ticket Médio & 0,244 & V08 \\
\hline VD 23 & Domínio do E-mail & 0,241 & V09 \\
\hline VD 34 & Comparação Telefone & 0,225 & V10 \\
\hline VD 08 & Valor da Transação Maior que Ticket Médio & 0,213 & V11 \\
\hline VD 13 & Diferença Valor Transação e Limite Superior & 0,210 & V12 \\
\hline VD 06 & Tempo de Validade do Cartão & 0,207 & V13 \\
\hline VO 41 & Tipo de Serviço & 0,202 & V14 \\
\hline VD 03 & Categoria Valor da Transação & 0,188 & V15 \\
\hline VO 10 & Valor da Transação & 0,183 & V16 \\
\hline VD 42 & Comparação QGRAM2 & 0,179 & V17 \\
\hline VD 19 & Região do CEP & 0,179 & V18 \\
\hline VD 39 & Comparação OSA2 & 0,177 & V19 \\
\hline VD10 & Limite Superior da Transação & 0,164 & V20 \\
\hline VD 18 & Estado do Telefone do Comprador & 0,143 & V21 \\
\hline VD 43 & Comparação QGRAM3 & 0,116 & V22 \\
\hline VD 16 & Estado Comprador & 0,105 & V23 \\
\hline VD 09 & Percentil 95 da Transação & 0,102 & V24 \\
\hline VO 39 & Verificação do CNPJ & 0,097 & V25 \\
\hline VD 26 & Idade do Titular do Cartão Categorizado & 0,090 & V26 \\
\hline VD 35 & Comparação Telefone e CEP & 0,085 & V27 \\
\hline VD 36 & Comparação Telefone e CPF & 0,079 & V28 \\
\hline VD 40 & Comparação OSA3 & 0,078 & V29 \\
\hline VD 02 & Período da Transação & 0,072 & V30 \\
\hline VD 29 & Tempo de Filiação do Estabelecimento por Período & 0,071 & V31 \\
\hline VD 31 & Comparação CPF & 0,070 & V32 \\
\hline VD 37 & Comparação CEP e CPF & 0,061 & V33 \\
\hline VO 6 & País do IP & 0,059 & V34 \\
\hline VD 25 & Idade do Titular do Cartão & 0,057 & V35 \\
\hline VO 12 & Tipo de Pagamento & 0,050 & V36 \\
\hline VD 27 & Estado do CPF do Titular do Cartão & 0,044 & V37 \\
\hline VD 33 & Comparação Diferença Datas de Nascimento & 0,037 & V38 \\
\hline VD 32 & Comparação Datas de Nascimento & 0,036 & V39 \\
\hline VO 37 & Tipo de Conta & 0,032 & V40 \\
\hline VD 20 & Subregião do CEP & 0,031 & V41 \\
\hline VD 14 & Tempo de Filiação do Comprador & 0,024 & V42 \\
\hline VD 24 & Tamanho do E-mail Categorizado & 0,024 & V43 \\
\hline VD 22 & Tamanho do E-mail & 0,021 & V44 \\
\hline VD 17 & Estado do CPF do Comprador & 0,021 & V45 \\
\hline VD 15 & Idade do Comprador & 0,015 & V46 \\
\hline VD 21 & Setor do CEP & 0,015 & V47 \\
\hline VD 04 & Número de Parcelas da Transação & 0,014 & V48 \\
\hline VO 29 & Verificação do CPF Comprador & 0,012 & V49 \\
\hline VO 30 & Tipo de Filiação & 0,012 & V50 \\
\hline VO 18 & Categoria do Comprador & 0,003 & V51 \\
\hline VD 01 & Dia da Semana da Transação & 0,002 & V52 \\
\hline
\end{tabular}

Tabela 6.2: Poder de discriminação (Valor da Informação) das variáveis independentes candidatas finais. 


\subsection{Amostragem}

O planejamento amostral é o primeiro passo quando se pretende estudar características de uma determinada população. Assim, nesta seção, apresentamos as técnicas de amostragem adotadas no estudo.

Como apresentado em diversos trabalhos relacionados à identificação de fraudes, como em Chan e Stolfo (1998) e Gadi et al. (2008), a distribuição dos dados relacionados a transações fraudulentas é altamente desbalanceada. Isto é, há poucos eventos de fraudes para muitas transações não fraude. Esse tipo de distribuição de dados também é conhecido como skewed data. Para os dados desse trabalho, encontramos a proporção de aproximadamente 29 transações fraudulentas para 10.000 transações não fraudulentas.

Dessa maneira, para que no processo de modelagem os modelos sejam capazes de identificar o perfil de fraude e não fraude, é adequada a utilização de uma amostragem estratificada.

Para obter as amostras estratificadas, primeiramente, avaliamos as variáveis com maior capacidade de discriminar as transações fraudulentas e não fraudulentas. Em seguida, usamos essas variáveis para formar as amostras estratificadas dos registros não fraude mantendo a mesma proporção. Por fim, essa proporção de registros não fraude foram combinados com todos os registros fraudulentos da base de dados.

Foram amostrados 428.256 registros, sendo 22.615 fraudes e 405.641 não fraude. Isso implica em uma proporção de aproximadamente 1 registro de fraude para cada 18 não fraude.

Esse valor de proporção entre fraude e não fraude aproxima-se bastante dos valores adotados para esse tipo de problema, conforme observado em experimentos anteriores de Chan e Stolfo (1998), Gadi (2006) e Gadi et al. (2008).

Após a coleta da amostra, para o processo de modelagem, a base foi dividida em $80 \%$ (342.605) para desenvolvimento do modelo e 20\% (85.651) para validação.

Devido à utilização da amostragem estratificada, é adequada a ponderação da pontuação ao final do processo de modelagem. Como estamos interessados em comparar a eficiência dos modelos, não aplicaremos as ponderações nas análises. Maiores referências podem ser encontradas em Frayback (2008) e Weiss et al. (2005).

Para sintetizar as etapas realizadas para se obter as amostras de desenvolvimento e validação a partir da base final, apresentamos na figura 6.6 o fluxo do processo de amostragem. 


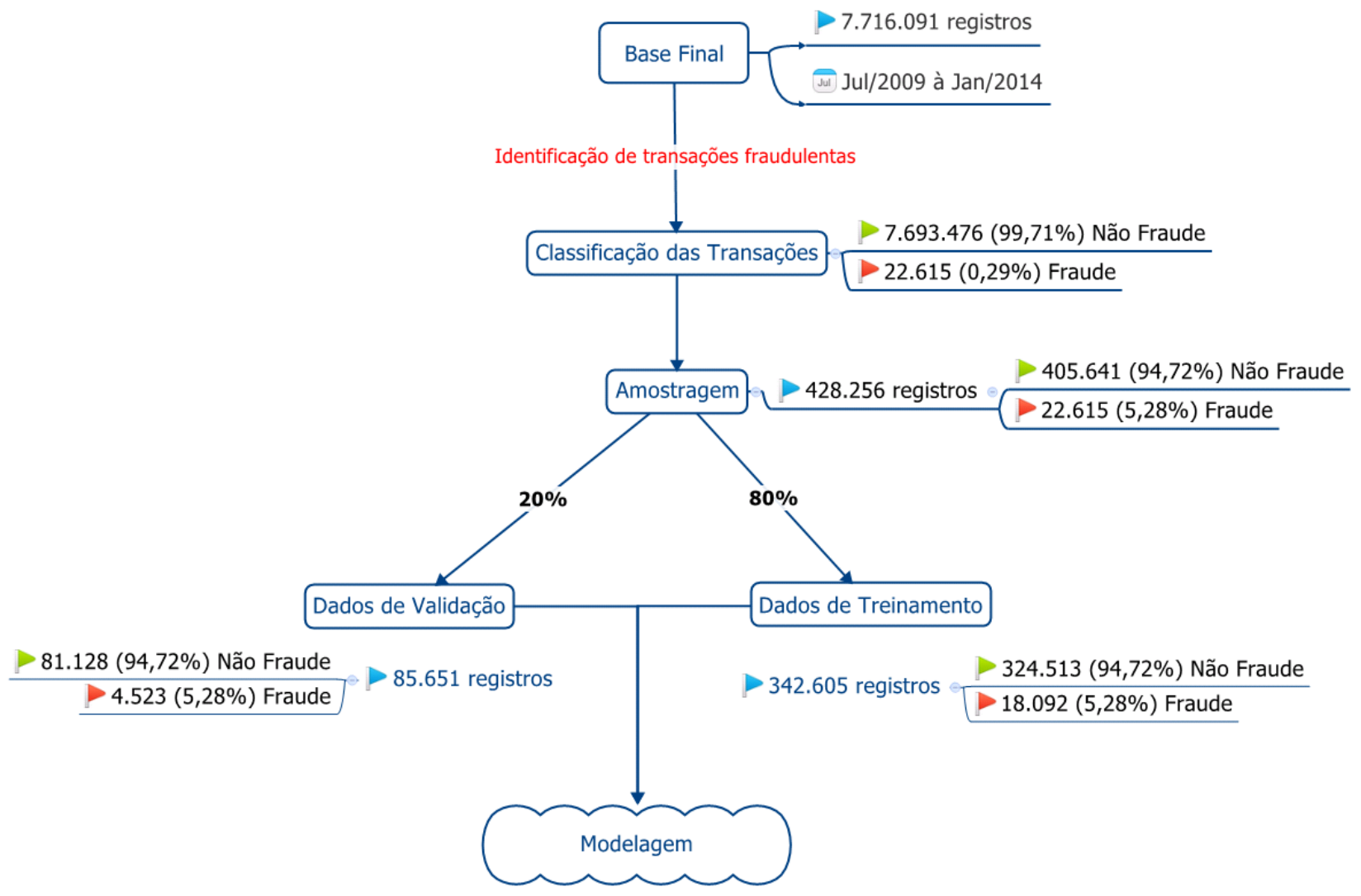

Figura 6.6: Fluxo do processo de amostragem. 


\section{Capítulo 7}

\section{Desenvolvimento dos Modelos}

Neste capítulo, apresentamos detalhes sobre o desenvolvimento dos modelos. Mais especificamente, na subseção 7.1 análise descritiva, estudamos o comportamento das variáveis candidatas com a apresentação dos valores de informação de cada variável, a correlação entre as variáveis candidatas, os gráficos de boxplot com suas medidas resumo e os valores médios em relação à variável resposta. Em seguida, na subseção 7.2, realizamos a modelagem dos dados utilizando o modelo de regressão logística binária clássica e DMA.

\subsection{Análise Descritiva}

Por meio da técnica de valor da informação que aplicamos nas variáveis candidatas, é possível ordená-las a fim de identificar quais contribuem para o processo de modelagem. Na figura 7.1, mostramos o valor da informação (IV) para cada variável candidata utilizando a amostra definida anteriormente. Nele, observamos que a variável V01 apresentou um IV alto $(0,64)$, o que pode representar uma variável com poder de discriminação questionável, conforme descreve Siddiqi (2006) . Adicionalmente, o gráfico apresenta que há 5 variáveis candidatas classificadas com poder discriminatório forte, 18 médio, 20 baixo e 8 muito baixo. 


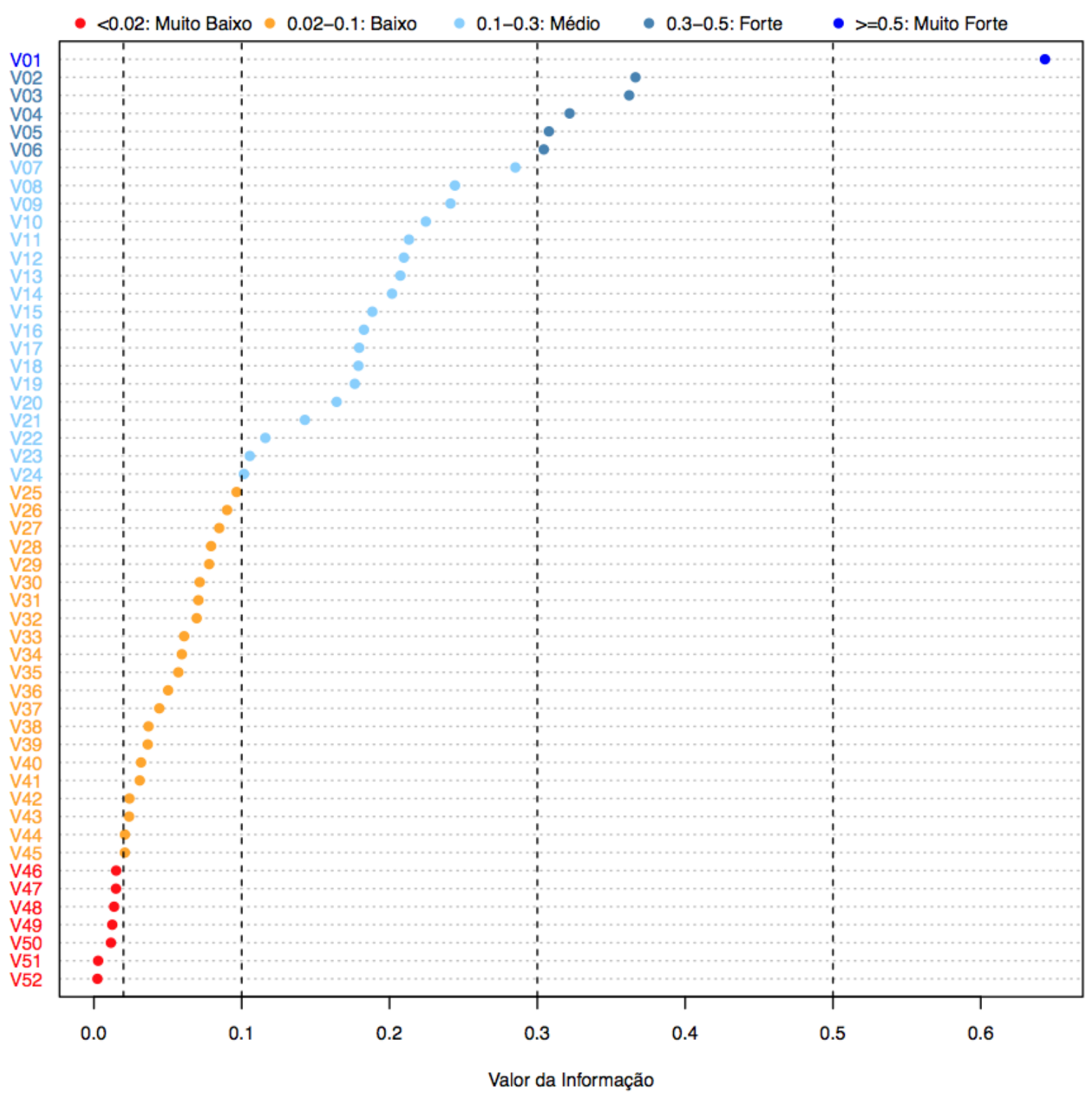

Figura 7.1: Poder discriminatório (valor da informação) das variáveis candidatas.

Para avaliar a relação entre as variáveis candidatas, calculamos o coeficiente de correlação de Pearson $(\rho)$ usando os valores de peso da evidência. Os valores de $\rho$, que variam entre -1 e 1, são interpretados da seguinte maneira:

- $\rho=1$ : significa uma correlação perfeita positiva entre as duas variáveis.

- $\rho=-1$ : significa uma correlação negativa perfeita entre as duas variáveis. Se o valor de uma variável aumenta, o da outra sempre diminui, e vice-versa.

- $\rho=0$ : significa que as duas variáveis não dependem linearmente uma da outra. Porém, pode existir uma dependência não linear.

Na figura 7.2, bem como na tabela A.1, que se encontra no apêndice deste trabalho, estão dispostos os resultados dos coeficientes de correlação das variáveis candidatas. 
Observamos que a maioria das variáveis (65\%) apresenta correlação entre 0 e 0,25 (verde). Avaliando outras faixas de correlação, temos $28 \%$ entre - 0,25 e 0 (amarelo), $5 \%$ entre 0,25 e 0,5 (azul claro), $1 \%$ entre 0,5 e 0,75 (azul) e 1\% entre 0,75 e 1 (azul escuro). Dado isso, temos a indicação de que $93 \%$ das variáveis candidatas apresentam correlação entre -0,25 e 0,25 (verde e amarelo), o que representa uma correlação fraca entre elas e um resultado positivo para evitar problemas de colineariade ou multicolinearidade ${ }^{7}$.

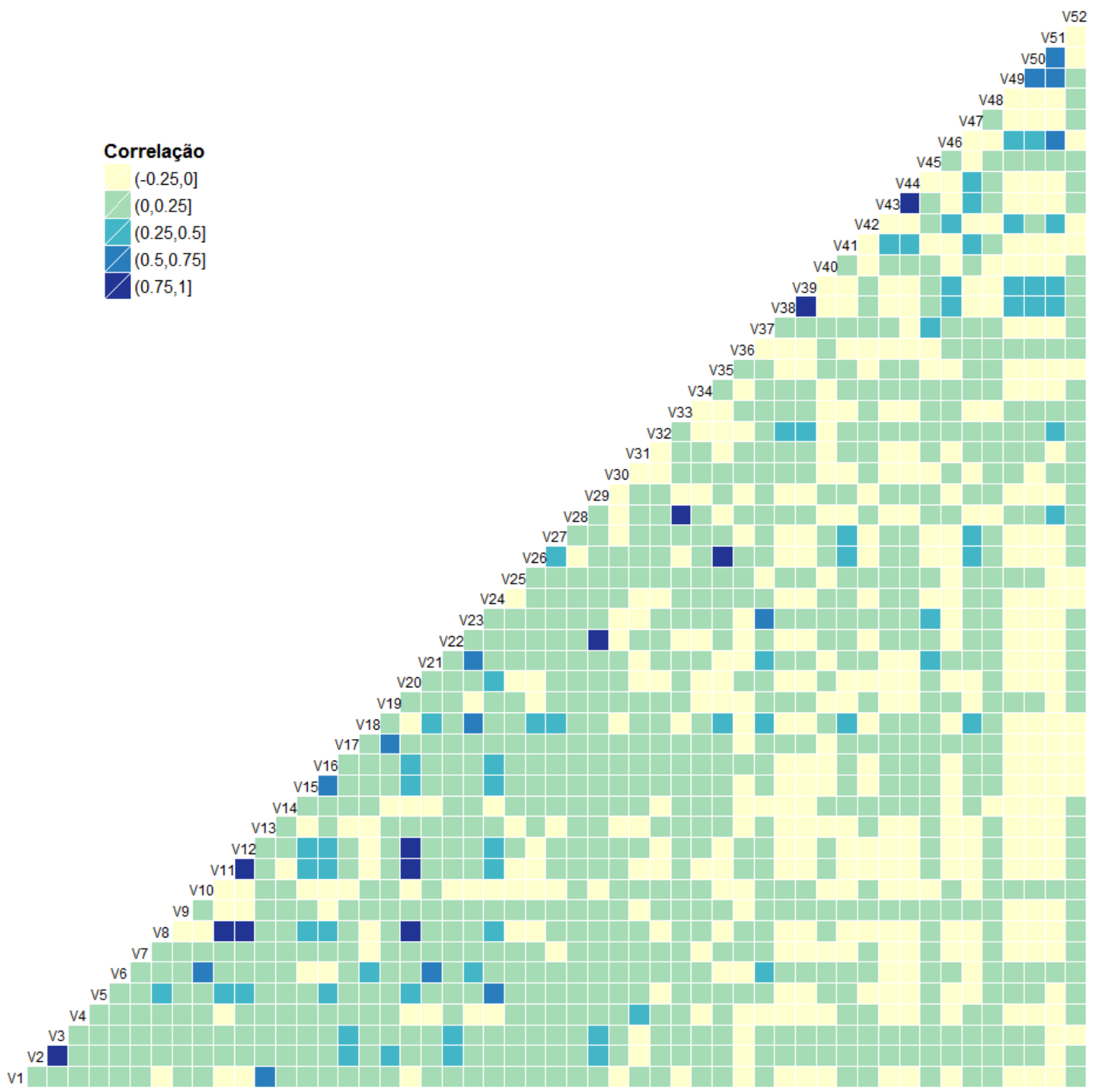

Figura 7.2: Correlação entre as variáveis candidatas para o modelo.

Para apresentar as estatísticas resumo dos valores do peso da evidência das variáveis candidatas, temos os gráficos de boxplot separados pelos grupos da variável resposta não fraude e fraude (figura 7.3). Nos gráficos das variáveis V25 a V52, observamos uma semelhança muito grande entre os grupos não fraude e fraude. É o mesmo conjunto de variáveis que apresentaram valores de IV abaixo de 0,1 , indicando um poder de discriminação baixo.

\footnotetext{
${ }^{7}$ Colinearidade(Multicolinearidade) são indicadores utilizados para indicar a existência forte de correlação entre duas (ou mais) variáveis independentes.
} 


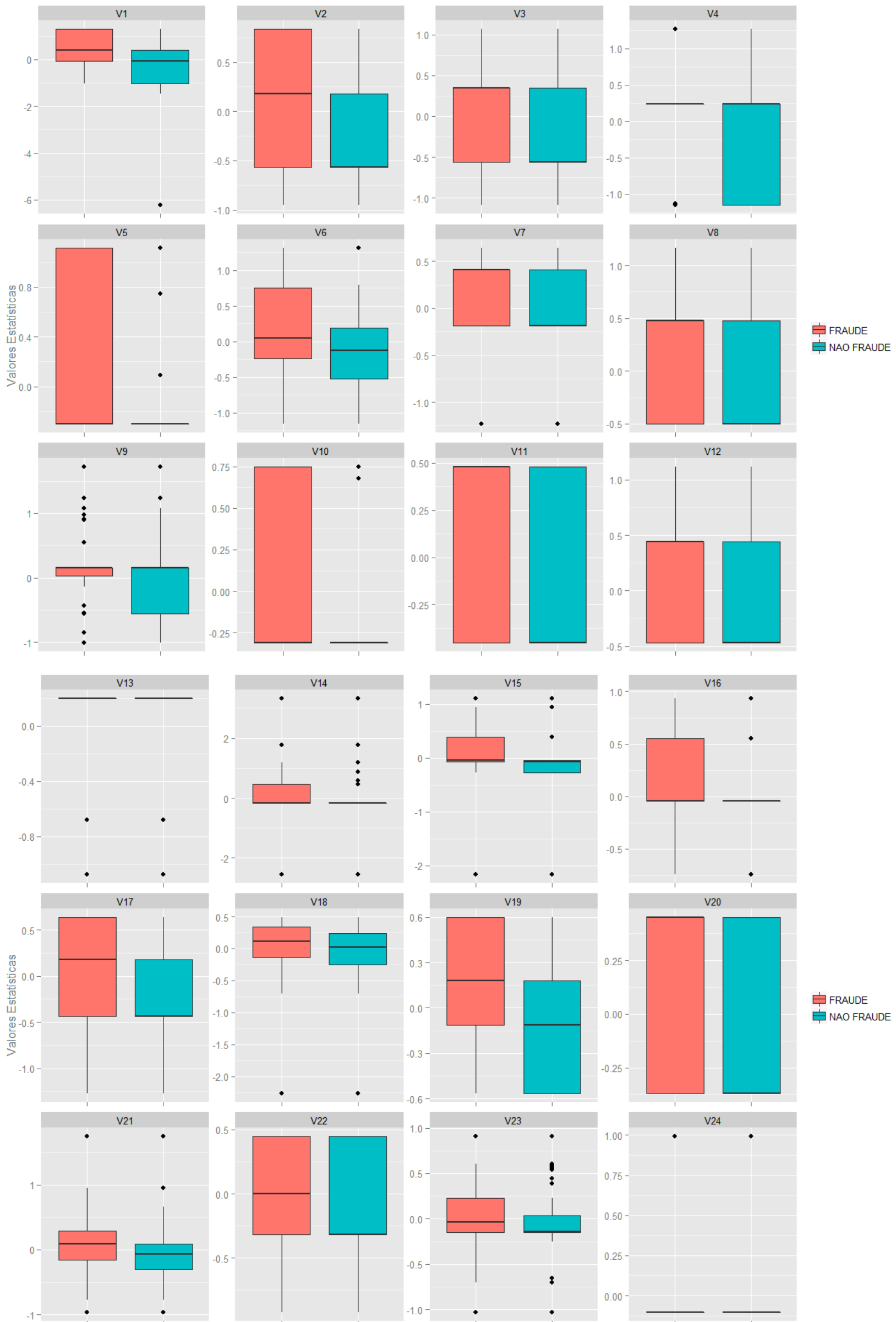



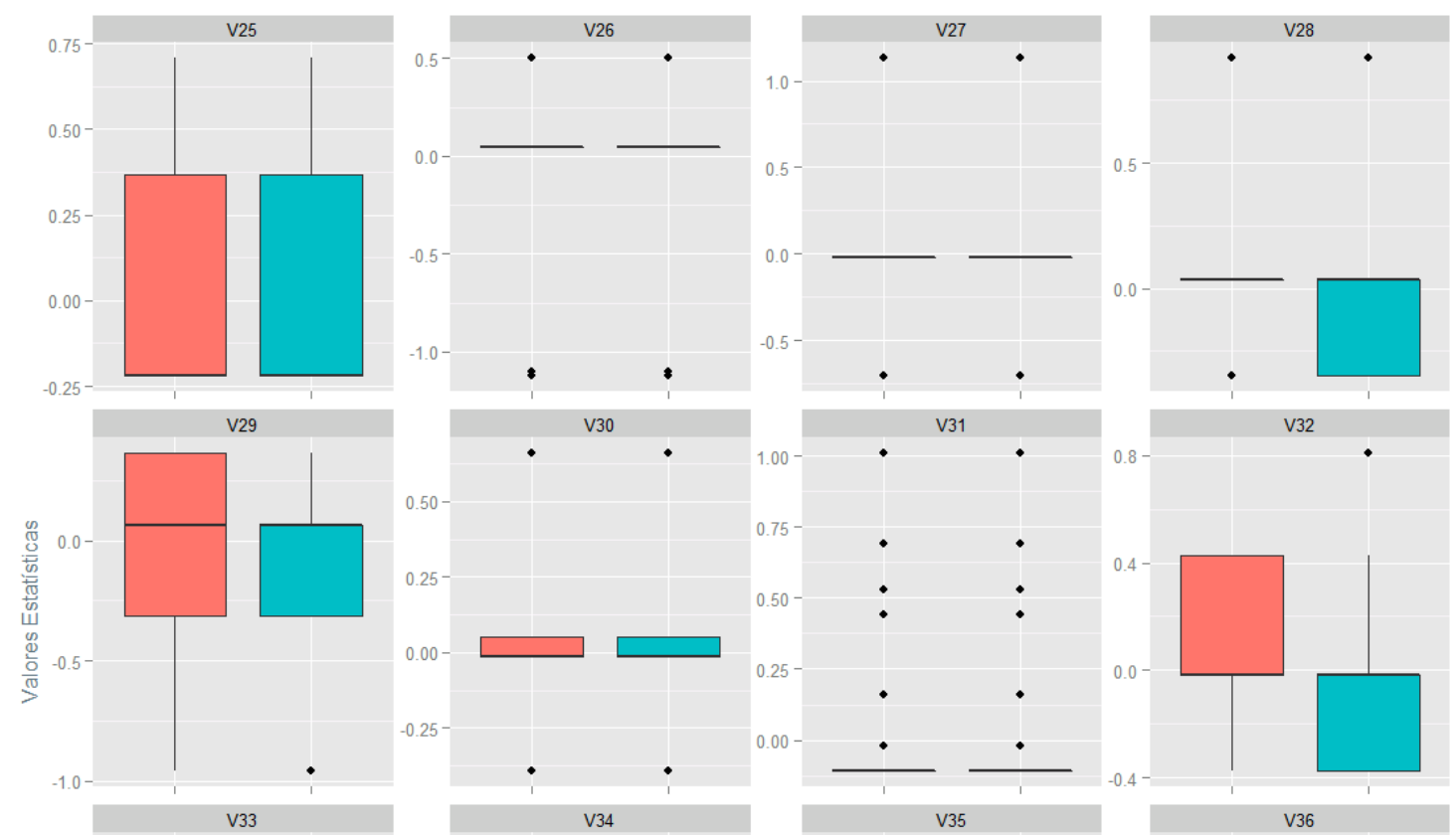

由 FRAUDE NAO FRAUDE
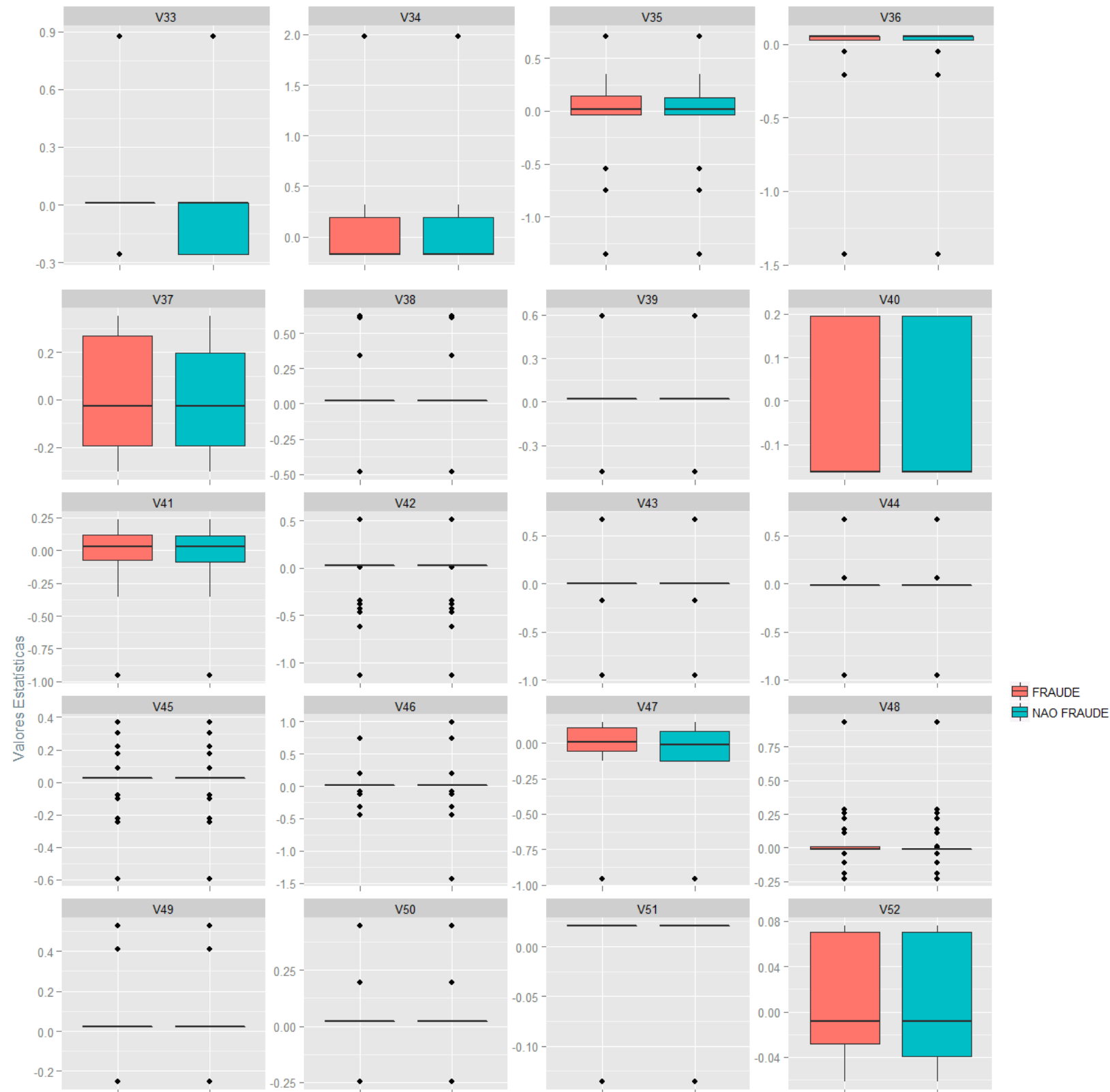

Figura 7.3: Boxplot do peso da evidência das variáveis candidatas para o modelo. 
Quando analisamos os gráficos das médias do peso da evidência das variáveis candidatas para cada grupo da variável resposta (não fraude e fraude), pode-se notar na figura 7.4 que, para todas as variáveis, existe, descritivamente, diferença entre as médias dentro de um intervalo de $95 \%$ de confiança. Dessa maneira, espera-se que os valores médios das variáveis contribuam para discriminar se uma transação é classificada no grupo não fraude ou fraude.
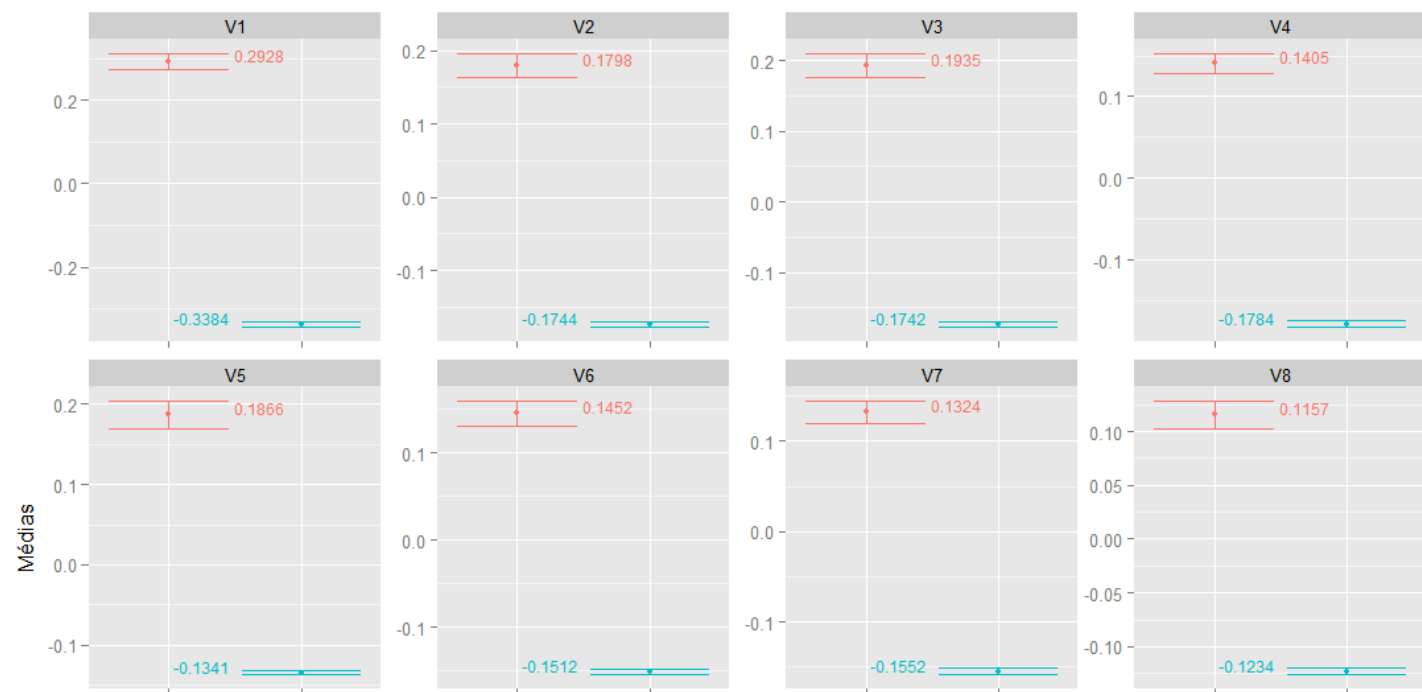

$\rightarrow$ FRAUDE

- NAO FRAUDE
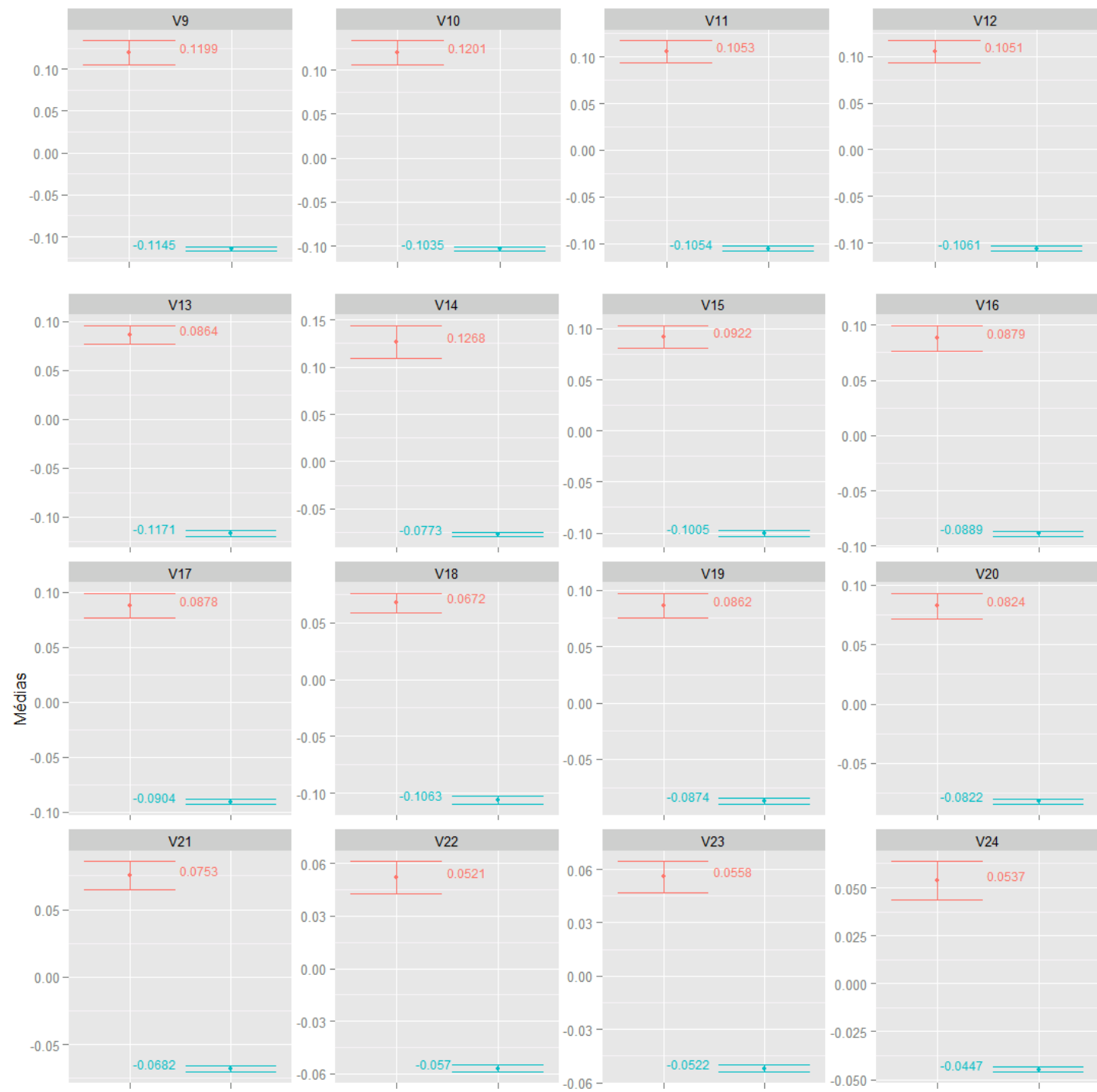


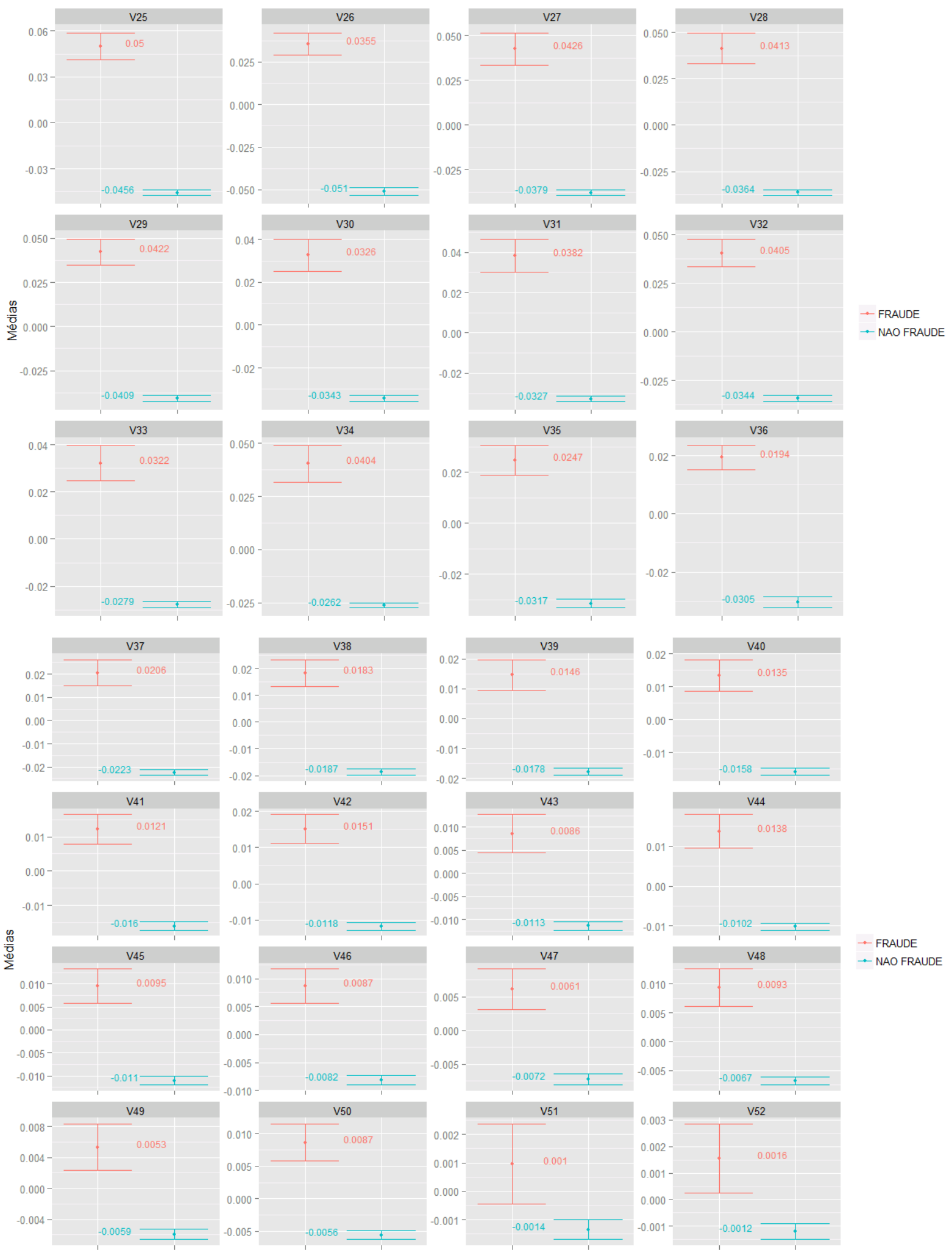

Figura 7.4: Médias do peso da evidência das variáveis candidatas com intervalo de $95 \%$ de confiança.

Nas próximas seções, apresentamos os resultados obtidos com o ajuste de um modelo de regressão logística binária clássica, muito utilizado para esse tipo de problema e que será utilizado como modelo de referência para a comparação e, em seguida, apresentamos o modelo DMA, cuja avaliação da performance é o principal objetivo deste trabalho. 


\subsection{Regressão Logística Binária Clássica}

O modelo de regressão logística binária é um método estatístico muito utilizado quando a variável resposta é categórica binária, ou seja, apresenta somente duas categorias. Essa técnica propõe um modelo que permita predições da variável resposta categórica através de variáveis explicativas (categóricas ou não) definidas no processo de modelagem.

A regressão logística binária é comparável às técnicas supervisionadas como árvores de decisão, redes neurais e análise discriminante. Isso faz com que essa técnica seja amplamente utilizada em diversas áreas, como em medicina, ciências sociais e economia.

Dado isso, vamos propor a seguinte estrutura do modelo de regressão logística binária clássica:

$$
\log \left(\frac{\pi_{i}}{1-\pi_{i}}\right)=\underset{\sim}{\beta} \underset{\sim}{X}
$$

em que:

$\pi_{i}$ : representa a probabilidade da i-ésima transação da amostra ser uma transação fraudulenta.

$\beta$ : é a matriz de parâmetros que será estimada.

$\underset{\sim}{X}$ : é a matriz com as variáveis do modelo.

\subsubsection{Ajuste do Modelo}

Para o ajuste do modelo de regressão logística binária clássica, utilizamos o software estatístico R versão 3.0.3 64 bits, juntamente com o pacote GLM. O R é um software muito conhecido e amplamente utilizado no meio acadêmico que permite grande flexibilidade no processo de análise e modelagem.

A escolha das variáveis explicativas para o modelo foi feita segundo o método stepwise, em que as variáveis foram incluídas no modelo com nível descritivo menor que 0,05 e retiradas do modelo com nível descritivo maior que 0,05. Após a inclusão de uma nova variável, verificamos se variáveis incluídas anteriormente poderiam ser excluídas devido à entrada da nova variável (Paula, 2004). Utilizando essa técnica, na tabela 7.1 estão apresentadas as variáveis que permaneceram no modelo final e suas respectivas estimativas, intervalo de confiança, erro e valor-p. 


\begin{tabular}{|c|c|c|c|c|}
\hline $\begin{array}{c}\# \\
\text { Variáveis }\end{array}$ & Variável & $\begin{array}{c}\text { Estimativa } \\
(\hat{\beta})\end{array}$ & $\begin{array}{c}\text { Erro } \\
\text { Padrão }\end{array}$ & Valor-p \\
\hline 1 & V03 & 0,682 & 0,007 & $<0,0001$ \\
\hline 2 & V06 & 0,617 & 0,009 & $<0,0001$ \\
\hline 3 & V07 & 0,622 & 0,008 & $<0,0001$ \\
\hline 4 & V09 & 0,865 & 0,009 & $<0,0001$ \\
\hline 5 & V11 & 0,989 & 0,009 & $<0,0001$ \\
\hline 6 & V13 & 0,615 & 0,009 & $<0,0001$ \\
\hline 7 & V17 & 0,549 & 0,01 & $<0,0001$ \\
\hline 8 & V18 & 0,302 & 0,012 & $<0,0001$ \\
\hline 9 & V21 & 0,444 & 0,018 & $<0,0001$ \\
\hline 10 & $\mathrm{~V} 23$ & $-0,457$ & 0,022 & $<0,0001$ \\
\hline 11 & $\mathrm{~V} 27$ & 0,800 & 0,018 & $<0,0001$ \\
\hline 12 & V30 & 1,004 & 0,016 & $<0,0001$ \\
\hline 13 & V34 & 0,833 & 0,021 & $<0,0001$ \\
\hline 14 & V36 & 0,745 & 0,017 & $<0,0001$ \\
\hline 15 & V38 & 0,563 & 0,024 & $<0,0001$ \\
\hline 16 & V40 & 0,944 & 0,024 & $<0,0001$ \\
\hline 17 & V42 & 0,715 & 0,03 & $<0,0001$ \\
\hline 18 & V44 & 0,444 & 0,034 & $<0,0001$ \\
\hline 19 & V45 & 0,067 & 0,032 & 0,0352 \\
\hline 20 & V46 & 0,514 & 0,038 & $<0,0001$ \\
\hline 21 & V47 & $-0,921$ & 0,039 & $<0,0001$ \\
\hline 22 & V48 & 0,211 & 0,036 & $<0,0001$ \\
\hline 23 & V49 & 0,750 & 0,05 & $<0,0001$ \\
\hline 24 & V50 & 1,464 & 0,054 & $<0,0001$ \\
\hline 25 & V51 & $-2,626$ & 0,122 & $<0,0001$ \\
\hline
\end{tabular}

Tabela 7.1: Variáveis selecionadas e estatísticas do modelo ajustado com stepwise.

O modelo, além de satisfazer o critério de convergência do software, apresentou ajuste adequado aos dados, como podemos observar pelos testes de máxima verossimilhança, score e Wald apresentados na tabela 7.2. Em contrapartida, o teste de Hosmer e Lemeshow, utilizado para medir a qualidade do ajuste do modelo, mostra que o modelo não foi ajustado adequadamente (valor-p $<0,0001$ ).

De maneira geral, o teste de Hosmer e Lemeshow forma grupos de casos e constrói uma estatística através da comparação dos valores observados e esperados de eventos em cada grupo. No entanto, em situações de ajuste de um modelo de regressão logística onde existem variáveis preditoras contínuas, o tamanho da amostra é grande ou mesmo se os dados são desbalanceados, sua utilização para avaliar o ajuste do modelo tem sido repensada (Allison , 2013) (Hosmer et al. , 1997). 


\begin{tabular}{lccc}
\hline \hline Testes & Qui-quadrado & GL & Valor-p \\
\hline Teste Global da Hipótese Nula $\beta=\mathbf{0}$ & & & \\
$\quad$ Máxima Verossimilhança & 118.830 & 25 & $<0,0001$ \\
$\quad$ Score & 101.692 & 25 & $<0,0001$ \\
$\quad$ Wald & 753.631 & 25 & $<0,0001$ \\
Qualidade do Ajuste & & & \\
$\quad$ Hosmer e Lemeshow & 228.359 & 8 & $<0,0001$ \\
\hline
\end{tabular}

Tabela 7.2: Testes para avaliação do modelo ajustado com stepwise.

Quando o tamanho da amostra é grande, a distribuição assintótica de algumas medidas segue a distribuição normal. Assim, observando o gráfico de resíduos (figura 7.5), temos maior concentração dos pontos entre -2 e 2, o que indica uma adequação do comportamento dos resíduos.

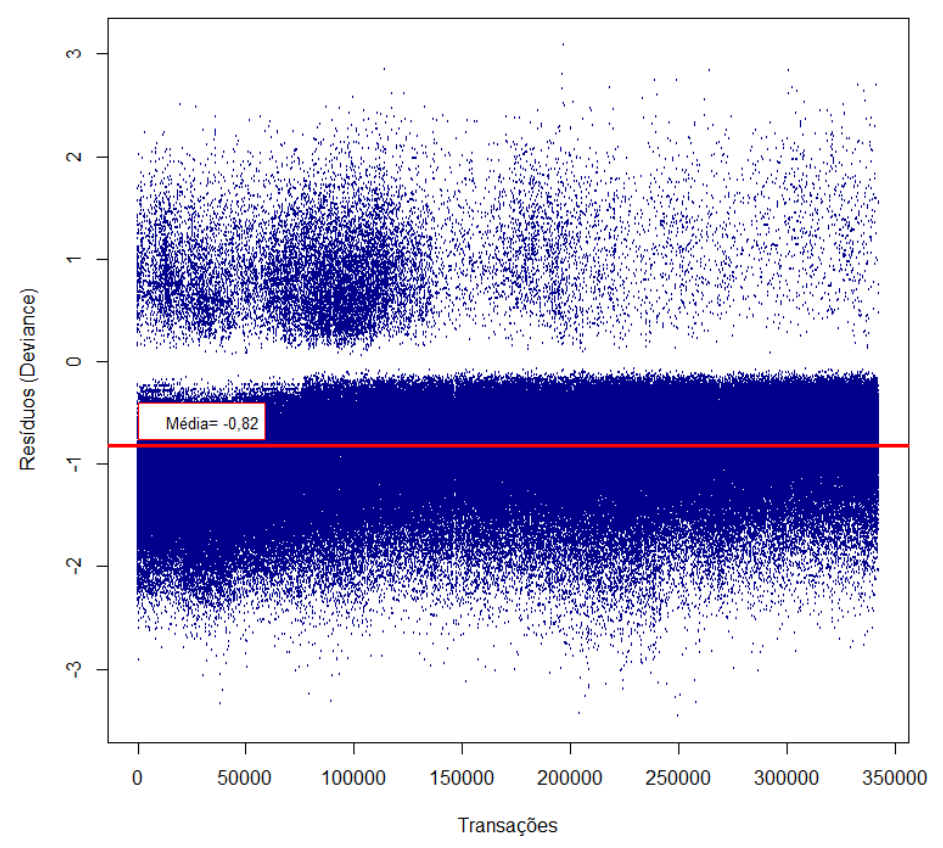

Figura 7.5: Resíduos deviance do modelo ajustado com stepwise.

\subsubsection{Medidas de Ajuste do Modelo}

A seguir, apresentamos algumas medidas de ajuste do modelo a fim de analisar se esse apresentou uma estrutura adequada aos dados.

\section{Estatística KS}

A estatística KS (Kolmogorov-Smirnov) também pode ser utilizada para avaliar o modelo ajustado. Ela é obtida pela maior distância entre as funções de distribuição acumulada das pontuações das transações não fraude e fraude, especificamente para esse trabalho, e avalia a aderência da distribuição das escoragens em relação à distribuição gerada pelo modelo. 


$$
\begin{gathered}
F_{\text {Não Fraude }}(k)=\frac{\# \text { transações não fraude com pontuação } \leq k}{\# \text { transações não fraude }} \\
F_{\text {Fraude }}(k)=\frac{\# \text { transações fraude com pontuação } \leq k}{\# \text { transações fraude }}
\end{gathered}
$$

onde $k$ são os possíveis valores do score no domínio entre 0 e 1 .

$$
K S=\operatorname{Máximo}\left(F_{\text {Não Fraude }}(k)-F_{\text {Fraude }}(k)\right)
$$

Espera-se que quanto maior o valor do KS, maior será a discriminação entre as transações não fraude e fraude, conforme tabela 7.3 proposta por Lecumberri e Júnior (2003), que observaram a opinião de diversos especialistas sobre medidas de KS.

\begin{tabular}{cl}
\hline \hline Valores de KS & Classificação \\
\hline$K S \leq 20 \%$ & Muito Baixo \\
$20 \%<K S \leq 30 \%$ & Baixo \\
$30 \%<K S \leq 40 \%$ & Bom \\
$40 \%<K S \leq 50 \%$ & Muito Bom \\
$K S>50 \%$ & Excelente \\
\hline
\end{tabular}

Tabela 7.3: Tabela para avaliação do valor de KS.

\begin{tabular}{|c|c|c|c|}
\hline $\begin{array}{l}\text { Probabiliade } \\
\text { Estimada de } \\
\text { Fraude }\end{array}$ & $\%$ Fraude & $\begin{array}{l}\% \text { Não } \\
\text { Fraude }\end{array}$ & $\mathrm{KS}$ \\
\hline $0-0,05$ & $0,2 \%$ & $4,5 \%$ & $4,3 \%$ \\
\hline $0,05-0,10$ & $1,1 \%$ & $14,3 \%$ & $13,2 \%$ \\
\hline $0,10-0,15$ & $2,8 \%$ & $24,4 \%$ & $21,6 \%$ \\
\hline $0,15-0,20$ & $4,6 \%$ & $33,9 \%$ & $29,3 \%$ \\
\hline $0,20-0,25$ & $7,1 \%$ & $42,5 \%$ & $35,3 \%$ \\
\hline $0,25-0,30$ & $10,1 \%$ & $50,1 \%$ & $40,0 \%$ \\
\hline $0,30-0,35$ & $13,4 \%$ & $57,0 \%$ & $43,6 \%$ \\
\hline $0,35-0,40$ & $17,0 \%$ & $63,3 \%$ & $46,3 \%$ \\
\hline $0,40-0,45$ & $21,5 \%$ & $69,0 \%$ & $47,5 \%$ \\
\hline $0,45-0,50$ & $26,1 \%$ & $74,2 \%$ & $48,1 \%$ \\
\hline $0,50-0,55$ & $31,2 \%$ & $78,9 \%$ & $47,7 \%$ \\
\hline $0,55-0,60$ & $37,1 \%$ & $83,1 \%$ & $46,1 \%$ \\
\hline $0,60-0,65$ & $43,5 \%$ & $86,9 \%$ & $43,4 \%$ \\
\hline $0,65-0,70$ & $50,6 \%$ & $90,3 \%$ & $39,7 \%$ \\
\hline $0,70-0,75$ & $58,7 \%$ & $93,2 \%$ & $34,5 \%$ \\
\hline $0,75-0,80$ & $66,9 \%$ & $95,7 \%$ & $28,8 \%$ \\
\hline $0,80-0,85$ & $76,4 \%$ & $97,6 \%$ & $21,2 \%$ \\
\hline $0,85-0,90$ & $85,8 \%$ & $99,0 \%$ & $13,2 \%$ \\
\hline $0,90-0,95$ & $94,6 \%$ & $99,8 \%$ & $5,1 \%$ \\
\hline $0,95-1,00$ & $100,0 \%$ & $100,0 \%$ & $0,0 \%$ \\
\hline
\end{tabular}

No modelo ajustado, conforme tabela 7.4, obtivemos um $\mathrm{KS}=48,1 \%$, sendo classificado como muito bom segundo a tabela 7.3.

Tabela 7.4: Cálculo do KS do modelo ajustado com stepwise. 


\section{Distribuição das Probabilidades Ajustadas}

Avaliando os números da tabela 7.5 a seguir, observamos que a proporção de transações fraude é maior do que as não fraude se, por exemplo, adotarmos o valor de probabilidade estimada de fraude maior que 0,60 .

\begin{tabular}{|c|c|c|c|c|c|c|c|c|}
\hline $\begin{array}{l}\text { Probabiliade } \\
\text { Estimada de } \\
\text { Fraude }\end{array}$ & \# Fraude & $\%$ Fraude & $\begin{array}{l}\text { \# Não } \\
\text { Fraude }\end{array}$ & $\begin{array}{l}\text { \% Não } \\
\text { Fraude }\end{array}$ & \# Total & $\%$ Total & $\begin{array}{c}\text { \# Fraude } \\
\text { Não Acumulado }\end{array}$ & $\begin{array}{l}\text { \# Não Fraude } \\
\text { Não Acumulado }\end{array}$ \\
\hline $0-0,05$ & 18.092 & $100,0 \%$ & 324.513 & $100,0 \%$ & 342.605 & $100,0 \%$ & 36 & 14.569 \\
\hline $0,05-0,10$ & 18.056 & $99,8 \%$ & 309.944 & $95,5 \%$ & 328.000 & $95,7 \%$ & 166 & 31.935 \\
\hline $0,10-0,15$ & 17.890 & $98,9 \%$ & 278.009 & $85,7 \%$ & 295.899 & $86,4 \%$ & 307 & 32.675 \\
\hline $0,15-0,20$ & 17.583 & $97,2 \%$ & 245.334 & $75,6 \%$ & 262.917 & $76,7 \%$ & 323 & 30.859 \\
\hline $0,20-0,25$ & 17.260 & $95,4 \%$ & 214.475 & $66,1 \%$ & 231.735 & $67,6 \%$ & 459 & 27.809 \\
\hline $0,25-0,30$ & 16.801 & $92,9 \%$ & 186.666 & $57,5 \%$ & 203.467 & $59,4 \%$ & 530 & 24.675 \\
\hline $0,30-0,35$ & 16.271 & $89,9 \%$ & 161.991 & $49,9 \%$ & 178.262 & $52,0 \%$ & 604 & 22.585 \\
\hline $0,35-0,40$ & 15.667 & $86,6 \%$ & 139.406 & $43,0 \%$ & 155.073 & $45,3 \%$ & 657 & 20.409 \\
\hline $0,40-0,45$ & 15.010 & $83,0 \%$ & 118.997 & $36,7 \%$ & 134.007 & $39,1 \%$ & 813 & 18.465 \\
\hline $0,45-0,50$ & 14.197 & $78,5 \%$ & 100.532 & $31,0 \%$ & 114.729 & $33,5 \%$ & 826 & 16.856 \\
\hline $0,50-0,55$ & 13.371 & $73,9 \%$ & 83.676 & $25,8 \%$ & 97.047 & $28,3 \%$ & 929 & 15.241 \\
\hline $0,55-0,60$ & 12.442 & $68,8 \%$ & 68.435 & $21,1 \%$ & 80.877 & $23,6 \%$ & 1.057 & 13.730 \\
\hline $0,60-0,65$ & 11.385 & $62,9 \%$ & 54.705 & $16,9 \%$ & 66.090 & $19,3 \%$ & 1.167 & 12.303 \\
\hline $0,65-0,70$ & 10.218 & $56,5 \%$ & 42.402 & $13,1 \%$ & 52.620 & $15,4 \%$ & 1.288 & 10.929 \\
\hline $0,70-0,75$ & 8.930 & $49,4 \%$ & 31.473 & $9,7 \%$ & 40.403 & $11,8 \%$ & 1.459 & 9.490 \\
\hline $0,75-0,80$ & 7.471 & $41,3 \%$ & 21.983 & $6,8 \%$ & 29.454 & $8,6 \%$ & 1.481 & 7.992 \\
\hline $0,80-0,85$ & 5.990 & $33,1 \%$ & 13.991 & $4,3 \%$ & 19.981 & $5,8 \%$ & 1.723 & 6.305 \\
\hline $0,85-0,90$ & 4.267 & $23,6 \%$ & 7.686 & $2,4 \%$ & 11.953 & $3,5 \%$ & 1.693 & 4.452 \\
\hline $0,90-0,95$ & 2.574 & $14,2 \%$ & 3.234 & $1,0 \%$ & 5.808 & $1,7 \%$ & 1.606 & 2.558 \\
\hline $0,95-1,00$ & 968 & $5,4 \%$ & 676 & $0,2 \%$ & 1.644 & $0,5 \%$ & 968 & 676 \\
\hline Total & & & & & & & 18.092 & 324.513 \\
\hline
\end{tabular}

Tabela 7.5: Tabela de classificação das transações e intervalo de pontuação pelo modelo ajustado com stepwise.

No figura 7.6, nota-se que as curvas de densidade se interceptam próximo ao valor de probabilidade de fraude igual a 0,5. Esse gráfico também demonstra uma boa discriminação entre as transações não fraude e fraude. 


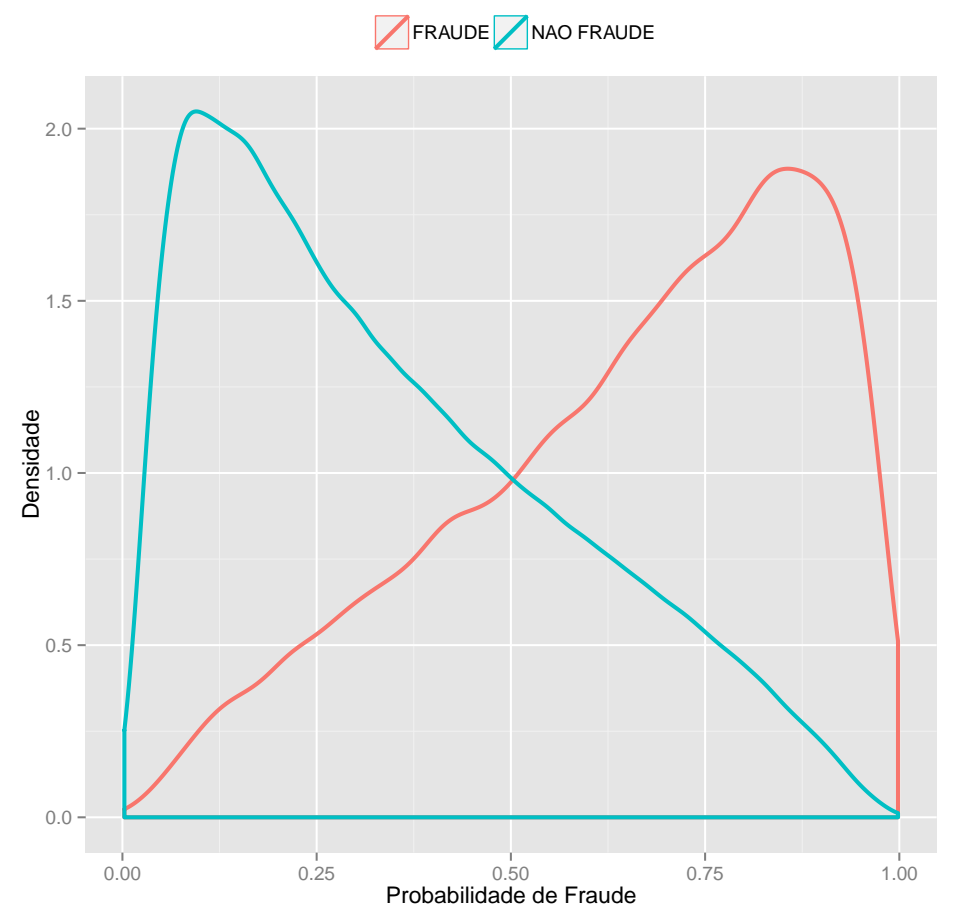

Figura 7.6: Densidade de fraude e não fraude do modelo ajustado com stepwise.

A área sob a curva ROC (Receiver Operating Characteristic) (AUC) é uma medida usada para avaliar a performance do sistema de classificação utilizado em algum conjunto de dados. Para este trabalho, avalia a performance do modelo de regressão logística binária clássica e do modelo DMA.

O gráfico da curva é definido em duas dimensões: sensibilidade e especificidade.

Sensibilidade : demonstra a capacidade de identificar as transações fraudulentas calculando a proporção de transações classificadas como fraudulentas corretamente em relação ao total de transações fraudulentas observadas.

Especificidade : demonstra a capacidade de identificar as transações não fraude calculando a proporção de transações classificadas como não fraude em relação ao total de transações não fraude observadas. O valor (1-especificidade) representa as transações não fraude classificadas como fraude, também conhecido como falso positivo.

Os valores de AUC podem ser classificados conforme a tabela 7.6 descrita em Wen Zhu e Wang (2010).

\begin{tabular}{cl}
\hline \hline Valores de AUC & Classificação \\
\hline $0,9<A U C \leq 1$ & Excelente \\
$0,8<A U C \leq 0,9$ & Bom \\
$0,7<A U C \leq 0,8$ & Baixo \\
$A U C \leq 0,7$ & Ruim \\
\hline
\end{tabular}

Tabela 7.6: Tabela para avaliação do valor de AUC. 
O valor de AUC obtido para o modelo de regressão logística clássica foi de 0,817 , que pode ser classificado como bom.

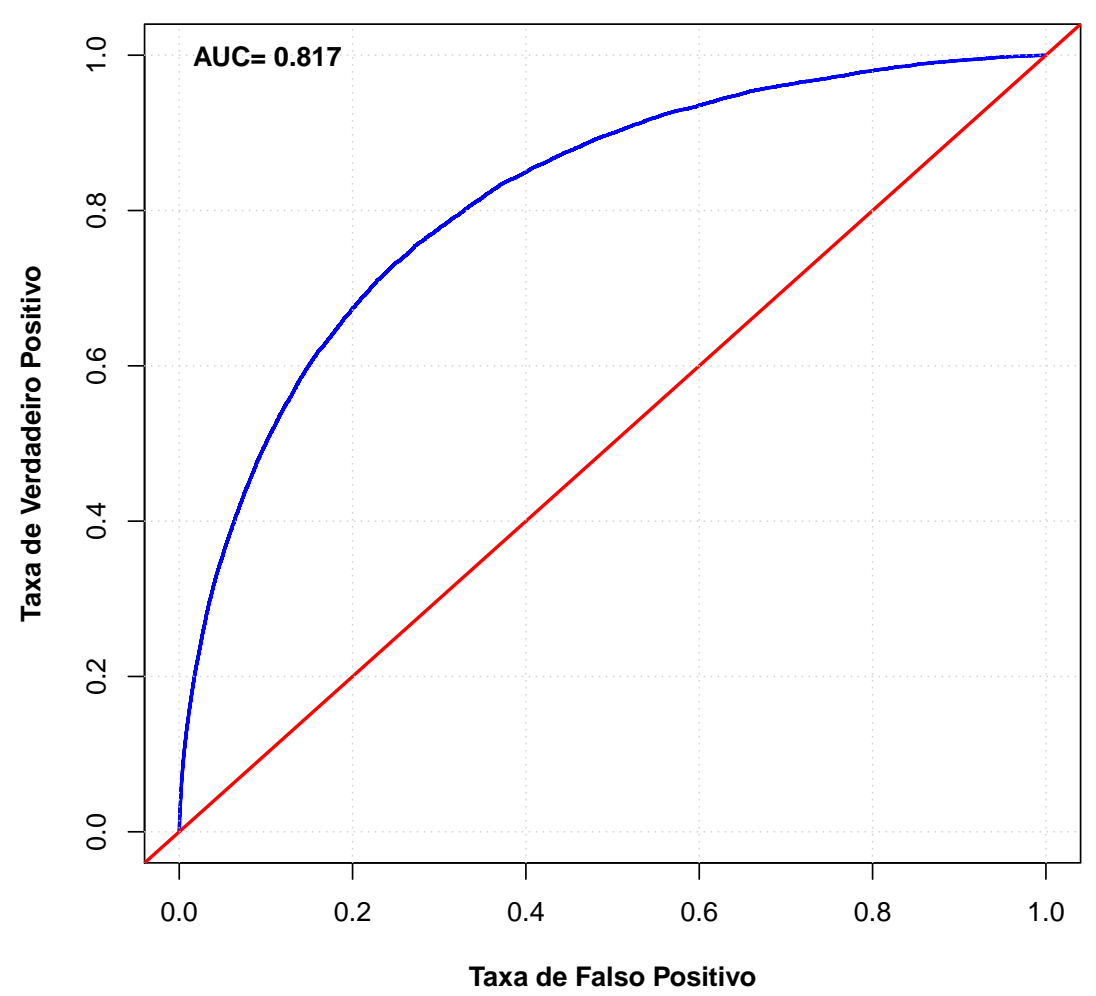

Figura 7.7: Curva ROC do modelo ajustado com stepwise (ponto de corte para probabilidade=0,6).

\subsubsection{Validação do Modelo}

Após apresentarmos as medidas de ajuste do modelo da amostra de desenvolvimento, também avaliaremos o comportamento sob a amostra de validação.

É uma etapa necessária para analisar se houve super ajustamento do modelo (overfitting) na amostra de desenvolvimento, bem como para avaliar a performance sob outras amostras.

\section{IEP}

O Índice de Estabilidade Populacional (IEP), também conhecido como PSI (Population Stability Index), é utilizado para comparar a distribuição das variáveis categorizadas (Thomas et al. , 2002). O índice pode ser calculado usando a seguinte fórmula:

$$
I E P=\left(v_{i}-d_{i}\right) * \ln \left(\frac{v_{i}}{d_{i}}\right)
$$

onde $v_{i}$ é a proporção de indivíduos na categoria i da amostra de validação e $d_{i}$ é a proporção de indivíduos da categoria i da amostra de desenvolvimento. Para avaliar o valor de IEP obtido, utilizamos a tabela 7.7 como referência: 


\begin{tabular}{cl}
\hline \hline Valores de IEP & Classificação \\
\hline$I E P<0,1$ & não houve alteração. \\
$0,1 \leq I E P<0,25$ & possível alteração. \\
$I E P \geq 0,25$ & mudança significativa de perfil. \\
\hline
\end{tabular}

Tabela 7.7: Valores de referência para IEP.

Como obtivemos IEP de 0,00030, não houve alteração e podemos dizer que as faixas de pontuação da amostra de validação não apresentaram diferenças significativas em relação à amostra de desenvolvimento. Isso demonstra a estabilidade do modelo ajustado.

\begin{tabular}{|c|c|c|c|}
\hline $\begin{array}{c}\text { Probabiliade } \\
\text { Estimada de } \\
\text { Fraude }\end{array}$ & $\begin{array}{l}\% \text { Amostra } \\
\text { Treinamento }\end{array}$ & $\begin{array}{l}\text { \% Amostra } \\
\text { Validação }\end{array}$ & IEP \\
\hline $0-0,05$ & $4,3 \%$ & $4,3 \%$ & 0,00000 \\
\hline $0,05-0,10$ & $9,4 \%$ & $9,1 \%$ & 0,00007 \\
\hline $0,10-0,15$ & $9,6 \%$ & $9,8 \%$ & 0,00002 \\
\hline $0,15-0,20$ & $9,1 \%$ & $9,0 \%$ & 0,00001 \\
\hline $0,20-0,25$ & $8,3 \%$ & $8,3 \%$ & 0,00000 \\
\hline $0,25-0,30$ & $7,4 \%$ & $7,5 \%$ & 0,00003 \\
\hline $0,30-0,35$ & $6,8 \%$ & $6,8 \%$ & 0,00000 \\
\hline $0,35-0,40$ & $6,1 \%$ & $6,2 \%$ & 0,00001 \\
\hline $0,40-0,45$ & $5,6 \%$ & $5,6 \%$ & 0,00001 \\
\hline $0,45-0,50$ & $5,2 \%$ & $5,1 \%$ & 0,00001 \\
\hline $0,50-0,55$ & $4,7 \%$ & $4,7 \%$ & 0,00001 \\
\hline $0,55-0,60$ & $4,3 \%$ & $4,3 \%$ & 0,00000 \\
\hline $0,60-0,65$ & $3,9 \%$ & $4,0 \%$ & 0,00001 \\
\hline $0,65-0,70$ & $3,6 \%$ & $3,7 \%$ & 0,00003 \\
\hline $0,70-0,75$ & $3,2 \%$ & $3,1 \%$ & 0,00001 \\
\hline $0,75-0,80$ & $2,8 \%$ & $2,7 \%$ & 0,00000 \\
\hline $0,80-0,85$ & $2,3 \%$ & $2,2 \%$ & 0,00005 \\
\hline $0,85-0,90$ & $1,8 \%$ & $1,8 \%$ & 0,00001 \\
\hline $0,90-0,95$ & $1,2 \%$ & $1,3 \%$ & 0,00003 \\
\hline $0,95-1,00$ & $0,5 \%$ & $0,5 \%$ & 0,00000 \\
\hline Total & $100,0 \%$ & $100,0 \%$ & 0,00030 \\
\hline
\end{tabular}

Figura 7.8: Índice de estabilidade populacional do modelo ajustado com stepwise.

Pelos gráficos de boxplot, histograma e densidade (figuras 7.9, 7.10 e 7.11, respectivamente), pode-se notar uma distribuição muito similar das probabilidades de fraude das amostras de desenvolvimento e validação. 


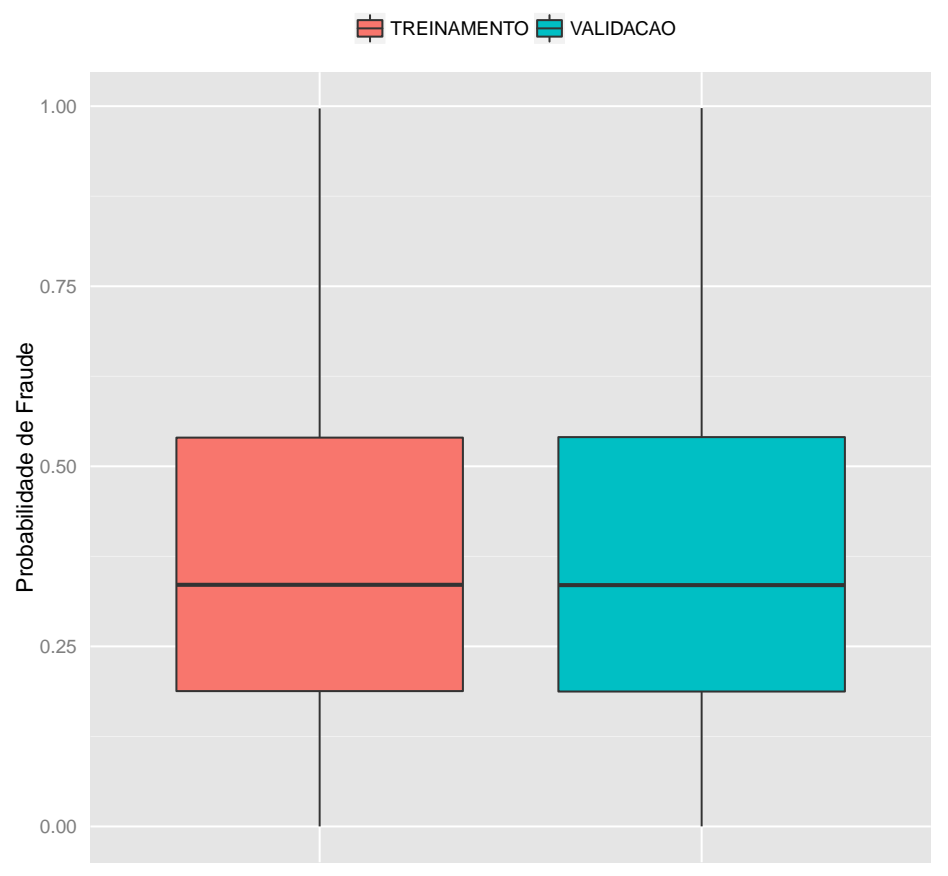

Figura 7.9: Boxplox das amostras de treinamento e validação do modelo ajustado com stepwise.

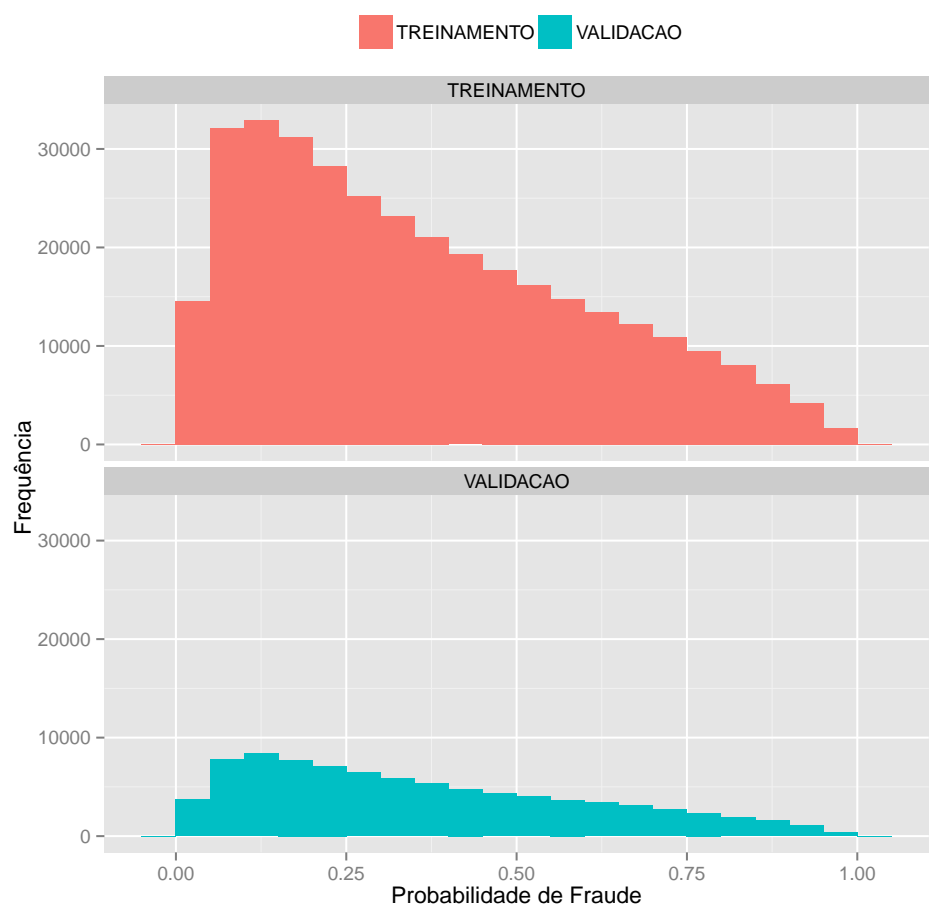

Figura 7.10: Histograma da amostra de treinamento e validação do modelo ajustado com stepwise. 


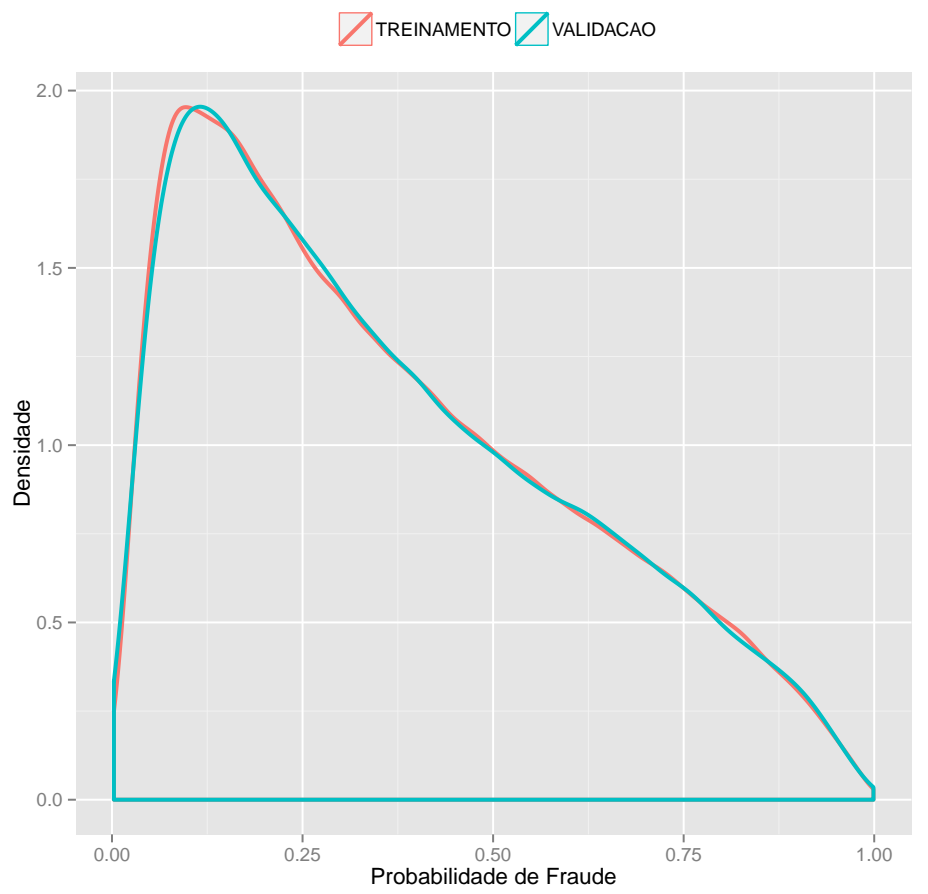

Figura 7.11: Densidade das amostras de treinamento e validação do modelo ajustado com stepwise.

Seguindo a mesma análise de AUC realizada para a amostra de desenvolvimento, obtivemos o valor de 0,816 de AUC para a amostra de validação, o que pode ser classificado como bom.

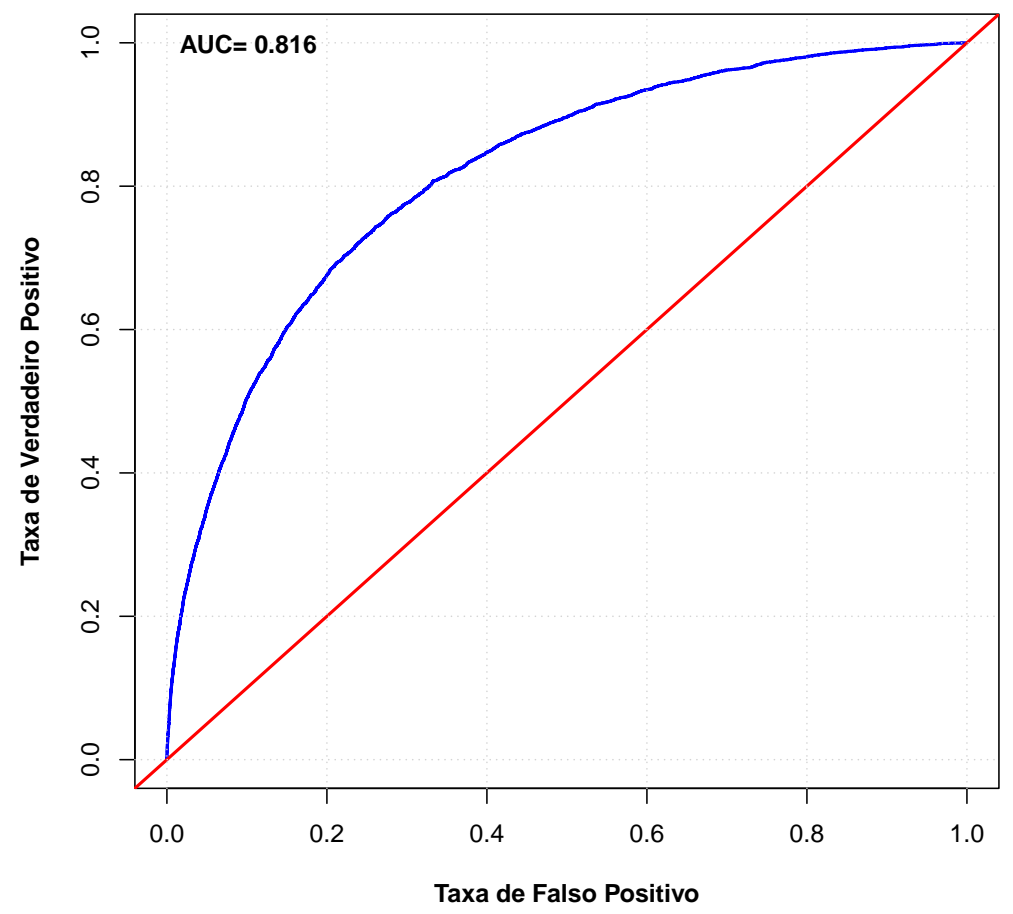

Figura 7.12: Curva ROC da amostra de validação (ponto de corte para probabilidade=0,6) do modelo ajustado com stepwise. 


\subsubsection{Indicadores de Performance}

Nesta seção, apresentamos a comparação da classificação original da transação como não fraude ou fraude e a classificação realizada pelo modelo ajustado com stepwise. Na tabela 7.8, observamos o percentual de classificação correta maior para o grupo não fraude (98\%) do que para o grupo de fraude (17\%). Essa diferença já era algo esperada pela característica desbalanceada que os dados do nosso trabalho possuem e a dificuldade de identificar transações fraudulentas.

\begin{tabular}{lccc}
\hline \hline Classificado & \multicolumn{2}{c}{ Observado } & \% Classificação \\
\cline { 2 - 3 } pelo Modelo & Fraude & Não Fraude & Correta \\
\hline Fraude & 11.385 & 54.705 & $17 \%$ \\
Não Fraude & 6.707 & 269.808 & $98 \%$ \\
\hline \% Classificação Correta & & $82 \%$ \\
\hline
\end{tabular}

Tabela 7.8: Tabela de classificação das transações pelo modelo ajustado com stepwise (ponto de corte para probabilidade=0,6).

Adicionalmente ao indicador AUC, que é utilizado para avaliar a performance do sistema de classificação, temos a medida $\mathrm{F}$ que é especificada pela média harmônica entre o indicador de precisão e cobertura, ou seja:

$$
\text { Medida } \mathrm{F}=2 * \frac{\text { Precisão } * \text { Cobertura }}{\text { Precisão }+ \text { Cobertura }}
$$

onde, para esse trabalho, a precisão representa o percentual de fraudes observadas e classificadas como fraude em relação ao total de transações classificadas como fraude e a cobertura, também conhecida como sensibilidade e taxa de detecção, corresponde ao percentual de fraudes observadas e classificadas como fraude em relação ao total de fraudes observadas.

Dado isso, apresentamos um conjunto de indicadores que avaliam a classificação realizada pelo modelo em relação à classificação original para as amostras de desenvolvimento e validação. Ambas as amostras apresentaram resultados muito similares, o que indica certa estabilidade do modelo.

Na tabela 7.9, os indicadores de acurácia e área sob a curva ROC indicam que o modelo teve uma boa performance para classificar as transações em geral. No entanto, essa precisão é muito maior para transações não fraude $(97,6 \%)$ do que para fraude $(17,2 \%)$. Para avaliar a cobertura e precisão, obtivemos o valor de $27 \%$ para a medida F.

De todas as transações não fraude classificadas originalmente, o modelo identificou 83,1\% (especificidade). Já para as transações fraudulentas, o modelo identificou 62,9\% do total de fraudes (sensibilidade) com taxa de falso positivo de 16,9\%. A relação não fraude/fraude ficou aproximadamente igual a 5, ou seja, a cada 5 transações observadas como não fraude e 
classificadas como fraude é possível encontrar uma transação observada e classificada como fraude.

\begin{tabular}{lcc}
\hline \hline \multirow{2}{*}{ Indicadores } & \multicolumn{2}{c}{ Amostra } \\
\cline { 2 - 3 } & Desenvolvimento & Validação \\
\hline Classificação de Fraude & & \\
Taxa de Deteç̃ão (Cobertura) & $62,9 \%$ & $63,2 \%$ \\
Taxa de Falso Positivo & $16,9 \%$ & $16,9 \%$ \\
Relação Não Fraude/Fraude & 4,8 & 4,8 \\
Precisão (Fraude) & $17,2 \%$ & $17,3 \%$ \\
Classificação de Não Fraude & & \\
Especificidade & $83,1 \%$ & $83,1 \%$ \\
Precisão (Não Fraude) & $97,6 \%$ & $97,6 \%$ \\
Classificação Geral & & \\
Acurácia & $82,1 \%$ & $82,0 \%$ \\
Área sob a curva ROC & $81,7 \%$ & $81,6 \%$ \\
Medida F & $27,0 \%$ & $27,1 \%$ \\
\hline
\end{tabular}

Tabela 7.9: Indicadores de performance do modelo de regressão logística clássica com stepwise.

\subsubsection{Variáveis adicionadas por conhecimento do domínio}

Usando a experiência do especialista do domínio, nesse caso, o especialista de fraude, foram incluídas as seguintes variáveis no modelo anterior obtido pela técnica stepwise: V04, V16, V28, V33 e V35. No entanto, a inclusão dessas variáveis fez com que as variáveis V38 e V48, que já estavam no modelo, fossem retiradas por apresentarem valor-p > 0,05. Com essas mudanças, o modelo final com a intervenção do especialista apresentou 28 variáveis. A análise completa desse modelo ajustado encontra-se no apêndice $\mathrm{C}$ deste trabalho.

Na tabela 7.10 comparamos os modelos desenvolvidos com a amostra de desenvolvimento utilizando somente a técnica stepwise e o stepwise modificado com a intervenção do especialista no domínio. 


\begin{tabular}{lcc}
\hline \hline \multirow{2}{*}{ Indicadores } & \multicolumn{2}{c}{ Modelo } \\
\cline { 2 - 3 } & Stepwise & Stepwise Modificado \\
\hline Classificação de Fraude & & \\
Taxa de Detecção (Cobertura) & $62,9 \%$ & $66,2 \%$ \\
Taxa de Falso Positivo & $16,9 \%$ & $16,1 \%$ \\
Relação Não Fraude/Fraude & 4,8 & 4,4 \\
Precisão (Fraude) & $17,2 \%$ & $18,7 \%$ \\
Classificação de Não Fraude & & \\
Especificidade & $83,1 \%$ & $83,9 \%$ \\
Precisão (Não Fraude) & $97,6 \%$ & $97,8 \%$ \\
Classificação Geral & & \\
Acurácia & $82,1 \%$ & $83,0 \%$ \\
Área sob a curva ROC & $81,7 \%$ & $83,9 \%$ \\
Medida F & $27,0 \%$ & $29,2 \%$ \\
\hline
\end{tabular}

Tabela 7.10: Indicadores de performance do modelo de regressão logística clássica com as técnicas stepwise e stepwise modificado.

\subsection{Modelagem com o Método DMA}

Para estudar o método DMA, utilizamos o pacote DMA disponível no software estatístico $\mathrm{R}$ versão 3.03. Esse pacote foi desenvolvido por Tyler H. McCormick, Adrian Raftery, David Madigan e Timothy J. Triche Jr. e implementa o modelo DMA para variáveis respostas binárias descritas no artigo de McCormick et al. (2012).

Inicialmente, ao executar a função logistic.dma do pacote DMA, apareceram alguns erros relacionados à inversão de matriz para a atualização dos parâmetros do modelo. Isso fez com que estudássemos todo o script desenvolvido por McCormick et al. (2012) para localizarmos em que ponto estava o erro. Ao localizarmos, verificamos que se tratava da precisão numérica que estava sendo utilizada para executar a inversão da matriz. Fizemos uma correção no script para trabalharmos com precisão de 10 algarismos e não enfrentamos maiores problemas na execução.

Para aumentar a performance do tempo de execução do script, utilizamos o pacote parallel do R, que realizou cálculos em paralelo para algumas funções do script. O tempo de execução do processamento do modelo DMA foi reduzido de 32 minutos, em média, para 18 minutos. Uma redução, em média, de $44 \%$.

Como explicado anteriormente na seção 5.3, a técnica de modelagem DMA incorpora a ideia de fator de esquecimento. Temos um fator de esquecimento utilizado na equação de predição do parâmetro do modelo e especificado por $\lambda$, que tem o papel de calibrar a influência de observações passadas e eliminar a necessidade de matrizes de transição entre 
os estados, tornando a predição online computacionalmente razoável.

Já o outro fator de esquecimento atua na equação de predição do modelo, e é especificado por $\alpha$. Com sua utilização, evita-se a especificação de matriz de transição.

Os valores de $\lambda$ e $\alpha$ costumam variar de 0,95 a 0,99 , conforme descrevem os artigos sobre essa técnica de Koop e Korobilis (2010) e McCormick et al. (2012). Assim, para avaliarmos o melhor valor de $\lambda$ e $\alpha$, iremos analisar a medida $\mathrm{F}$ e a área sob a curva ROC (AUC) da combinação dois a dois dos valores $0,95,0,975$ e 0,99 .

Dada essa estratégia de análise para os valores de $\lambda$ e $\alpha$, obtivemos os seguintes resultados apresentados na tabela 7.11.

\begin{tabular}{cccc}
\hline \hline$\lambda$ & $\alpha$ & Medida F & AUC \\
\hline 0,99 & 0,99 & $46,7 \%$ & $88,8 \%$ \\
0,99 & 0,975 & $48,6 \%$ & $89,2 \%$ \\
0,99 & 0,95 & $49,4 \%$ & $89,5 \%$ \\
0,975 & 0,99 & $53,8 \%$ & $91,2 \%$ \\
0,975 & 0,975 & $54,6 \%$ & $91,5 \%$ \\
0,975 & 0,95 & $55,3 \%$ & $91,8 \%$ \\
0,95 & 0,99 & $56,9 \%$ & $92,3 \%$ \\
0,95 & 0,975 & $57,7 \%$ & $92,6 \%$ \\
0,95 & 0,95 & $58,2 \%$ & $92,9 \%$ \\
\hline
\end{tabular}

Tabela 7.11: Avaliação de $\lambda$ e $\alpha$ para o modelo DMA.

Desses resultados, observamos que os valores para $\lambda=\alpha=0,95$ apresentaram melhor performance para a medida F e AUC e para $\lambda=\alpha=0,99$ a pior. Assim, para descrever a execução do modelo DMA, no apêndice D encontra-se a análise completa para o modelo DMA com $\lambda=\alpha=0,99$, o qual chamaremos de modelo DMA 99, e apresentamos nas subseções a seguir para $\lambda=\alpha=0,95$, que denominaremos modelo DMA 95.

\subsubsection{Seleção de Modelos e Variáveis}

Através dos princípios de Occam's Window descrito na seção 5.6.1 deste trabalho, executamos no software $\mathrm{R}$ versão 3.0.3 pelo pacote BMA a escolha dos modelos para servir como input na execução do DMA. Considerando que temos 52 variáveis preditoras, essa abordagem evita que utilizemos as $2^{52}$ combinações de modelos possíveis, o que poderia levar a problemas computacionais e estatísticos no processo de estimação.

Na tabela 7.12 apresentamos os modelos ${ }^{8}$ e variáveis selecionadas pelo método de Occam's Window. Os modelos estão ordenados de maneira decrescente pela média das probabilidades a posteriori durante todo o período de observação, sendo que o modelo 1 apresenta a maior média da probabilidade a posteriori e o modelo 6 a menor.

\footnotetext{
${ }^{8}$ Lembramos que um modelo no método DMA corresponde a uma seleção de variáveis. Os parâmetros $\theta$ das variáveis são ajustados dinamicamente.
} 
Modelo / \# Variáveis

\begin{tabular}{|c|c|c|c|c|c|c|}
\hline & & & & & & \\
\hline & 1 & 2 & 3 & 4 & 5 & 6 \\
\hline Variável & 31 & 33 & 33 & 34 & 34 & 32 \\
\hline$\overline{\mathrm{V} 1}$ & $\bar{x}$ & $\bar{x}$ & $\bar{x}$ & $\bar{x}$ & $\bar{x}$ & $\bar{x}$ \\
\hline V2 & $x$ & 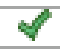 & $\checkmark$ & $x$ & $x$ & $\checkmark$ \\
\hline V3 & 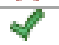 & 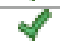 & $x$ & $x$ & $x$ & $x$ \\
\hline V4 & 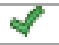 & $\sqrt{7}$ & 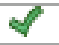 & 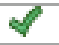 & 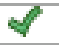 & 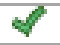 \\
\hline V5 & 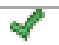 & $\checkmark$ & $\checkmark$ & $x$ & $x$ & $\checkmark$ \\
\hline V6 & 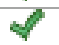 & $\checkmark$ & 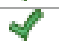 & $\neg$ & $\checkmark$ & $\checkmark$ \\
\hline V7 & $x$ & $x$ & $x$ & $x$ & $x$ & $x$ \\
\hline V8 & 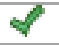 & 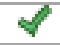 & $\mathscr{7}$ & 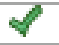 & 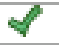 & $\checkmark$ \\
\hline V9 & 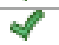 & $\checkmark$ & 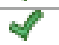 & 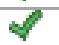 & 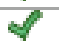 & $\checkmark$ \\
\hline V10 & 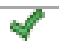 & $\checkmark$ & 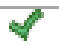 & 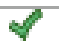 & $\checkmark$ & $\checkmark$ \\
\hline V11 & $x$ & 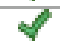 & $\checkmark$ & $\checkmark$ & $\checkmark$ & $\checkmark$ \\
\hline $\mathrm{V} 12$ & $x$ & $\checkmark$ & $\checkmark$ & $\checkmark$ & $\checkmark$ & $\checkmark$ \\
\hline V13 & $x$ & $x$ & $x$ & $x$ & $x$ & $x$ \\
\hline V14 & $x$ & $\checkmark$ & $\neg$ & $\checkmark$ & $\checkmark$ & $x$ \\
\hline V15 & 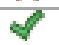 & $\checkmark$ & 9 & $x$ & $x$ & $\checkmark$ \\
\hline V16 & $x$ & $\checkmark$ & $\checkmark$ & $\checkmark$ & $\checkmark$ & 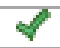 \\
\hline V17 & 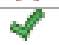 & 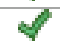 & $x$ & $x$ & $x$ & $\checkmark$ \\
\hline V18 & $x$ & $\checkmark$ & $\checkmark$ & $\mathscr{q}$ & $\checkmark$ & $\checkmark$ \\
\hline V19 & $\checkmark$ & $\checkmark$ & $x$ & $x$ & $x$ & $x$ \\
\hline $\mathrm{V} 20$ & $x$ & $\checkmark$ & $\checkmark$ & $\checkmark$ & $\checkmark$ & $\checkmark$ \\
\hline $\mathrm{V} 21$ & 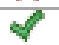 & $x$ & $\mathscr{q}$ & $\mathscr{q}$ & $\checkmark$ & $x$ \\
\hline V22 & 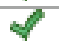 & $x$ & $x$ & $x$ & $x$ & $x$ \\
\hline V23 & $x$ & $\checkmark$ & $\checkmark$ & $\checkmark$ & $\checkmark$ & $\checkmark$ \\
\hline V24 & 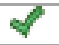 & $x$ & $\checkmark$ & $\checkmark$ & $\checkmark$ & $\checkmark$ \\
\hline $\mathrm{V} 25$ & 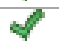 & $\checkmark$ & $\checkmark$ & $\checkmark$ & $\checkmark$ & $\checkmark$ \\
\hline V26 & $x$ & $x$ & $\checkmark$ & $\checkmark$ & $\checkmark$ & 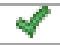 \\
\hline V27 & $x$ & $\checkmark$ & $x$ & $\checkmark$ & $\checkmark$ & $x$ \\
\hline V28 & $x$ & $x$ & $\checkmark$ & $\checkmark$ & $\checkmark$ & $\checkmark$ \\
\hline $\mathrm{V} 29$ & $x$ & $\checkmark$ & $x$ & $x$ & $x$ & $x$ \\
\hline V30 & 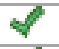 & $x$ & $\checkmark$ & $x$ & $\checkmark$ & $\checkmark$ \\
\hline V31 & $\mathscr{q}$ & $x$ & 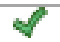 & $\mathscr{I}$ & $\checkmark$ & $x$ \\
\hline V32 & 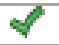 & $x$ & $\checkmark$ & $\checkmark$ & $\checkmark$ & $x$ \\
\hline V33 & $\checkmark$ & $\checkmark$ & $x$ & $x$ & $x$ & $x$ \\
\hline V34 & $\checkmark$ & $\checkmark$ & $x$ & $x$ & $x$ & $x$ \\
\hline V35 & $\checkmark$ & $\checkmark$ & $\checkmark$ & $\checkmark$ & $\checkmark$ & $\checkmark$ \\
\hline V36 & $\checkmark$ & $x$ & $x$ & $\checkmark$ & $\checkmark$ & $x$ \\
\hline V37 & 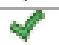 & $\checkmark$ & $x$ & $\checkmark$ & $\checkmark$ & $x$ \\
\hline V38 & $x$ & $\checkmark$ & $x$ & $\checkmark$ & $x$ & $\checkmark$ \\
\hline V39 & 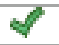 & $x$ & $x$ & $x$ & $\checkmark$ & $x$ \\
\hline V40 & $\checkmark$ & $\checkmark$ & $\checkmark$ & $x$ & $x$ & $\checkmark$ \\
\hline V41 & $x$ & $\checkmark$ & $x$ & $\checkmark$ & $\checkmark$ & $\checkmark$ \\
\hline V42 & 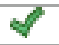 & $x$ & $\checkmark$ & $\checkmark$ & $\checkmark$ & $\checkmark$ \\
\hline V43 & $x$ & $\checkmark$ & $\checkmark$ & $\checkmark$ & $\checkmark$ & $\checkmark$ \\
\hline V44 & 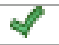 & $\checkmark$ & $x$ & $\checkmark$ & $x$ & $\checkmark$ \\
\hline V45 & $\checkmark$ & $x$ & $x$ & $x$ & $x$ & $x$ \\
\hline V46 & $\checkmark$ & $\checkmark$ & $\checkmark$ & $\checkmark$ & $\checkmark$ & $\checkmark$ \\
\hline V47 & $x$ & $\checkmark$ & $x$ & $x$ & $x$ & $\checkmark$ \\
\hline V48 & $x$ & $x$ & $\checkmark$ & $\checkmark$ & $\checkmark$ & $x$ \\
\hline V49 & $\checkmark$ & $x$ & $\checkmark$ & $\checkmark$ & $\checkmark$ & $x$ \\
\hline V50 & 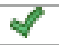 & $x$ & $\checkmark$ & $\checkmark$ & $\checkmark$ & $\checkmark$ \\
\hline V51 & $x$ & $\checkmark$ & $\checkmark$ & $\checkmark$ & $\checkmark$ & $\checkmark$ \\
\hline V52 & $\checkmark$ & $x$ & $\checkmark$ & $\checkmark$ & $\checkmark$ & $\checkmark$ \\
\hline
\end{tabular}

Tabela 7.12: Modelos e variáveis selecionadas. 
Na figura 7.13, temos que os modelos 1 e 2 agrupam grande parte da probabilidade a posteriori para o modelo DMA $95(68,5 \%)$.

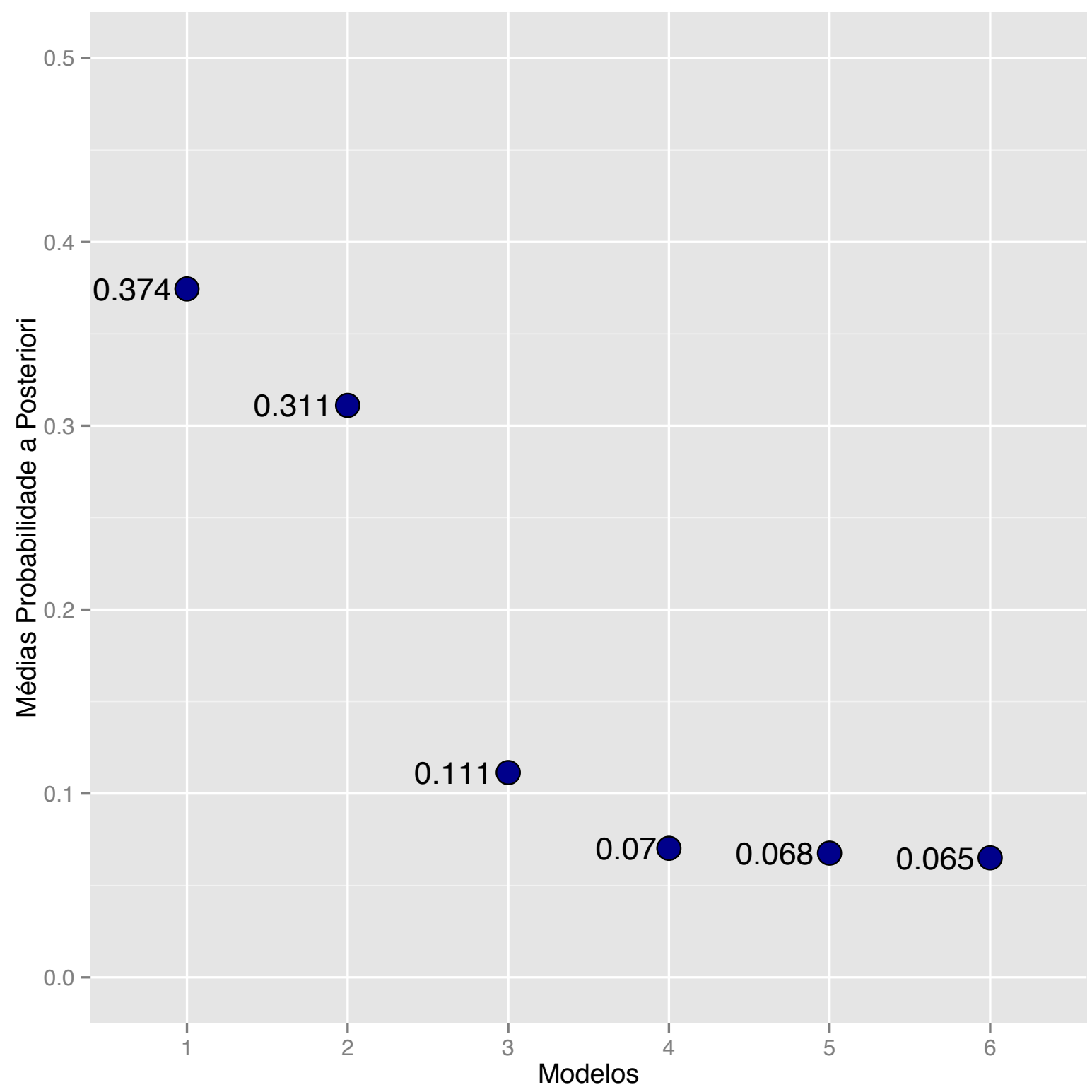

Figura 7.13: Média das probabilidades a posteriori dos modelos selecionados para o modelo DMA 95. 


\subsubsection{Ajuste do Modelo}

Com a seleção dos 6 modelos descritos anteriormente, a probabilidade a posteriori de cada um deles sofre alteração ao longo do tempo. A seguir, apresentamos graficamente a evolução e comportamento dessas probabilidades.

Na figura 7.14, apresentamos os histogramas dos modelos para todas as transações da amostra de desenvolvimento. Em todos os modelos, nota-se maior concentração no intervalo de probabilidades entre 0 e 0,05 . No entanto, avaliando o segundo maior intervalo no histograma, temos os modelos 1 e 2 para o intervalo entre 0,95 e 1 .

Modelo 1

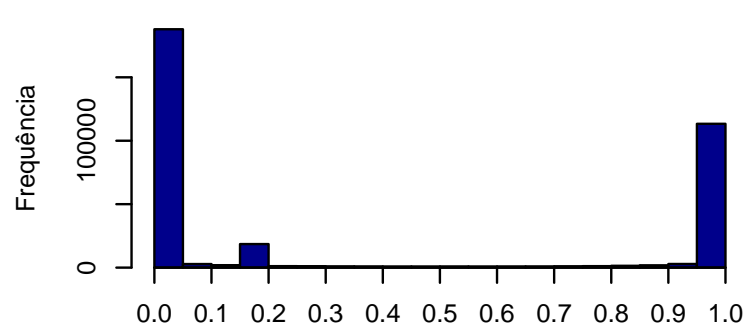

Probabilidade Posteriori

Modelo 3

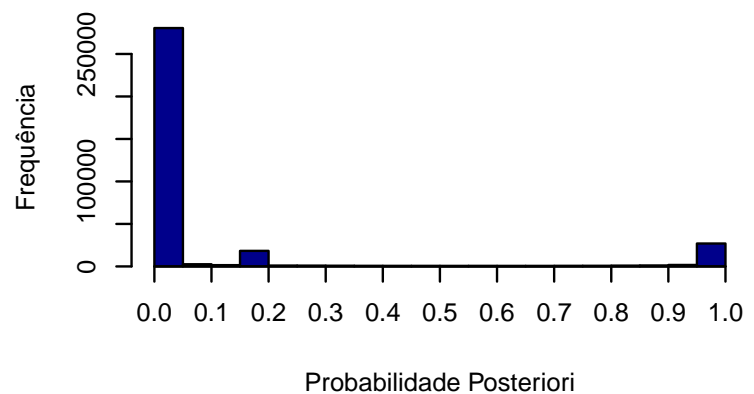

Modelo 5

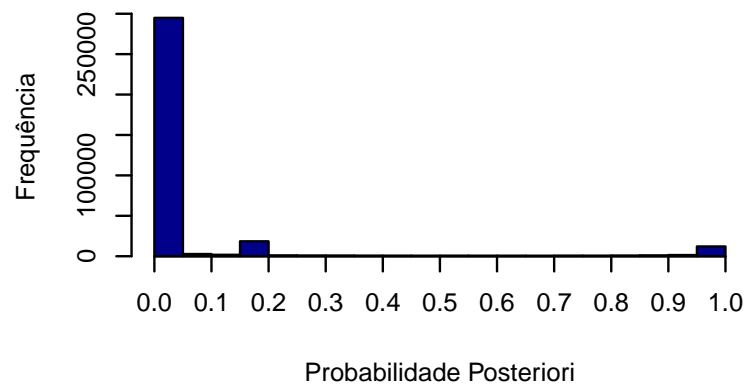

Modelo 2

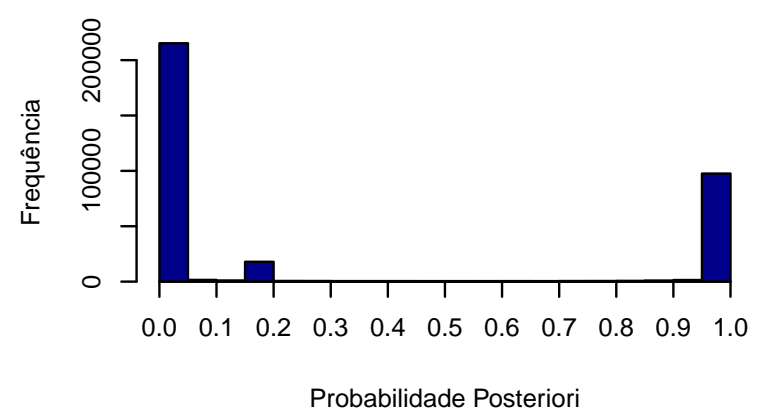

Modelo 4

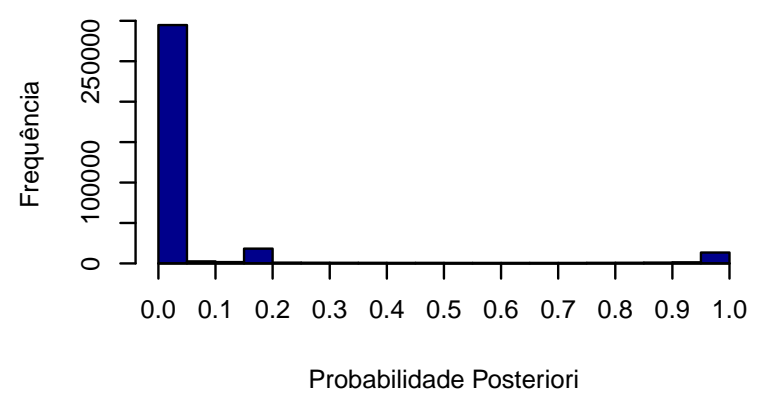

Modelo 6

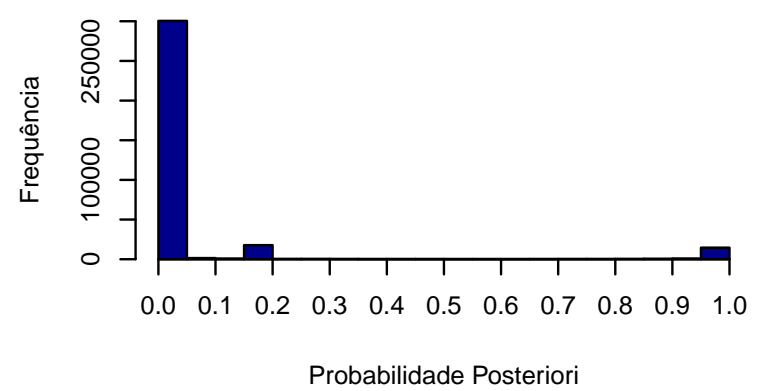

Figura 7.14: Histogramas das probabilidades a posteriori dos modelos selecionados para o modelo DMA 95. 
Como a cada transação existe atualização tanto dos parâmetros do modelo quanto das suas probabilidades a posteriori, para tornar possível a visualização da evolução de seus valores, a cada 1.000 transações os valores assumidos naquele momento foram observados e mostrados na figura 7.15 .
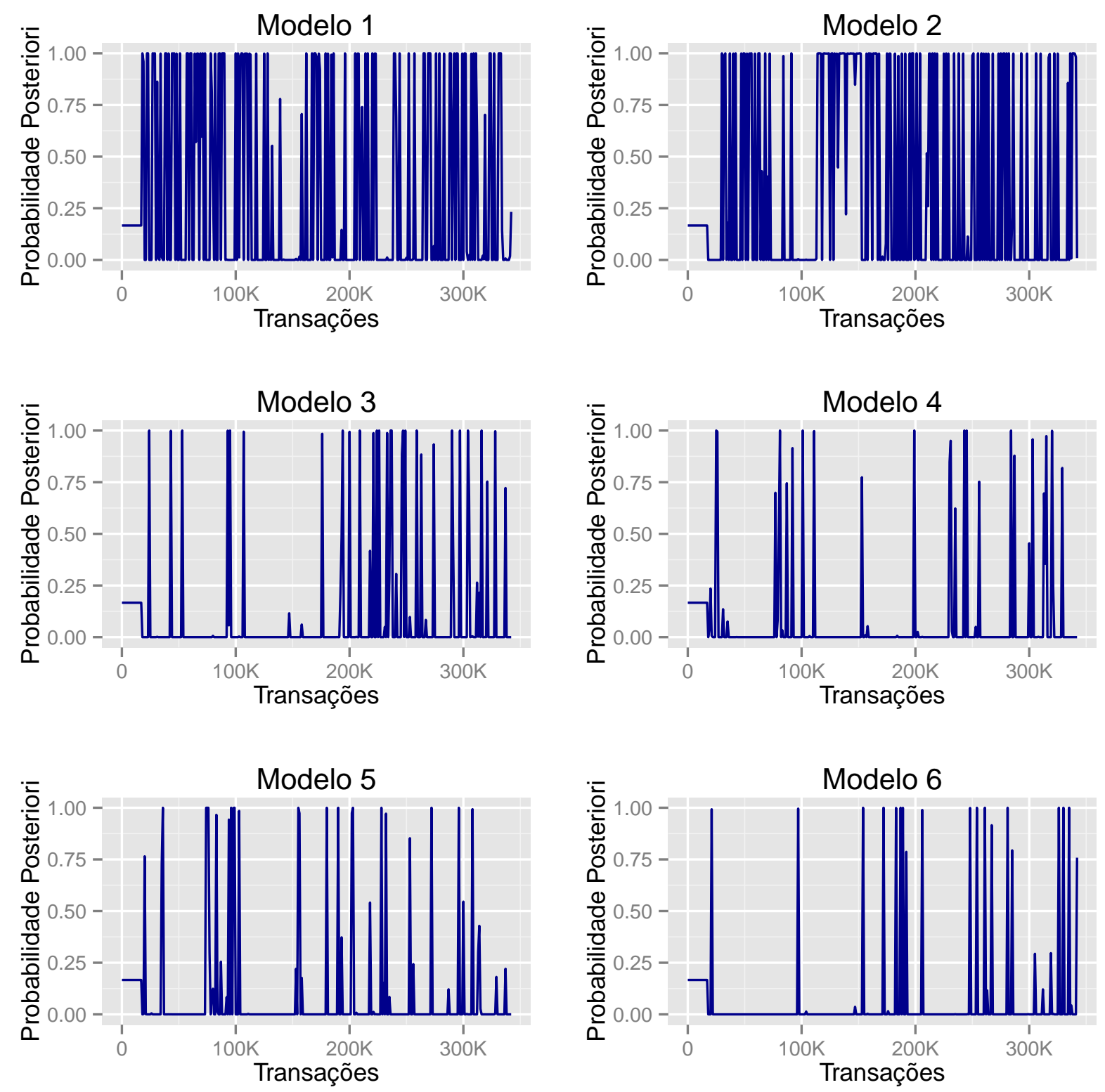

Figura 7.15: Probabilidade a posteriori dos modelos selecionados para o modelo DMA 95 a cada 1.000 transações no tempo. 
Já na figura 7.16 apresentamos a evolução da probabilidade a posteriori dos 6 modelos juntos a cada 10.000 transações.

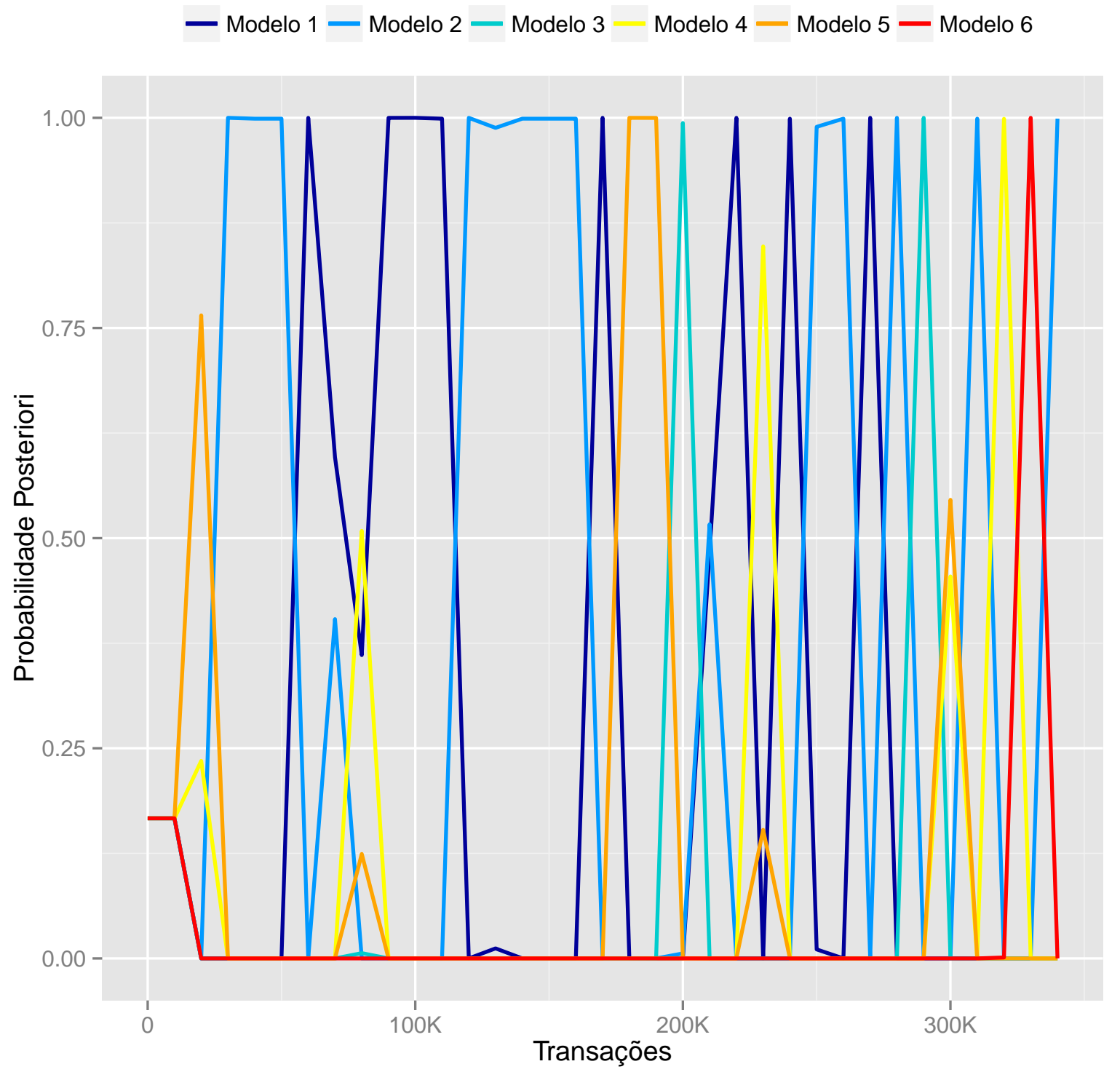

Figura 7.16: Probabilidade a posteriori dos modelos selecionados para o modelo DMA 95 a cada 10.000 transações no tempo.

Como a principal característica do modelo DMA é a atualização dinâmica das estimativas dos modelos ao longo do tempo, nas figuras a seguir mostramos a evolução dessas estimativas para as 52 variáveis. As variáveis com estimativas iguais a zero para todos os modelos não fazem parte de nenhum modelo, como ocorre, por exemplo, com o parâmetro $\theta_{1}$ da variável V1. Para as demais variáveis, os valores ao longo do tempo são apresentados para cada modelo. 

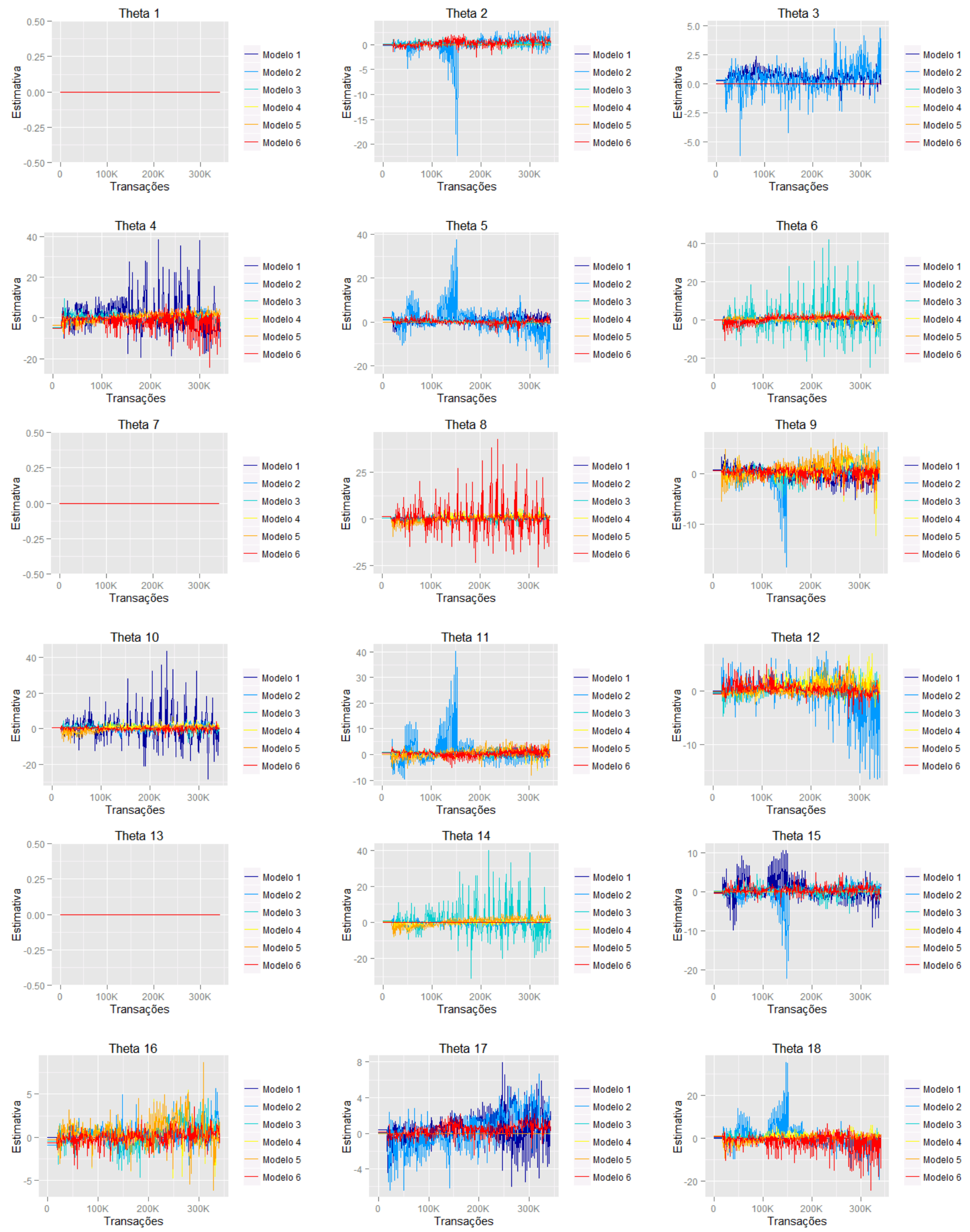

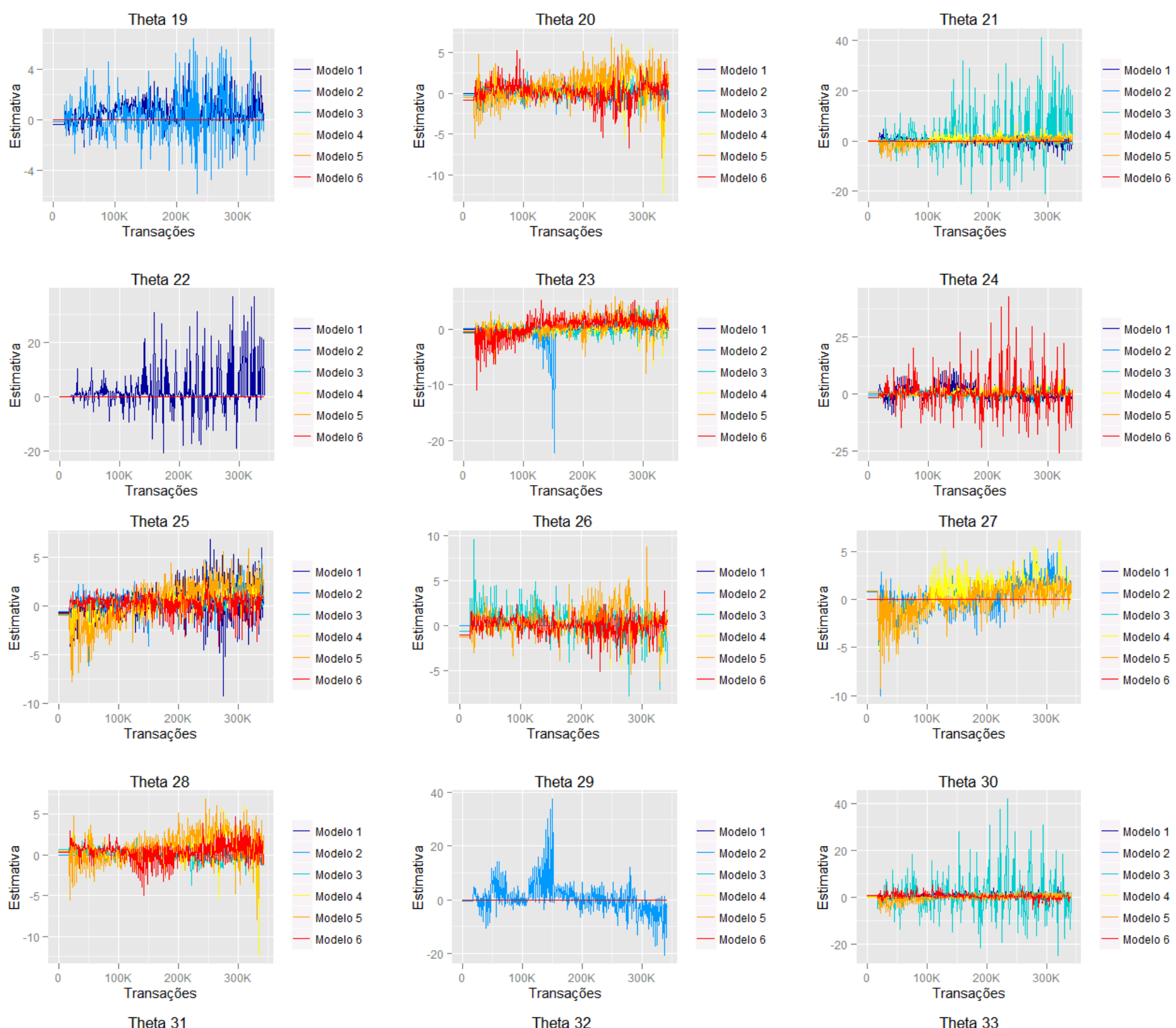

- Modelo 1

- Modelo

- Modelo 2

- Modelo 3

Modelo 4

- Modelo 5

— Modelo 6

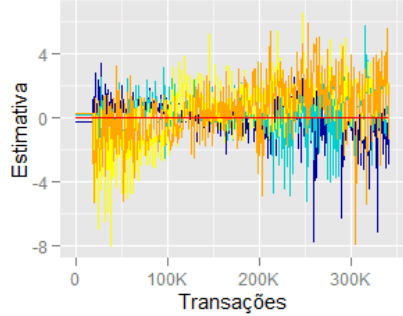

\begin{tabular}{r} 
- Modelo 1 \\
- Modelo 2 \\
- Modelo 3 \\
\hline Modelo 4 \\
- Modelo 5 \\
- Modelo 6
\end{tabular}
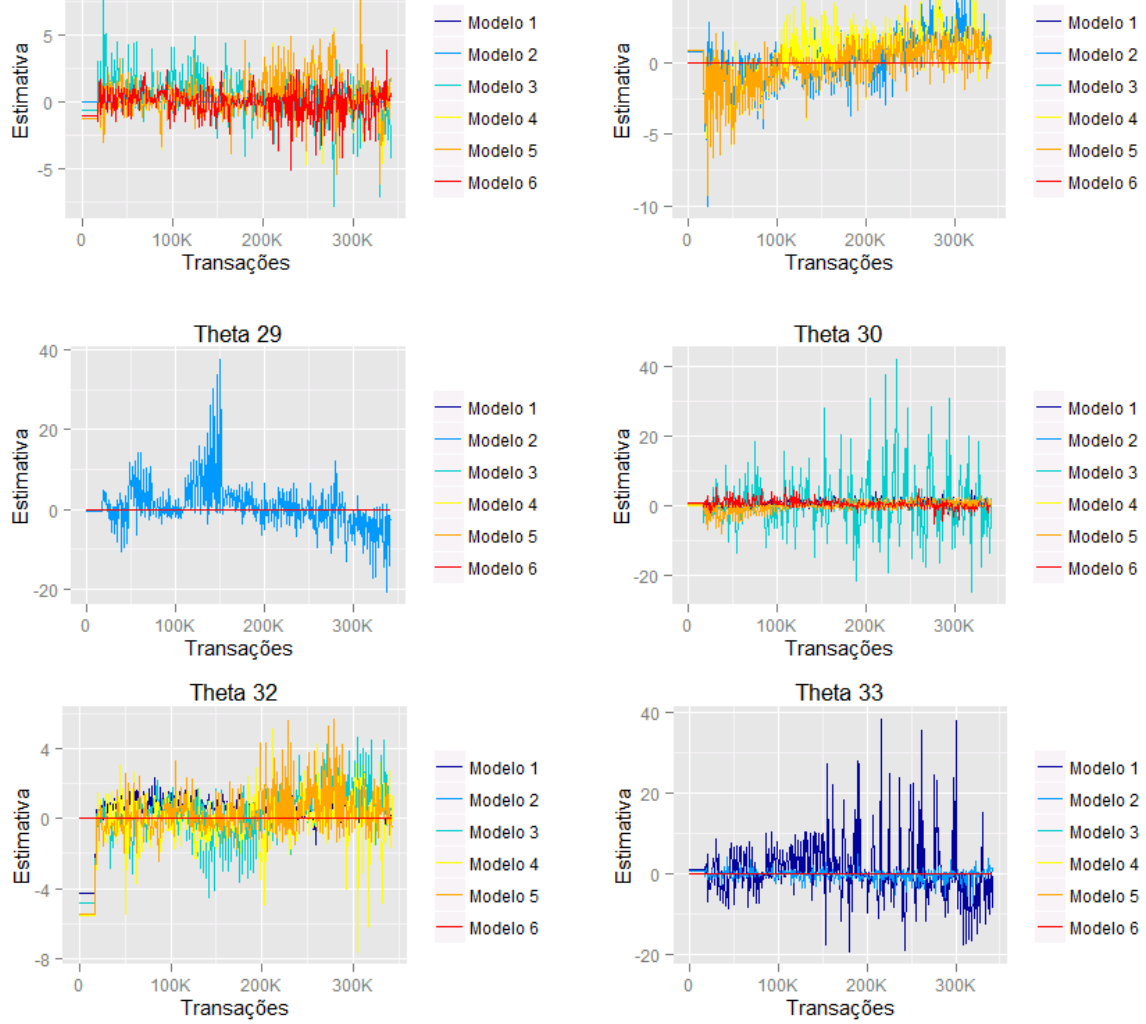

Theta 34
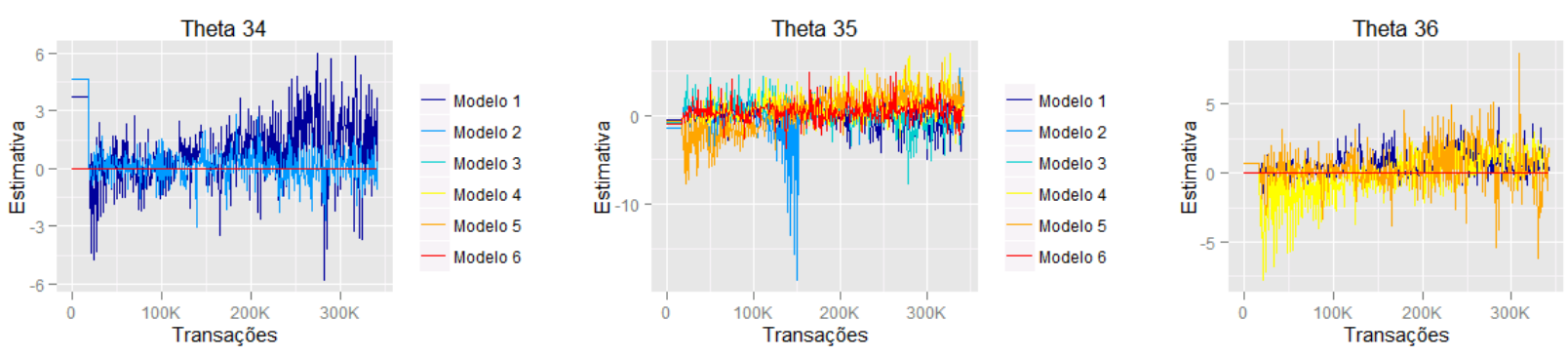

-Modelo 1
- Modelo 2
- Modelo 3
Modelo 4
- Modelo 5
- Modelo 6
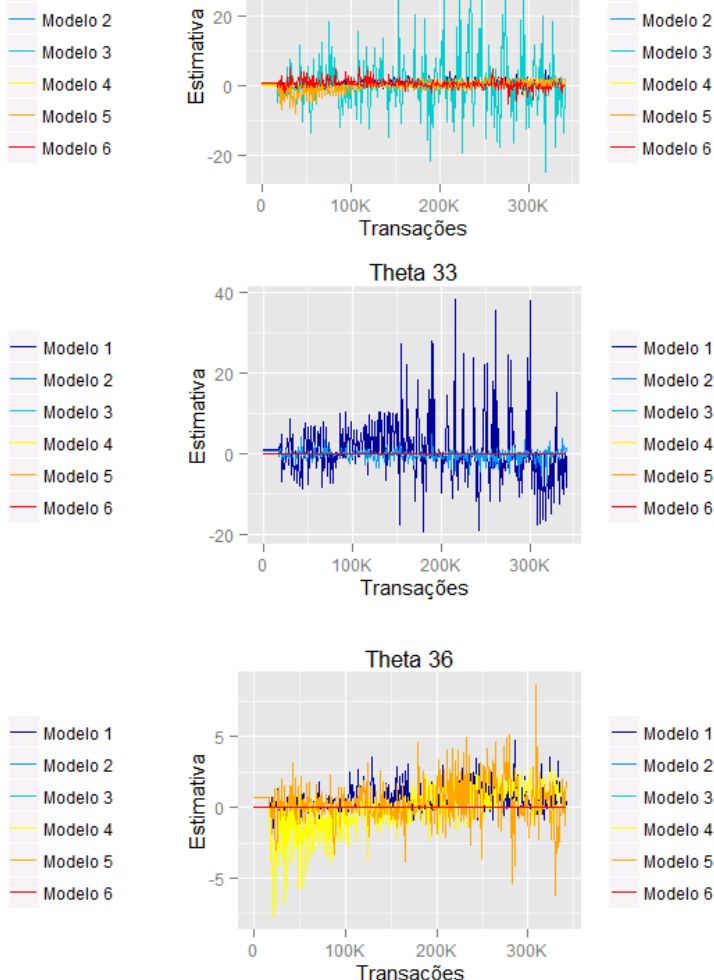

- Modelo 3

Modelo 4

Modelo 5

- Modelo 6

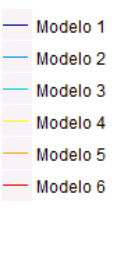



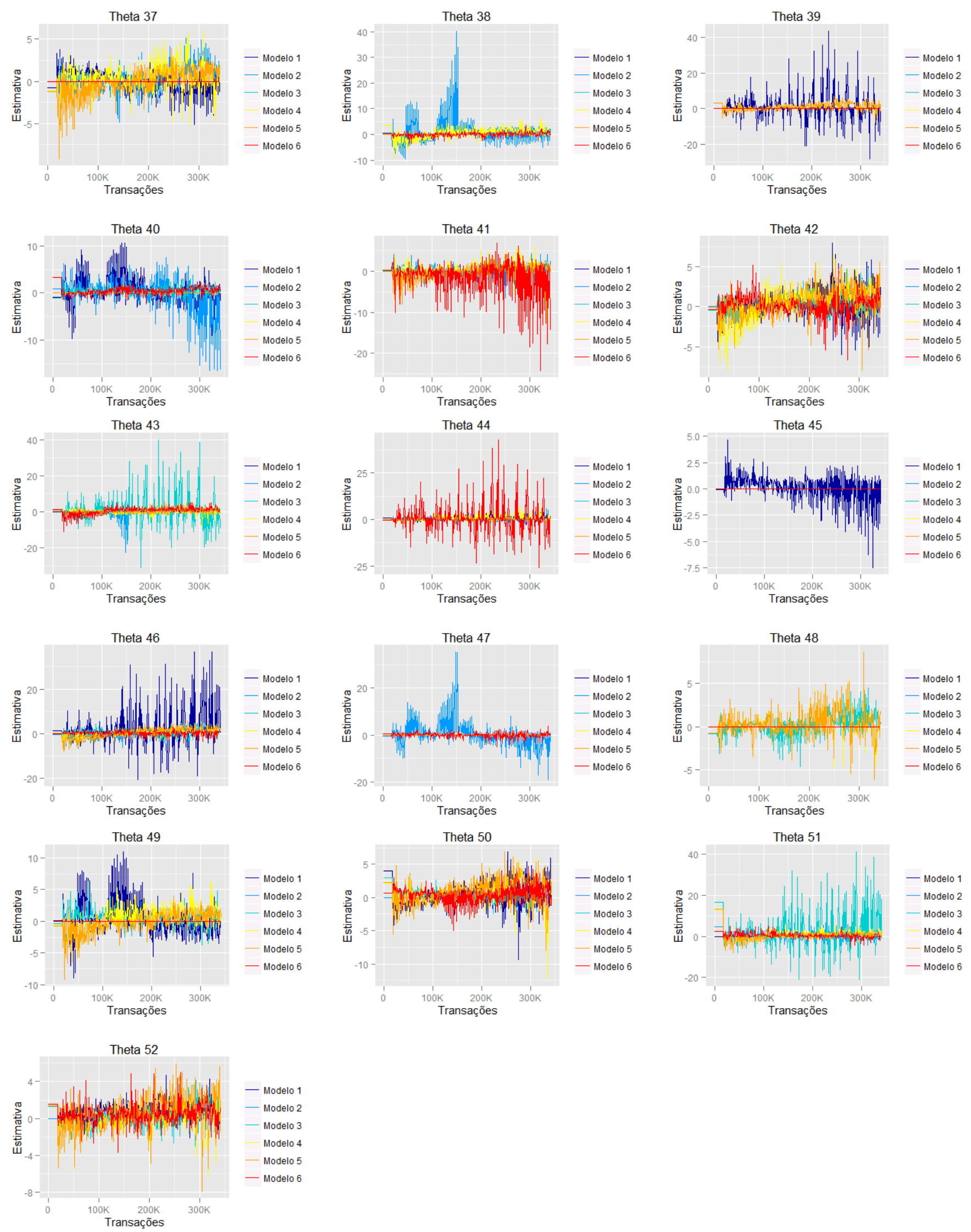

Figura 7.17: Estimativas dos parâmetros dos modelos selecionados para o modelo DMA 95 a cada 1.000 transações no tempo $(\lambda=\alpha=0,95)$. 
No gráfico de resíduos (figura 7.18), observamos a média dos resíduos (-0,065) próxima de zero.

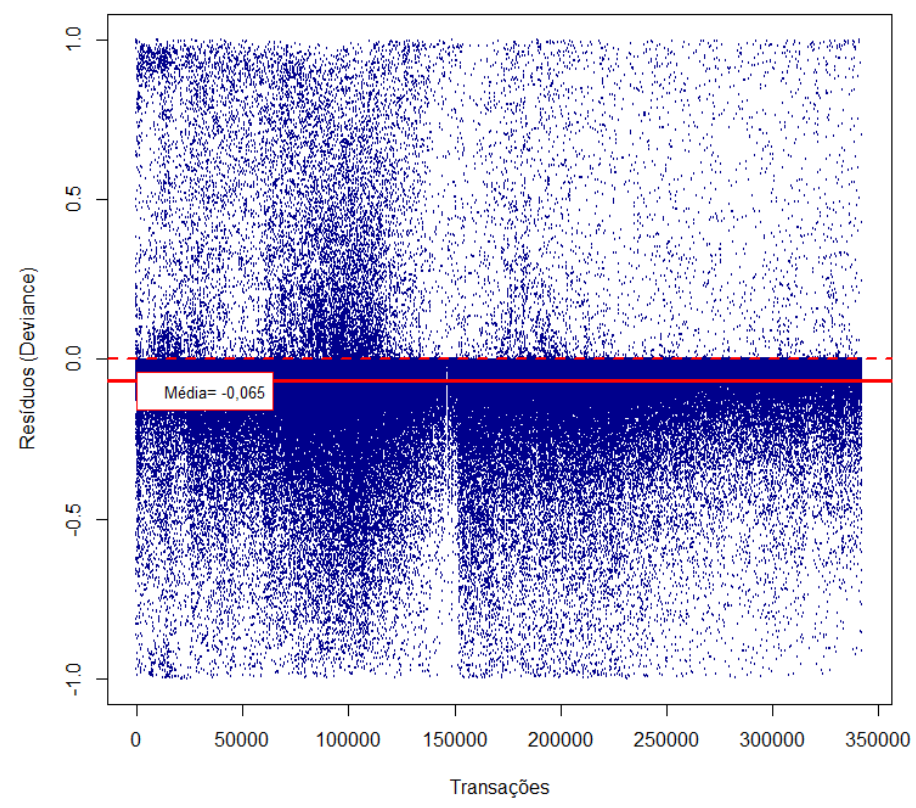

Figura 7.18: Resíduos deviance do modelo DMA 95.

\subsubsection{Medidas de Ajuste do Modelo}

\section{Estatística KS}

No modelo DMA 95, conforme tabela 7.13, obtivemos um $\mathrm{KS}=70,4 \%$, o qual pode ser classificado como excelente segundo a tabela 7.3.

\begin{tabular}{|c|c|c|c|}
\hline $\begin{array}{c}\text { Probabiliade } \\
\text { Estimada de } \\
\text { Fraude }\end{array}$ & $\%$ Fraude & $\begin{array}{c}\% \text { Não } \\
\text { Fraude }\end{array}$ & KS \\
\hline $\mathbf{0}-\mathbf{0 , 0 5}$ & $4,0 \%$ & $58,8 \%$ & $54,9 \%$ \\
\hline $\mathbf{0 , 0 5}-\mathbf{0 , 1 0}$ & $8,8 \%$ & $74,7 \%$ & $65,8 \%$ \\
\hline $\mathbf{0 , 1 0}-\mathbf{0 , 1 5}$ & $12,7 \%$ & $82,3 \%$ & $69,5 \%$ \\
\hline $\mathbf{0 , 1 5}-\mathbf{0 , 2 0}$ & $16,3 \%$ & $86,8 \%$ & $70,4 \%$ \\
\hline $\mathbf{0 , 2 0}-\mathbf{0 , 2 5}$ & $19,8 \%$ & $89,8 \%$ & $70,0 \%$ \\
\hline $\mathbf{0 , 2 5}-\mathbf{0 , 3 0}$ & $23,0 \%$ & $92,0 \%$ & $69,0 \%$ \\
\hline $\mathbf{0 , 3 0}-\mathbf{0 , 3 5}$ & $26,2 \%$ & $93,7 \%$ & $67,4 \%$ \\
\hline $\mathbf{0 , 3 5}-\mathbf{0 , 4 0}$ & $29,5 \%$ & $94,9 \%$ & $65,5 \%$ \\
\hline $\mathbf{0 , 4 0}-\mathbf{0 , 4 5}$ & $32,7 \%$ & $95,9 \%$ & $63,2 \%$ \\
\hline $\mathbf{0 , 4 5}-\mathbf{0 , 5 0}$ & $36,2 \%$ & $96,7 \%$ & $60,5 \%$ \\
\hline $\mathbf{0 , 5 0}-\mathbf{0 , 5 5}$ & $39,7 \%$ & $97,4 \%$ & $57,6 \%$ \\
\hline $\mathbf{0 , 5 5}-\mathbf{0 , 6 0}$ & $43,5 \%$ & $97,9 \%$ & $54,4 \%$ \\
\hline $\mathbf{0 , 6 0}-\mathbf{0 , 6 5}$ & $47,3 \%$ & $98,4 \%$ & $51,0 \%$ \\
\hline $\mathbf{0 , 6 5}-\mathbf{0 , 7 0}$ & $52,1 \%$ & $98,7 \%$ & $46,6 \%$ \\
\hline $\mathbf{0 , 7 0}-\mathbf{0 , 7 5}$ & $57,0 \%$ & $99,0 \%$ & $42,1 \%$ \\
\hline $\mathbf{0 , 7 5}-\mathbf{0 , 8 0}$ & $62,4 \%$ & $99,3 \%$ & $36,8 \%$ \\
\hline $\mathbf{0 , 8 0}-\mathbf{0 , 8 5}$ & $68,5 \%$ & $99,5 \%$ & $31,0 \%$ \\
\hline $\mathbf{0 , 8 5}-\mathbf{0 , 9 0}$ & $75,8 \%$ & $99,7 \%$ & $23,9 \%$ \\
\hline $\mathbf{0 , 9 0}-\mathbf{0 , 9 5}$ & $85,3 \%$ & $99,8 \%$ & $14,5 \%$ \\
\hline $\mathbf{0 , 9 5}-\mathbf{1 , 0 0}$ & $100,0 \%$ & $100,0 \%$ & $0,0 \%$ \\
\hline & & & \\
\hline
\end{tabular}

Tabela 7.13: Cálculo do KS do modelo DMA 95. 


\section{Distribuição das Probabilidades Ajustadas}

Na tabela 7.14 de classificação de probabilidade estimada obtida para o modelo DMA 95, observamos que a proporção de transações fraude é maior do que a não fraude se, por exemplo, adotarmos o valor de probabilidade estimada de fraude maior que 0,60. Da mesma maneira, se observamos as pontuações de menor valor, menor do que 0,10, por exemplo, nota-se a maior concentração dos casos de não fraude. Essa análise fica explícita no gráfico de densidade da figura 7.19. Isso indica uma boa classificação das transações não fraude e fraude.

\begin{tabular}{|c|c|c|c|c|c|c|c|c|}
\hline $\begin{array}{c}\text { Probabiliade } \\
\text { Estimada de } \\
\text { Fraude }\end{array}$ & \# Fraude & $\%$ Fraude & $\begin{array}{l}\text { \# Não } \\
\text { Fraude }\end{array}$ & $\begin{array}{l}\text { \% Não } \\
\text { Fraude }\end{array}$ & \# Total & $\%$ Total & $\begin{array}{c}\text { \# Fraude } \\
\text { Não Acumulado }\end{array}$ & $\begin{array}{l}\text { \# Não Fraude } \\
\text { Não Acumulado }\end{array}$ \\
\hline $0-0,05$ & 18.092 & $100,0 \%$ & 324.513 & $100,0 \%$ & 342.605 & $100,0 \%$ & 715 & 190.830 \\
\hline $0,05-0,10$ & 17.377 & $96,0 \%$ & 133.683 & $41,2 \%$ & 151.060 & $44,1 \%$ & 884 & 51.445 \\
\hline $0,10-0,15$ & 16.493 & $91,2 \%$ & 82.238 & $25,3 \%$ & 98.731 & $28,8 \%$ & 705 & 24.731 \\
\hline $0,15-0,20$ & 15.788 & $87,3 \%$ & 57.507 & $17,7 \%$ & 73.295 & $21,4 \%$ & 654 & 14.601 \\
\hline $0,20-0,25$ & 15.134 & $83,7 \%$ & 42.906 & $13,2 \%$ & 58.040 & $16,9 \%$ & 617 & 9.808 \\
\hline $0,25-0,30$ & 14.517 & $80,2 \%$ & 33.098 & $10,2 \%$ & 47.615 & $13,9 \%$ & 582 & 7.181 \\
\hline $0,30-0,35$ & 13.935 & $77,0 \%$ & 25.917 & $8,0 \%$ & 39.852 & $11,6 \%$ & 590 & 5.311 \\
\hline $0,35-0,40$ & 13.345 & $73,8 \%$ & 20.606 & $6,3 \%$ & 33.951 & $9,9 \%$ & 584 & 4.162 \\
\hline $0,40-0,45$ & 12.761 & $70,5 \%$ & 16.444 & $5,1 \%$ & 29.205 & $8,5 \%$ & 589 & 3.177 \\
\hline $0,45-0,50$ & 12.172 & $67,3 \%$ & 13.267 & $4,1 \%$ & 25.439 & $7,4 \%$ & 633 & 2.558 \\
\hline $0,50-0,55$ & 11.539 & $63,8 \%$ & 10.709 & $3,3 \%$ & 22.248 & $6,5 \%$ & 636 & 2.204 \\
\hline $0,55-0,60$ & 10.903 & $60,3 \%$ & 8.505 & $2,6 \%$ & 19.408 & $5,7 \%$ & 683 & 1.718 \\
\hline $0,60-0,65$ & 10.220 & $56,5 \%$ & 6.787 & $2,1 \%$ & 17.007 & $5,0 \%$ & 692 & 1.482 \\
\hline $0,65-0,70$ & 9.528 & $52,7 \%$ & 5.305 & $1,6 \%$ & 14.833 & $4,3 \%$ & 868 & 1.181 \\
\hline $0,70-0,75$ & 8.660 & $47,9 \%$ & 4.124 & $1,3 \%$ & 12.784 & $3,7 \%$ & 874 & 990 \\
\hline $0,75-0,80$ & 7.786 & $43,0 \%$ & 3.134 & $1,0 \%$ & 10.920 & $3,2 \%$ & 991 & 820 \\
\hline $0,80-0,85$ & 6.795 & $37,6 \%$ & 2.314 & $0,7 \%$ & 9.109 & $2,7 \%$ & 1.103 & 694 \\
\hline $0,85-0,90$ & 5.692 & $31,5 \%$ & 1.620 & $0,5 \%$ & 7.312 & $2,1 \%$ & 1.313 & 574 \\
\hline $0,90-0,95$ & 4.379 & $24,2 \%$ & 1.046 & $0,3 \%$ & 5.425 & $1,6 \%$ & 1.721 & 526 \\
\hline $0,95-1,00$ & 2.658 & $14,7 \%$ & 520 & $0,2 \%$ & 3.178 & $0,9 \%$ & 2.658 & 520 \\
\hline Total & & & & & & & 18.092 & 324.513 \\
\hline
\end{tabular}

Tabela 7.14: Tabela de classificação das transações e intervalo de pontuação pelo modelo DMA 95. 


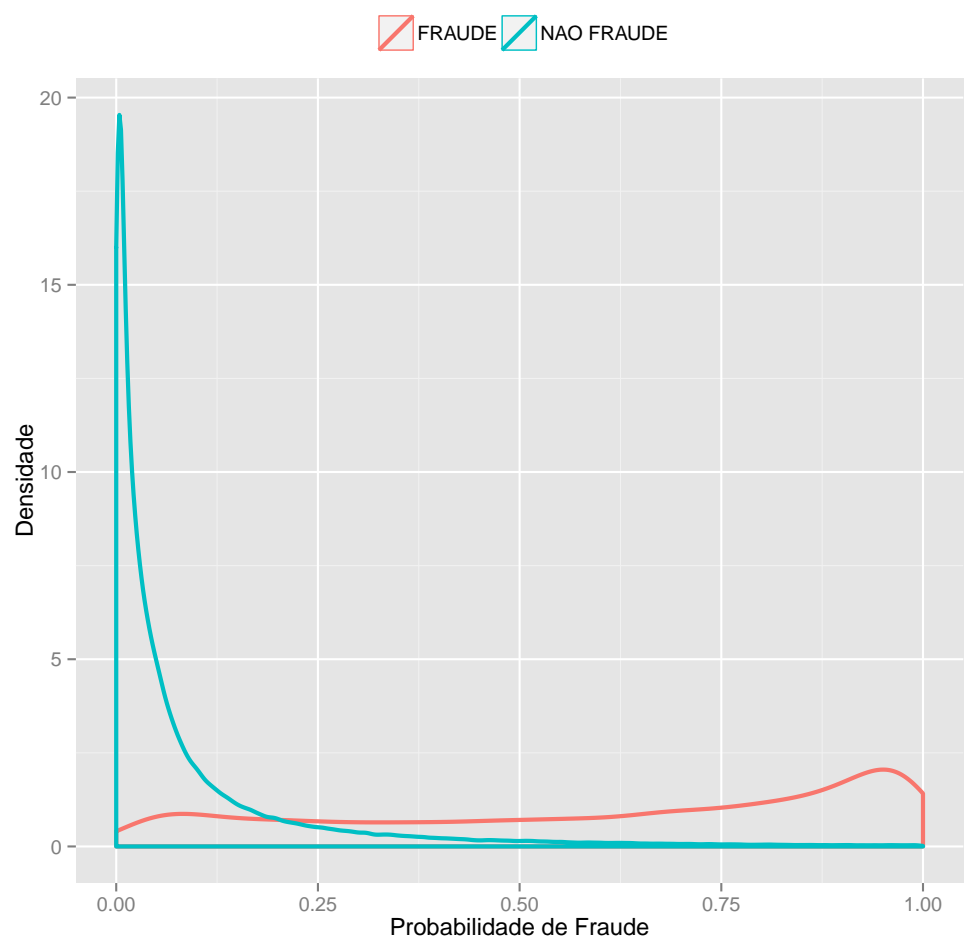

Figura 7.19: Densidade de fraude e não fraude do modelo DMA 95.

O valor de AUC obtido para o modelo DMA 95 foi de 0,929, e pode ser classificado como excelente pela tabela 7.6.

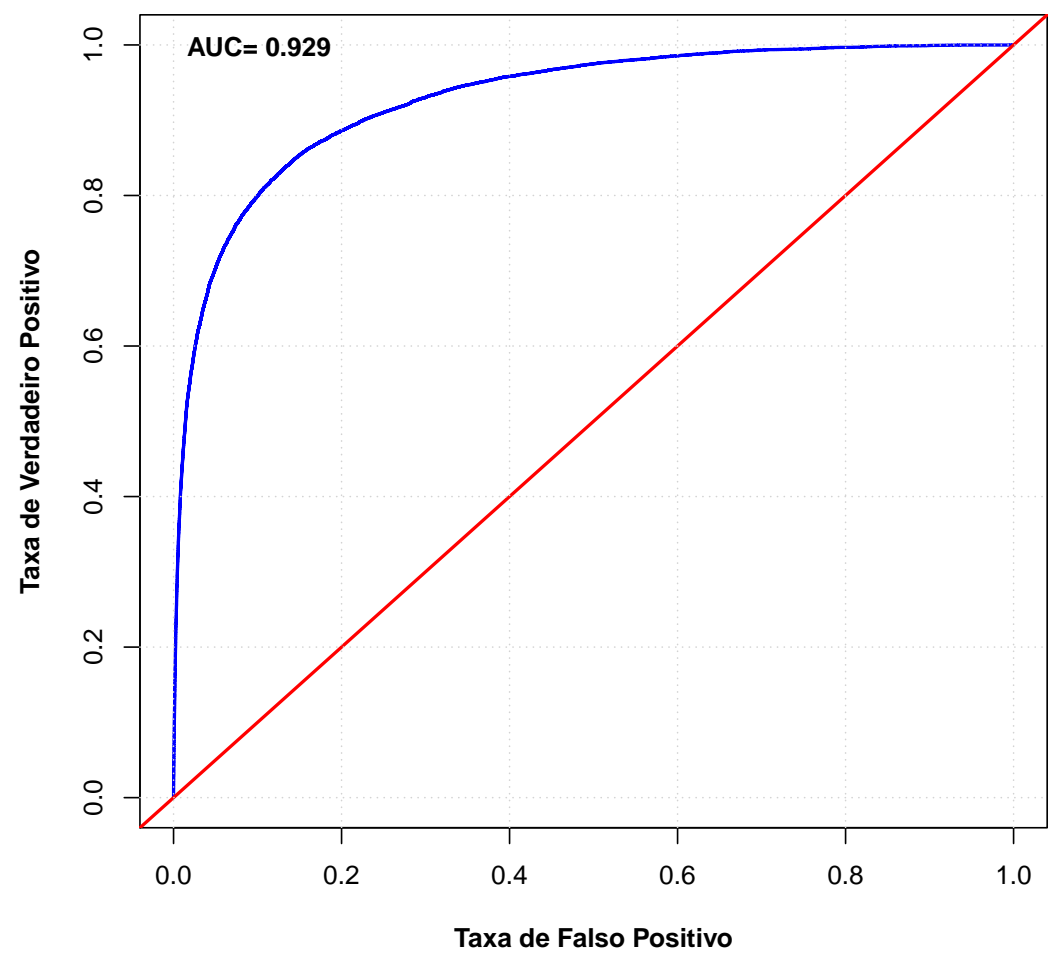

Figura 7.20: Curva ROC da amostra de desenvolvimento do modelo DMA 95. 


\subsubsection{Validação do Modelo}

\section{IEP}

Com um valor de IEP de 0,00157, não houve alteração entre as faixas de pontuação das amostras de desenvolvimento e validação, o que demonstra a estabilidade do modelo DMA 95 ajustado.

\begin{tabular}{|c|c|c|c|}
\hline $\begin{array}{c}\text { Probabiliade } \\
\text { Estimada de } \\
\text { Fraude }\end{array}$ & $\begin{array}{c}\% \text { Amostra } \\
\text { Treinamento }\end{array}$ & $\begin{array}{l}\text { \% Amostra } \\
\text { Validação }\end{array}$ & IEP \\
\hline $0-0,05$ & $55,9 \%$ & $54,3 \%$ & 0,00046 \\
\hline $0,05-0,10$ & $15,3 \%$ & $15,6 \%$ & 0,00006 \\
\hline $0,10-0,15$ & $7,4 \%$ & $7,5 \%$ & 0,00002 \\
\hline $0,15-0,20$ & $4,5 \%$ & $4,5 \%$ & 0,00001 \\
\hline $0,20-0,25$ & $3,0 \%$ & $3,2 \%$ & 0,00009 \\
\hline $0,25-0,30$ & $2,3 \%$ & $2,4 \%$ & 0,00013 \\
\hline $0,30-0,35$ & $1,7 \%$ & $1,8 \%$ & 0,00008 \\
\hline $0,35-0,40$ & $1,4 \%$ & $1,4 \%$ & 0,00000 \\
\hline $0,40-0,45$ & $1,1 \%$ & $1,2 \%$ & 0,00011 \\
\hline $0,45-0,50$ & $0,9 \%$ & $1,0 \%$ & 0,00008 \\
\hline $0,50-0,55$ & $0,8 \%$ & $0,8 \%$ & 0,00000 \\
\hline $0,55-0,60$ & $0,7 \%$ & $0,8 \%$ & 0,00008 \\
\hline $0,60-0,65$ & $0,6 \%$ & $0,7 \%$ & 0,00001 \\
\hline $0,65-0,70$ & $0,6 \%$ & $0,6 \%$ & 0,00000 \\
\hline $0,70-0,75$ & $0,5 \%$ & $0,6 \%$ & 0,00006 \\
\hline $0,75-0,80$ & $0,5 \%$ & $0,5 \%$ & 0,00000 \\
\hline $0,80-0,85$ & $0,5 \%$ & $0,6 \%$ & 0,00004 \\
\hline $0,85-0,90$ & $0,6 \%$ & $0,6 \%$ & 0,00001 \\
\hline $0,90-0,95$ & $0,7 \%$ & $0,7 \%$ & 0,00002 \\
\hline $0,95-1,00$ & $0,9 \%$ & $1,1 \%$ & 0,00030 \\
\hline Total & $100,0 \%$ & $100,0 \%$ & 0,00157 \\
\hline
\end{tabular}

Figura 7.21: Indice de estabilidade populacional do modelo DMA 95. 
Os gráficos de boxplot, histograma e densidade (figuras 7.22, 7.23 e 7.24, respectivamente) apresentaram representações similares para as transações não fraude e fraude para as amostras de desenvolvimento e validação.

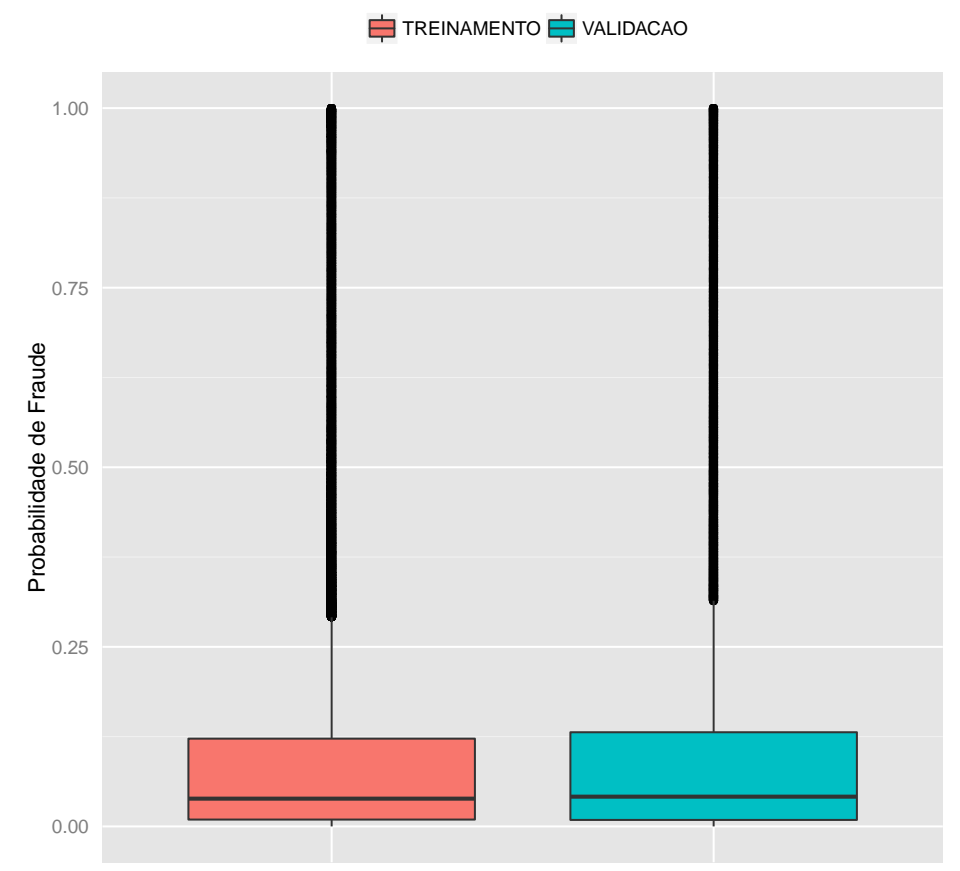

Figura 7.22: Boxplox das amostras de treinamento e validação do modelo DMA 95.

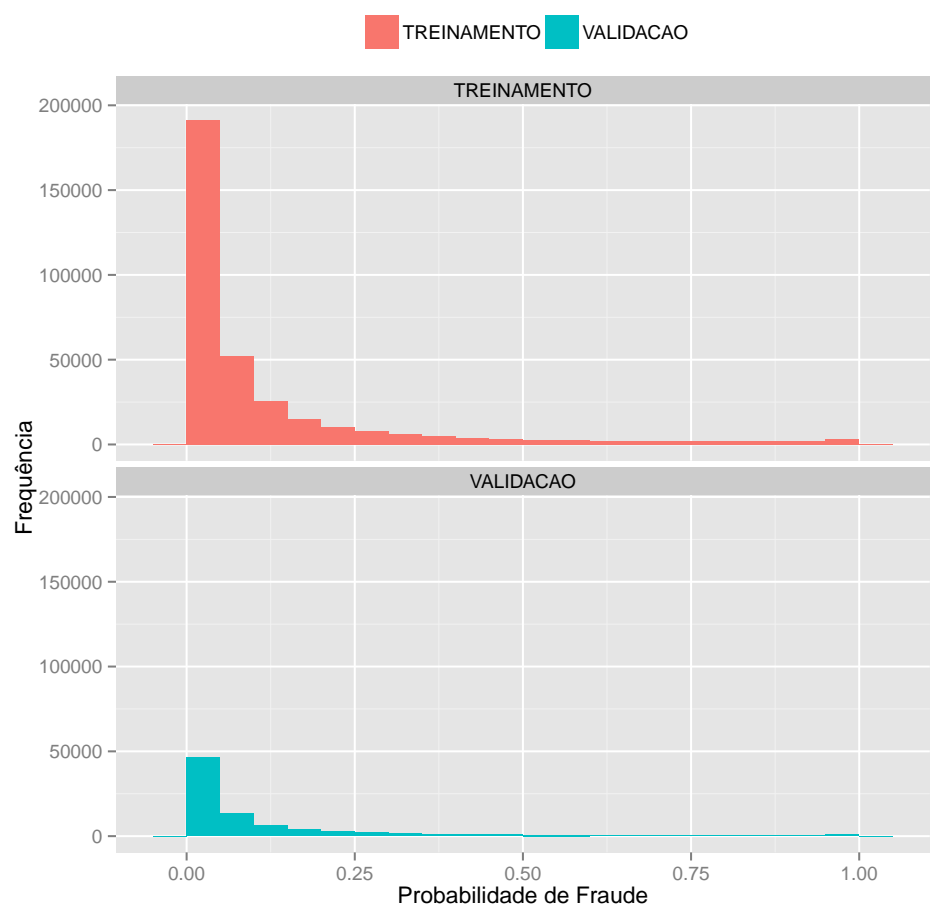

Figura 7.23: Histograma das amostras de treinamento e validação do modelo DMA 95. 


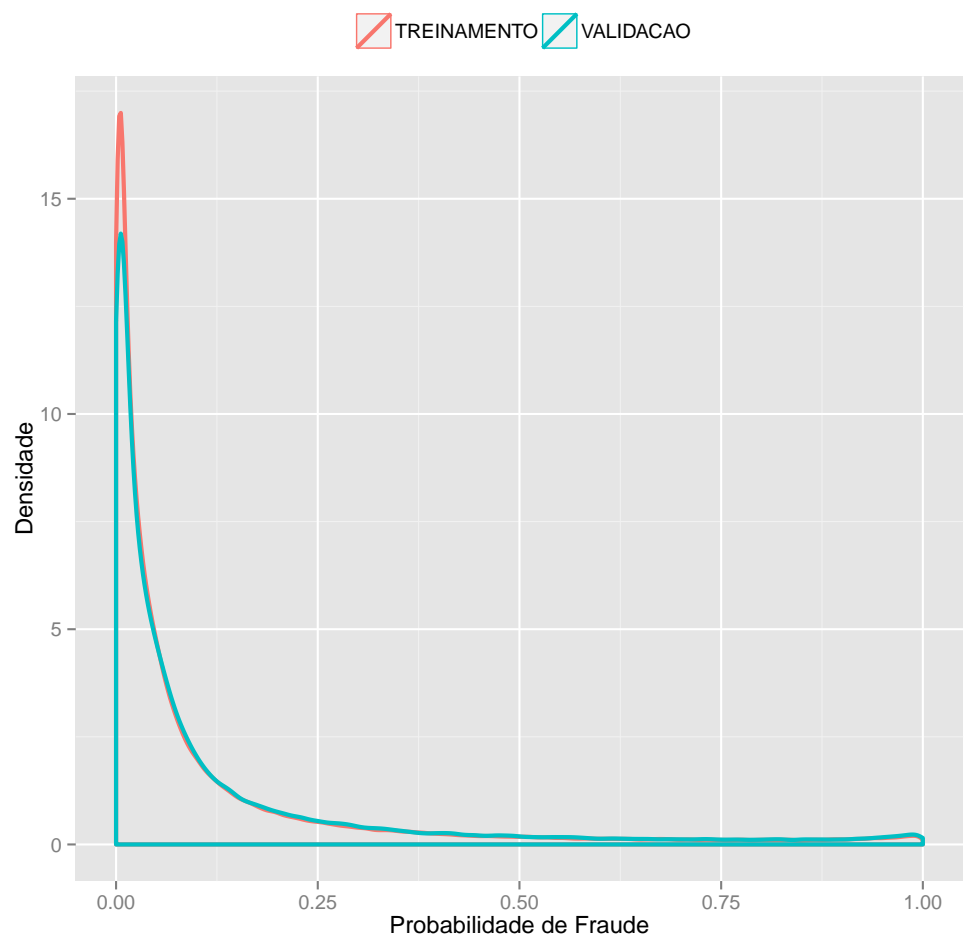

Figura 7.24: Densidade das amostras de treinamento e validação do modelo DMA 95.

O valor obtido da AUC para a amostra de validação é de 0,923, classificado como excelente pela tabela 7.6.

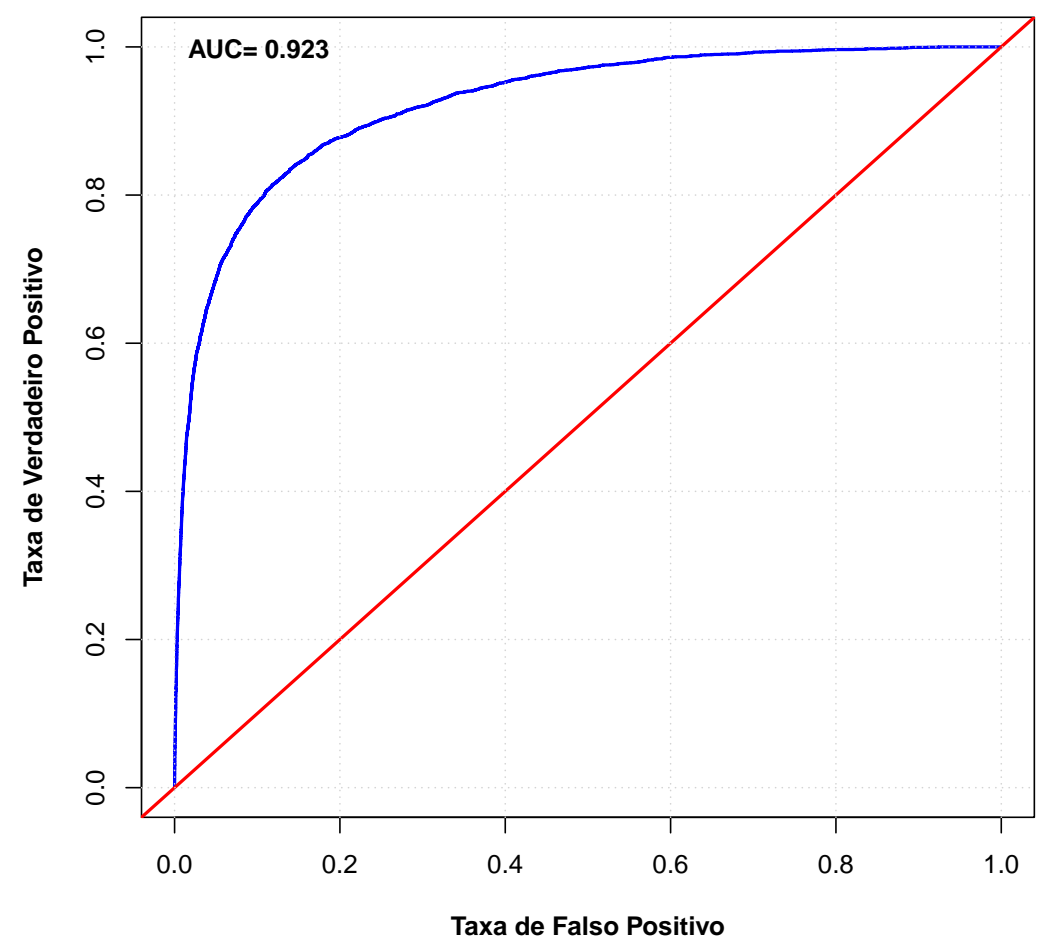

Figura 7.25: Curva ROC da amostra de validação do modelo DMA 95. 


\subsubsection{Indicadores de Performance}

Na tabela 7.15, observamos uma classificação correta para o grupo não fraude de $98 \%$ e para o fraude de $60 \%$. Em geral, o modelo DMA 95 classificou corretamente $96 \%$ das transações.

\begin{tabular}{lccc}
\hline \hline Classificado & \multicolumn{2}{c}{ Observado } & \% Classificação \\
\cline { 2 - 3 } pelo Modelo & Fraude & Não Fraude & Correta \\
\hline Fraude & 10.220 & 6.787 & $60 \%$ \\
Não Fraude & 7.872 & 317.726 & $98 \%$ \\
\hline \% Classificação Correta & & $96 \%$ \\
\hline
\end{tabular}

Tabela 7.15: Tabela de classificação das transações pelo modelo DMA 95 (ponto de corte para probabilidade $=0,6)$.

Os indicadores de performance para a amostra de desenvolvimento e validação apresentaram valores muito similares com diferenças não significativas.

Na tabela 7.16, os indicadores de acurácia e área sob a curva ROC indicam que o modelo teve uma boa performance para classificar as transações em geral, com valores de 95,7\% e 92,9\%, respectivamente. Como esperado, a precisão é maior para transações não fraude $(97,6 \%)$ do que para fraude $(60,1 \%)$.

De todas as transações não fraude classificadas originalmente, o modelo conseguiu identificar $97,9 \%$ (especificidade). Já para as transações fraudulentas, foram identificadas 56,5\% do total de fraudes (taxa de detecção/sensibilidade) com taxa de falso positivo de $2,1 \%$. A relação não fraude/fraude ficou em 0,7 .

\begin{tabular}{lcc}
\hline \hline \multirow{2}{*}{ Indicadores } & \multicolumn{2}{c}{ Amostra } \\
\cline { 2 - 3 } & Desenvolvimento & Validação \\
\hline Classificação de Fraude & $56,5 \%$ & $57,0 \%$ \\
Taxa de Deteçã̃o (Cobertura) & $2,1 \%$ & $2,5 \%$ \\
Taxa de Falso Positivo & 0,7 & 0,8 \\
Relação Não Fraude/Fraude & $60,1 \%$ & $56,4 \%$ \\
Precisão (Fraude) & & \\
Classificação de Não Fraude & $97,9 \%$ & $97,5 \%$ \\
Especificidade & $97,6 \%$ & $97,6 \%$ \\
Precisão (Não Fraude) & & \\
Classificação Geral & $95,7 \%$ & $95,4 \%$ \\
Acurácia & $92,9 \%$ & $92,3 \%$ \\
Área sob a curva ROC & $58,2 \%$ & $56,7 \%$ \\
Medida F &
\end{tabular}

Tabela 7.16: Indicadores de performance do modelo DMA 95. 


\subsection{Sumário dos Resultados Experimentais}

Com o objetivo de compararmos a técnica de regressão logística clássica com a técnica DMA, desenvolvemos 2 modelos para cada tipo de técnica.

Para regressão logística clássica, desenvolvemos um modelo que utiliza somente a seleção de variáveis feita pela técnica stepwise, selecionando 25 variáveis, e outro que chamamos de stepwise modificado, em que um especialista do domínio, no caso um especialista de fraude, incluiu 5 variáveis que acredita serem importantes para a identificação de transações fraudulentas. Com a inclusão dessas variáveis pelo especialista, outras 2 ficaram com as estimativas dos parâmetros não significantes (valor-p >0,05) e foram eliminadas, resultando em 28 variáveis.

Para a técnica DMA, também foram desenvolvidos dois modelos, um utilizando $\lambda=\alpha=0,95$, o qual apresentou a melhor performance na avaliação da medida F e AUC, e outro com $\lambda=\alpha=0,99$, o qual teve desempenho um pouco inferior, ainda melhor que os dois modelos de regressão logística clássica (tabela 7.11).

Para ambos os modelos, as estimativas dos parâmetros foram estatisticamente significantes (valor-p $<0,05)$ (tabelas 7.1 e C.1), bem como para os testes globais para $\beta=0$, Máxima Verossimilhança, Score e Wald (valor-p < 0,0001) (tabelas 7.2 e C.2 ). Os resíduos do modelo apresentaram uma distribuição no intervalo entre -2 e 2 (figuras 7.5 e C.1), considerado um comportamento assintótico adequado devido ao tamanho da amostra.

Já para os modelos DMA, os valores das estimativas de $\theta$ e suas respectivas variâncias são atualizados dinamicamente no tempo. Para valores de $\theta$ distantes de zero, significa que o parâmetro contribui mais positivamente ou negativamente para a predição naquele momento t (figuras 7.17, B.1, D.5 e D.6).

A média dos resíduos ficou próxima de zero para ambos os modelos $(-0,06$ e -0,08) e apresentou uma distribuição no intervalo entre -1 e 1 (figuras 7.18 e D.7).

Sobre as medidas de ajuste, o KS apresentou discriminação classificada como muito bom $(\mathrm{KS}=48 \%)$ para o modelo Stepwise e excelente $(\mathrm{KS}=52 \%)$ para o modelo Stepwise modificado (figuras 7.4 e C.3). Para a AUC, o desempenho para ambos os modelos foi classificada como bom, $82 \%$ e $84 \%$, respectivamente (figuras 7.7 e C.3).

Para os modelos DMA 95 e DMA 99, obtivemos valores de $\mathrm{KS}=70 \%$ e $\mathrm{KS}=61 \%$, respectivamente (figuras 7.13 e D.1). Sendo assim, foram classificados com um poder de discriminação excelente. Os valores e AUC foram de 88\% (boa performance) e 93\% (excelente performance) (figuras 7.20 e D.9).

$\mathrm{Na}$ validação do modelo, o IEP apresentou valores que indicam a estabilidade para ambos os modelos (0,0003 e 0,02995) (figuras 7.8 e C.5). Os gráficos de boxplot, histograma, densidade e AUC também apresentaram distribuições similares para a amostra de desenvolvimento e validação (figuras 7.9,7.10, 7.11, 7.12 para o modelo Stepwise e figuras C.4, C.5, C.6 e C.7 para o modelo Stepwise Modificado).

Da mesma forma, os modelos DMA 95 e DMA 99 apresentaram valores de IEP de 0,00157 
e 0,01072 (figuras 7.21 e D.3), bem como os gráficos de boxplot, histograma, densidade e AUC apresentaram distribuições similares ao compararmos as amostras de desenvolvimento e validação (figuras 7.22, 7.23, 7.24 e 7.25 para o modelo DMA 95 e figuras D.10, D.11, D.12 e D.13 para o modelo DMA 99).

Desta maneira, todos os quatro modelos apresentaram estabilidade para utilização em transações futuras.

\subsection{Comparação Final dos Modelos}

Conforme apresentado na tabela 7.17, avaliando separadamente a performance dos modelos de regressão logística clássica e DMA, temos que o modelo Stepwise Modificado e o DMA $95(\lambda=\alpha=0,95)$ apresentaram os melhores indicadores de performance.

No entanto, de maneira geral, nota-se que os modelos DMA têm melhor performance para todos os indicadores em relação aos modelos de regressão logística clássica, exceto para a taxa de detecção, em que apresenta, aproximadamente, uma diferença de $10 \%$ se compararmos o modelo Stepwise e DMA 95.

\begin{tabular}{lcccc}
\hline \hline \multirow{2}{*}{ Indicadores } & \multicolumn{4}{c}{ Modelos } \\
\cline { 2 - 5 } & Stepwise & $\begin{array}{c}\text { Stepwise } \\
\text { Modificado }\end{array}$ & $\begin{array}{c}\text { DMA 99 } \\
(\lambda=\alpha=0,99)\end{array}$ & $\begin{array}{c}\text { DMA 95 } \\
(\lambda=\alpha=0,95)\end{array}$ \\
\hline Classificação de Fraude & & & \\
Taxa de Detecção & $62,9 \%$ & $\mathbf{6 6 , 2 \%}$ & $50,8 \%$ & $56,5 \%$ \\
Taxa de Falso Positivo & $16,9 \%$ & $16,1 \%$ & $3,7 \%$ & $\mathbf{2 , 1 \%}$ \\
Relação Não Fraude/Fraude & 4,8 & 4,4 & 1,3 & $\mathbf{0 , 7}$ \\
Precisão (Fraude) & $17,2 \%$ & $18,7 \%$ & $43,2 \%$ & $\mathbf{6 0 , 1 \%}$ \\
Classificação de Não Fraude & & & & \\
Especificidade & $83,1 \%$ & $83,9 \%$ & $96,3 \%$ & $\mathbf{9 7 , 9 \%}$ \\
Precisão (Não Fraude) & $97,6 \%$ & $\mathbf{9 7 , 8 \%}$ & $97,2 \%$ & $97,6 \%$ \\
Classificação Geral & & & & \\
KS & $48,1 \%$ & $52,1 \%$ & $61,3 \%$ & $\mathbf{7 0 , 4 \%}$ \\
IEP & $\mathbf{0 , 0 0 0 3 0}$ & 0,02995 & 0,01072 & 0,00157 \\
Acurácia & $82,1 \%$ & $83,0 \%$ & $93,9 \%$ & $\mathbf{9 5 , 7 \%}$ \\
Área sob a curva ROC & $81,7 \%$ & $83,9 \%$ & $88,3 \%$ & $\mathbf{9 2 , 9 \%}$ \\
Medida F & $27,0 \%$ & $29,2 \%$ & $46,7 \%$ & $\mathbf{5 8 , 2 \%}$ \\
\hline
\end{tabular}

Valores em negrito indicam os melhores resultados.

Tabela 7.17: Comparação da performance dos modelos ajustados. 
Na figura 7.26 são apresentadas as curvas e valores de AUC para os 4 modelos desenvolvidos. Se usarmos o modelo Stepwise como base de comparação, temos que o modelo Stepwise Modificado, DMA 99 e DMA 95 tiveram, respectivamente, performance relativa de 3\%, 8\% e $14 \%$ melhor.

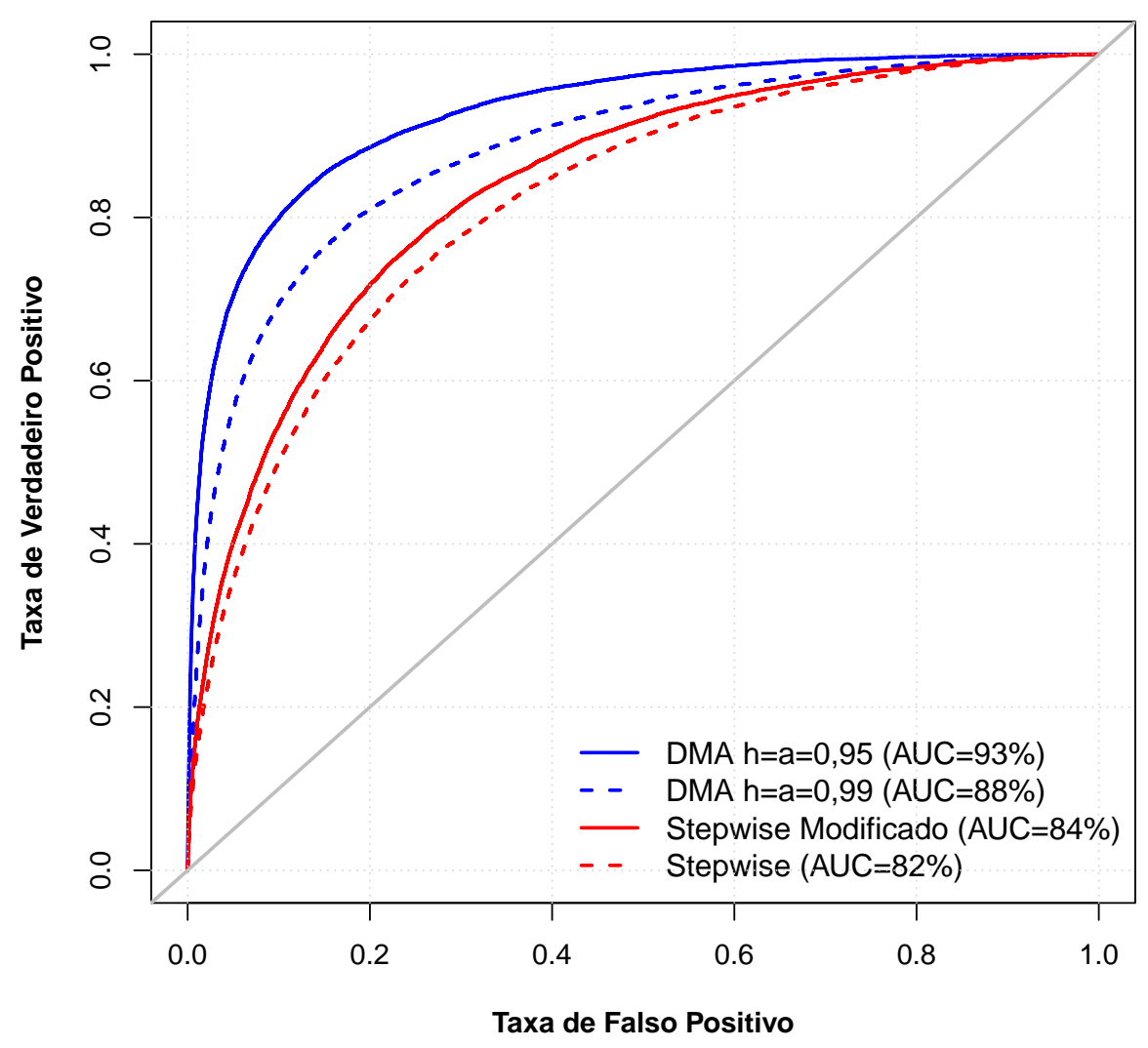

Figura 7.26: Curva ROC dos modelos ajustados.

Como temos interesse na taxa de detecção e precisão de fraude dos modelos desenvolvidos, podemos usar a medida F para comparar a performance entre eles. Na tabela 7.18, observamos que os modelos DMA apresentaram melhor performance e, em particular, o DMA 95.

\begin{tabular}{lc}
\hline \hline Modelo & Medida $\mathbf{F}$ \\
\hline DMA $95(\lambda=\alpha=0,95)$ & $\mathbf{5 8 \%}$ \\
DMA $99(\lambda=\alpha=0,99)$ & $47 \%$ \\
Stepwise Modificado & $29 \%$ \\
Stepwise & $27 \%$ \\
\hline
\end{tabular}

Tabela 7.18: Valores da medida F para os modelos ajustados. 


\section{Capítulo 8}

\section{Conclusões e Trabalhos Futuros}

\subsection{Conclusões}

O nosso trabalho investigou a utilização do método DMA aplicado ao modelo de regressão logística bayesiana para a identificação de transações fraudulentas no ambiente de comércio eletrônico. Essa abordagem permitiu que os modelos e as variáveis preditoras selecionadas a priori pelo método de Occam's Window fossem atualizadas ao longo do tempo.

No nosso experimento, apesar dos dados de fraude serem desbalanceados, os modelos DMA desenvolvidos apresentaram resultados melhores que os modelos de regressão logística clássica utilizando a técnica Stepwise, mesmo que melhorado com a intervenção de um especialista do domínio.

O modelo DMA $95(\lambda=\alpha=0,95)$ apresentou os melhores indicadores de performance na classificação de transações fraudulentas.

Considerando os resultados encontrados para os modelos DMA, sua característica de atualização ao longo do tempo se mostra como um grande diferencial em dados como os de fraude, que sofrem mudanças de comportamento a todo momento.

Deste modo, sua aplicação se mostra adequada no processo de detecção de transações fraudulentas no ambiente de comércio eletrônico.

\subsection{Trabalhos Futuros}

É de grande importância no desenvolvimento de qualquer tipo de modelo a disponibilidade de variáveis preditoras que se relacionam com a variável resposta. No decorrer do experimento, notamos uma oportunidade para o desenvolvimento de um algoritmo específico que consiga analisar a similaridade do nome do comprador ou nome do portador do cartão com o endereço de e-mail informado.

Apesar de utilizarmos no trabalho dois algoritmos de aproximação de caracteres conhecidos como OSA (Optimal String Alignment distance) e Q-GRAM (sequência de caracteres), que apresentaram forte poder de discriminação analisando o valor de informação (figura 6.2), 
um trabalho futuro seria a criação de um algoritmo eficiente que realize a comparação do nome do comprador com o endereço de e-mail de maneira que discrimine os casos de não fraude e fraude. 


\section{Apêndices}

A Análise Descritiva 


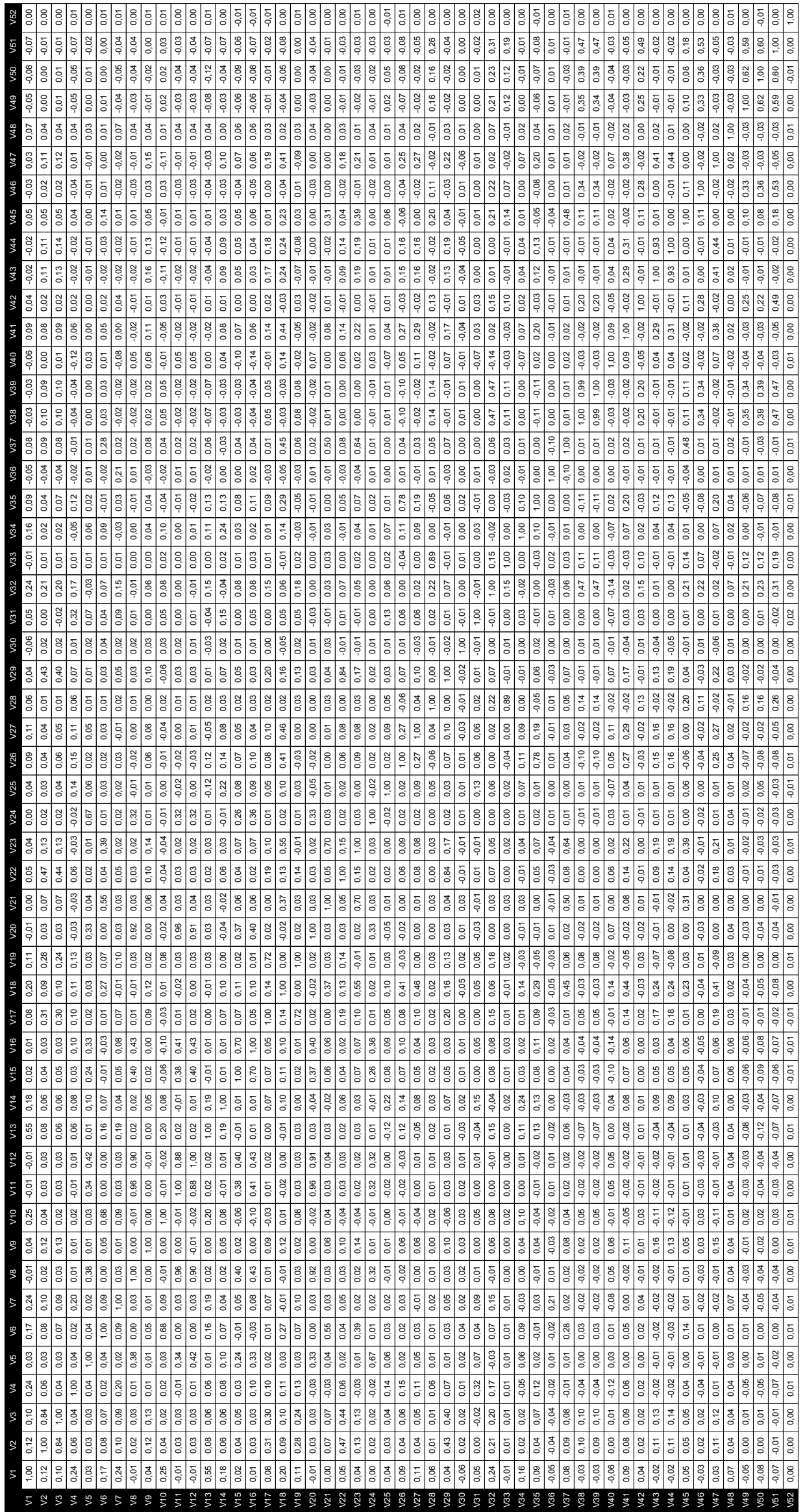

Tabela A.1: Matriz de correlação das variáveis candidatas. 


\section{B Variância do Modelo DMA $95(\lambda=\alpha=0,95)$}
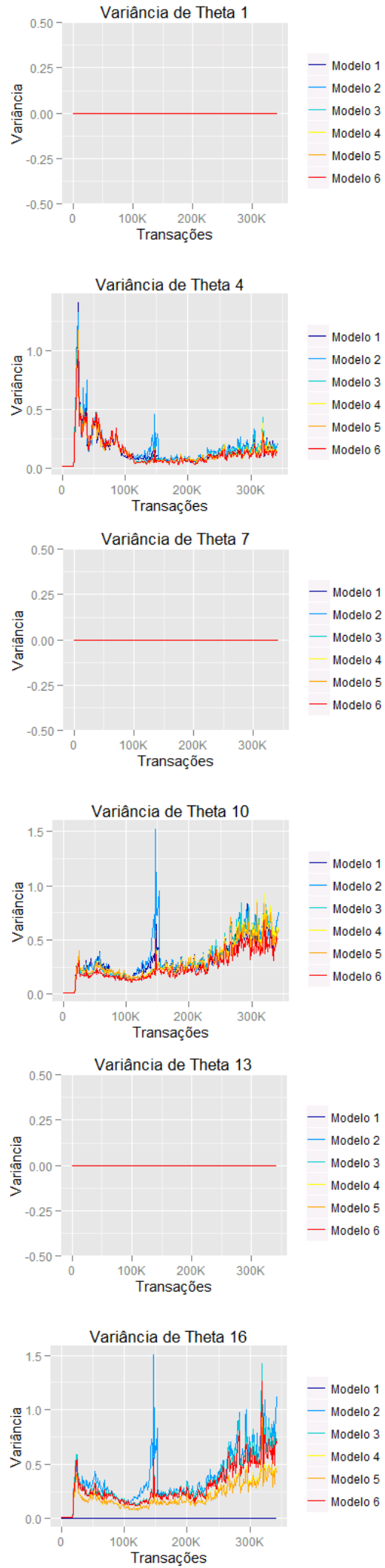
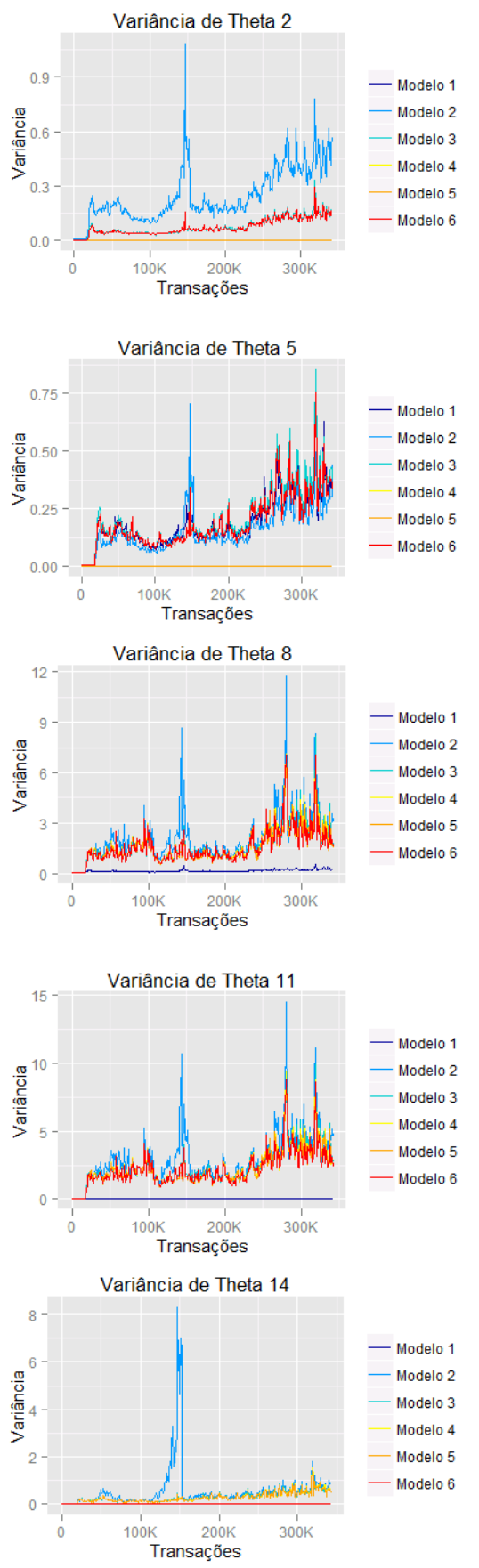

-Modelo 1
- Modelo 2
- Modelo 3
Modelo 4
- Modelo 5
- Modelo 6

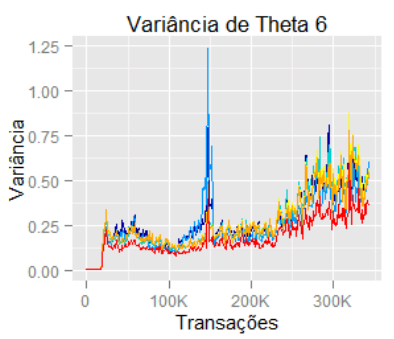

-Modelo 1
- Modelo 2
- Modelo 3
Modelo 4
- Modelo 5
- Modelo 6

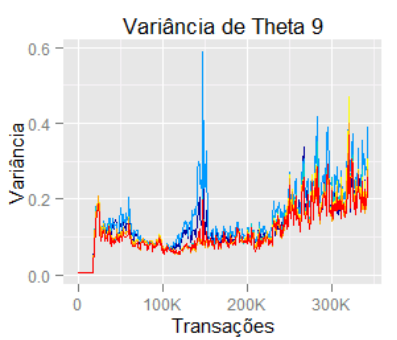

- Modelo 1

— Modelo 2

- Modelo 3

Modelo 4

- Modelo 5

- Modelo 6

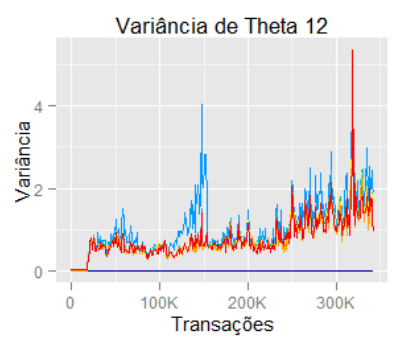

-Modelo 1
- Modelo 2
- Modelo 3
Modelo 4
- Modelo 5
- Modelo 6

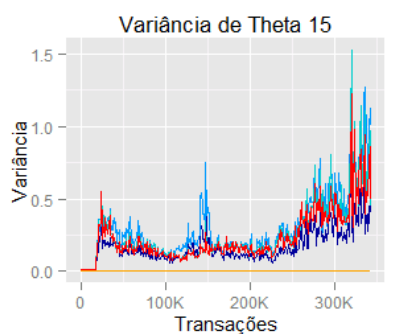

- Modelo 1

- Modelo 2

- Modelo 3

Modelo 4

- Modelo 5

- Modelo 6

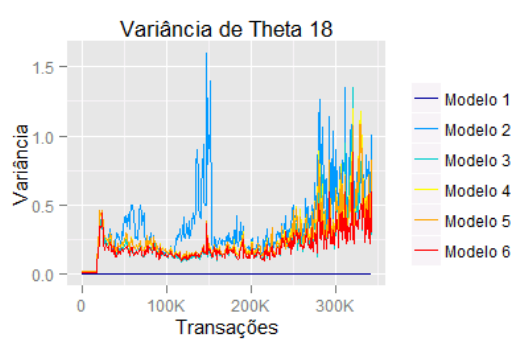



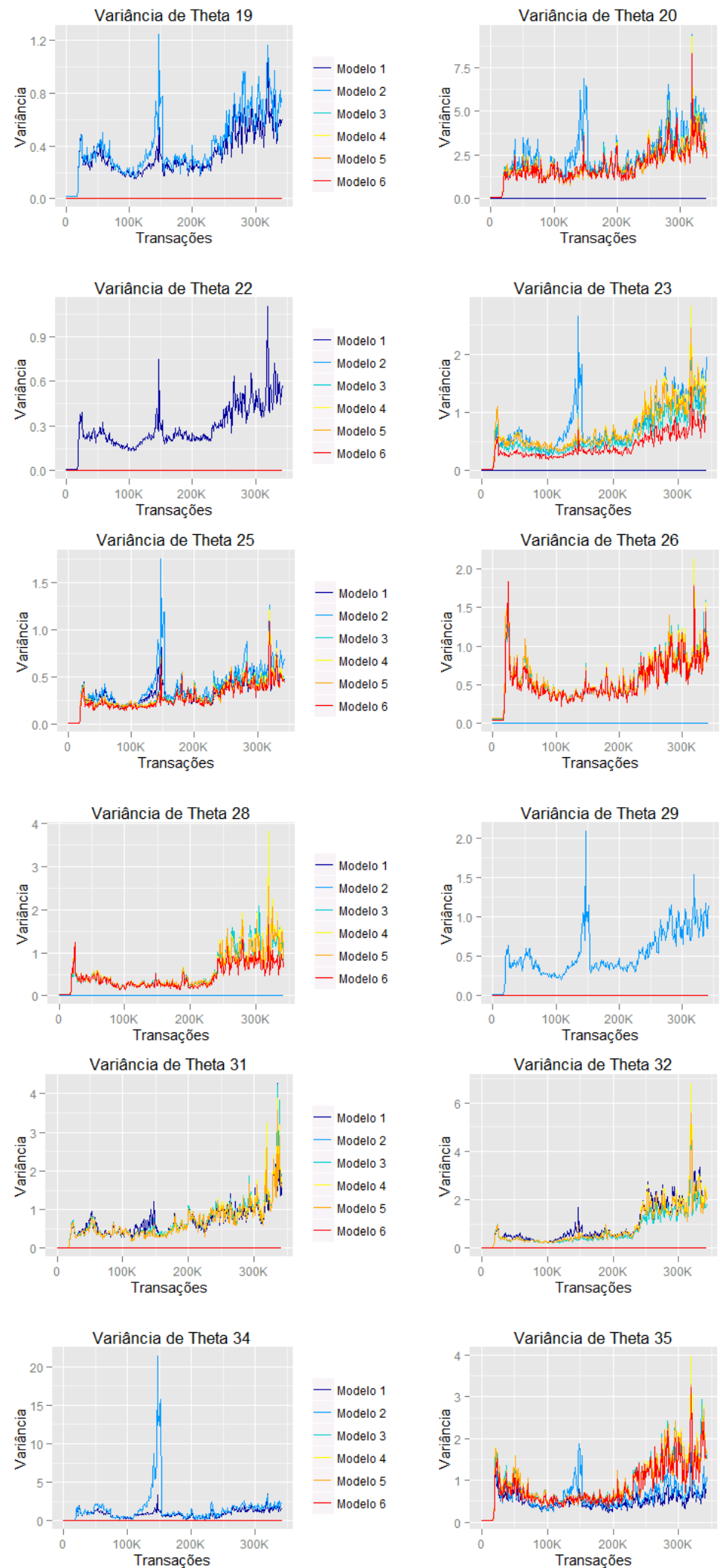
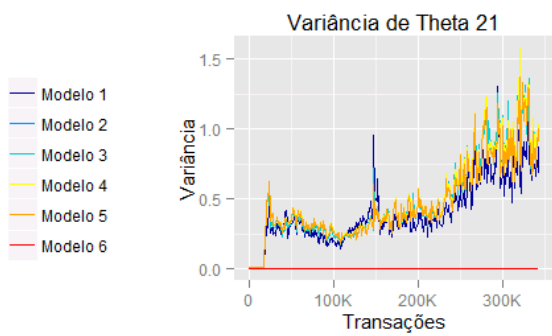

- Modelo 1

— Modelo 2

- Modelo 3

Modelo 4

- Modelo 5
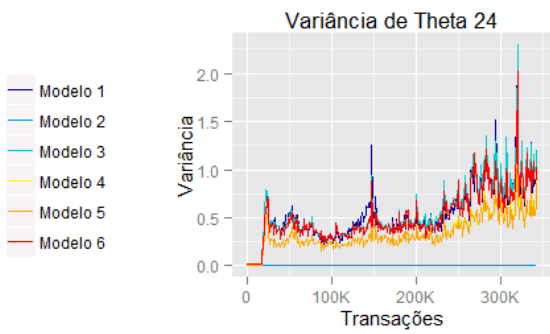

— Modelo 1

- Modelo 2

- Modelo 3

Modelo 4

- Modelo 5

- Modelo 6

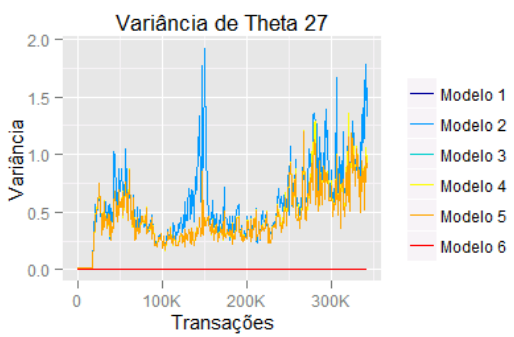

— Modelo 1

- Modelo 2

- Modelo 3

Modelo 4

- Modelo 5

— Modelo 6

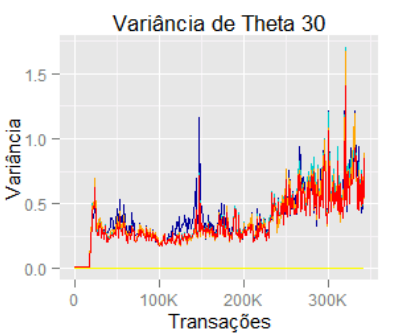

- Modelo 1

- Modelo 1

- Modelo 2

- Modelo 3

Modelo 4

- Modelo 5

— Modelo 6

- Modelo 1

— Modelo 2

- Modelo 3

Modelo 4

- Modelo 5

- Modelo 6

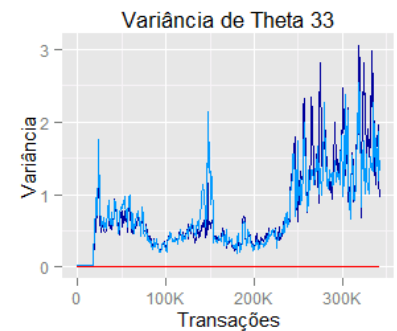

— Modelo 1

- Modelo 2

- Modelo 3

Modelo 4

- Modelo 5

—Modelo 6

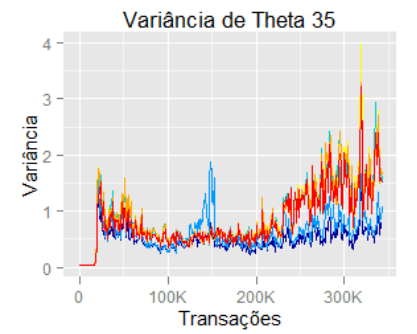

- Modelo 1

— Modelo 2

- Modelo 3

Modelo 4

- Modelo 5

- Modelo 6

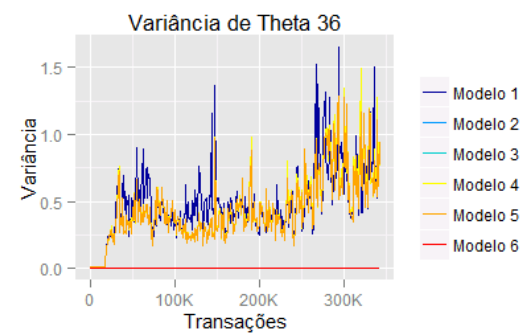




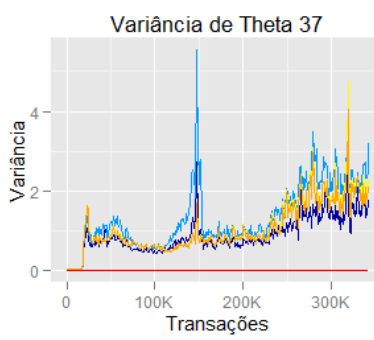

- Modelo 1

- Modelo 2

- Modelo 3

Modelo 4

- Modelo 5

- Modelo 6

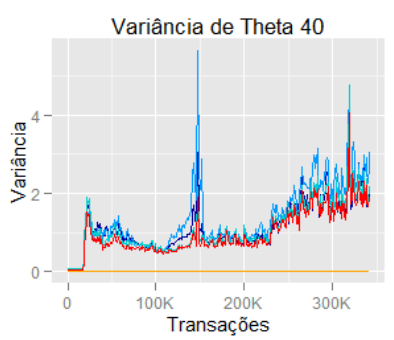

- Modelo 1
- Modelo 2
- Modelo 3
Modelo 4
- Modelo 5
- Modelo 6

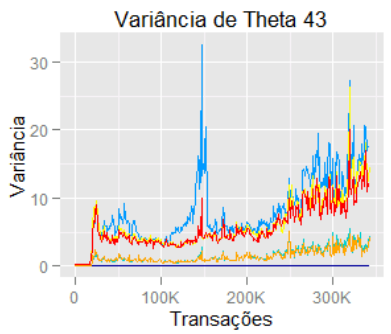

- Modelo 1

- Modelo 2

— Modelo 3

Modelo 4

- Modelo 5

- Modelo 6
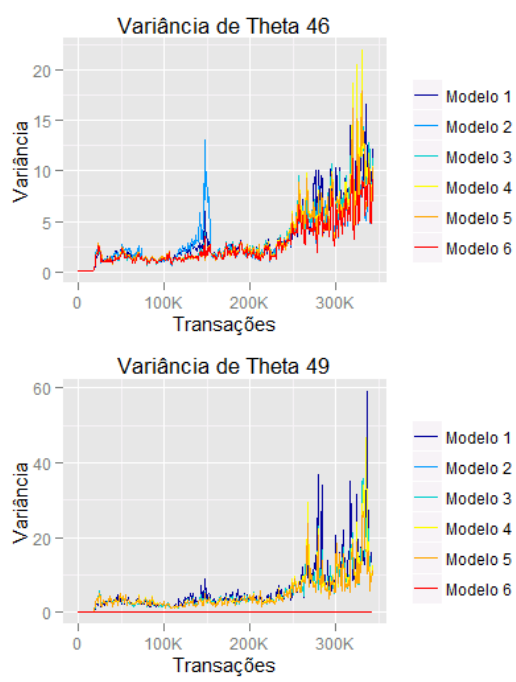

- Modelo 1

- Modelo 2

- Modelo 3

Modelo 4

- Modelo 5

— Modelo 6

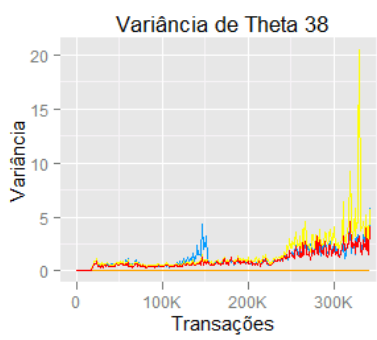

- Modelo 1

- Modelo 2

- Modelo 3

Modelo 4

-Modelo 5

- Modelo 6

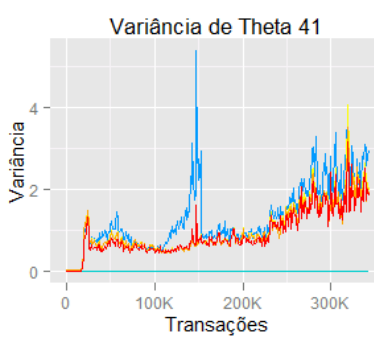

- Modelo

- Modelo 2

- Modelo 3

Modelo 4

- Modelo 5

— Modelo 6

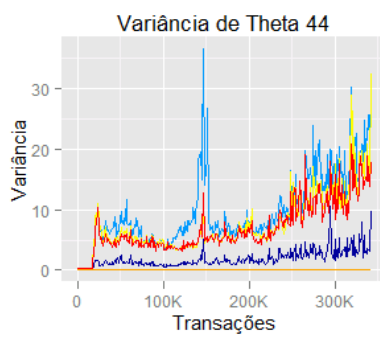

- Modelo 1
- Modelo 2
- Modelo 3
Modelo 4
- Modelo 5
- Modelo 6
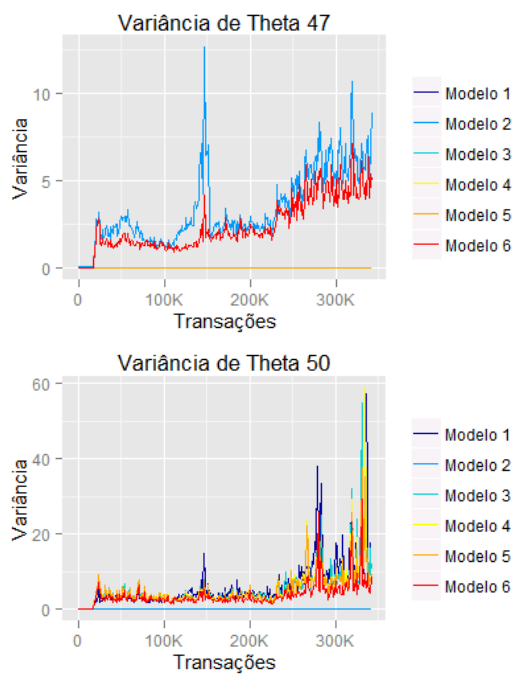

- Modelo 1

- Modelo 2

- Modelo 3

Modelo 4

- Modelo 5

- Modelo 6

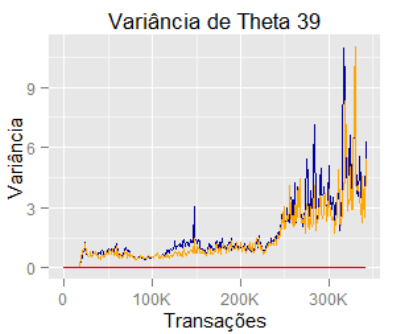

- Modelo

— Modelo 2

- Modelo 3

Modelo 4

- Modelo 5

— Modelo 6
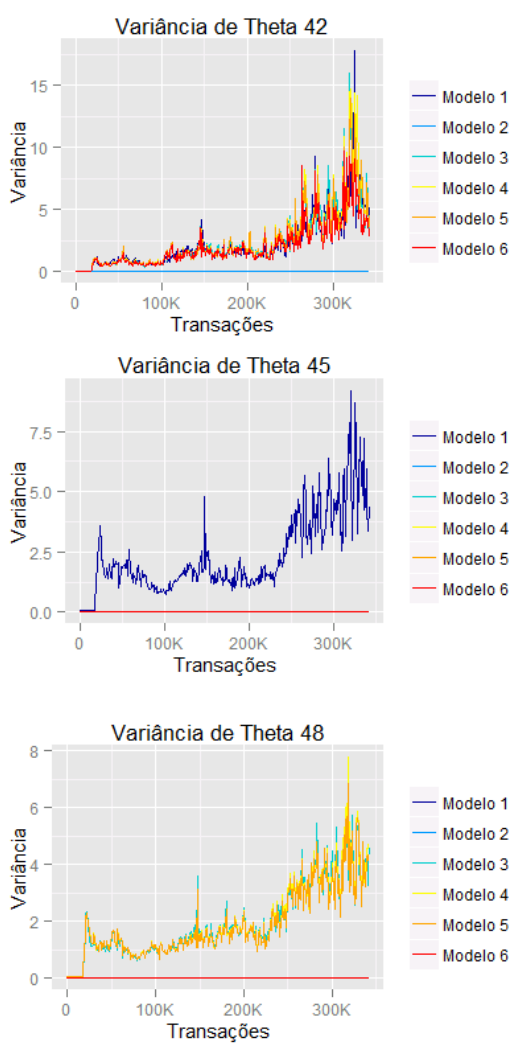

- Modelo 1

- Modelo 2

- Modelo 3

Modelo 4

Modelo 5

- Modelo 6

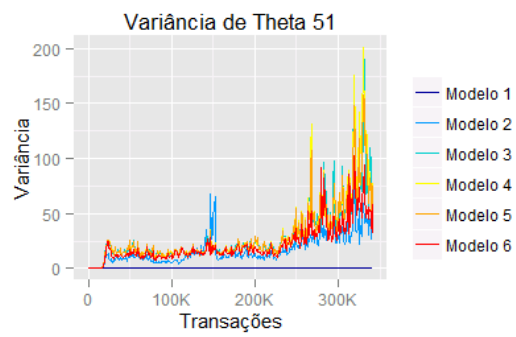

Figura B.1: Variância dos parâmetros dos modelos selecionados para o modelo DMA 95 a cada 1.000 transações no tempo. 


\section{Modelo de Regressão Logística Clássica com Stepwise Modificado}

\begin{tabular}{|c|c|c|c|c|}
\hline $\begin{array}{c}\# \\
\text { Variáveis }\end{array}$ & Variável & $\begin{array}{c}\text { Estimativa } \\
\text { (Beta) }\end{array}$ & $\begin{array}{c}\text { Erro } \\
\text { Padrão }\end{array}$ & Valor-p \\
\hline 1 & V03 & 0,704 & 0,008 & $<0,0001$ \\
\hline 2 & V04 & 0,756 & 0,007 & $<0,0001$ \\
\hline 3 & V06 & 0,685 & 0,009 & $<0,0001$ \\
\hline 4 & V07 & 0,45 & 0,008 & $<0,0001$ \\
\hline 5 & V09 & 0,877 & 0,01 & $<0,0001$ \\
\hline 6 & V11 & 0,769 & 0,01 & $<0,0001$ \\
\hline 7 & V13 & 0,529 & 0,009 & $<0,0001$ \\
\hline 8 & V16 & 0,605 & 0,011 & $<0,0001$ \\
\hline 9 & V17 & 0,461 & 0,011 & $<0,0001$ \\
\hline 10 & V18 & 0,096 & 0,014 & $<0,0001$ \\
\hline 11 & V21 & 0,419 & 0,018 & $<0,0001$ \\
\hline 12 & V23 & $-0,223$ & 0,022 & $<0,0001$ \\
\hline 13 & V27 & 0,655 & 0,019 & $<0,0001$ \\
\hline 14 & V28 & 0,358 & 0,04 & $<0,0001$ \\
\hline 15 & V30 & 0,979 & 0,017 & $<0,0001$ \\
\hline 16 & V33 & 0,732 & 0,045 & $<0,0001$ \\
\hline 17 & V34 & 1,044 & 0,022 & $<0,0001$ \\
\hline 18 & V35 & 0,126 & 0,018 & $<0,0001$ \\
\hline 19 & V36 & 0,818 & 0,017 & $<0,0001$ \\
\hline 20 & V40 & 1,646 & 0,025 & $<0,0001$ \\
\hline 21 & V42 & 0,536 & 0,03 & $<0,0001$ \\
\hline 22 & V44 & 0,496 & 0,034 & $<0,0001$ \\
\hline 23 & V45 & $-0,372$ & 0,034 & $<0,0001$ \\
\hline 24 & V46 & 0,749 & 0,039 & $<0,0001$ \\
\hline 25 & V47 & $-0,873$ & 0,04 & $<0,0001$ \\
\hline 26 & V49 & 0,828 & 0,051 & $<0,0001$ \\
\hline 27 & V50 & 1,685 & 0,055 & $<0,0001$ \\
\hline 28 & V51 & $-2,227$ & 0,123 & $<0,0001$ \\
\hline
\end{tabular}

Tabela C.1: Variáveis selecionadas e estimativas dos parâmetros do modelo com stepwise modificado. 


\begin{tabular}{lccc}
\hline \hline Testes & Qui-quadrado & GL & Valor-p \\
\hline Teste Global da Hipótese Nula Beta=0 & & & \\
$\quad$ Máxima Verossimilhança & 137.501 & 28 & $<0,0001$ \\
$\quad$ Score & 114.912 & 28 & $<0,0001$ \\
Wald & 810.013 & 28 & $<0,0001$ \\
Qualidade do Ajuste & & & \\
$\quad$ Hosmer e Lemeshow & 218.007 & 8 & $<0,0001$ \\
\hline
\end{tabular}

Tabela C.2: Testes para avaliação do modelo ajustado com stepwise modificado.

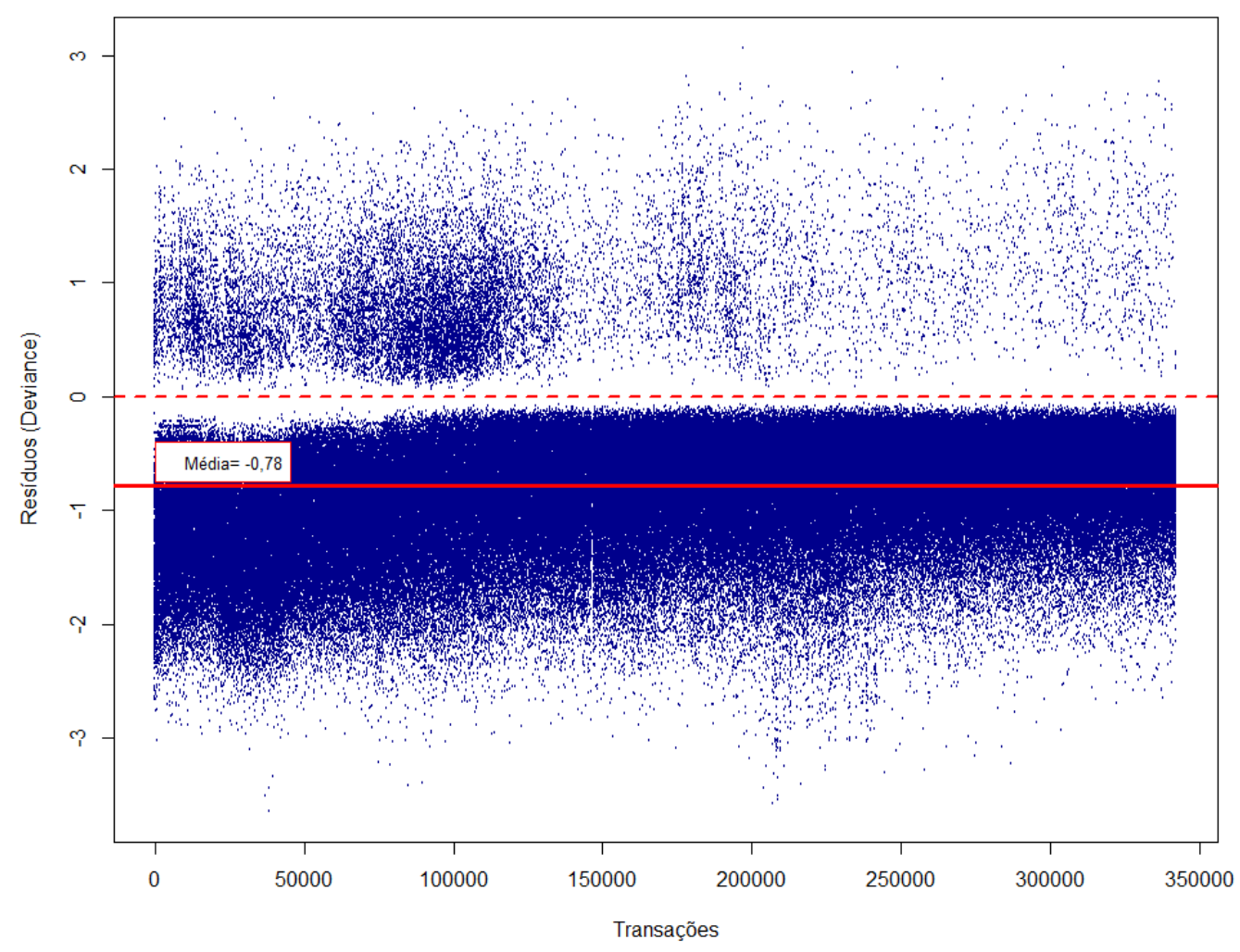

Figura C.1: Resíduos deviance do modelo ajustado com stepwise modificado. 


\begin{tabular}{|c|c|c|c|}
\hline $\begin{array}{c}\text { Probabiliade } \\
\text { Estimada de } \\
\text { Fraude }\end{array}$ & $\%$ Fraude & $\begin{array}{l}\text { \% Não } \\
\text { Fraude }\end{array}$ & KS \\
\hline $0-0,05$ & $0,4 \%$ & $7,9 \%$ & $7,5 \%$ \\
\hline $0,05-0,10$ & $1,6 \%$ & $19,7 \%$ & $18,1 \%$ \\
\hline $0,10-0,15$ & $3,1 \%$ & $30,2 \%$ & $27,1 \%$ \\
\hline $0,15-0,20$ & $5,0 \%$ & $39,6 \%$ & $34,6 \%$ \\
\hline $0,20-0,25$ & $7,1 \%$ & $47,5 \%$ & $40,5 \%$ \\
\hline $0,25-0,30$ & $9,8 \%$ & $54,6 \%$ & $44,9 \%$ \\
\hline $0,30-0,35$ & $12,8 \%$ & $60,8 \%$ & $48,0 \%$ \\
\hline $0,35-0,40$ & $16,0 \%$ & $66,4 \%$ & $50,4 \%$ \\
\hline $0,40-0,45$ & $19,7 \%$ & $71,4 \%$ & $51,7 \%$ \\
\hline $0,45-0,50$ & $23,9 \%$ & $76,0 \%$ & $52,1 \%$ \\
\hline $0,50-0,55$ & $28,4 \%$ & $80,1 \%$ & $51,7 \%$ \\
\hline $0,55-0,60$ & $33,8 \%$ & $83,9 \%$ & $50,2 \%$ \\
\hline $0,60-0,65$ & $39,8 \%$ & $87,3 \%$ & $47,5 \%$ \\
\hline $0,65-0,70$ & $46,2 \%$ & $90,4 \%$ & $44,2 \%$ \\
\hline $0,70-0,75$ & $53,5 \%$ & $93,1 \%$ & $39,6 \%$ \\
\hline $0,75-0,80$ & $61,5 \%$ & $95,5 \%$ & $34,0 \%$ \\
\hline $0,80-0,85$ & $70,8 \%$ & $97,4 \%$ & $26,6 \%$ \\
\hline $0,85-0,90$ & $81,0 \%$ & $98,8 \%$ & $17,9 \%$ \\
\hline $0,90-0,95$ & $91,7 \%$ & $99,7 \%$ & $8,1 \%$ \\
\hline $0,95-1,00$ & $100,0 \%$ & $100,0 \%$ & $0,0 \%$ \\
\hline
\end{tabular}

Tabela C.3: Cálculo do KS do modelo ajustado com stepwise modificado.

\begin{tabular}{|c|c|c|c|c|c|c|c|c|}
\hline $\begin{array}{l}\text { Probabiliade } \\
\text { Estimada de } \\
\text { Fraude }\end{array}$ & \# Fraude & $\%$ Fraude & $\begin{array}{l}\text { \# Não } \\
\text { Fraude }\end{array}$ & $\begin{array}{l}\text { \% Não } \\
\text { Fraude }\end{array}$ & \# Total & $\%$ Total & $\begin{array}{c}\text { \# Fraude } \\
\text { Não Acumulado }\end{array}$ & $\begin{array}{l}\text { \# Não Fraude } \\
\text { Não Acumulado }\end{array}$ \\
\hline $0-0,05$ & 18.092 & $100,0 \%$ & 324.513 & $100,0 \%$ & 342.605 & $100,0 \%$ & 67 & 25.508 \\
\hline $0,05-0,10$ & 18.025 & $99,6 \%$ & 299.005 & $92,1 \%$ & 317.030 & $92,5 \%$ & 216 & 38.413 \\
\hline $0,10-0,15$ & 17.809 & $98,4 \%$ & 260.592 & $80,3 \%$ & 278.401 & $81,3 \%$ & 281 & 34.223 \\
\hline $0,15-0,20$ & 17.528 & $96,9 \%$ & 226.369 & $69,8 \%$ & 243.897 & $71,2 \%$ & 333 & 30.357 \\
\hline $0,20-0,25$ & 17.195 & $95,0 \%$ & 196.012 & $60,4 \%$ & 213.207 & $62,2 \%$ & 383 & 25.772 \\
\hline $0,25-0,30$ & 16.812 & $92,9 \%$ & 170.240 & $52,5 \%$ & 187.052 & $54,6 \%$ & 485 & 23.060 \\
\hline $0,30-0,35$ & 16.327 & $90,2 \%$ & 147.180 & $45,4 \%$ & 163.507 & $47,7 \%$ & 555 & 20.112 \\
\hline $0,35-0,40$ & 15.772 & $87,2 \%$ & 127.068 & $39,2 \%$ & 142.840 & $41,7 \%$ & 568 & 17.913 \\
\hline $0,40-0,45$ & 15.204 & $84,0 \%$ & 109.155 & $33,6 \%$ & 124.359 & $36,3 \%$ & 679 & 16.302 \\
\hline $0,45-0,50$ & 14.525 & $80,3 \%$ & 92.853 & $28,6 \%$ & 107.378 & $31,3 \%$ & 750 & 14.827 \\
\hline $0,50-0,55$ & 13.775 & $76,1 \%$ & 78.026 & $24,0 \%$ & 91.801 & $26,8 \%$ & 822 & 13.376 \\
\hline $0,55-0,60$ & 12.953 & $71,6 \%$ & 64.650 & $19,9 \%$ & 77.603 & $22,7 \%$ & 971 & 12.521 \\
\hline $0,60-0,65$ & 11.982 & $66,2 \%$ & 52.129 & $16,1 \%$ & 64.111 & $18,7 \%$ & 1.098 & 11.015 \\
\hline $0,65-0,70$ & 10.884 & $60,2 \%$ & 41.114 & $12,7 \%$ & 51.998 & $15,2 \%$ & 1.154 & 9.911 \\
\hline $0,70-0,75$ & 9.730 & $53,8 \%$ & 31.203 & $9,6 \%$ & 40.933 & $11,9 \%$ & 1.319 & 8.794 \\
\hline $0,75-0,80$ & 8.411 & $46,5 \%$ & 22.409 & $6,9 \%$ & 30.820 & $9,0 \%$ & 1.439 & 7.667 \\
\hline $0,80-0,85$ & 6.972 & $38,5 \%$ & 14.742 & $4,5 \%$ & 21.714 & $6,3 \%$ & 1.689 & 6.258 \\
\hline $0,85-0,90$ & 5.283 & $29,2 \%$ & 8.484 & $2,6 \%$ & 13.767 & $4,0 \%$ & 1.839 & 4.705 \\
\hline $0,90-0,95$ & 3.444 & $19,0 \%$ & 3.779 & $1,2 \%$ & 7.223 & $2,1 \%$ & 1.934 & 2.854 \\
\hline $0,95-1,00$ & 1.510 & $8,3 \%$ & 925 & $0,3 \%$ & 2.435 & $0,7 \%$ & 1.510 & 925 \\
\hline Total & & & & & & & 18.092 & 324.513 \\
\hline
\end{tabular}

Tabela C.4: Tabela de classificação das transações e intervalo de pontuação pelo modelo ajustado com stepwise modificado. 


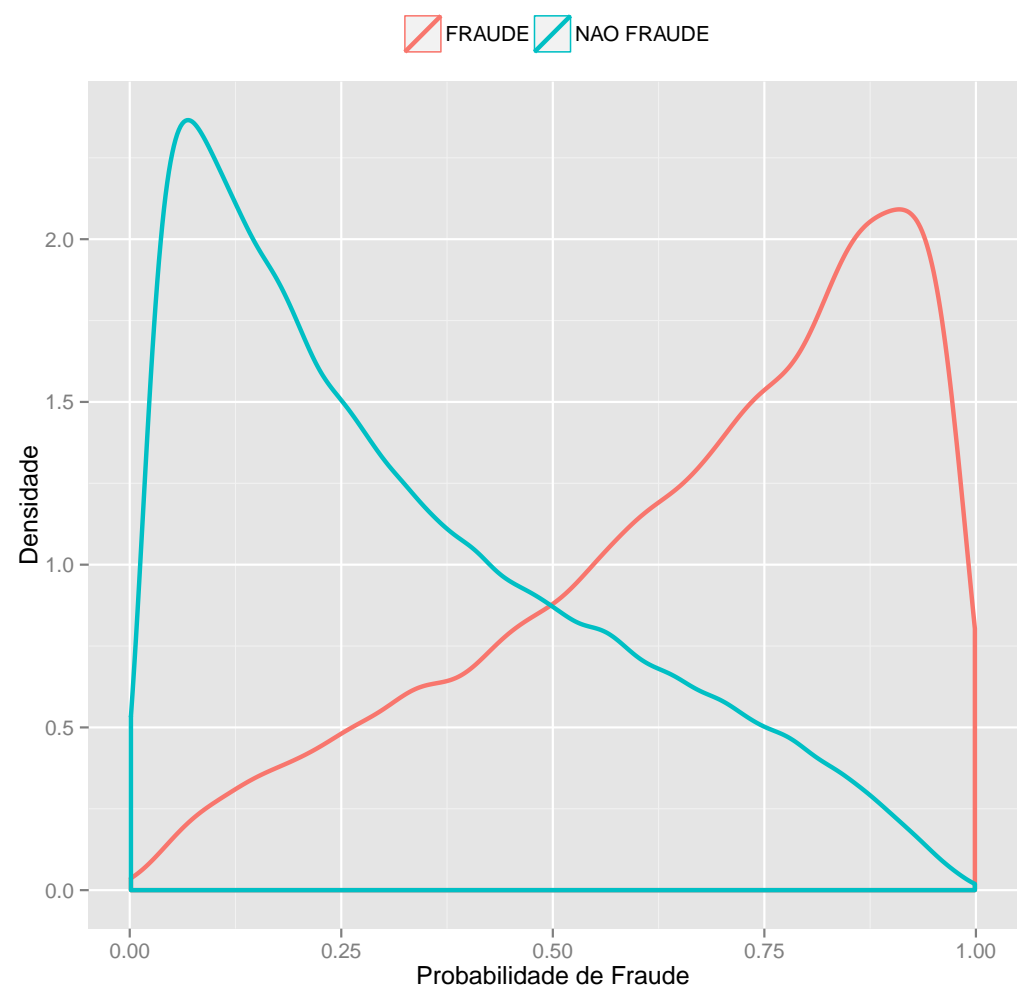

Figura C.2: Densidade de fraude e não fraude do modelo ajustado com stepwise modificado.

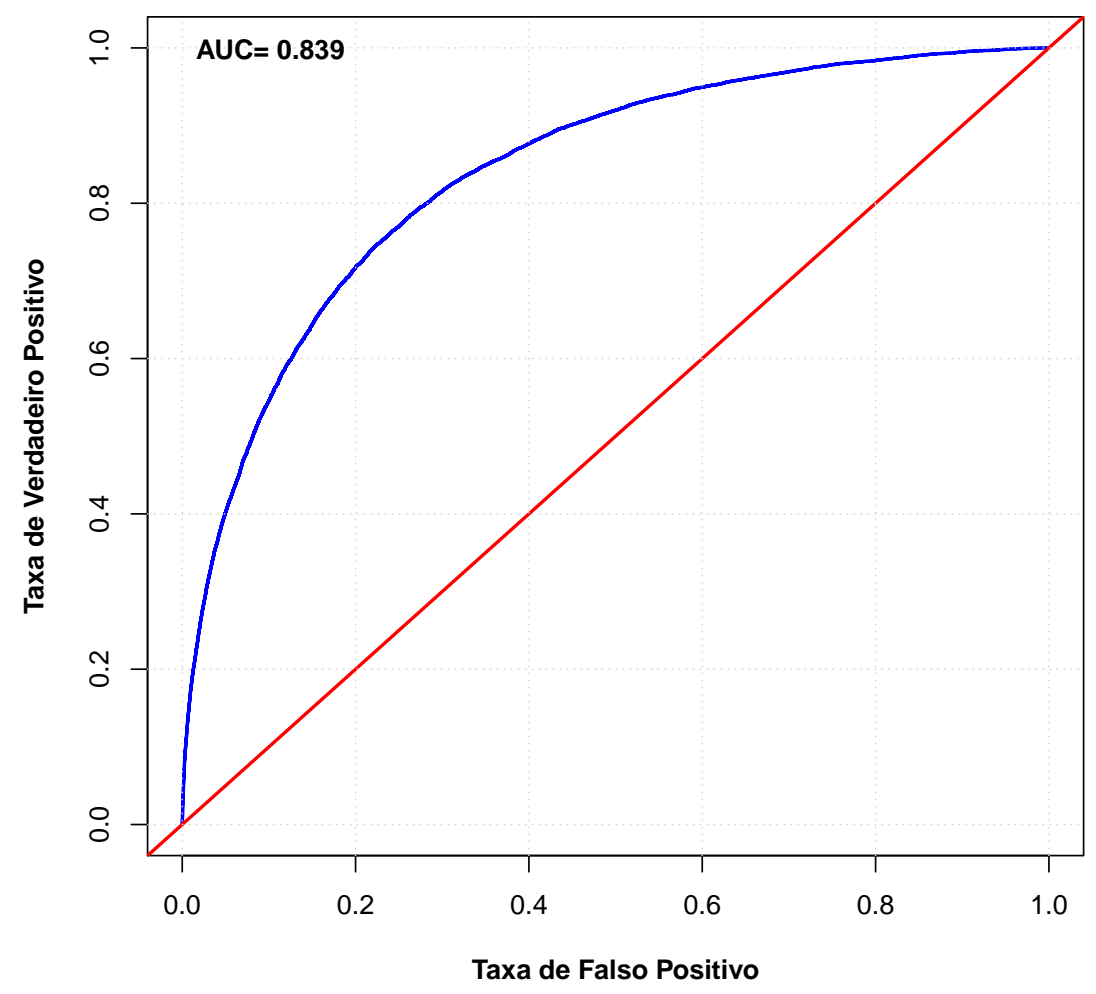

Figura C.3: Curva ROC do modelo ajustado com stepwise modificado (ponto de corte para probabilidade $=0,6)$. 


\begin{tabular}{|c|c|c|c|}
\hline $\begin{array}{c}\text { Probabiliade } \\
\text { Estimada de } \\
\text { Fraude }\end{array}$ & $\begin{array}{c}\text { \% Amostra } \\
\text { Treinamento }\end{array}$ & $\begin{array}{l}\text { \% Amostra } \\
\text { Validação }\end{array}$ & IEP \\
\hline $0-0,05$ & $7,5 \%$ & $4,3 \%$ & 0,01737 \\
\hline $0,05-0,10$ & $11,3 \%$ & $9,1 \%$ & 0,00456 \\
\hline $0,10-0,15$ & $10,1 \%$ & $9,8 \%$ & 0,00010 \\
\hline $0,15-0,20$ & $9,0 \%$ & $9,0 \%$ & 0,00001 \\
\hline $0,20-0,25$ & $7,6 \%$ & $8,3 \%$ & 0,00057 \\
\hline $0,25-0,30$ & $6,9 \%$ & $7,5 \%$ & 0,00055 \\
\hline $0,30-0,35$ & $6,0 \%$ & $6,8 \%$ & 0,00091 \\
\hline $0,35-0,40$ & $5,4 \%$ & $6,2 \%$ & 0,00115 \\
\hline $0,40-0,45$ & $5,0 \%$ & $5,6 \%$ & 0,00071 \\
\hline $0,45-0,50$ & $4,5 \%$ & $5,1 \%$ & 0,00064 \\
\hline $0,50-0,55$ & $4,1 \%$ & $4,7 \%$ & 0,00061 \\
\hline $0,55-0,60$ & $3,9 \%$ & $4,3 \%$ & 0,00030 \\
\hline $0,60-0,65$ & $3,5 \%$ & $4,0 \%$ & 0,00055 \\
\hline $0,65-0,70$ & $3,2 \%$ & $3,7 \%$ & 0,00057 \\
\hline $0,70-0,75$ & $3,0 \%$ & $3,1 \%$ & 0,00013 \\
\hline $0,75-0,80$ & $2,7 \%$ & $2,7 \%$ & 0,00003 \\
\hline $0,80-0,85$ & $2,3 \%$ & $2,2 \%$ & 0,00003 \\
\hline $0,85-0,90$ & $1,9 \%$ & $1,8 \%$ & 0,00004 \\
\hline $0,90-0,95$ & $1,4 \%$ & $1,3 \%$ & 0,00011 \\
\hline $0,95-1,00$ & $0,7 \%$ & $0,5 \%$ & 0,00103 \\
\hline Total & $100,0 \%$ & $100,0 \%$ & 0,02995 \\
\hline
\end{tabular}

Tabela C.5: Índice de estabilidade populacional do modelo ajustado com stepwise modificado.

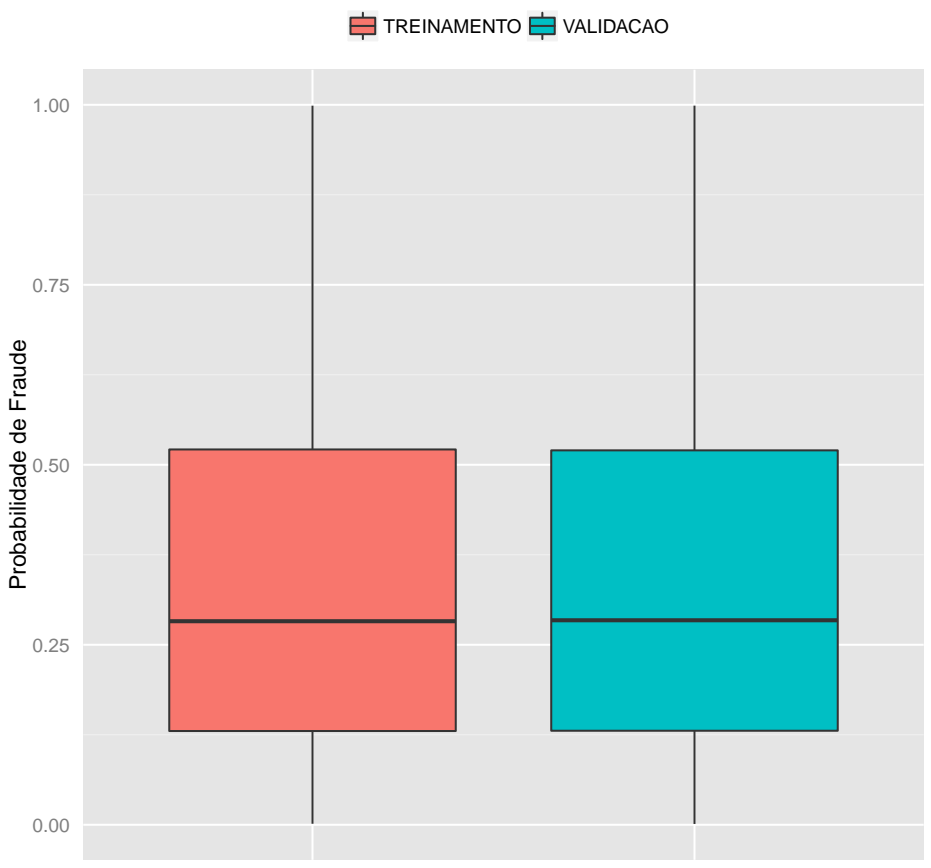

Figura C.4: Boxplox das amostras de treinamento e validação do modelo ajustado com stepwise modificado. 


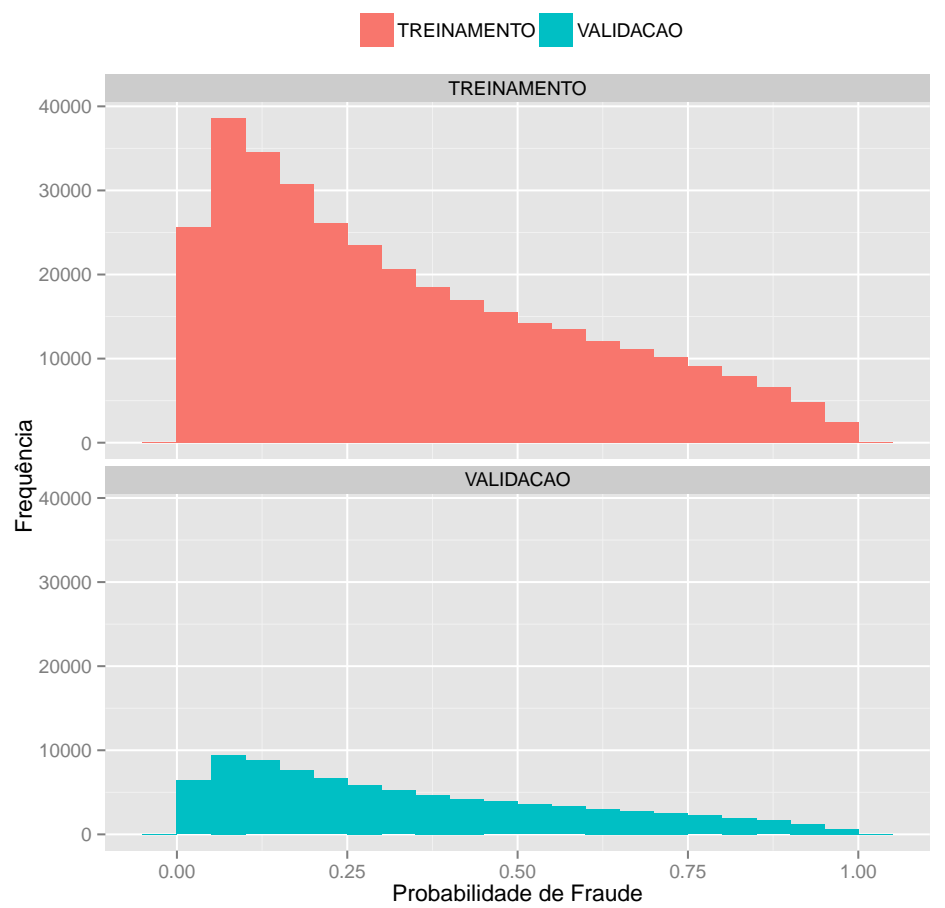

Figura C.5: Histograma da amostra de treinamento e validação do modelo ajustado com stepwise modificado.

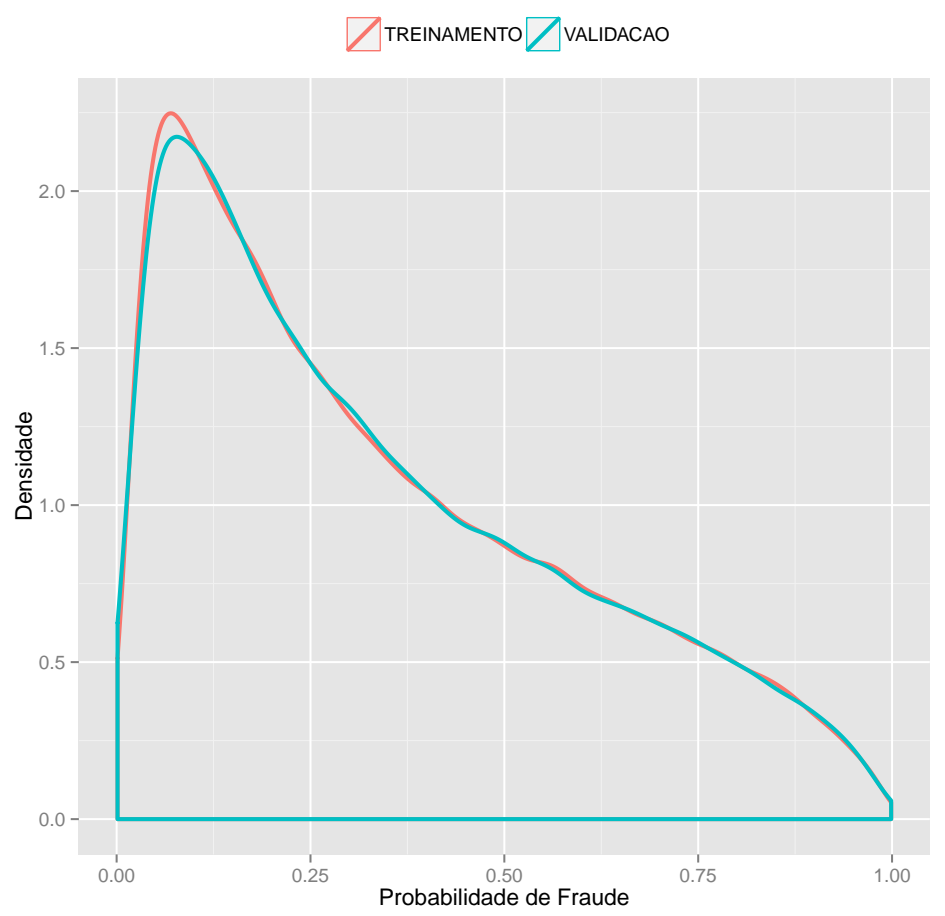

Figura C.6: Densidade das amostras de treinamento e validação do modelo ajustado com stepwise modificado. 


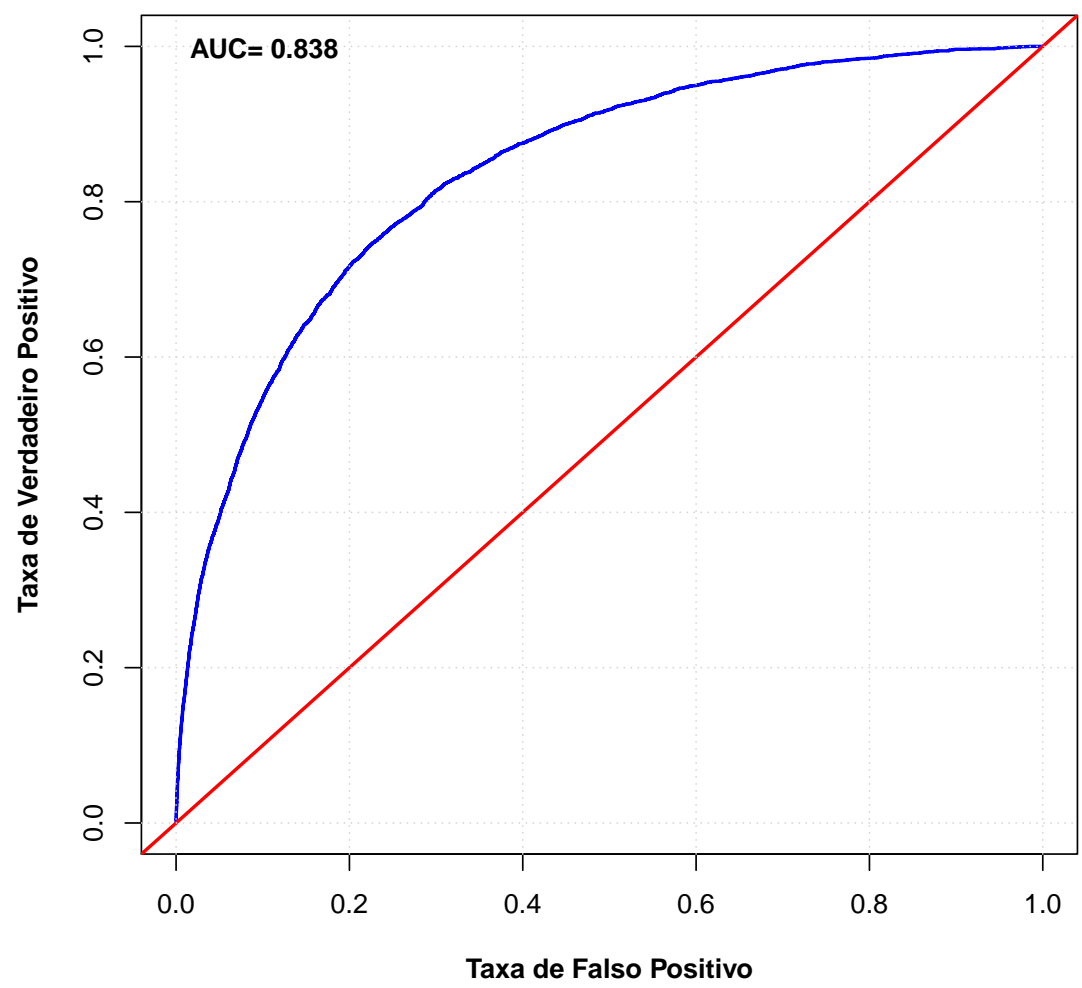

Figura C.7: Curva ROC da amostra de validação do modelo ajustado com stepwise modificado (ponto de corte para probabilidade=0,6).

\begin{tabular}{lccc}
\hline \hline Classificado & \multicolumn{2}{c}{ Observado } & \% Classificação \\
\cline { 2 - 3 } pelo Modelo & Fraude & Não Fraude & Correta \\
\hline Fraude & 11.982 & 52.129 & $19 \%$ \\
Não Fraude & 6.110 & 272.384 & $98 \%$ \\
\hline \% Classificação Correta & & $83 \%$ \\
\hline
\end{tabular}

Tabela C.6: Tabela de classificação das transações pelo modelo ajustado com stepwise modificado (ponto de corte para probabilidade=0,6). 


\begin{tabular}{lcc}
\hline \hline \multirow{2}{*}{ Indicadores } & \multicolumn{2}{c}{ Amostra } \\
\cline { 2 - 3 } & Desenvolvimento & Validação \\
\hline Classificação de Fraude & $66,2 \%$ & $65,9 \%$ \\
Taxa de Deteção (Cobertura) & $16,1 \%$ & $16,0 \%$ \\
Taxa de Falso Positivo & 4,4 & 4,4 \\
Relação Não Fraude/Fraude & $18,7 \%$ & $18,6 \%$ \\
Precisão (Fraude) & & \\
Classificação de Não Fraude & $83,9 \%$ & $84,0 \%$ \\
Especificidade & $97,8 \%$ & $97,8 \%$ \\
Precisão (Não Fraude) & & \\
Classificação Geral & $83,0 \%$ & $83,0 \%$ \\
Acurácia & $83,9 \%$ & $83,8 \%$ \\
Área sob a curva ROC & $29,2 \%$ & $29,1 \%$ \\
Medida F & & \\
\hline
\end{tabular}

Tabela C.7: Indicadores de performance do modelo ajustado com stepwise modificado. 


\section{Modelo DMA $99(\lambda=\alpha=0,99)$}

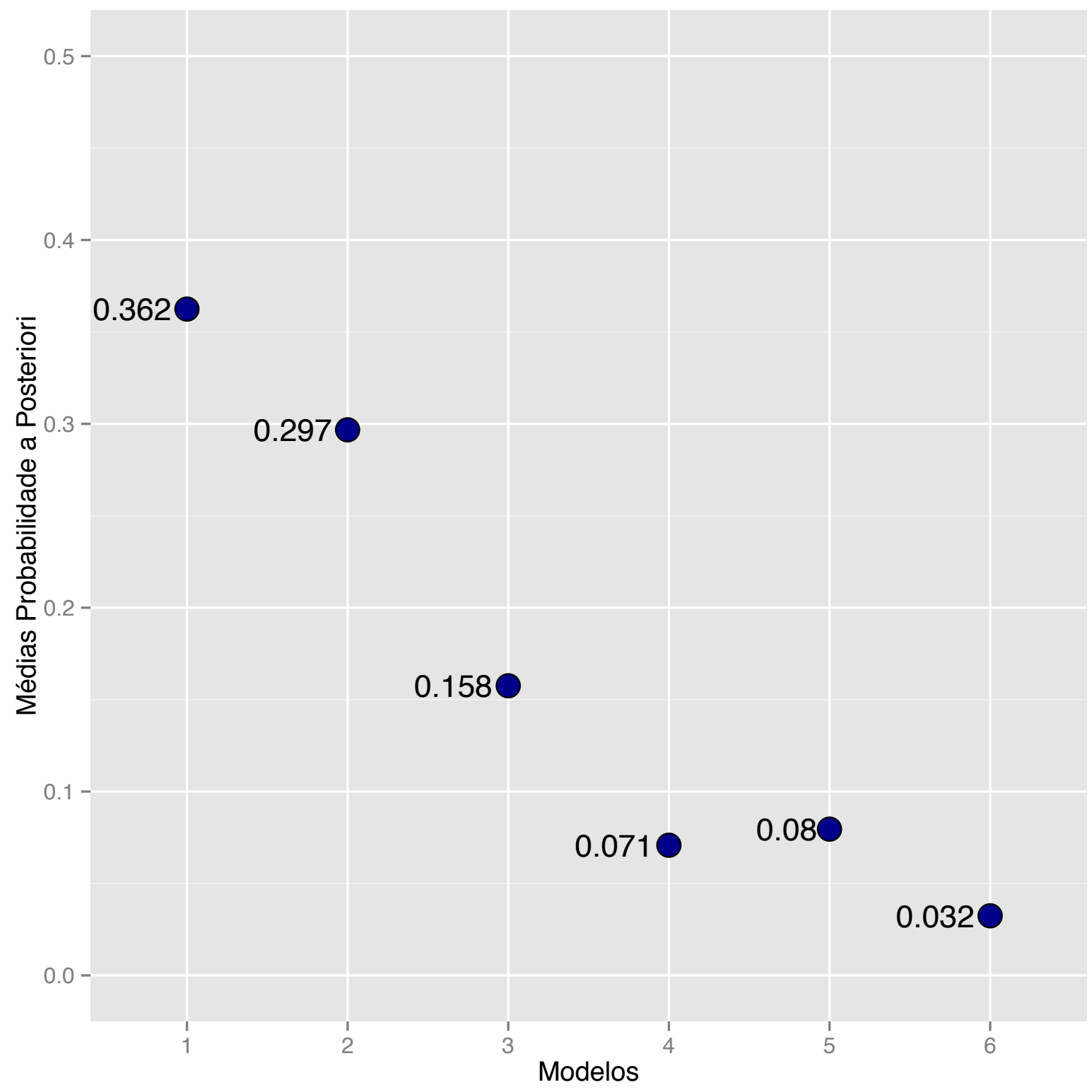

Figura D.1: Médias das probabilidades a posteriori dos modelos selecionados para o modelo DMA 99. 

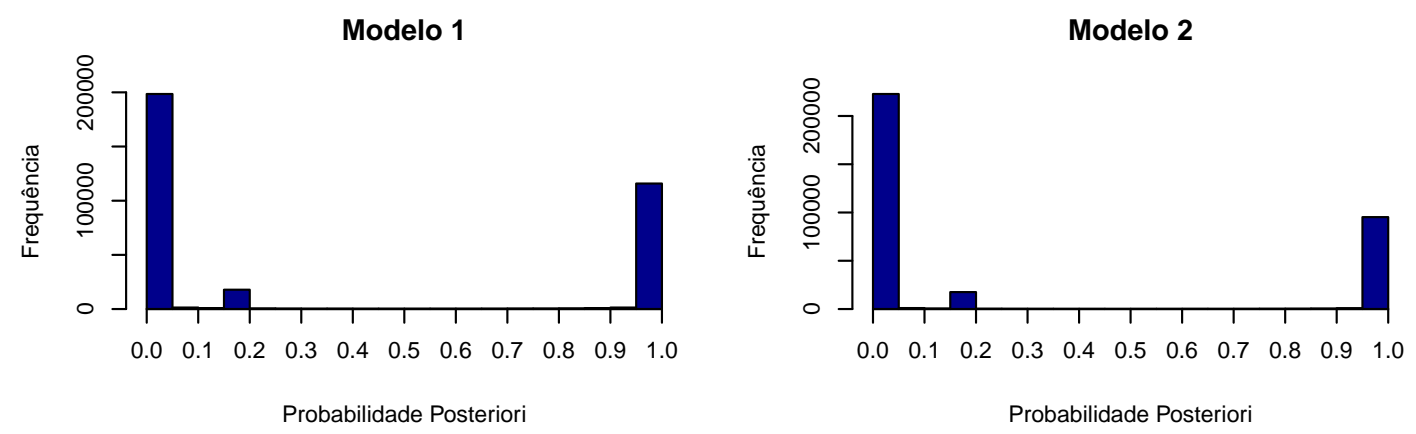

Modelo 3

Modelo 4
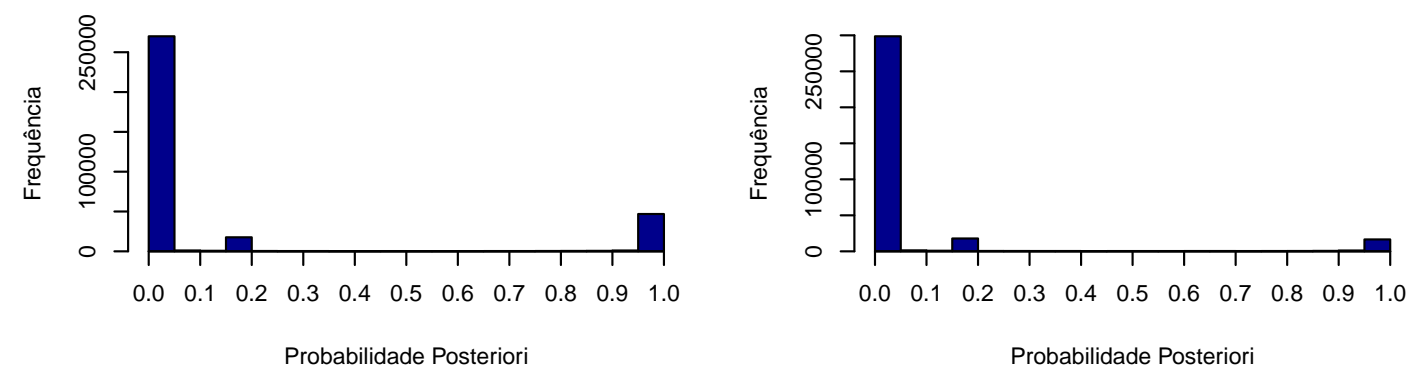

Modelo 5

Modelo 6
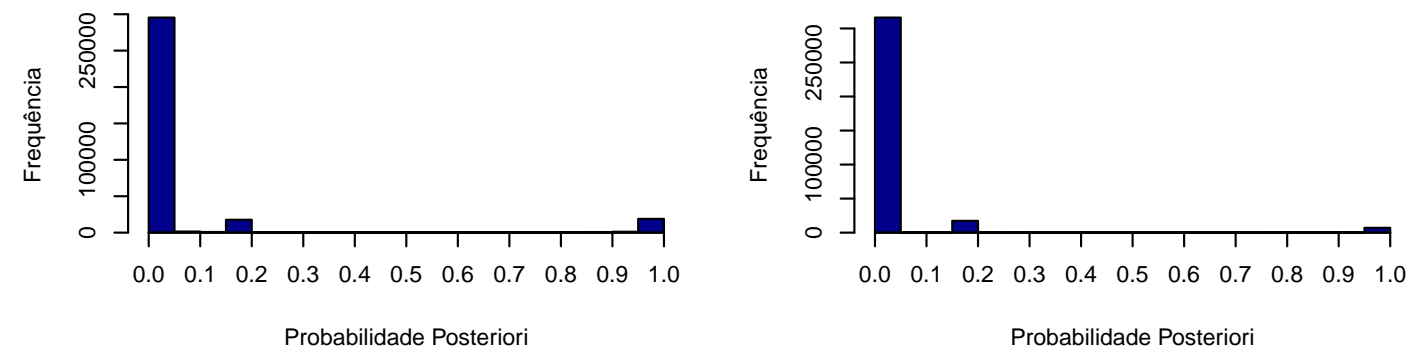

Figura D.2: Histogramas das probabilidades a posteriori dos modelos selecionados para o modelo DMA 99 . 

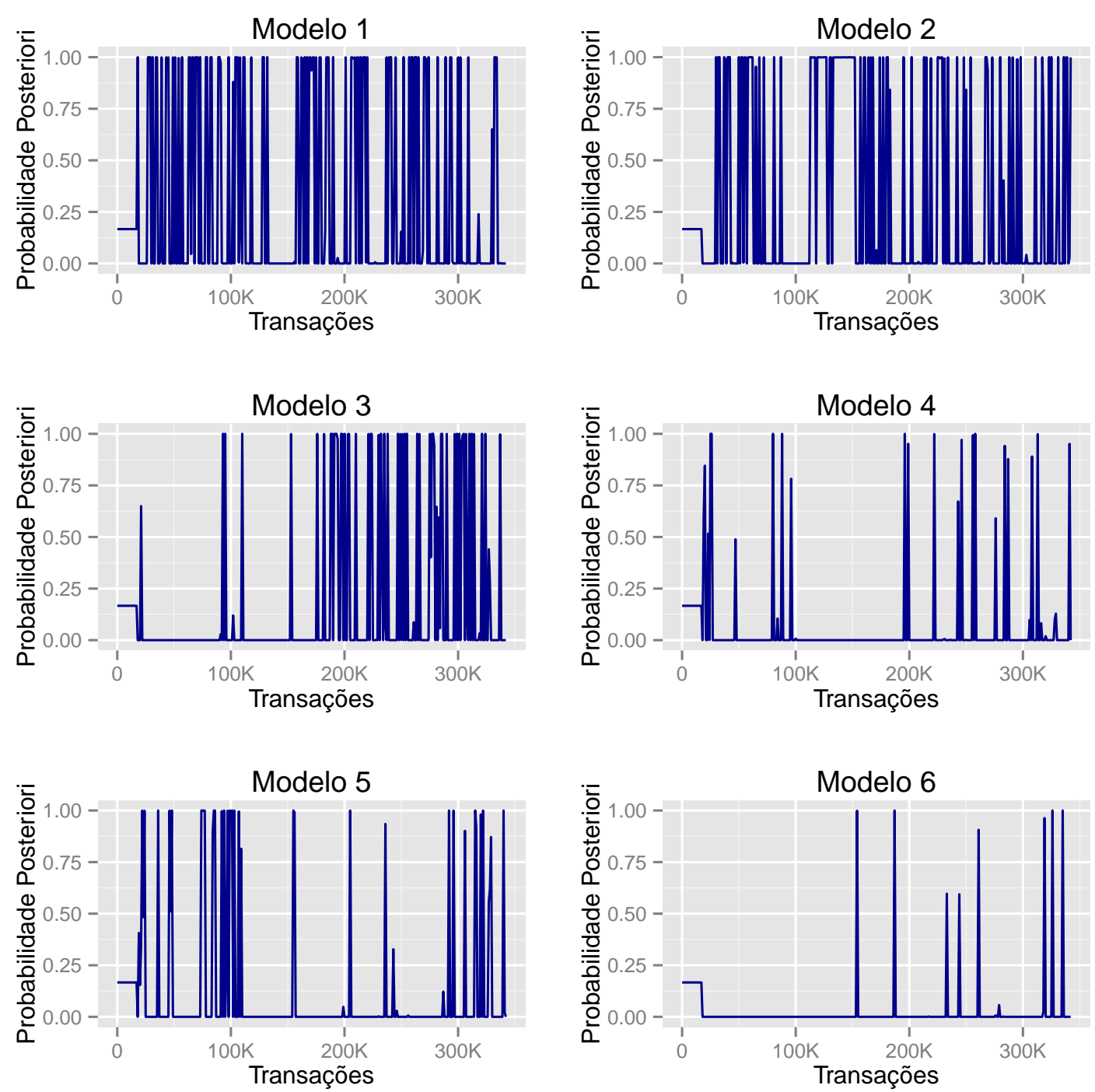

Figura D.3: Probabilidades a posteriori dos modelos selecionados para o modelo DMA 99 a cada 1.000 transações no tempo. 


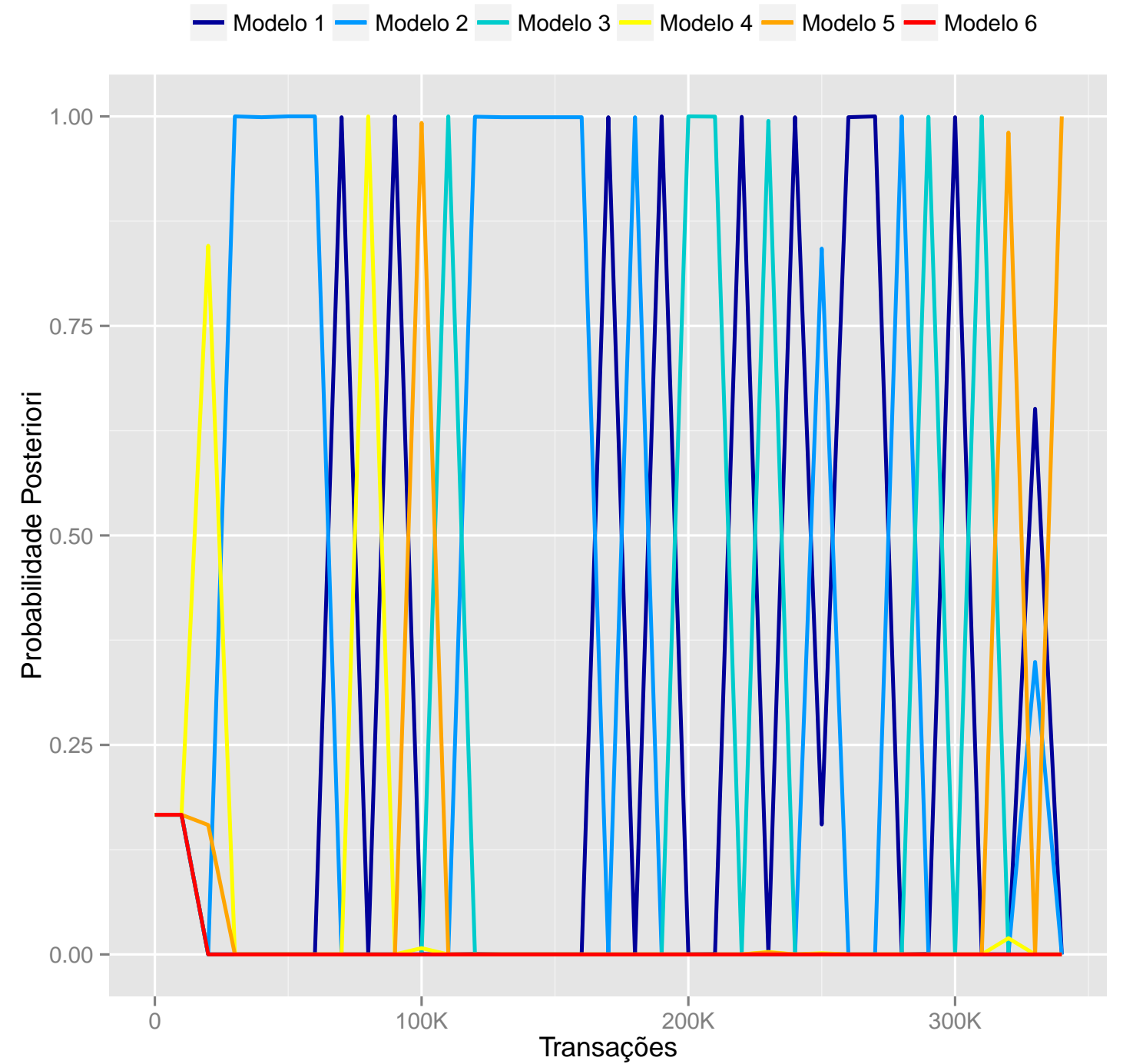

Figura D.4: Probabilidades a posteriori dos modelos selecionados para o modelo DMA 99 a cada 10.000 transações no tempo. 

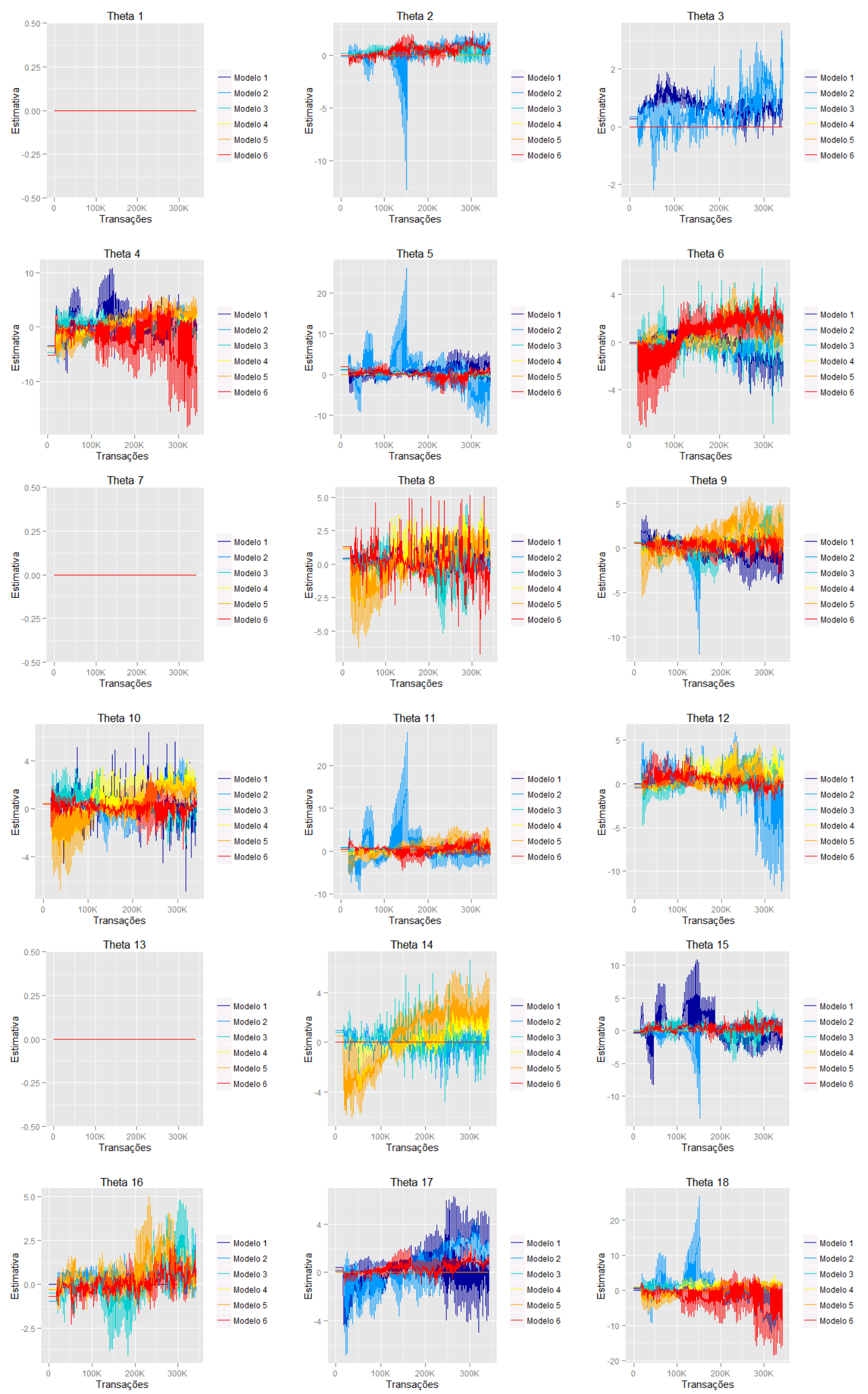

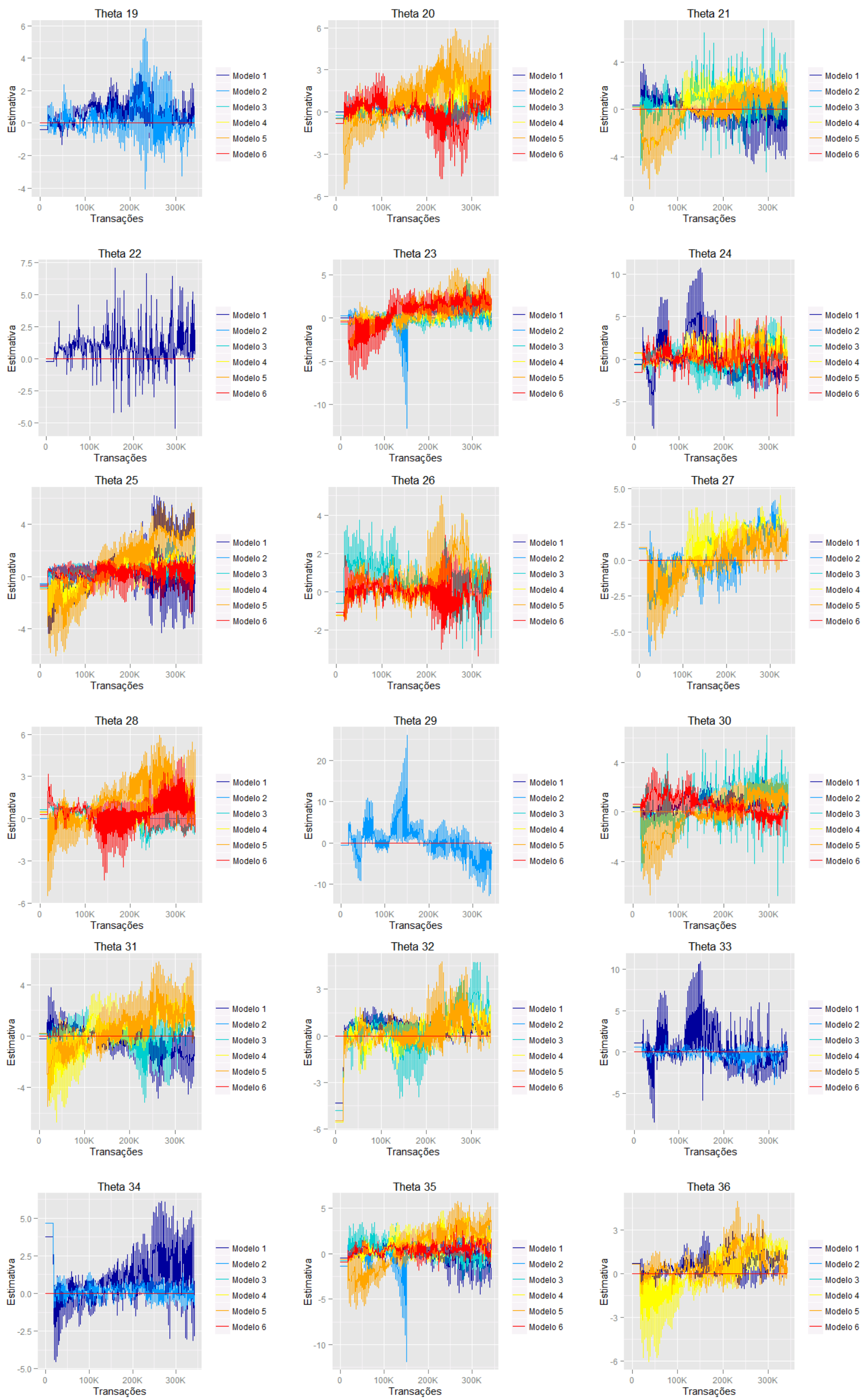

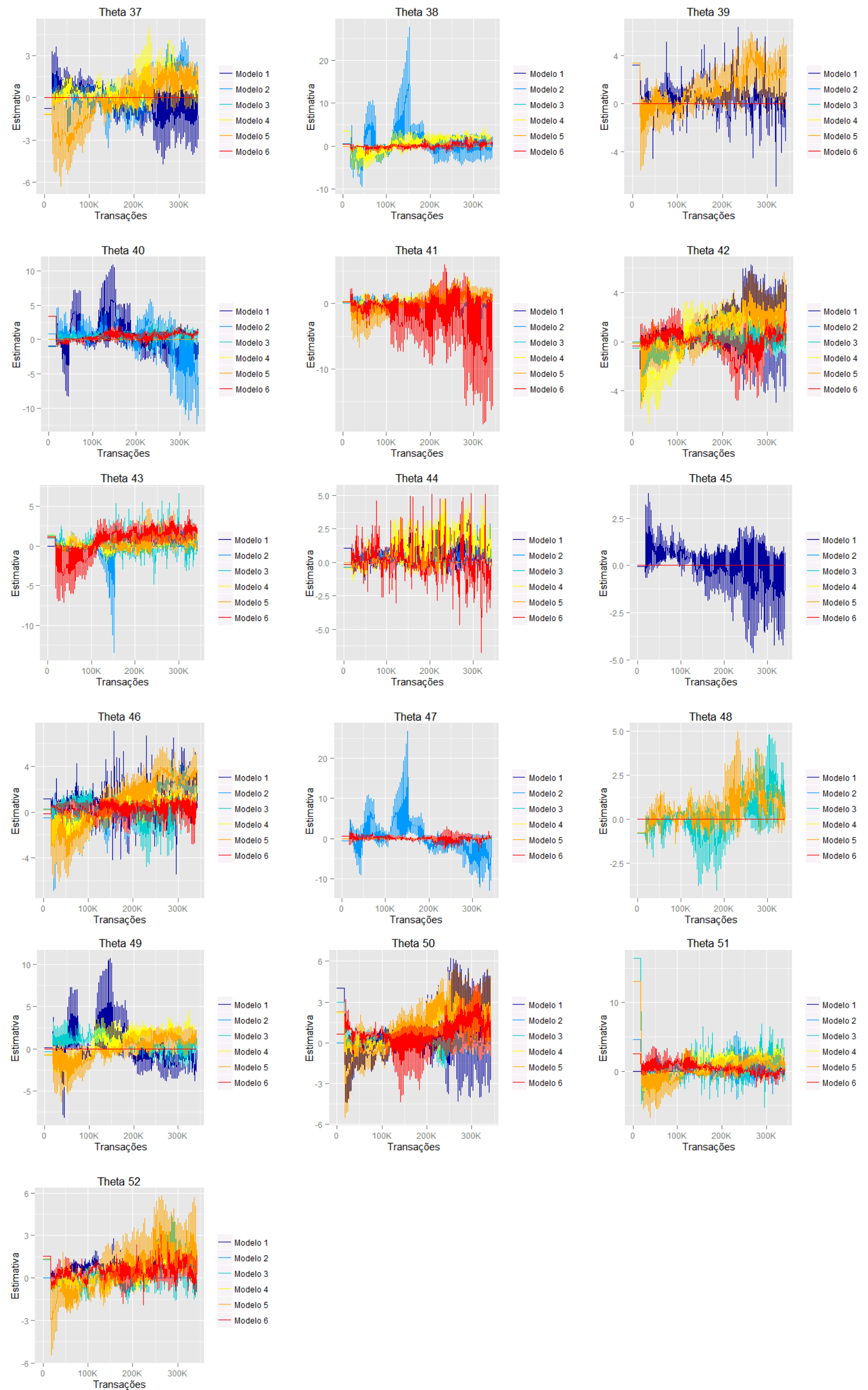

Figura D.5: Estimativas dos parâmetros dos modelos selecionados para o modelo DMA 99 a cada 1.000 transações no tempo. 

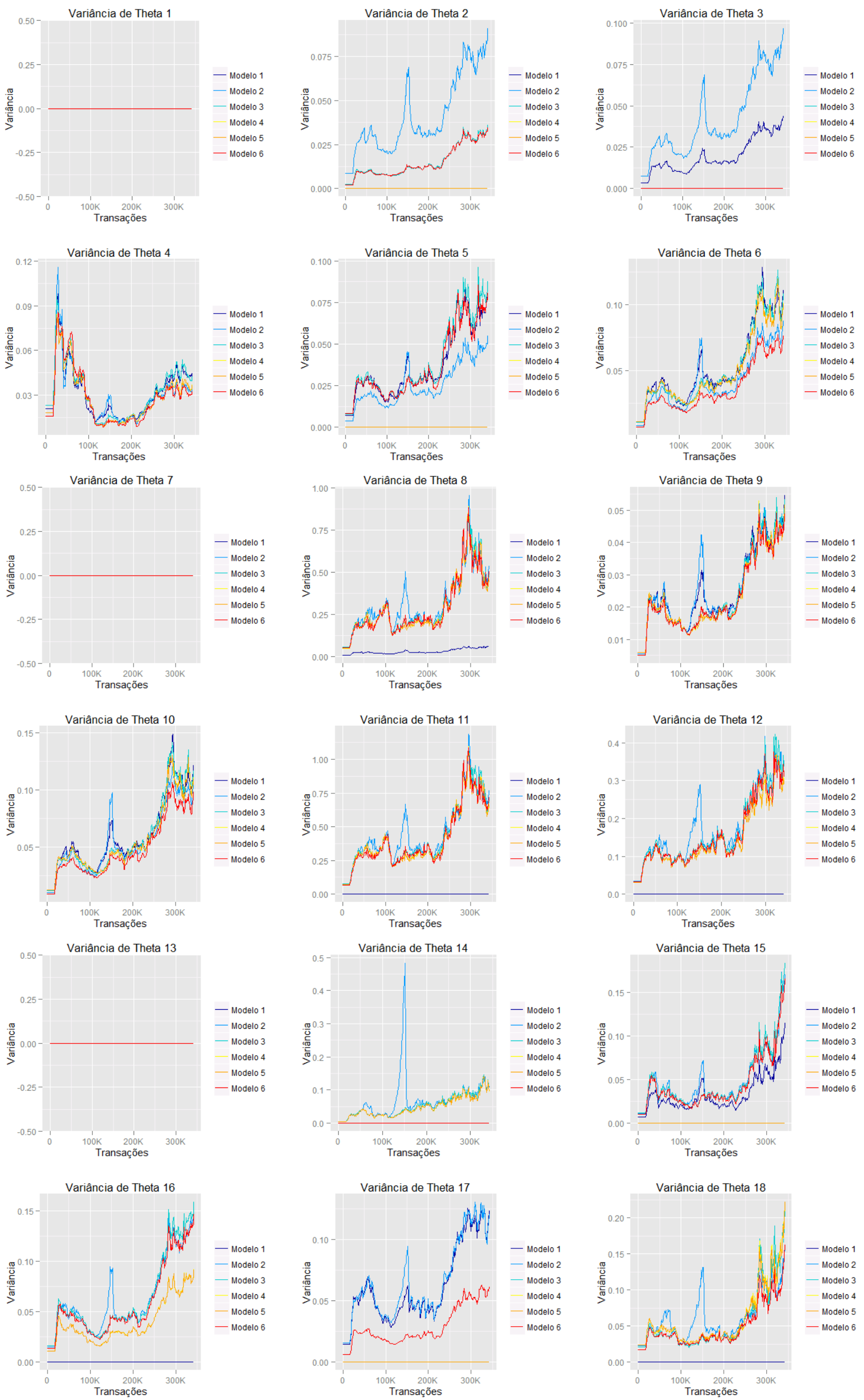

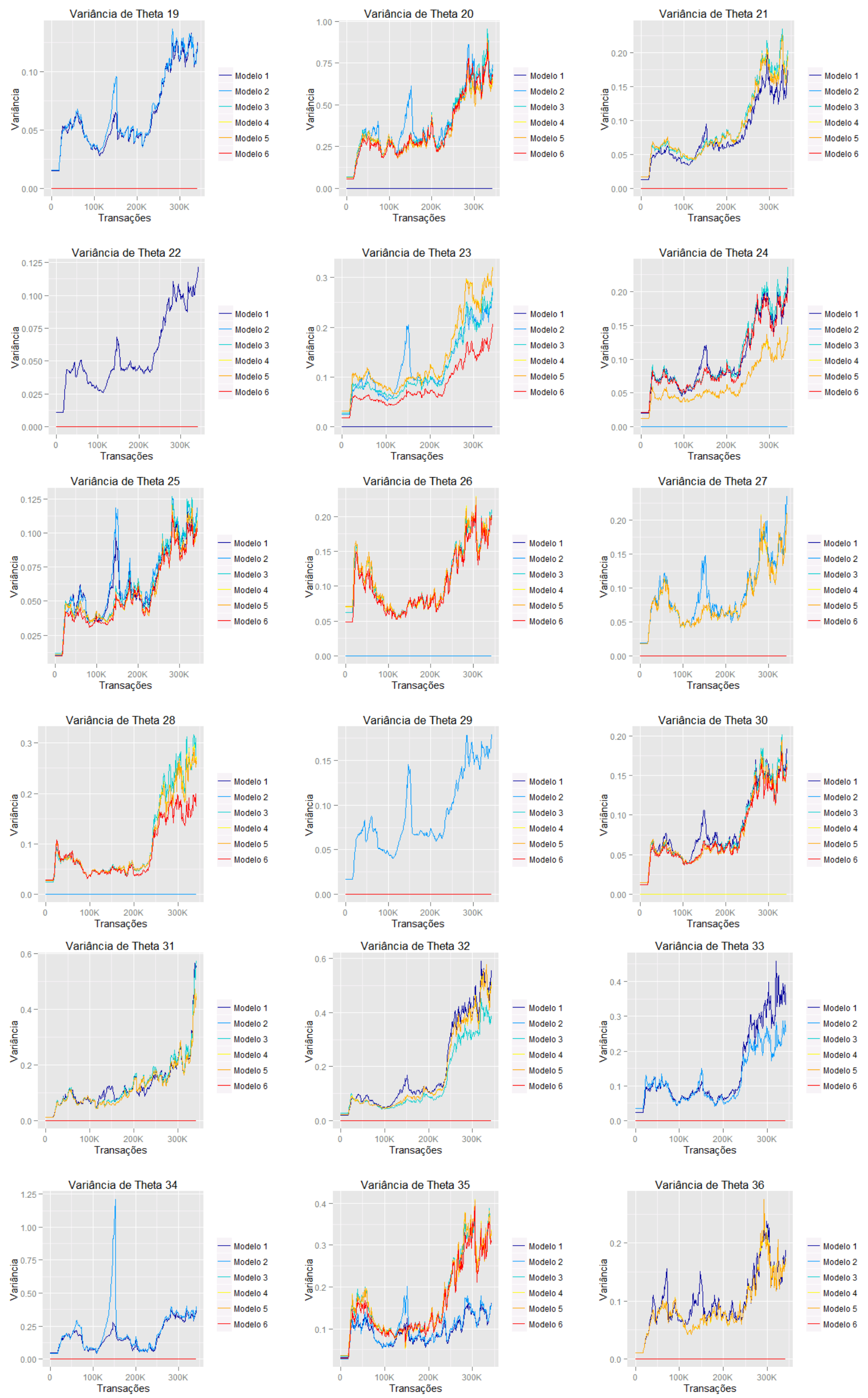

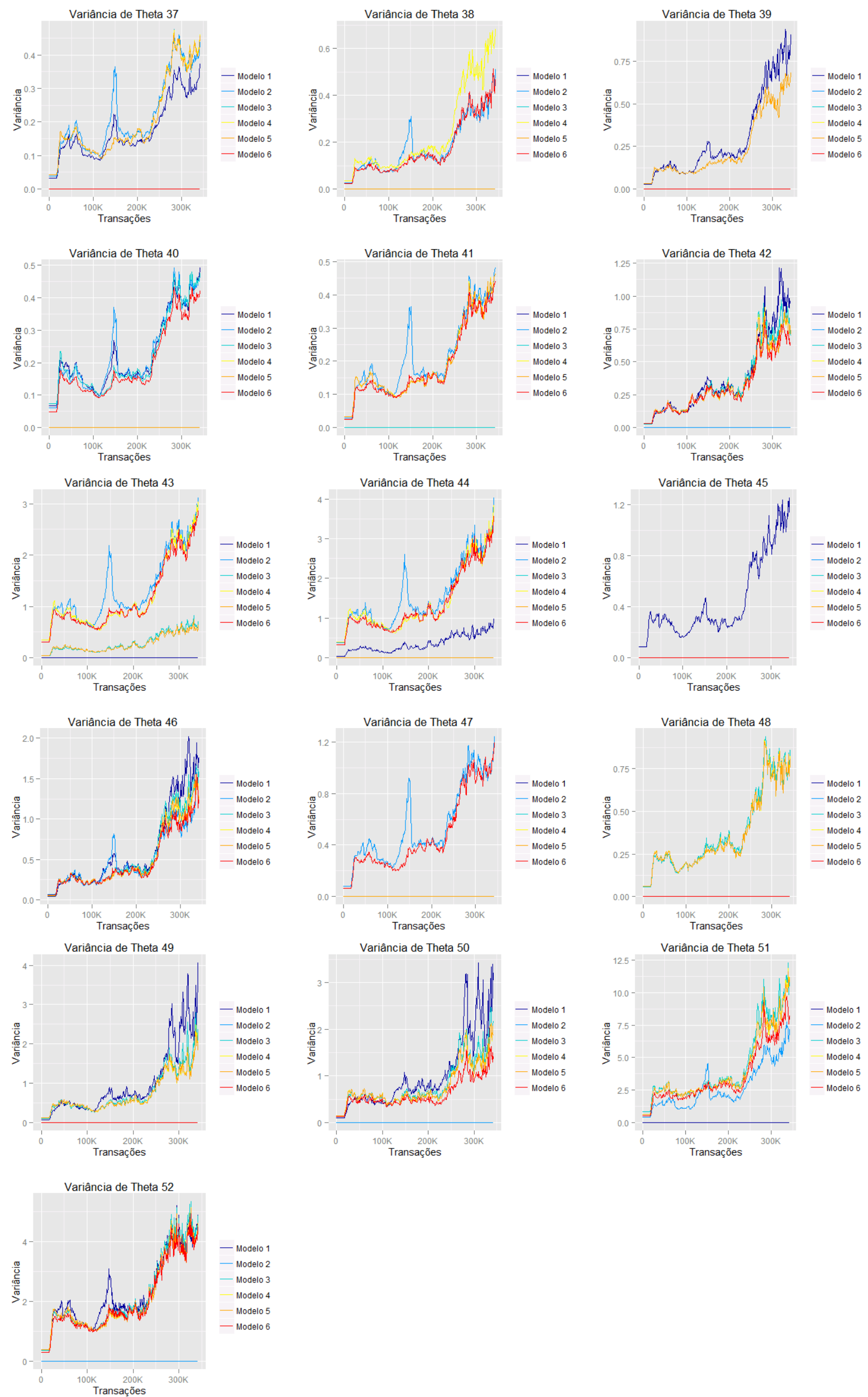

Figura D.6: Variância dos parâmetros dos modelos selecionados para o modelo DMA 99 a cada 1.000 transações no tempo. 


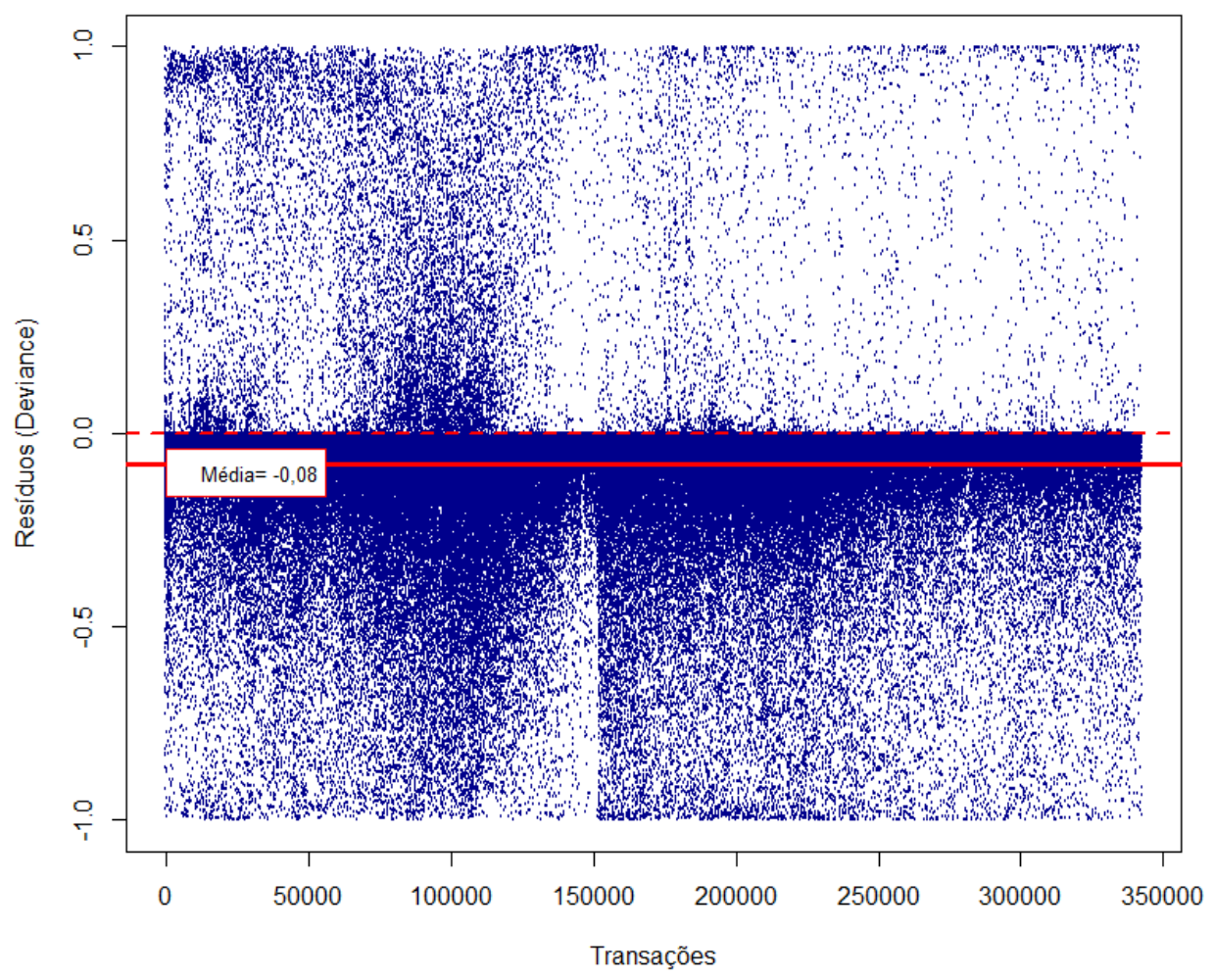

Figura D.7: Resíduos deviance do modelo DMA 99.

\begin{tabular}{|c|c|c|c|}
\hline $\begin{array}{c}\text { Probabiliade } \\
\text { Estimada de } \\
\text { Fraude } \\
\end{array}$ & $\%$ Fraude & $\begin{array}{l}\text { \% Não } \\
\text { Fraude }\end{array}$ & KS \\
\hline $0-0,05$ & $7,3 \%$ & $55,3 \%$ & $48,0 \%$ \\
\hline $0,05-0,10$ & $13,9 \%$ & $71,7 \%$ & $57,7 \%$ \\
\hline $0,10-0,15$ & $18,7 \%$ & $79,5 \%$ & $60,8 \%$ \\
\hline $0,15-0,20$ & $22,9 \%$ & $84,2 \%$ & $61,3 \%$ \\
\hline $0,20-0,25$ & $26,6 \%$ & $87,3 \%$ & $60,7 \%$ \\
\hline $0,25-0,30$ & $29,8 \%$ & $89,6 \%$ & $59,8 \%$ \\
\hline $0,30-0,35$ & $33,1 \%$ & $91,3 \%$ & $58,1 \%$ \\
\hline $0,35-0,40$ & $36,4 \%$ & $92,7 \%$ & $56,3 \%$ \\
\hline $0,40-0,45$ & $9,6 \%$ & $93,8 \%$ & $54,2 \%$ \\
\hline $0,45-0,50$ & $42,8 \%$ & $94,8 \%$ & $52,0 \%$ \\
\hline $0,50-0,55$ & $45,9 \%$ & $95,6 \%$ & $49,7 \%$ \\
\hline $0,55-0,60$ & $49,2 \%$ & $96,3 \%$ & $47,1 \%$ \\
\hline $0,60-0,65$ & $52,5 \%$ & $96,9 \%$ & $44,4 \%$ \\
\hline $0,65-0,70$ & $56,2 \%$ & $97,4 \%$ & $41,2 \%$ \\
\hline $0,70-0,75$ & $60,2 \%$ & $97,9 \%$ & $37,6 \%$ \\
\hline $0,75-0,80$ & $64,8 \%$ & $98,3 \%$ & $33,5 \%$ \\
\hline $0,80-0,85$ & $70,0 \%$ & $98,7 \%$ & $28,7 \%$ \\
\hline $0,85-0,90$ & $76,7 \%$ & $99,1 \%$ & $22,4 \%$ \\
\hline $0,90-0,95$ & $85,1 \%$ & $99,5 \%$ & $14,4 \%$ \\
\hline $0,95-1,00$ & $100,0 \%$ & $100,0 \%$ & $0,0 \%$ \\
\hline
\end{tabular}

Tabela D.1: Cálculo do KS do modelo DMA 99. 


\begin{tabular}{|c|c|c|c|c|c|c|c|c|}
\hline $\begin{array}{l}\text { Probabiliade } \\
\text { Estimada de } \\
\text { Fraude }\end{array}$ & \# Fraude & $\%$ Fraude & $\begin{array}{c}\text { \# Não } \\
\text { Fraude }\end{array}$ & $\begin{array}{c}\text { \% Não } \\
\text { Fraude }\end{array}$ & \# Total & $\%$ Total & $\begin{array}{c}\text { \# Fraude } \\
\text { Não Acumulado }\end{array}$ & $\begin{array}{l}\text { \# Não Fraude } \\
\text { Não Acumulado }\end{array}$ \\
\hline $0-0,05$ & 18.092 & $100,0 \%$ & 324.513 & $100,0 \%$ & 342.605 & $100,0 \%$ & 1.329 & 179.595 \\
\hline $0,05-0,10$ & 16.763 & $92,7 \%$ & 144.918 & $44,7 \%$ & 161.681 & $47,2 \%$ & 1.190 & 52.959 \\
\hline $0,10-0,15$ & 15.573 & $86,1 \%$ & 91.959 & $28,3 \%$ & 107.532 & $31,4 \%$ & 870 & 25.540 \\
\hline $0,15-0,20$ & 14.703 & $81,3 \%$ & 66.419 & $20,5 \%$ & 81.122 & $23,7 \%$ & 752 & 15.119 \\
\hline $0,20-0,25$ & 13.951 & $77,1 \%$ & 51.300 & $15,8 \%$ & 65.251 & $19,0 \%$ & 672 & 10.018 \\
\hline $0,25-0,30$ & 13.279 & $73,4 \%$ & 41.282 & $12,7 \%$ & 54.561 & $15,9 \%$ & 578 & 7.398 \\
\hline $0,30-0,35$ & 12.701 & $70,2 \%$ & 33.884 & $10,4 \%$ & 46.585 & $13,6 \%$ & 605 & 5.557 \\
\hline $0,35-0,40$ & 12.096 & $66,9 \%$ & 28.327 & $8,7 \%$ & 40.423 & $11,8 \%$ & 589 & 4.638 \\
\hline $0,40-0,45$ & 11.507 & $63,6 \%$ & 23.689 & $7,3 \%$ & 35.196 & $10,3 \%$ & 580 & 3.651 \\
\hline $0,45-0,50$ & 10.927 & $60,4 \%$ & 20.038 & $6,2 \%$ & 30.965 & $9,0 \%$ & 575 & 3.106 \\
\hline $0,50-0,55$ & 10.352 & $57,2 \%$ & 16.932 & $5,2 \%$ & 27.284 & $8,0 \%$ & 572 & 2.671 \\
\hline $0,55-0,60$ & 9.780 & $54,1 \%$ & 14.261 & $4,4 \%$ & 24.041 & $7,0 \%$ & 584 & 2.181 \\
\hline $0,60-0,65$ & 9.196 & $50,8 \%$ & 12.080 & $3,7 \%$ & 21.276 & $6,2 \%$ & 599 & 1.896 \\
\hline $0,65-0,70$ & 8.597 & $47,5 \%$ & 10.184 & $3,1 \%$ & 18.781 & $5,5 \%$ & 680 & 1.769 \\
\hline $0,70-0,75$ & 7.917 & $43,8 \%$ & 8.415 & $2,6 \%$ & 16.332 & $4,8 \%$ & 724 & 1.570 \\
\hline $0,75-0,80$ & 7.193 & $39,8 \%$ & 6.845 & $2,1 \%$ & 14.038 & $4,1 \%$ & 822 & 1.333 \\
\hline $0,80-0,85$ & 6.371 & $35,2 \%$ & 5.512 & $1,7 \%$ & 11.883 & $3,5 \%$ & 938 & 1.293 \\
\hline $0,85-0,90$ & 5.433 & $30,0 \%$ & 4.219 & $1,3 \%$ & 9.652 & $2,8 \%$ & 1.211 & 1.249 \\
\hline $0,90-0,95$ & 4.222 & $23,3 \%$ & 2.970 & $0,9 \%$ & 7.192 & $2,1 \%$ & 1.522 & 1.291 \\
\hline $0,95-1,00$ & 2.700 & $14,9 \%$ & 1.679 & $0,5 \%$ & 4.379 & $1,3 \%$ & 2.700 & 1.679 \\
\hline Total & & & & & & & 18.092 & 324.513 \\
\hline
\end{tabular}

Tabela D.2: Tabela de classificação das transações e intervalo de pontuação pelo modelo DMA 99.

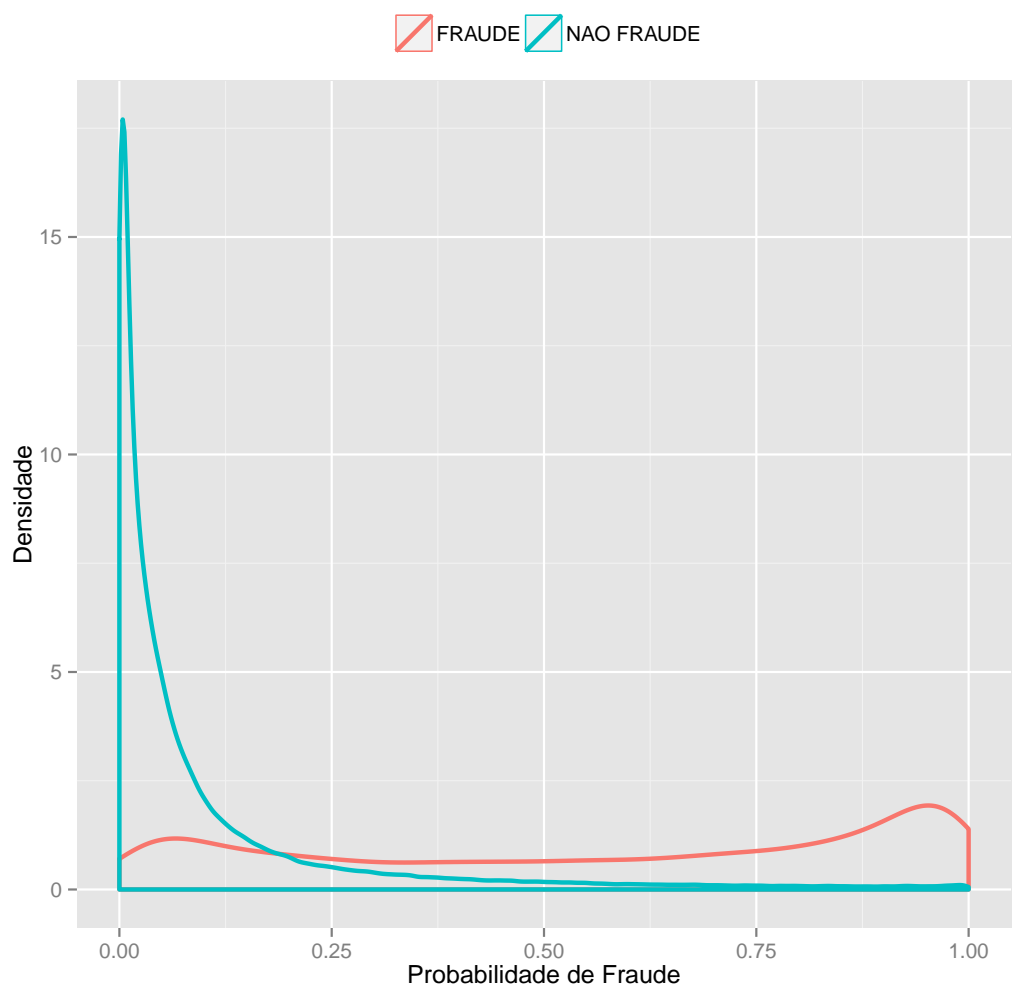

Figura D.8: Densidade de fraude e não fraude do modelo DMA 99. 


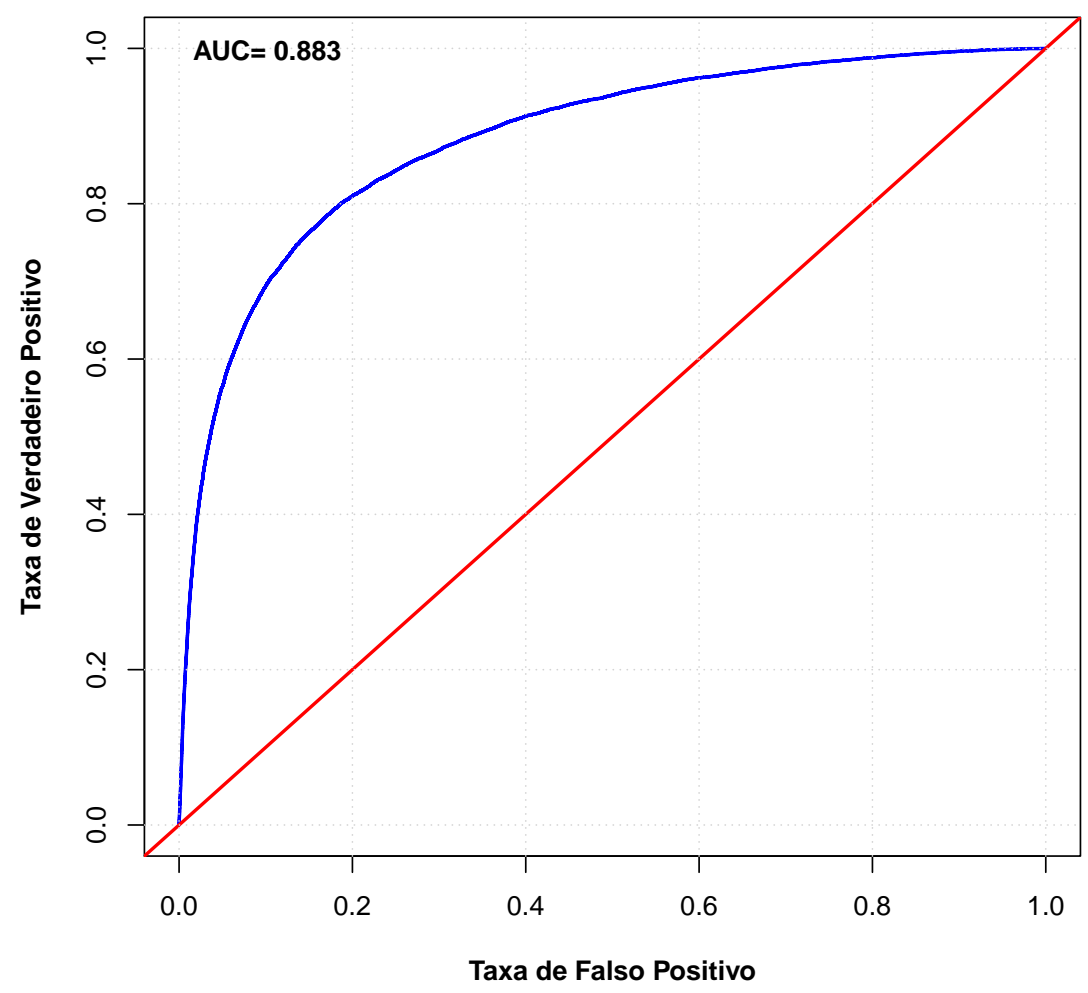

Figura D.9: Curva ROC do modelo DMA 99.

\begin{tabular}{|c|c|c|c|}
\hline $\begin{array}{l}\text { Probabiliade } \\
\text { Estimada de } \\
\text { Fraude }\end{array}$ & $\begin{array}{c}\% \text { Amostra } \\
\text { Treinamento }\end{array}$ & $\begin{array}{l}\text { \% Amostra } \\
\text { Validação }\end{array}$ & IEP \\
\hline $0-0,05$ & $52,8 \%$ & $47,8 \%$ & 0,00501 \\
\hline $0,05-0,10$ & $15,8 \%$ & $17,3 \%$ & 0,00130 \\
\hline $0,10-0,15$ & $7,7 \%$ & $8,3 \%$ & 0,00048 \\
\hline $0,15-0,20$ & $4,6 \%$ & $5,1 \%$ & 0,00051 \\
\hline $0,20-0,25$ & $3,1 \%$ & $3,5 \%$ & 0,00038 \\
\hline $0,25-0,30$ & $2,3 \%$ & $2,7 \%$ & 0,00060 \\
\hline $0,30-0,35$ & $1,8 \%$ & $2,1 \%$ & 0,00062 \\
\hline $0,35-0,40$ & $1,5 \%$ & $1,8 \%$ & 0,00039 \\
\hline $0,40-0,45$ & $1,2 \%$ & $1,5 \%$ & 0,00046 \\
\hline $0,45-0,50$ & $1,1 \%$ & $1,1 \%$ & 0,00002 \\
\hline $0,50-0,55$ & $0,9 \%$ & $1,1 \%$ & 0,00014 \\
\hline $0,55-0,60$ & $0,8 \%$ & $0,9 \%$ & 0,00015 \\
\hline $0,60-0,65$ & $0,7 \%$ & $0,9 \%$ & 0,00022 \\
\hline $0,65-0,70$ & $0,7 \%$ & $0,8 \%$ & 0,00004 \\
\hline $0,70-0,75$ & $0,7 \%$ & $0,7 \%$ & 0,00001 \\
\hline $0,75-0,80$ & $0,6 \%$ & $0,7 \%$ & 0,00012 \\
\hline $0,80-0,85$ & $0,7 \%$ & $0,7 \%$ & 0,00000 \\
\hline $0,85-0,90$ & $0,7 \%$ & $0,7 \%$ & 0,00001 \\
\hline $0,90-0,95$ & $0,8 \%$ & $0,9 \%$ & 0,00012 \\
\hline $0,95-1,00$ & $1,3 \%$ & $1,4 \%$ & 0,00015 \\
\hline Total & $100,0 \%$ & $100,0 \%$ & 0,01072 \\
\hline
\end{tabular}

Tabela D.3: Índice de estabilidade populacional do modelo DMA 99. 


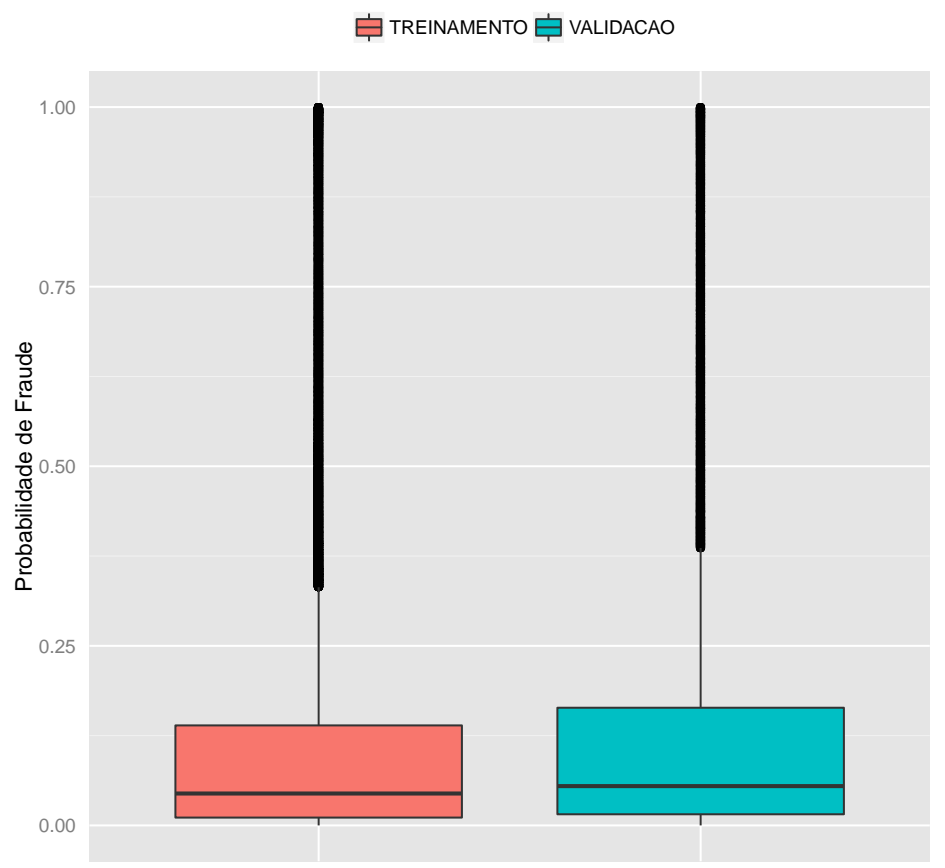

Figura D.10: Boxplox das amostras de treinamento e validação do modelo DMA 99.

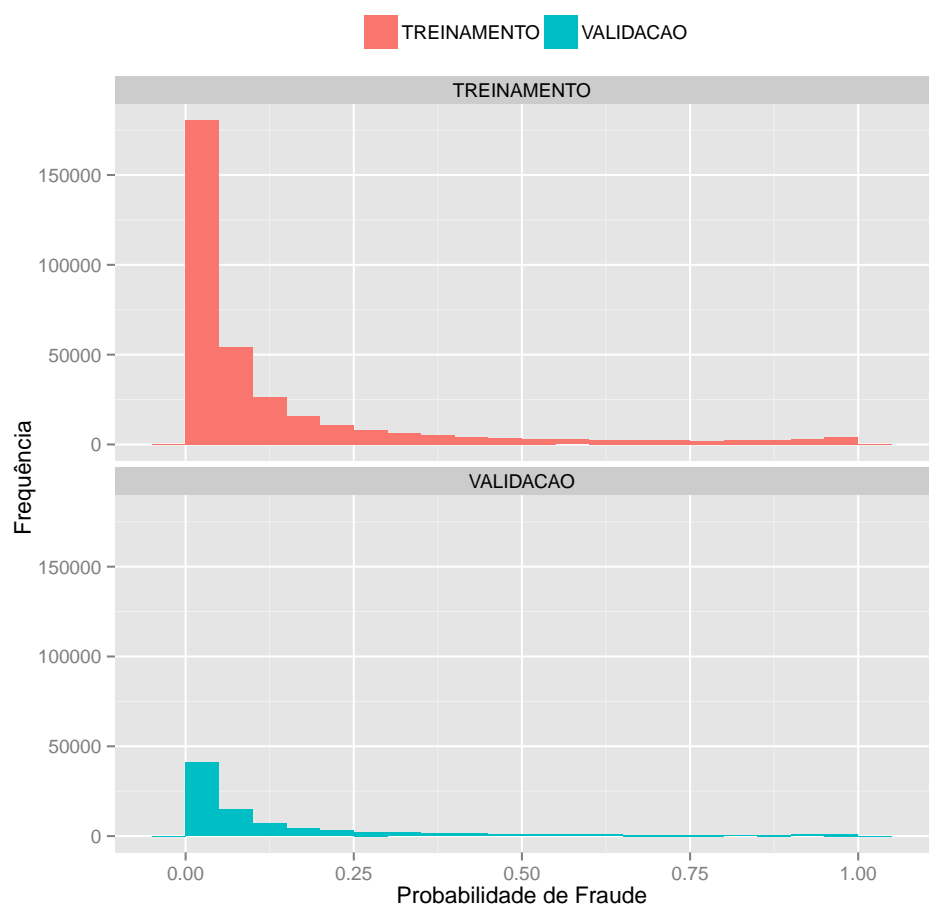

Figura D.11: Histograma das amostras de treinamento e validação do modelo DMA 99. 


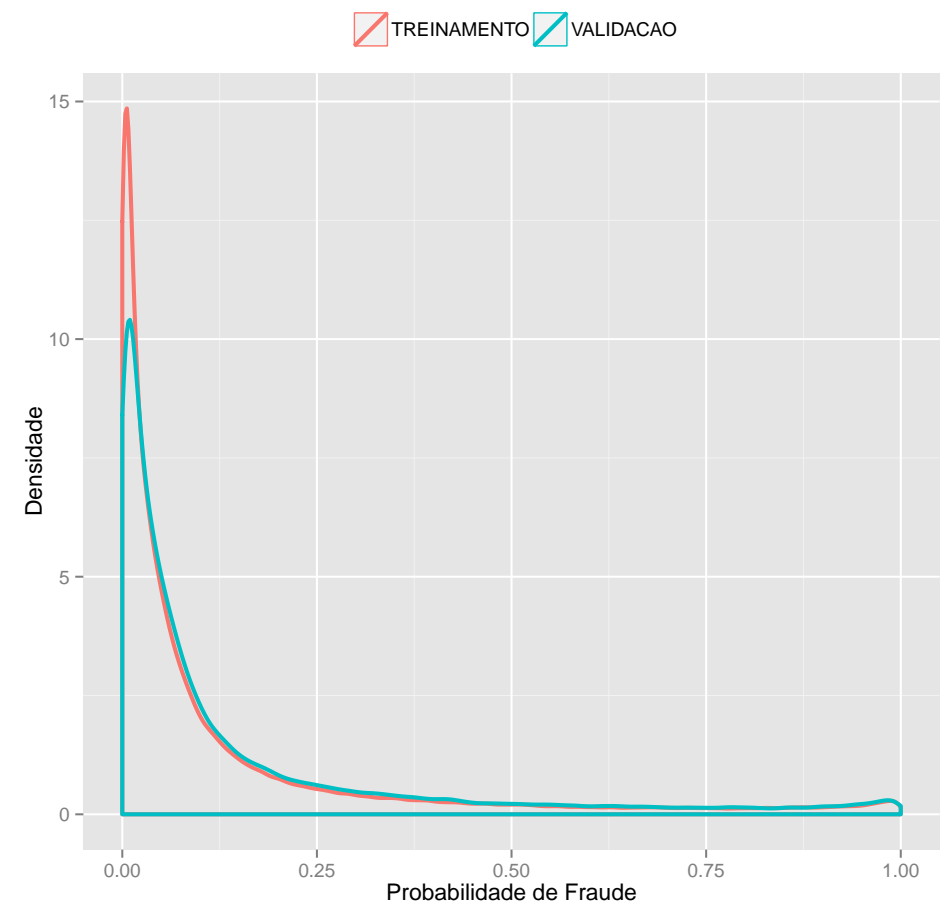

Figura D.12: Densidade das amostras de treinamento e validação do modelo DMA 99.

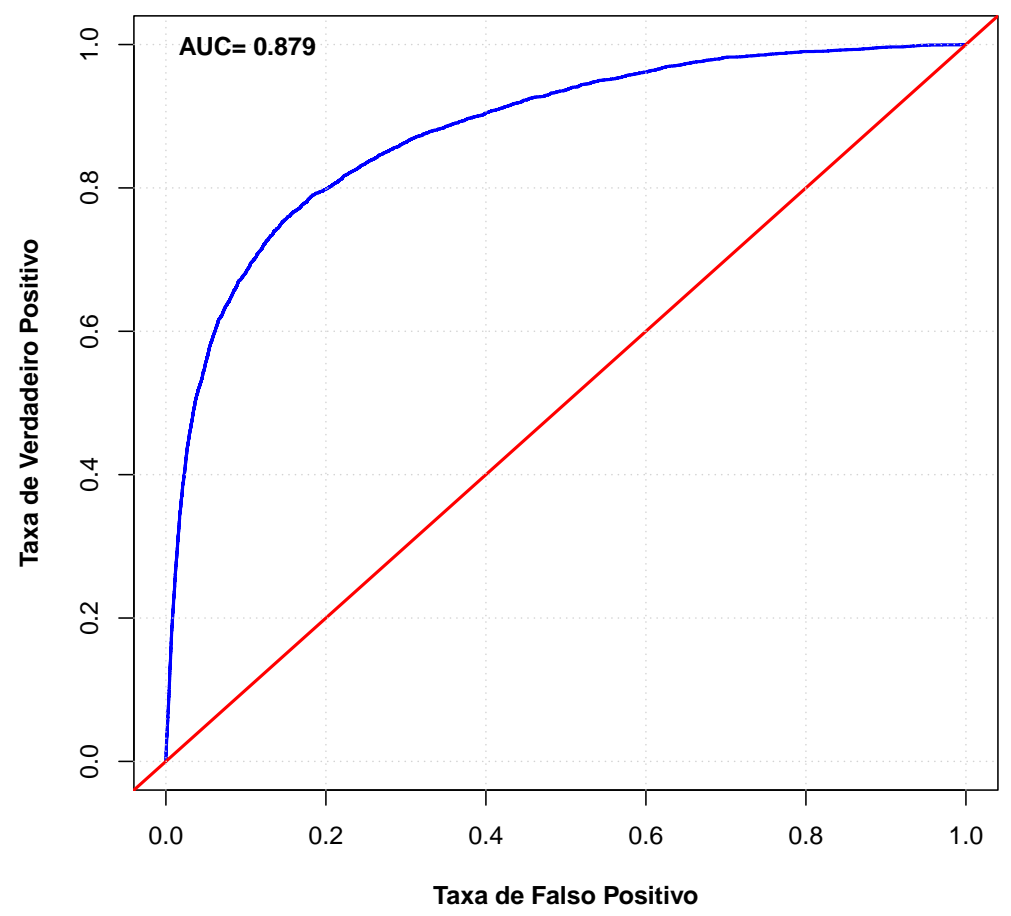

Figura D.13: Curva ROC da amostra de validação do modelo DMA 99. 


\begin{tabular}{lccc}
\hline \hline Classificado & \multicolumn{2}{c}{ Observado } & \% Classificação \\
\cline { 2 - 3 } pelo Modelo & Fraude & Não Fraude & Correta \\
\hline Fraude & 9.196 & 12.080 & $43 \%$ \\
Não Fraude & 8.896 & 312.433 & $97 \%$ \\
\hline \% Classificação Correta & & $94 \%$ \\
\hline
\end{tabular}

Tabela D.4: Tabela de classificação das transações pelo modelo DMA 99 (ponto de corte para probabilidade $=0,6)$

\begin{tabular}{lcc}
\hline \hline \multirow{2}{*}{ Indicadores } & \multicolumn{2}{c}{ Amostra } \\
\cline { 2 - 3 } & Desenvolvimento & Validação \\
\hline Classificação de Fraude & $50,8 \%$ & $52,4 \%$ \\
Taxa de Deteção (Cobertura) & $3,7 \%$ & $4,2 \%$ \\
Taxa de Falso Positivo & 1,3 & 1,4 \\
Relação Não Fraude/Fraude & $43,2 \%$ & $40,8 \%$ \\
Precisão (Fraude) & & \\
Classificação de Não Fraude & $96,3 \%$ & $95,8 \%$ \\
Especificidade & $97,2 \%$ & $97,3 \%$ \\
Precisão (Não Fraude) & & \\
Classificação Geral & $93,9 \%$ & $93,5 \%$ \\
Acurácia & $88,3 \%$ & $87,9 \%$ \\
Área sob a curva ROC & $46,7 \%$ & $45,9 \%$ \\
Medida F & &
\end{tabular}

Tabela D.5: Indicadores de performance do modelo DMA 99. 


\section{Referências Bibliográficas}

ABECS (2012) ABECS. Ranking de mercado de cartões - associação brasileira das empresas de cartão de crédito e serviços, 2012. URL http://www.abecs.org.br/. Consultado em 20 de maio de 2013. Citado na pág. viii, 7, 8

Al-Khatib (2012) Adnan M. Al-Khatib. Electronic payment fraud detection techniques. World of Computer Science and Information Technology Journal, 2(4):137-141. Citado na pág. xi, 27, 33, 34

Allison (2013) Paul Allison. Why i don't trust the hosmer-lemeshow test for logistic regression, 2013. URL http://www.statisticalhorizons.com/hosmer-lemeshow. Consultado em 02 agosto de 2014. Citado na pág. 77

BACEN (2013) BACEN. http://www.bcb.gov.br - banco central do brasil, 2013. URL http://www.bcb.gov.br. Citado na pág. 5

BDO (2008) BDO. Fraud: A global challenge - stoy hayward annual survey, 2008. URL http://www.bdo.co.uk/fraudtrack. Consultado em 10 de maio de 2013. Citado na pág. 16

Bolton e Hand (2002) Richard J. Bolton e David J. Hand. Statistical fraude detection: A review. In Statistical Science, 17:235-255. Citado na pág. iii, v, 1, 27, 29

Candolo (2004) C. Candolo. Um estudo de simulação considerando a incorporação da incerteza na seleção de modelos em regressão linear. Revista de Matemática e Estatística, 20(2):111-126. Citado na pág. 38

Chan e Stolfo (1998) Philip K. Chan e Salvatore J. Stolfo. Toward scalable learning with non-uniform class and cost distribution: A case study in credit card detection. In Proceeding of the Fourth International Conference on Knowledge Discovery and Data Mining, páginas 164-168. Citado na pág. 28, 67

Chan et al. (1999) Philip K. Chan, Wei Fan, Andreas L. Prodromidis e Salvatore J. Stolfo. Distributed data mining in credit card fraud detection. IEEE Intelligent Systems, 14: 67-74. Citado na pág. iii, v, 1

Cybersource (2013) Cybersource. 2013 online report : Online payment fraud trends, merchant practices and benchmarks. (14). Citado na pág. viii, 23

de Moraes (2008) Dalila de Moraes. Modelagem de fraude em cartão de crédito. Dissertação de Mestrado - UFSCAR. Citado na pág. 20

Doody et al. (2008) Helenne Doody, Fraud e Risk Management Working Group. Fraud risk management: A guide to good practice. Chartered Institute of Management Accountants - CIMA, (2). Citado na pág. 16 
E-bit (2014) E-bit. E-commerce brasileiro em 2013, 2014. URL http://www.ebitempresa. com.br. Consultado em 08 agosto de 2014. Citado na pág. 13

Fawcett e Provost (1997) Tom Fawcett e Foster Provost. Adaptive fraud detection. data mining and knowledge discovery. In Proceeding of the Fourth International Conference on Knowledge Discovery and Data Mining. Citado na pág. 28

FEBRABAN (2012) FEBRABAN. Perdas com fraude eletrônica - federação brasileira de bancos, 2012. URL http://http://www.febraban.org.br. Consultado em 3 de maio de 2013. Citado na pág. 1

FecomércioSP (2014) FecomércioSP. Vi congresso fecomercio de crimes eletrônicos, 2014. URL http://www.fecomercio.com.br. Consultado em 08 agosto de 2014. Citado na pág. 22

fraudes.org (2013) fraudes.org. Breve história dos cartões de crédito, 2013. URL http: //www.fraudes.org/showpage1.asp?pg=106. Consultado em 10 de janeiro de 2013. Citado na pág. 7

Frayback (2008) Dennis G. Frayback. Sample design and weight calculation. The National Health Measurement Study. University of Wisconsin-Madison. Citado na pág. 67

Gadi (2006) Manoel Fernando Alonso Gadi. Uma comparação de métodos de classificação aplicados à deteç̧ão de fraude em cartões de crédito. Dissertação de Mestrado - Instituto de Matemática e Estatística da Universidade de São Paulo. Citado na pág. 9, 13, 67

Gadi et al. (2008) Manoel Fernando Alonso Gadi, Xidi Wang e Alair Pereira do Lago. Comparison with parametric optimization in credit card fraud detection. Seventh International Conference on Machine Learning and Applications, páginas 279-285. Citado na pág. 2,67

Hagendorf et al. (2007) B. A. Hagendorf, J. G. Liao, M. R. Price e R. S. Burd. Evaluation of race and insurance status as predictors of under- going laparoscopic appendectomy in children. Annals of Surgery, 245:118-125. Citado na pág. 46, 47

Hand et al. (2002) D. Hand, N. Adams e R. Bolton. Pattern detection and discovery. Springer. Citado na pág. 15

Hand (1981) D. J. Hand. Discrimination and Classification. Wiley, Chinchester. Citado na pág. 30

Hill (1995) Theodore P. Hill. A statistical derivation of the signicant-digit law. Statistical Science, 10(4):354-363. Citado na pág. 29

Hoeting (1994) J. A. Hoeting. Accounting for model uncertainty in linear regression. Thesis (Ph.D.) - University of Washington, página 170. Washington. Citado na pág. 38

Hosmer et al. (1997) D. W. Hosmer, T. Hosmer, S. LE Cessie e S. Lemeshow. A comparison of goodness-of-fit tests for the logistic regression model. Statistics in Medicine, 16:965-980. Massachusetts. Citado na pág. 77

Koop e Korobilis (2010) Gary Koop e Dimitris Korobilis. Forecasting inflation using dynamic model averaging. página 32. Citado na pág. viii, xi, 48, 49, 50, 89

Land e Brotherton (2014) Bruce Land e David Brotherton. Information values statistic. Midwest SAS Users Group, (Paper AA-14-2013). Detroit. Citado na pág. 65 
Leamer (1978) E. E. Leamer. Specification searches. New York: John Wiley, página 370. Citado na pág. 38

Lecumberri e Júnior (2003) Luis Fernando L. Lecumberri e Antonio M. Duarte Júnior. Uma metodologia para o gerenciamento de modelos de escoragem em operações de crédito de varejo no brasil. Revista de Economia Aplicada, 7(4):795-818. São Paulo. Citado na pág. 79

Leonard (1993) Kevin J. Leonard. Detecting credit card fraud using expert systems. Computers and Industrial Engineering, 25(1-4):103-106. Citado na pág. 2, 28

Lewis e Raftery (1997) S. M. Lewis e A. E. Raftery. Estimating bayes factors via posterior simulation with the laplace-metropolis estimator. Journal of the American Statistical Assocation, (92):648-655. Citado na pág. 38, 41

Madigan e Raftery (1994) David Madigan e Adrian E. Raftery. Model selection and accounting for model uncertainty in graphical models using occam's window. American Statistical Association, 89(428):1535-1546. Washington. Citado na pág. 51

Maes et al. (2002) Sam Maes, Karl Tuyls, Bran Vanschoenwinkel e Bernard Manderick. Credit card fraud detection using bayesian and neural network. Citado na pág. 15, 28

McCormick et al. (2012) Tyler H. McCormick, Adrian E. Raftery, David Madigan e Randall S. Burd. Dynamic logistic regression and dynamic model averaging for binary classification. Biometrics, (68):23-30. Citado na pág. viii, 37, 38, 40, 41, 46, 47, 48, 88, 89

McLachlan (1992) G. J. McLachlan. Discriminant Analysis and Statistical Pattern Recognition. Wiley, New York. Citado na pág. 30

Montague (2004) David A. Montague. Fraud Prevention Techniques for Credit Card Fraud. Trafford, Canada. Citado na pág. 32

Nunes (2005) Hélio R. C. Nunes. Ponderação bayesiana de modelos em regressão linear clássica. Dissertação de Mestrado - Escola Superior de Agricultura "Luiz de Queiroz Universidade de São Paulo. Citado na pág. 38

Paula (2004) Gilberto A Paula. Modelos de regressão: com apoio computacional. IME USP. São Paulo. Citado na pág. 76

PCI-Council (2012) PCI-Council. Pci data security standards, 2012. URL https://www. pcisecuritystandards.org/security_standards/. Citado na pág. xi, 14

PCI-DSS (2013) PCI-DSS. Payment card industry (pci) - data security standard, 2013. URL https://www.pcisecuritystandards.org/documents. Citado na pág. 53

Raftery et al. (2010) Adrian E. Raftery, Miroslav Karny e Pavel Ettler. Online prediction under model uncertainty via dynamic model averaging: Application to a cold rolling mill. American Statistical Association, 52(1). Citado na pág. iii, v, viii, xi, 3, 37, 38, 39, 42, 43, 44, 45,46

Ripley (1996) B. D. Ripley. Pattern Recognition and Neural Networks. Cambridge University Press, Cambridge. Citado na pág. 30

Rochet e Tirole (2004) J. Rochet e J. Tirole. Two-sided markets: An overview. Working Paper, IDEI. Toulouse. Citado na pág. 4 
Sesame (2013) Credit Sesame. Indebted to plastic: The history of credit cards, 2013. URL http://cdn.getoutofdebt.org/wp-content/uploads/2009/12/Credit-Card-History-3. png?7d8816. Consultado em 20 maio de 2013. Citado na pág. 5

Siddiqi (2006) Naeem Siddiqi. Credit risk scorecards: Developing and implementing intelligent credit scoring. SAS Institute, páginas 79-83. North Carolina. Citado na pág. 69

Stolfo et al. (1997) Salvatore J. Stolfo, David W. Fan, Wenke Lee e Andreas L. Prodromidis. Credit card fraud detection using meta-learning: Issues and initial results. Citado na pág. 28, 32

Thomas et al. (2002) Lyn C. Thomas, David B. Edelman e Jonathan N. Crook. Credit scoring and its applications. SIAM - Society for Industrial and Applied Mathematics. Philadelphia. Citado na pág. 82

Unisys (2010) Unisys. Brasileiros estão em segundo lugar entre os que mais temem fraude na web, 2010. URL http://www.indicadorbrasil.com.br/tag/unisys/. Consultado em 14 de maio de 2013. Citado na pág. 2, 22

Users (2013) Wikipedia-Worldwide Internet Users. Worldwide internet users, 2013. URL http://en.wikipedia.org/wiki/Global_Internet_usage. Consultado em 2 de junho de 2013. Citado na pág. 13

Webb (1999) Andrew R. Webb. Statistical Pattern Recognition. Wiley, London. Citado na pág. 30

Weiss et al. (2005) Gary M. Weiss, Kate McCarthy e Bibi Zabar. Cost-sensitive learning vs. sampling: Which is best for handling unbalanced classes with unequal error costs? Department of Computer and Information Science. Fordham University. Citado na pág. 67

Wen Zhu e Wang (2010) Nancy Zeng Wen Zhu e Ning Wang. Sensitivity, specificity, accuracy, associated confidence interval and roc analysis with practical sas implementations. Northeast SAS Users Group Conference 2010, NESUG 2010. Citado na pág. 81

Wikipedia-Chargeback (2014) Wikipedia-Chargeback. Chargeback, 2014. URL http: //en.wikipedia.org/wiki/Chargeback. Consultado em 02 junho de 2014. Citado na pág. 58 